Bulletin 16

DEPARTMENT OF THE INTERIOR

BUREAU OF MINES

JOSEPH A. HOLMES, DIREeTOR

\title{
THE USES OF PEAT \\ FOR FUEL AND OTHER PURPOSES
}

BY

CHARLES A. DAVIS

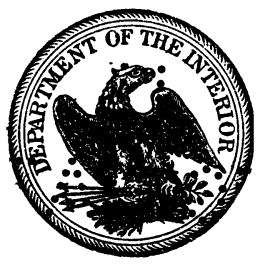





\section{CONTENTS.}

Page.
Introduction

Scope and purpose of report.................................. 7

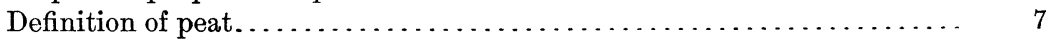

General properties of peat.................................. 8

Brief history of the use of peat as a fuel........................ 9

Present interest....................................... 9

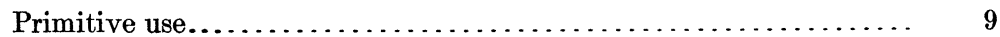

Later use......................................... 10

Advances in utilization................................... 10

Use in the United States................................. 11

Peat deposits in the United States............................. 12

Quantity of peat available............................... 12

Distribution of deposits.................................. 13

Résumé................................................... 14

Comparative cost of peat and coal as fuel..................... 14

Relative value of peat fuel ................................ 15

Origin and formation of peat...................................... $\quad 16$

Necessary climatic and surface conditions....................... 16

Regions in North America favorable for the formation of peat........... $\quad 16$

Conditions favoring the growth of plants....................... 18

Plant deposits in depressions filled with water...................... 19

Aquatic plants........................................... 19

Seed plants..................................................... 20

Aquatic seed plants................................... 20

Effect of sunlight and depth of water........................ 21

Deposition of plant tissues.................................. ${ }_{2} 22$

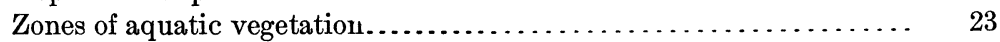

Vegetation of wet sedge mat................................. 24

Herbs and shrubs...................................... 24

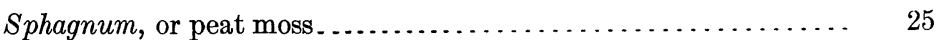

Coniferous trees...................................... 26

Deciduous trees..................................... $\quad 26$

Depths at which different kinds of peat are formed............. $\quad 26$

Summary and conclusions regarding the peat of water-filled depres-

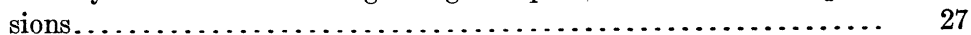

Peat formation on poorly drained, flat-land surfaces.................. 28

Drainage conditions....................................... 28

Vegetation and vegetable deposits.......................... 28

Relative importance of different types of plants.............. $\quad 30$

Significance of the types of peat structure.................... 31

Peat formation on subsiding coastal areas...................... 31

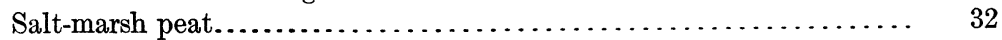

Relation of formation to tidal level......................... 33

Economic value of salt-marsh peat......................... 33

Peat formation above filled depressions...................... 34 
Origin and formation of peat-Continued. Page.

Lateral growth of peat beds................................. 34

Rate of peat formation............................................ 35

General conclusions relative to the formation of peat.............. 35

Practical application of the principles of peat formation.............. 35

Physical and chemical properties of peat as related to its fuel value........ $\quad 37$

Physical properties........................................ 37

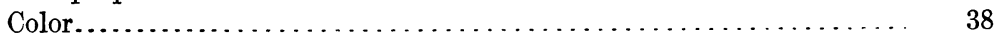

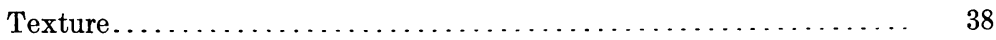

Composition........................................ 40

Water-holding capacity................................... 42

Weight, density, and specific gravity...................... 43

Relations of the physical condition of included vegetable matter to

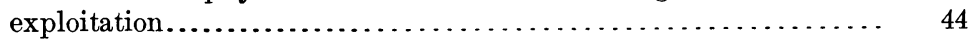

Classification by physical characters.......................... 45

Chemical properties........................................ 46

General composition................................... 46

Chemical composition of the ash......................... 47

Relation of ash to fuel value.......................... 48

Proximate and ultimate analyses........................ 49

Determination of calorific value......................... 50

Characteristics determining fuel value...................... 54

Comparative fuel value of peat in differing conditions............... 54

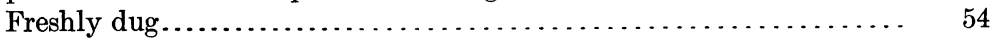

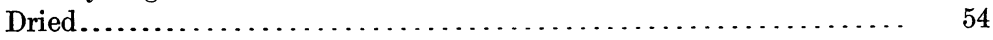

Effect of exposure to air............................... 55

Conditions of ignition.................................... 55

(haracter and effect of ash................................. 55

Air-dried peat compared with coal........................ 56

Use of peat fuel in Europe............................... 56

Efficiency of peat fuel for steam generation...................... 57

Calorific value of peat fuel................................ 57

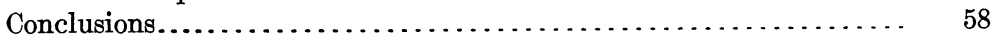

Chemical effects of artificial drying........................... 59

Practical or economic calorific value and evaporative effect of peat....... 60

Improvements probable................................ 63

Action of volatile hydrocarbons............................ 64

Preparation and manufacture of peat fuel.......................... 65

Essential preliminary considerations.......................... 65

Errors that have caused past failures........................ $\quad 65$

Ignorance and inexperience........................... $\quad 66$

Faulty engineering....................................... 66

Factors governing profitable utilization of peat deposits.............. 67

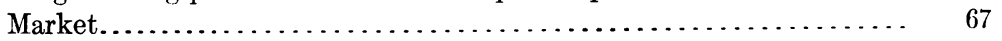

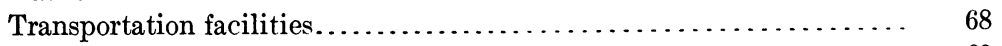

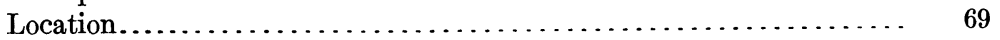

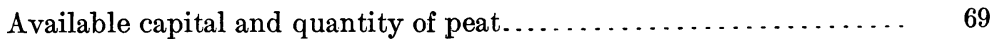

Practical method of computation....................... $\quad 69$

Smallest workable size of bog........................ $\quad 70$

Methods of prospecting peat bogs and estimating their contents....... 71

Bogs lying below the ground-water level or containing marl..... $\quad 72$

Approximate determination of productiveness.............. $\quad 73$

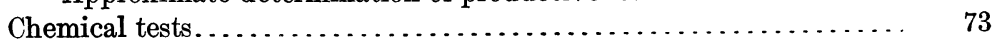

Mechanical tests............................................. 75 
Preparation and manufacture of peat fuel-Continued.

Page.

Factors governing profitable utilization of peat deposits-Continued.

Source and percentage of ash................................ 76

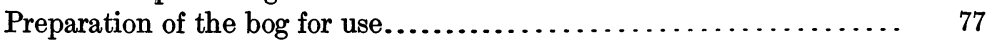

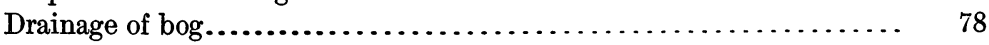

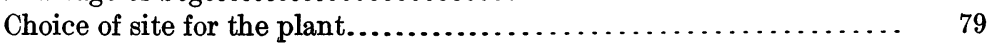

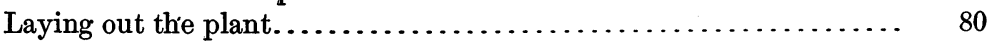

Selection of processes and machinery...................... 81

Character of the plant.................................. 82

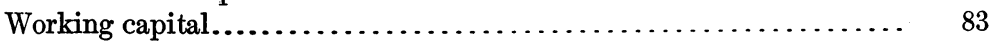

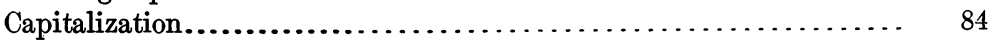

Experimental work in new plants.......................... 85

Cut peat.................................................... ${ }_{86}$

Machine peat................................................. 89

General statement............................................. 89

Methods in use for macerating peat without special machinery....... $\quad 90$

Reasons for extended discussion of method of manufacture........... 92

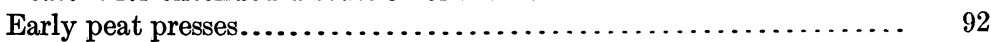

Essential processes..................................... 93

Description of peat machine............................. 93

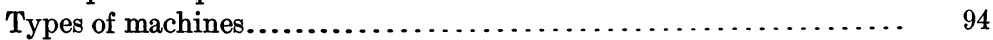

Desirable qualities of machines............................ 94

Methods of mounting machines............................... 95

Digging machinery........................................... 96

Dipper dredges.................................. $\quad 96$

Auger digging machines.............................. $\quad 97$

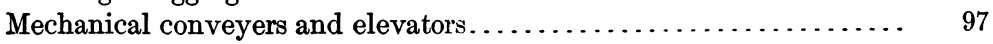

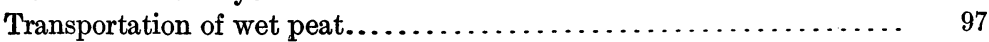

Tramcars.............................................. 97

Cable and cars.................................................. 98

Conveyers........................................... 99

Chain conveyers......................................... 99

Aerial cables........................................... $\quad 99$

Centrifugal and vacuum pumps..................... 100

Drying on racks....................................... 100

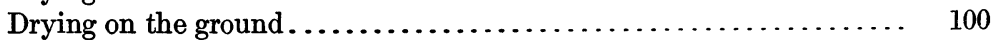

Advantages of a compact plant............................ 100

Requirements for a commercial plant....................... 101

Cost of plant........................................... 101

Estimated cost of plants equipped with American machinery .... 101

Cost of plants equipped with European machinery ............ 103

Price of the bog......................................... 103

Working capital........................................ 104

Probable output from a small plant....................... 104

Cost of manufacture..................................... 104

Selling prices........................................... 105

Length of operating season.............................. 106

Comparison with other industries........................ 106

The labor question...................................... 106

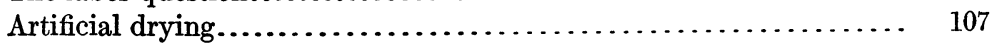

The practical problem.............................. 107

Waste heat must be utilized......................... 109

Weight of water to be evaporated in drying to various percentages of moisture......................................... 
Preparation and manufacture of peat fuel-Continued. Page.

Peat powder....................................... 110

Methods and advantages of use of powdered fuel................ 111

European tests....................................... 112

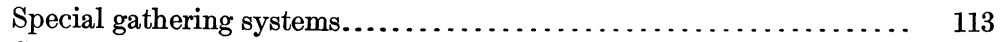

Cost of equipment......................................... 114

Types of drying machines............................. 114

Peat briquets............................................... 116

Advantages of briquetting............................... 116

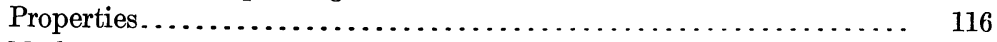

Methods of manufacture............................... 117

Types of presses..................................... 117

Treatment of peat preliminary to briquetting................ 118

Cost of plants..................................... 119

Comparative cost of briquets and machine peat.................. 121

Comparative fuel efficiency ............................... 121

Electric processes for drying peat............................ 122

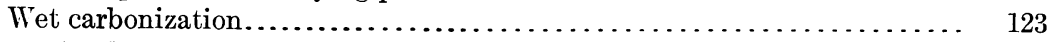

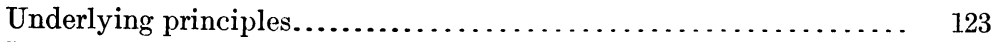

Process of treatment................................... 124

Properties of peat after treatment........................ 124

Cost of briquets by this process............................ 125

Cost of plant......................................... 125

Claims of inventor...................................... 125

Prospective value of process............................. $\quad 126$

Fuel products derived from the distillation of peat............... 126

Peat charcoal........................................ 126

Peat coke........................................... 127

Early attempts at manufacture......................... 127

Dry distillation in retorts............................. 128

The Ziegler peat-coking process...................... 128

Recovery of by-products........................... 130

Properties of peat coke.............................. 130

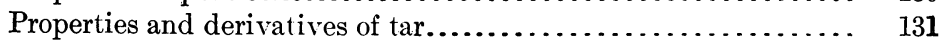

Methods of recovering tar and of purifying tar derivatives....... 131

Derivatives from tar water............................ 133

Permanent gases from coking retorts..................... 134

Quantity of by-products obtained from coking peat............ 136

Cost of plant for making peat coke and recovering by-products.... 138

Manufacture of peat coke in the United States................. 138

Manufacture of gas from peat................................... 139

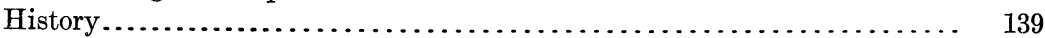

Illuminating gas............................................... 140

Requirements for successful production...................... 140

Composition.......................................... 141

Quantity of gas per unit of peat....................... 142

Causes of failure in past experiments......................... 142

Present status of gas manufacture.......................... 142

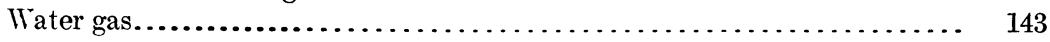

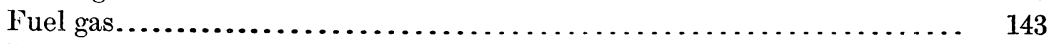

Producer gas.............................................. 144

Description of gas producer............................. 144

Scrubbers and regenerators.......................... 145

'Theory of gas formation in a gas producer.................... 145 
Manufacture of gas from peat-Continued.

Page.

Producer gas-Continued.

Types of gas producers.................................. 146

Use of peat in gas producers in Europe..................... 147

Producer gas compared with other commercial gases............ 148

Volume of producer gas obtained from peat.................... $\quad 149$

Calorific value of producer gas............................ $\quad 150$

Gas-producer tests by the United States Geological Survey........... 152

Peat as fuel in the gas producer........................... $\quad 155$

Cost of gas-producer power plants........................... $\quad 156$

By-product gas producers................................. $\quad 158$

$\begin{array}{ll}\text { Peat required for producing a unit of power in the gas producer....... } & 159\end{array}$

Utilization of producer gas from peat..................... 160

General conclusions on peat fuel.............................. 161

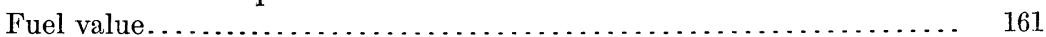

Utilization of deposits...................................... 161

Producer-gas plants.......................................... 161

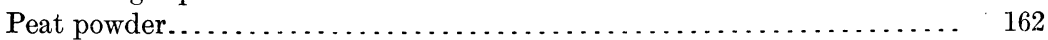

Domestic uses............................................ 162

Peat coke............................................... 163

Peat as a raw material for products other than fuel..................... 164

Chemical products.......................................... 164

Alcohol.................................................. 165

Ammonium compounds...................................... 166

The Frank-Caro process ................................. 166

The Woltereck process................................. 166

Nitrates.............................................. 167

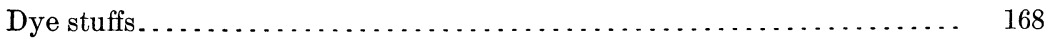

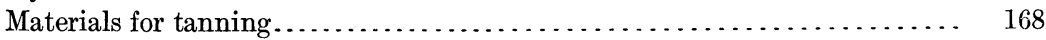

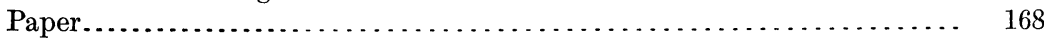

Woven fabrics............................................... 169

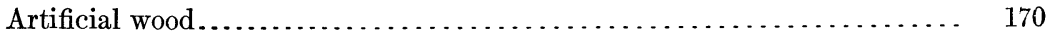

Mattresses and sanitary appliances........................... 170

Mosś litter and mull........................................ 171

Cost of a plant........................................ 171

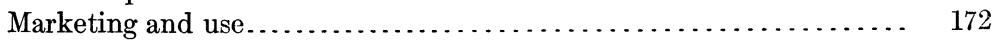

Packing material...................................... 173

Fertilizer filler........................................ 173

Peat as a fertilizer.......................................... 175

Conclusions................................................ 175

Agricultural uses of peat..................................... 177

Peat soils................................................. 177

Fertilizer............................................... 178

Absorbent and disinfectant................................. 179

Litter and bedding for stock................................ 179

Insulating material....................................... 180

Stock food................................................... 180

Packing material....................................... 181

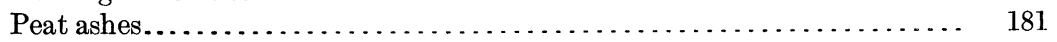

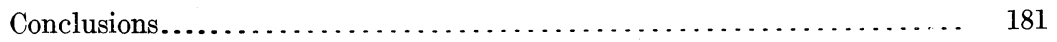

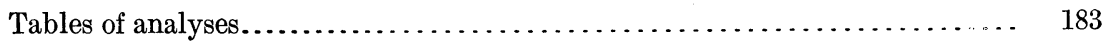

Collection of samples...................................... 183

Methods of collection...................................... 183

Analytical methods.......................................... 184 
Tables of analyses-Continued.

Moisture.

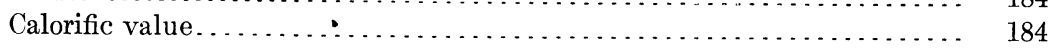

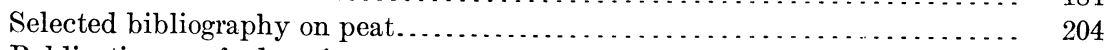

Publications on fuel testing.

\section{ILLUSTRATIONS.}

Plate I. Distribution of peat deposits in Lnited States............. In pocket FIgURE 1. Relation between weight and moisture content of peat........ 110 


\title{
THE USES OF PEAT FOR FUEL AND OTHER PURPOSES.
}

\author{
By Charles A. Davis.
}

\section{INTRODUCTION.}

\section{SCOPE AND PURPOSE OF REPORT.}

The Bureau of Mines is making a comprehensive investigation of the composition, heat value, and utility of the mineral fuels in the United States. In the course of its research the bureau is giving particular attention to methods of mining and utilizing fuels to the end that waste may be avoided and deposits of low-grade fuels now lying unmined may be made important assets of the Nation's mineral wealth. The investigation as a whole is a continuation of the testing and analyzing of fuels, as carried on by the United States Geological Survey, from the inception of the work in 1904 to the transfer thereof to the Bureau of Mines on July 1, 1910. In consequence of the transfer of authority this bulletin is published by the Bureau of Mines, though it was prepared under the direction of the Geological Survey.

The bulletin sets forth the results of an investigation that was undertaken to determine whether peat, a fuel widely used in some countries, could be made serviceable in the United States, where, though labor and economic conditions differ from those in the peatusing countries, there are opportunities for the introduction of a fuel selling at prices that should make the mining and shipment of peat to near-by markets profitable. In connection with the investigation of the possibilities of utilizing peat as fuel, attention was incidentally given the possible development of other uses with the view of increasing the value of a material that hitherto has not been generally considered an important natural resource of the United States.

\section{DEFINITION OF PEAT.}

The difficulties which have always been encountered in utilizing peat for fuel are due to the fact that in its natural state the material 
contains only about 10 per cent of combustible matter, the remaining 90 per cent, more or less, being water; this water is inherent because of the nature of the processes by which the peat is formed. The foregoing statement leads logically to the following definition:

Peat is partly decomposed and disintegrated vegetable matter that has accumulated in any place where the ordinary decay or chemical decomposition of such material has been more or less suspended, although the form and a considerable part of the structure of the plant organs are more or less destroyed.

Water makes an excellent medium for preserving the remains of dead plants, and hence also for aiding peat formation, since it excludes air and most of the organisms that are the chief agents that cause wood and other plant structures to rot and finally disappear. The water may contain certain poisonous organic chemical compounds that originated in the growing plants, as the result of their activities, or were formed as decomposition products. These compounds may act with water to prevent the growth of the organisms which cause decomposition, but that excess of water is the paramount factor in the preservation of the vegetable matter seems capable of demonstration.

The above statement is so generally true that peat deposits within the limits of the United States are practically always formed in situations where water for the greater part of the year either saturates or wholly covers the plant débris from which peat originates. In those places where vegetable material is saturated with water for only a part of the time and is subjected to periodical and prolonged drying out, true peat is not formed, but a more nearly complete decomposition takes place that results finally in the formation of humus; or, if the drying is continued long enough and other conditions are favorable, decomposition may go on until nothing is left of the plant material but the ash or mineral part.

GENERAL PROPERTIES OF PEAT.

According to its origin and the conditions under which it accumulates, peat may vary in color from brown to black. In texture it may vary from light, spongy matter that is porous, coarse, fibrous, or even woody, and easily falls to pieces when dry, to forms that are nearly or quite devoid of structure and when wet are as plastic as clay and when dry form dense, hard masses resembling lignite. In all cases, as noted above, peat is nearly or quite saturated with water, containing, under usual natural conditions, from 80 to 95 per cent.

When dry, peat is generally lighter in color than when freshly dug and will usually float if placed in water, although this is not always true of the dark-colored, plastic kinds that are high in ash and when thoroughly dry are as compact and nearly as hard as coal. Except 
for such types, raw or untreated peat is easily crumbled to powder when handled, and makes bulky and unsubstantial fuel that does not bear transportation well. The name "muck" is commonly applied to black, impure peats of the more completely decomposed types.

\section{BRIEF HISTORY OF THE USE OF PEAT AS A FUEL.}

\section{PRESENT INTEREST.}

Within the past few years a marked depletion of the visible supplies of coal, the approaching exhaustion of the supply of wood available for fuel, and a constantly growing demand for fuel for industrial and domestic uses have led to a general advance in the prices of both coal and wood.

This condition has caused economic geologists, economists, and others to seek out and appraise new sources of fuel supply, and to contrive means of conserving and more perfectly utilizing the present supplies. The tendency toward more efficient utilization is shown in the development of interest in briquetting as a means of saving coal-mine waste and converting it into useful fuel, in the increasing use of internal-combustion engines as sources of power, and in the steady improvement of boiler furnaces and combustion chambers for burning solid fuels most economically. The same tendency is shown in the increasing use of compound steam engines and of devices for assuring complete combustion. Another manifestation of this tendency is the growing desire to investigate and utilize hitherto unconsidered kinds of fuel and to make use of sources of power other than fuel.

\section{PRIMITIVE USE.}

The earliest use of peat was for fuel, and dates back to the dawn of history. Latin authors of the time of the conquest of northern and western Europe by the Romans commented on the miserable condition of some of the people of those regions, who dug the soil from their marsh lands with their hands, and, after drying it, burned it to warm themselves and cook their food. In Ireland, of necessity, peat has been the only domestic fuel of the mass of the people from the traditional time when the forests of that country were finally cleared away.

Scarcely less ancient is the use of peat for fuel in other parts of northern Europe-Holland, Germany, Russia, and parts of France and Austria. The disappearance of the forests at a comparatively early period, while agriculture was the most important industry of these countries, led to the widespread use of peat fuel, especially by the poorer classes of people. 


\section{LATER USE.}

Peat has long betal generally used in Europe as fuel for heating and other domestic uses, and more recently for power generation. Its production in compacted forms suitable for transportation and storage is growing constantly, so that at present every European country having any considerable area of peat deposits is increasing the output of peat fuel. In addition, Ireland and the countries of continental Europe are encouraging its use by direct appropriation of funds to aid new and promising methods of preparation, and are supporting experiment stations for investigating and perfecting new processes for utilizing this important natural resource.

In some parts of Canada, because of climatic conditions, the lack of any considerable deposits of coal, and the existence of generally distributed and extensive peat beds, more or less successful attempts have been made for 50 or more years to utilize peat as fuel. The matter has recently received new impetus there because of an industrial awakening and because of improvements made in gas producers and gas engines in Sweden, Germany, and the United States that permit satisfactory use of low-grade fuels. As a direct result of these factors, an experimental gas power station using peat is being established under governmental control and thoroughly equipped with the best European machinery. $a$

In the United States, for obvious reasons, peat had received but scant attention, except at the hands of a few widely scattered experimenters, until the winter of the year 1902-3, when the memorable long-continued strike of the miners in the anthracite regions of Pennsylvania brought a large section of the country to a realizing sense of its almost complete dependence on that group of men for its supply of fuel.

Since that time there has been an important, if unsuccessful, series of attempts to produce peat fuel on a commercial scale, and in the aggregate hundreds of thousands of dollars have been spent in equipping plants to manufacture it for the general market.

\section{ADVANCES IN UTILIZATION.}

After the development of the steam engine, and the great impetus which this gave to the commercial and manufacturing industries of all European nations, peat was used in constantly increasing amounts for the generation of power by those nations poorly supplied with

$a$ During a part of the season of 1910 the Mines Branch of the Canada Department of Mines operated on a commercial basis a demonstration peat-fuel plant. This was located at Alfred, Ontario, about 30 miles from Ottawa, and was equipped with Swedish machinery. Part of the 1,600 tons of air-dried machine peat produced by the plant was sold to those wishing to try the fuel, and part was used in the gas-producer plant established by the Government in Ottawa for testing peat, lignite, and similar fuel. These plants are fully described in Bull. No. 4, Can. Dept. of Mines, Mines Branch, 2d edition, 1910. 
other fuels. Such use naturally led to material improvements in the ways of preparing peat for fuel, and to much experimenting aimed to increase the quality of the fuel produced and the rapidity of production. The period of experimentation covered more than half a century.

The experimental work has not been wholly confined to ways of utilizing peat as fuel, but has included efforts to discover numerous other uses to which the substance, or some part of it, might be adapted as raw material for some manufacture in regions where raw materials for the specified purpose were either not produced, were scarce, or were expensive.

Therefore, anyone desirous of undertaking the use of peat for any purpose will find it profitable carefully and critically to review the work that has been done in Europe, especially in Germany, Denmark, Norway, and Sweden, in order to get the benefit of the great amount of information that is stored in the literature relating to the subject. Not the least important sources of such knowledge are the records of failures which have occurred, because mistakes made and recorded need not be repeated.

In America much less need has arisen for the study of the possible uses of peat. In Canada, partly because of its small coal fields and cold climate, partly because of the greater abundance of peat, and doubtless, also, partly because of the fact that many of the settlers before coming to this country were accustomed to using peat as fuel and liked it, more persistent attempts have been made to develop a peat-fuel industry than in the United States. For 50 years or more some peat fuel has been produced in the Provinces of Ontario and Quebec and has found ready sale, although the manufacture seemingly has never been a great success commercially.

\section{USE IN THE UNITED STATES.}

In the United States peat fuel, in the form of cut peat, was used in parts of New England almost continuously from the time of settlement until the use of coal became general. Peat bogs in various parts of Massachusetts and Rhode Island still show depressions that were made years ago by the removal of the peat for fuel, and in places remote from railroads some peat is probably still cut for local or individual use.

During the latter part of the Civil War, and in the years immediately following the war, considerable interest was shown in New York, Boston, and in some other parts of the United States, in the production of peat fuel on a large scale, and plants were established at various places in New York, New Jersey, Virginia, and New England to experiment with machinery and processes for peat manufacture. These plants seem usually to have had little financial backing, 
however, and none of them, so far as known, ever reached the commercial stage of production. The one which probably came nearest that point was that of the Boston Peat Co. at East Lexington, Mass., where an excellent quality of peat and an efficient machine for macerating and forming it into bricks made a good product possible. The enterprise was carried along for some years, but was eventually discontinued.

In 1902-3 the strike of the anthracite coal miners already referred to created a fuel famine such as had never before been experienced in the United States, and revived the interest in the use of peat as fuel. Since that time many attempts have been made to produce fuel from peat on a profitable commercial scale, but for many reasons, some of which are considered hereafter, very little peat fuel of any sort has yet appeared in American markets. However, at least $\$ 1,000,000$ in the aggregate has been spent in erecting plants and in experimenting with various processes of handling and preparing the substance. Because the closing of larger plants before they had reached a stage of demonstrated success was so general, more conservative developments have been planned for making a thorough trial of the material in favorably situated places under American conditions of production and fuel supply. Some of these are about to be started under much more favorable auspices than any of their predecessors.

It is evident from the foregoing that as yet no peat-fuel industry can be said to exist in the United States, although much experimental work has been done and great sums of money spent to establish one. In Europe the peat beds of various nations are sources of raw materials for industries of some magnitude, although their development is still in an experimental stage, as is pointed out in succeeding pages. In the United States, with few exceptions, the use of peat for other than fuel purposes has not yet been attempted, partly because of the great quantities of better materials available for the purposes, and partly because manufacturers are not sufficiently informed regarding the possibilities of different kinds of peat.

\section{PEAT DEPOSITS IN THE UNITED STATES.}

\section{QUANTITY OF PEAT AVAILABLE.}

So little exact information has been obtained in regard to the area and depth of the peat deposits in the United States that an accurate estimate of the quantity available is impossible. On the assumption that there are in the United States, exclusive of Alaska, 139,855 square miles of swamp lands, ${ }_{2}{ }^{a}$ it is estimated that 8 per cent of this area, or 
11,188 square miles, will have peat deposits of good quality. Assuming further that the average depth of the peat in this area is at least 9 feet, and that the average yield will be 200 tons of salable fuel per acre for each foot of depth, the total available fuel in these deposits will reach 12,888,500,000 tons; this quantity, if converted into machine-peat bricks and sold at $\$ 3$ per ton, would have a value of $\$ 38,665,700,000$-no mean resource, but one that would furnish heat and power for the entire country for many years.

\section{DISTRIBU'TION OF DEPOSITS.}

Peat beds are not uniformly distributed over the country (see map, Pl. I), but lie chiefly in the region north of a somewhat irregular line extending westward from close to the southern boundary of New York nearly to the ninetieth meridian and thence northward to Canada. This region is supplemented by a narrow strip of land that extends along the Atlantic coast to Florida, includes the whole of that State, and reaches westward, probably across Texas, to the Mexican border. In the Pacific coast States there are some peat areas of workable size in California, and also in the valleys of some of the lakes and rivers of Oregon and Washington, but little is known of the extent and character of the deposits.

The reasons for this peculiar distribution of peat are not evident, but extended investigation will doubtless show it to be definitely correlated with certain geologic and climatic conditions which can not be discussed here.

It is an exceedingly interesting coincidence and a most important economic consideration, however, that the regions where peat is most abundant are relatively remote from the coal fields, the only exception being an overlapping of peat and coal in Michigan. In that State, however, as geologists are aware, the part of the coal field known to be commercially productive is not of large extent, but, so far as developed, is confined to small areas on the eastern and southern margins, the interior yielding but little coal. Aside from this area, the much-less marked overlapping of peat and coal in Illinois, and the slight coinciding of peat and lignites in the western border of the peat-bearing regions, there is a well-marked separation of the coal fields and the areas that contain peat. This is clearly shown on Plate I.

When one also notes that the more Northern States, in which fuel is most needed, and the parts of the Southern States where other kinds of fuel are not readily available, are rich in peat, it seems strange that a more careful examination into the possibilities of the peat resources of the country has not been made, because potentially they have large value and great possibilities. 


\section{RESUME.}

On the whole, then, it may be said that the use of peat for any purpose in the United States is small as compared with that in European countries. The peat beds are a great and neglected resource which, when properly and fully developed, will add to our national wealth no inconsiderable quantity of good fuel and of raw material for important arts and manufactures. The discussion will of necessity be devoted largely to the uses of peat in European countries and to the methods of securing marketable products in commercially paying quantities there. Only by carefully considering these can the mistakes and failures of the past be avoided and improvements of existing processes made.

It must also be considered that any mechanical devices and processes for making peat fuel and other products which are in successful operation abroad are those which have established themselves by demonstrating through a long period of years their value in competition with many others which have been eliminated because of failure to meet the demands put upon them by the requirements of actual commercial operations. These devices and processes are therefore all the more worthy of careful study by prospective investors in this country.

To summarize: The foundation of all successful development and growth of peat industries in the United States must be a thorough scientific study of the occurrence, nature, qualities, and peculiarities of peat itself and a careful and honest investigation of the status of these industries in the European countries in which they have reached self-supporting existence. To begin without these preliminary studies would be the height of folly.

\section{COMPARATIVE COST OF PEAT AND COAL AS FUEL.}

Comparing the cost of peat fuel with that of coal, the former could be produced with less danger and with a much less expensive equipment if it needed only to be dug, because it lies at or just below the surface of the ground. A readily marketable type of peat fuel, in the form of air-dried, slightly compressed blocks, can probably be produced at an expense of from 75 cents to $\$ 1.25$ or $\$ 1.50$ per ton, and, with properly devised and properly arranged machinery, production on a large scale would considerably lower the higher price for peat of well-decomposed types.

On the basis of the comparisons of the heating values given in the following sections, and at the prices of production noted, clearly more heat units for the same investment of money could be obtained from peat than from coal, for 2 tons of peat could doubtless be bought for the same price as 1 ton of coal, and even the best coals 
do not have twice the heating value, pound for pound, of good fuel peat. No peat fuel has yet been produced at such low cost in this country, however, and that the figures based upon European production can be made the basis of calculation for American conditions remains to be demonstrated. That the bulkiness of air-dried peat fuel will make the cost of transportation and of storage under cover relatively high must also be noted. The high cost of transportation will probably prevent the shipment of the product for any considerable distance from the place of origin except by water routes; the high cost of storage will easily adjust itself when consumers have an opportunity to learn the value of peat fuel.

Both transportation and storage are facilitated and objections of the sort mentioned are reduced to a minimum if the peat is compacted by thorough maceration, or pressed into small, dense, compact briquets by the use of powerful briquetting presses. As pointed out below, however, there are serious difficulties in the way of using the latter process, and until these have been removed and this method of preparation is a demonstrated commercial success no conclusions of value can be based upon it as a factor in this discussion.

\section{Relative VALUe OF PEAT FUeL.}

In conclusion, peat fuel may be said to be especially useful for certain purposes for which wood was formerly in general use and for which coal has not yet been altogether successfully introduced, such as brick and other forms of ceramic firing and lime burning. It appears to reach its highest value, however, as a source of producer gas in properly constructed gas producers, and, as shown in the sections of this report devoted to the uses of peat (pp. 144-161), this is a very efficient way in which to use its energy.

The fact must be noted that no quantity of peat fuel of any type sufficient to prove its value has yet been produced in the United States; until this has been done, although the outlook and European experience warrant further investigation of its possible uses and value, no final conclusions as to the commercial value of American peat as compared with coal can be reached.

$$
661^{\circ}-\text { Bull. } 16-11 \longrightarrow 2
$$




\section{ORIGIN AND FORMATION OF PEAT.}

NECESSARY CLIMATIC AND SURFACE CONDITIONS.

Peat is found in all parts of the earth where the conditions of moisture are favorable, but it is most uniformly present in regions where the rainfall is regular and abundant and the relative humidity of the air is constantly high. The first factor supplies the necessary water, and the second prevents excessive evaporation. As cool or cold air is much more readily saturated with water vapor than is warm air, the temperate and cold parts of the earth generally have more humid atmosphere than the warmer parts, and in this respect are favorable to peat formation.

The form of land surface is also an important factor in determining the relative frequency of occurrence of deposits of peat, especially in regions where rainfall is somewhat irregular, where the climate approaches dryness, or where hot, dry summers are somewhat frequent, as, for example, in the greater portion of the valley of the Mississippi and the southern part of the basin of the Great Lakes. In regions of this character the presence of numerous depressions in which water may collect and stand permanently at a nearly constant level, and of poorly drained valleys or plains, largely controls the quantity of peat that will be found, since these depressions furnish places where accumulations of vegetable matter may be kept from desiccation and complete decomposition.

From climatic causes the factors mentioned as favoring peat formation are most generally present in the cold and temperate regions of the earth. Especially is this true in the Northern Hemisphere, where there are land masses of great extent in which surface drainage has been profoundly affected by glacial ice so recently that there has not been time for it to become reestablished, and in consequence shallow, undrained basins and broad, flat valleys are numerous.

\section{REGIONS IN NORTH AMERICA FAVORABIE FOR THE FORMA- TION OF PEAT.}

Conditions such as have been mentioned are general in the eastern part of North America north of $40^{\circ}$ north latitude, hence peat deposits are more numerous and more widely distributed in that part of the continent than to the southward and southwestward, whereas aridity is an unfavorable factor in the region west of the ninetieth meridian. In Canada, which lies practically wholly within the firstmentioned region, more than 35,000 square miles of land surface are covered by peat deposits; that part of the United States adjacent 
to the Canadian boundary and east of North Dakota is equally favorable in situation and has, in the aggregate, large areas of workable peat beds.

Southward of the fortieth parallel higher summer temperatures, longer summers, more frequent long droughts, and the prevalent drying winds, together with the more thorough drainage of the land surface, combine to bring about conditions adverse to peat formation; hence deposits are fewer and smaller than to the northward, or are entirely absent.

In this more southerly region the low relative humidity of the air for long periods during the summer months is doubtless an important factor in restricting the accumulation of peat. The drying winds and the heated air characteristic of summer in this part of the country constantly evaporate the water from the surface of the soil; the warmth of the soil decreases the viscosity of the soil water and permits it to drain away readily. Combined, these factors keep the surface of the ground in such a condition that very little peat can form upon it, despite the great abundance and luxuriance of plant growth induced by favorable climate and a long growing season. In the far north, on the other hand, where the growing season is short, even though other factors favor the development of peat, little will be formed because the vegetation of the region is too limited in amount to form accumulations of sufficient size. It is apparently true that peat may form to considerable thickness, even in high latitudes, in both the Northern and Southern Hemispheres wherever the climate is oceanic or the ground permanently frozen. No reports of the vegetable structure of these types of peat are available, however, and some of the observed accumulations may possibly represent a milder climate than that which now prevails in the regions under discussion.

The present state of our knowledge indicates that the deepest deposits of peat in North America, as well as those of greatest extent, are to be found from 100 to 150 miles on either side of the boundary between the eastern United States and Canada.

East of the Appalachian mountain system, however, the proximity of the Atlantic Ocean causes a considerably greater rainfall and much moister atmospheric conditions than are found west thereof. This is especially true of the Coastal Plain, a flat, imperfectly drained, relatively narrow strip of land that borders the ocean southward from New York, and, geologically speaking, has very recently come above sea level. There is evidently a combination of factors here which makes peat formation possible farther southward than is possible under the conditions on the western side of the mountains, viz: Poorly drained, flat land surface, heavy rainfall, and highly humid air. 
From the foregoing statements it seems that two kinds of land surface are more suitable than others for the development of peat beds. These are basins and gently sloping or flat areas. In addition, a sufficient and regular rainfall and usually humid atmospheric conditions are essential in order that the basins may be permanently filled by water and the surfaces of the plains remain continually moist or wet.

It may be added also that wherever the precipitation is great enough, and the relative humidity of the air is high enough, or wherever, because of low air and soil temperatures, evaporation and run-off are slight, peat will form on any surface on which the necesrary plant material can accumulate. Such conditions are not usual within the borders of the United States, although widespread in Alaska, and need not be discussed at this time.

\section{CONDITIONS FAVORING THE GROWTH OF PLANTS.}

Before going further into details relative to peat formation it is essential for a correct understanding of the way in which different kinds of peat may originate to consider briefly the principles of the relationship of plants to their environment and the conditions under which vegetation of different types can grow. An understanding of these makes possible a statement of the kinds of plants which may contribute to the peat of given regions and an absolute determination of certain of its characteristics. The matter also has an important practical bearing on questions relating to the use of peat for specific purposes.

At the outset it may be stated that green plants are the only types capable of independent existence and therefore the only ones that can make any considerable contributions to peat deposits. All of these, in order to grow, must have light, heat, air, water or moisture, and certain mineral and gaseous chemical compounds, which are dissolved in the water or intimately mixed with the air. The most important gases derived by plants from the air are carbon dioxide and oxygen. By the aid of light and heat the plants carry on in their green parts the very complicated chemical processes by which the raw food materials, consisting of carbon dioxide, oxygen and other gases, water, and mineral and other compounds, are converted into food and then into living cells, tissues, and organs.

The most durable parts of these structures after they have served their purpose in the economy of a plant remain more or less unchanged after its death, and under favorable conditions form peat. In the larger plants, like trees, some of these durable parts are in the form of wood, a hard, very complicated chemical substance; but the leaves of trees and the entire plant in many of the smaller and lower types of plants are made up of a softer, less dense, but very stable material called cellulose. It is from this material, which is a com- 
pound of carbon, hydrogen, and oxygen, that a great part of peat substance originates.

Every plant requires for its existence and growth a certain quantity of each of the essential factors mentioned above, but each plant has its own particular needs, and differs from all others in the least or minimum quantity of some or all of these factors which it must have in order to maintain itself and in the tolerance which it shows to the presence of a quantity in excess of its needs.

Thus some plants require much light; others can flourish in or must have the shade; some grow well in dry places; others must have quantities of water if they are to live at all. On the other hand, an excess of light, heat, water, or of dissolved minerals or other soluble matter is detrimental, and may completely stop growth quite as certainly as deprivation. These matters, however, need not be discussed at length in this place, as they are fully illustrated in the succeeding paragraphs.

\section{PLANT DEPOSITS IN DEPRESSIONS FILLED WITH WATER.}

Water-filled basins, lakes, and ponds are first considered because they present in a way the simplest conditions of growth for plants, and in them the combinations of the essential factors of plant growth as related to the formation of peat are most easily understood.

\section{AQUATIC PLANTS.}

Plants of several great groups or classes habitually grow wholly or partly submerged in water. The algæ, certain mosses, and a few other less frequent kinds of spore-bearing plants, which are the lowest types of vegetation, normally grow entirely beneath the surface of the water. They either float without attachment just below the surface or deeper, or are attached to the bottom or to other fixed or floating forms in shoal water.

The algæ are purely aquatic plants represented by great numbers of species and often by enormous numbers of individuals in a given locality. Fresh-water algæ, with which this discussion is chiefly concerned, are plants of simplest structure and of small, often microscopic, size. In them the vegetative body is without differentiation into roots, stem, and leaves, as in most seed plants, but consists of one or more cells which perform the essential functions of all of these organs. The most common and easily recognized fresh-water algæ are the bright green "pond scums" so abundant in still water during the spring and summer. Since these plants float about in the water their remains may be found at any depth from the surface to the bottom.

Of the great groups of plants higher than the algæ, none of importance is made up exclusively of aquatic plants; in fact, none has more than a relatively small number of representatives which grow 
wholly in the water. Among these higher types may be mentioned the mosses, the liverworts, a few of the fern allies, and the flowering or seed plants. The mosses and liverworts are small in size, simple in structure, and generally rootless, but under favorable circumstances they sometimes flourish in vast numbers, even to the exclusion of other types, and they may then form extensive beds of peat by their growth and partial decay.

SEED PIANTS.

The seed plants, or flowering plants as they are often called, are more differentiated in structure than the types already considered and are correspondingly more rigid in their requirements than the algæ and mosses. Among other well-marked distinctions is their very general dependence upon the soil for water and mineral matter. These they take up by subterranean organs, specially adapted to this purpose and called roots, with which they are usually provided.

Aside from the general necessity of attaching themselves to the soil, the seed plants also differ from the lower types by having their cells organized into tissues, and these are further differentiated into organs with special functions. This more complicated organism implies in turn certain exacting requirements as to favorable conditions for growth and development, and the various kinds of tissues, some of which possess great strength, enable the seed plants to reach large size; hence they usually contribute more abundantly and more noticeably than the smaller plants to any accumulations of vegetable matter which may be formed where they can grow. In general, except under the unusual conditions given below, they constitute the chief peatforming types, but they are land-loving forms, and only a relatively small proportion of the entire group is able to live in the water.

AQUATIC SEED PLANTS.

The aquatic seed plants may at once be classed in two chief groups: First, the kinds that are truly aquatic and grow habitually under water, sending only their flowers to the surface, and, second, those with a part or all of their vegetative organs, leaves, and stems, as well as flowers, reaching the surface and floating upon it, or rising into the air above it.

As most of these plants have roots which penetrate the soil at the bottom, each species is restricted in the depth of water in which it can grow by the depth to which sufficient light and heat can penetrate to permit the development of young plants from seeds and other propagating organs. The precise maximum depth at which this occurs apparently varies with the clearness and temperature of the water of individual lakes, but it rarely exceeds 15 to 18 feet, and very few species are able to start growth, or to persist after starting in water of such depth. 


\section{EFFECT OF SUNLIGHT AND DEPTH OF WATER.}

Toward shore from the maximum depth at which seed plants grow the number of individuals and species increases; each species, however, is limited by the depth of water in which it can thrive. Hence where the slope and the character of the bottom are constant enough to give uniform conditions at given depths entirely around the basin the growing plants will obviously distribute themselves around the deep water in definite bands or zones whose width will depend upon the angle of slope of the bottom.

Those species growing in water of the greatest depth are wholly submerged, and are characterized principally by slender, flexible stems, and long thin leaves. In somewhat shallower water, types like the water lilies will grow. Such types have leaves that rise to the surface of the water and float.

Plants of the last-mentioned kinds intercept the light falling upon their leaves, and when abundant so darken the water below that they keep submerged species from successfully competing, or suppress them entirely, and thus develop a zone distinct from that in deeper water. Plants of the pond-lily type thrive in moderately shallow water, except where they do not receive full sunlight. They are, therefore, restricted on the shoreward side to a depth of water in which grow those species whose stems and leaves reach above the water's surface and expand in the air above, intercepting the light and casting shadows. Plants of this sort are well represented by the bulrushes, some of the water-loving sedges and grasses, and other types, like the pickerel weed, that frequently grow in dense masses in shallow water along the margins of lakes and slow streams, especially where the bottom soil is good.

The plants of this type most tolerant of water and poor soil conditions are the lake bulrushes, Scirpus validus Vahl., and closely related species, which may spring up and thrive in water somewhat more than 5 feet deep. Species with floating leaves may obviously be overshadowed at this depth.

Shoreward from this maximum depth of slightly more than 5 feet, the light may be intercepted above the surface by plants that increase in numbers of species and individuals as the depth of water decreases. These plants crowd into the shallows and frequently take complete possession of the bottom by means of strong, tough, much-branched, underground stems and deeply penetrating fibrous roots, which by degrees form a firm dense turf by constantly increasing accretions of new growth. Periods of drought and consequent low water doubtless aid the advance of plants of this kind. Such periods afford conditions that are favorable to development of these plants and hasten the time when the turf may become so strong and buoyant as to build out from the firmer part of the bottom and form a floating marginal 
shelf or mat. This mat, rising and falling with the water level, is gradually extended by the constantly advancing plants until the open water in the basin is entirely filled and covered.

\section{DEPOSITION OF PLANT TISSUES.}

In the orderly sequence of plant groups above detailed each member of all of the associations adds to the bottom from which it has grown, at least a part of the tissues that it has built by its life processes. The more highly organized plants in sinking carry the numerous attached or entangled algæ and other organisms and fine sediments, and by so much increase the total deposit.

By this constant accretion of dead tissues the bottom on which any group of plants has established itself is built up, shoaling the water, and opportunity is given for shoreward types to occupy the new territory thus made available to them. They may then push lakeward or crowd out entirely the deep-water species that have so far held the ground and made it more habitable.

Each plant zone makes its advance in order from the older to the new position. But as the shoreward zones are more densely populated than those farther lakeward, and as the plants forming their associations are more abundantly supplied with firm, tough tissues and other vegetative structures, the upbuilding goes on more rapidly in shallow water. Because of these facts a tendency develops for the deep-water zones to become narrow as the slope of the lakeward face of the deposit gradually grows steeper. On the other hand, the tendency of deep-water zones to become narrow is checked to some extent by the spreading out of the accumulations of the shoal-water zones. Winds and currents act to spread these accumulations after they have been loosened by storm waves. In consequence the deposits are finally built up near enough to the surface to be covered and protected by the turf-forming plants. These are quick to occupy any areas of the bottom which approach the surface of the water, and prevent further disturbance of the surface of the deposit by holding the material firmly in place, so that from the time they gain roothold the growth of the deposit goes on steadily until its surface is raised above the level of the water.

Once started under natural conditions, this process goes on with only such interruptions as are due to fluctuations of the water level caused by variations in rainfall and evaporation, or by disturbances of the drainage of the basin, the lake becomes slowly but continually shallower and smaller until it entirely disappears and a marsh replaces it, and the basin is completely closed by the peaty remains of the plants that have grown in the water or slightly above its surface.

Therefore, the peat which accumulates in lakes, ponds, or other water-filled basins is built up at first by aquatic plants, including 
minute algæ, that form a deposit from the bottom and around the sides of the depression, extending out from the shore to a depth of about 15 feet. The material thus formed is added to in many cases and in varying quantity by drift material blown in from the shores by the winds or carried in suspension by inflowing streams.

\section{ZONES OF AQUATIC VEGETATION.}

In basins where the conditions of plant growth are favorable and certain kinds of plants become established, the aquatic vegetation arranges itself in well-defined zones more or less concentric around the deepest part of the lake. Each zone is characterized by some dominant group of plants, which in the northern United States are, broadly speaking, always as follows, beginning with the zone in the deepest water and progressing shoreward: (1) the pond weeds, Potamogeton; (2) the white and yellow pond lilies, Castalia and Nymphaea; (3) the lake bulrushes, Scirpus; (4) the amphibious sedges, Carex, Eleocharis, etc., especially the turf-forming slender sedge, Carex filiformis L., or species of similar habits. In the open water of any depth the unattached algæ and certain rootless seed plants may grow, and these often are abundant enough to constitute a considerable element in the formation of peat; very rarely certain mosses, including Sphagnum, are found growing in this way.

In the southern border of that part of the country where lakes and ponds are numerous and southward thereof, a peculiar semiaquatic plant, the swamp loosestrife Decodon verticillatus (L.) Ell., is usually found bordering the open water in a broad, dense zone, excluding all other species. This plant establishes itself by means of long, slender, arching branches, the tips of which develop buds and roots when they touch water, and thus form new plants from 1 to 3 feet away from the original station.

By the stem from which it grew the new plant is held in place for a year or more, during which time it may be able to secure firm roothold on the bottom below. In this way the open water of the basin is closed in, as fast as the peat is built up, by aquatic plants near enough to the surface for the roots of the Decodon to reach bottom.

The species forms dense woody stools, the tops of which rise several inches or even a foot above the water level. On these many kinds of plants find growing places and close in the open spaces between the stools until there is formed a firm structure on which shrubs and trees may at once establish themselves without the intervening period of the dominance of sedges.

Plants of each of these zones contribute to the vegetable accumulations, and as the mass of débris is slowly spread into the deeper parts of the basin, if these exceed the depth of 15 feet and the bottom is raised sufficiently so that the plants may grow upon it, they move 
into the newly made territory in the same order in which they have occupied the old.

It should be noted, however, that any or all of the zones of aquatic plants may, without perceptible cause, be absent from a part or the whole of lakes in which they might be expected to occur, and that few ponds in a given region have exactly the same species or the same abundance of individuals of the kinds present. It is nevertheless true that where the various zones of plants are at all completely represented, the order of occurrence given above is invariable, unless the bottom of the basin is broken by shallows or by deep holes.

\section{VEGETATION OF WET SEDGE MAT.}

With respect to the vegetation of the wet, poorly drained soils formed by the advance of plants upon a body of water, the conditions which exist in those places where a floating mat or marginal platform of turf has been formed by the sedges do not materially change until the mat is given stability and is fixed with regard to the normal water level by grounding or by becoming so thick that it no longer rises and falls with temporary changes of the water level. The mat is always sufficiently buoyant to prevent its sinking much below water level, and even when very old and sufficiently firm to support large trees it is rarely more than 4 or 5 feet in thickness. Where thickest and oldest it is always sharply differentiated in its structure from the deposit formed by the remains of the true aquatic plants below it, so that its rertical limits may be exactly determined.

In its younger stages of formation the mat is thin, being often less than 18 inches thick, and may have several feet of clear water below it. It also lacks the firmness found in later stages.

Upon the surface of the selge-formed turf, after it has ceased to rise and fall with the changes in height of the water, other plants than the selges make their appearance, and these also arrange themselves in zones, in accordance with their requirements for or tolerance of water about their roots. Most land plants require that their roots shall receive, by contact in the soil, the air which they need, and an excess of water, in so far as it excludes air, is detrimental. Thus, unless plants have special adaptations for supplying air to their roots, they are soon drowned out of saturated or very wet soils. This need of air for their roots is a most important factor in limiting the distribution of those terrestrial plants which are concerned in the formation of peat, and one which becomes operative as soon as a deposit reaches the surface of the water, or, in the case of the sedge mat, as soon as there is a portion of it exposed to the air.

HERBS AND SHRUBS.

Among the very first plants to appear upon such a surface are certain herbs, which may grow even on drift materials brought together 
by winds and waves on the mat while it is still floating, or on slight ridges formed by ice shove. The fact that these plants grow only on such elevations above the level of the water is a plain indication that they can not endure as much water as the semiaquatic sedges. It is by no means uncommon to find many of these first invaders of the sedge mat growing as epiphytes attached to the stools formed by groups of the stems of sedges, or attached to the stems of the larger types of sedges some inches above the water, their roots growing into the dead leaves and other débris that has found lodgment in such places.

Such pioneer herbs, principally annuals and therefore able to take advantage of a single favorable season, are quickly followed out on to the drier and firmer parts of the mat by certain shrubs of the heath and willow families.

Over much of the region where this kind of peat deposit occurs the most common of the pioneer heaths are the leather leaf, or Cassandra, Chamaedaphne calyculata (L.) Mœnch, and the Andromeda, Andromeda polifolia L.; other species of shrubs occur, but they are less general in their distribution or later in their appearance. The species mentioned form long, horizontal, underground stems, from which arise at intervals erect leafy branches; in this way the plants spread rapidly when once established and make a dense growth, which before very long shades and destroys the sedges.

SPHAGNUM, OR PEAT MOSS.

Sooner or later after the conditions enumerated have become established Sphagnum, the so-called "peat moss" appears, generally following the shrubs-more rarely, with them. Sphagnum is the large, grayish-green, whitish and pinkish moss, so widely distributed in swamps and bogs, ${ }^{a}$ especially in the northern part of the United States and in Canada. The plants grow continually at the top, dying below, and in favorable places individual plants may be found that have made a growth of more than a foot in length before the lower part of the stem is lost in the disintegrated mass below. As the individual plants approach the limits to which they can grow above the water level, growth becomes very slow, and they appear stunted and may finally dry up completely and be succeeded by other types.

On the other hand, the moss grows rapidly when once established and quickly raises the surface of the peat by pushing up among the branches of the shrubs with which it grows. As shown above, it is limited in its upward growth by the height to which water will rise from the general level through the spongy mass below the living tips, and this height, except in very moist climates, rarely exceeds a few feet. In Michigan the distance is seldom more than 3 feet and is often

a At least one of the species of Sphagnum occurring in the northern United States is aquatic and in one locality has been found growing as a floating plant in the open water of a small lake. 
less, but if the water level rises with the upgrowth of the peat, the moss débris may become many feet thick.

CONIFEROUS TREES.

Following the shrubs and Sphagnum appear a variety of coniferous trees, among which are the tamarack, Larix laricina (Du Roi) Koch; the black or swamp spruce, Picea Mariana (Mill.) BSP.; the arbor vitae, Thuja occidentalis $\mathrm{L}$., and, in certain places, the pines, especially the scrub pines, Pinus Banksiana Lamb. and Pinus rigida Mill.; and less often the white pine, Pinus Strobus L. These trees are replaced by others in the Coastal Plain region, but for each climatic district there are usually tree species that establish themselves after the sphagnum-shrub association has raised the general surface of the peat above water level. They appear first as scattered individuals and subsequently form a zone near the shore. From this vantage ground, as the basin is more completely filled or the water level is lowered, they eventually cover the entire area, and as they grow taller than the other plants and intercept a large amount of light they soon destroy such plants as require the full sunlight for development.

\section{DECIDUOUS TREES.}

Following the coniferous species, certain broad-leaved deciduous trees secure foothold and in their turn displace the conifers by overshadowing the latter during youth. The deciduous trees form the end of the cycle. By the time they have become dominant the surface of the peat has reached such a height, above the level of the ground water that disintegration and decomposition go on each year at about the same rate as accumulation from additions to the deposit made at the surface by the trees, and thus the conditions of the soil are kept stable.

At any time, however, if there is a marked and sufficiently long elevation of the water level the trees will be destroyed, and those lower-growing types of plants that are adapted to the new conditions will reappear. These will begin again the work of peat forming, and the series of stages above described will be passed through until once more the trees are established.

\section{DEPTHS AT WHICH DIFFERENT KINDS OF PEAT ARE FORMED.}

The many minor variations of the way in which lakes and ponds are filled are of scientific interest and importance. It is, however, sufficient to note here that where the depth of water is less than 10 feet the plant species usually restricted to water of greater depth may be entirely absent and a whole lake may have only a single type of plants conspicuously present or only such zones as are found in shallow 
water. Or, even in shallow basins, the water may be so dark colored from the presence of suspended and dissolved organic matter that all but floating aquatic plants are absent. Under such conditions the basins fill from the margins chiefly and from material washed and blown into them, and the actual formation of peat makes little progress.

Lakes in peaty swamps, such as those in the southern part of the Coastal Plain, have water of this character and are conspicuous for their lack of aquatic vegetation and for the small amount of peat that they contain; those in the same latitude with clear water have an abundance of plant life and are often partly filled with peat. The writer attributes the absence of plants in lakes with dark water to lack of light rather than to other factors, because the shores and shallow waters of such lakes are often crowded with the same kinds of plants that live in similar habitats in clear lakes. The absence of aquatic vegetation has also been noted in lakes of brown water in other regions than that mentioned, and there also the same close connection between water coloration and plant growth seems to exist.

SUMMARY AND CONCLUSIONS REGARDING THE PEAT OF WATERFILLED DEPRESSIONS.

In general, it may be said that ponds and lakes are often filled with peat nearly to water level by the accumulation of the remains of aquatic plants, which vary definitely in type according to the depth of the water; that from near the water's surface to slightly above it sedges are the important contributors to the peat; and that because of slow elevation of the water level from any cause or because of slight sinking of the turf which they form, their remains may constitute several feet of the top of the peat deposit.

After the surface of a peat accumulation is raised so far above the water that it no longer is overfiowed, herbs of many kinds may replace the sedges; when it is permanently from 6 inches to a foot above the water level, shrubs and Sphagnum usually take possession. When the accumulation has reached a depth of a few inches more, trees become the dominant plants. With their appearance the peat practically ceases to increase in depth unless there is an elevation of the water level. The chief points to be noted are: (1) That peat which has been formed in basins is largely built up by aquatic plants; (2) that the vertical range of the growth of such plants is from the surface to a depth rarely exceeding 15 feet, at which depth the formation of peat by plants attached to the bottom practically ceases. Peat of greater depth than this below a water level that has been constant since the filling began is generally made up of the remains of floating 
organisms mixed with fine organic and mineral silt and other mineral matter brought in by streams, etc.

These facts have a definite bearing on commercial exploitation in that they point out the limits of depth at which certain kinds of peat may be expected to occur in filled basins. Since water retards decomposition and carbonization, the peat found below the water level in basins will be only slightly decomposed although usually thoroughly disintegrated.

PEAT FORMATION ON POORLY DRAINED, FLAT-LAND SURFACES.

\section{DRAINAGE CONDITIONS.}

A consideration of the accumulation of peat on moist, or wet, poorly drained land surfaces, whether these are without inclination or sloping, will involve the same laws of plant growth as in the preceding discussion. Peat will form wherever plants will grow, provided that the organic matter is kept constantly saturated with water.

Included as flat areas in this discussion are plains, plateaus, lake and stream terraces, valley floors, deltas. flood plains, and other types of land surface, which are too young, too flat, or too frequently covered by water to be well drained, and on which, therefore, the water level for the greater part of the time is at or near the surface, the soil below being saturated. On such surfaces the conditions of peat accumulation are manifestly different from those already discussed in that the level of the water is below the surface, or, at most, only slightly above it. This at once eliminates all of the kinds of plants enumerated above except those of the very shallow water or the wet shore.

\section{VEGETATION AND VEGETABLE DEPOSITS.}

The plant types most commonly found in the kind of places under consideration are grasslike in form. They have long, slender leaves and weak aërial stems that die down to the ground or perish wholly at the end of the growing season. Many of them, however, have horizontal underground stems that persist through several years; from these grow great numbers of long, threadlike, much-branched roots that penetrate the soil for considerable distances. Sedges, grasses, rushes, bulrushes, and cat-tail flags illustrate this type of vegetation. The whole group may be called turf-forming plants, since the underground stems of individuals of many of the species spread out horizontally in all directions and soon become interwoven and bound together by the numerous roots to form a compact, tough mat of regetable matter. To this the growth of each succeeding year adds material, and after a time it may be stripped from the underlying soil without breaking. 
The aërial parts of the plants, falling to the ground at the end of the growing season first form a covering for, and later, by the processes of decay, are added to the top layers of the soil and become incorporated in the turf.

If a poorly drained, wet area of mineral soil is freshly exposed to the ordinary influences of the climate of the region in which it lies, the usual results are that the seeds of many kinds of plants fall upon it, through various agencies of seed dispersal; that some of these seeds germinate; and that some of the seedlings reach maturity. Plants of such origin vary largely in their power to adapt themselves to the conditions of growth that surround them in the new environment; some will persist and others utterly fail to establish themselves.

Those that establish themselves, however, almost immediately begin to modify the soil conditions (1) by hindering evaporation from the ground surface and (2) by checking the run-off of the surface waters, which are thus held back in their passage over the area, and consequently rise to a higher level than before the plants appeared. The increased wetness is unfavorable to many kinds of plants which may appear on such land, and they disappear from the area more or less promptly, according to their tolerance to excess of water in the soil.

After a time, which varies according to the existing conditions in a given locality, but especially according to the level permanently reached by the ground water at the end of any period of plant occupation, the area will be covered by a definite group of plants, which even casual examination will show to be made up of large numbers of individuals of a much smaller number of species. Under the supposed conditions, peat formation begins soon after the establishment of plant associations that permanently cover the ground, provided that the water level remains high enough in the ground to prevent the complete decomposition and disintegration of the débris resulting from the growth and death of the plants constituting the associations.

The commencement of peat formation introduces still other complications into the conditions that vegatation must meet in order to maintain itself, because the structure, texture, and composition of the soil are changed, its wetness increased, and certain products of growth and decay that are injurious or even poisonous to some kinds of plants are introduced into it. The soil water is increased because the decaying vegetable matter and the peat act like a sponge-holding the water absorbed by them. They also clog up small drainage channels and thus hinder the run-off of meteoric water falling on the surface. The substratum in which the plants must grow becomes fibrous; it also becomes poor in mineral matter and in available necessary gases and, sometimes, rich in toxic matter. 
After a time, however, the period of adjustment is completed and a state of stability is reached; then the plants fitted to thrive in or endure the environment offered are able to establish permanent associations. Following the state of stability, if other factors of plant growth remain unchanged, the development of the peat may go on rapidly; this in turn may check the outflow of water from the area. Hence, as the deposit is built up, the water level may rise and maintain a nearly constant relation to the surface. The invasion of new kinds of plants is thus prevented and the peat may accumulate to the depth of many feet, as the result of the growth of plants of the same type, associated much as they were in the early stages of peat formation.

\section{RELATIVE IMPORTANCE OF DIFFERENT TYPES OF PLANTS.}

Although the herbaceous types of plants assumed to take possession of the wet area in the foregoing discussion are those which are most frequently found in such places, it is evident that they are not the only ones which may become dominant. If the average water level on the area were from the first sufficiently far below the surface, woody plants (shrubs and trees) instead of the kinds described would form the permanent plant covering. Such a plant association would imply better aëration of the soil than would herbs. It would also involve more complete decomposition and carbonization of the finer vegetable structures that reached the ground, and hence the accumulation of a darker colored and less fibrous peat. This, however, would usually contain considerable quantities of partly decomposed wood.

The formation of peat by woody plants seems to be more frequent in southern than in northern parts of the United States. This condition may be attributed to the greater rapidity with which the water level is lowered in the warmer climate of the south by evaporation and run-off as well as to differences in the texture of the original mineral soils, owing to diflerences in origin.

It is also possible, where the air is very humid, as in places near sea level and close to the margin of the ocean, that some of the lower types of plants, such as mosses, will become the most important members of the group of plants growing on the area, and may form peat beds of considerable depth and extent. The best illustrations of this type of peat bog occur in the extreme northeastern part of the region under consideration, in eastern Maine, where beds of peat built up to more than 20 feet in thickness, chiefly by Sphagnum, are not uncommon. 
SIGNIFICANCE OF THE TYPES OF PEAT STRUCTURE.

When the growth of the peat is not accompanied with a corresponding rise of water level, there will clearly be a change in the plant associations and in the types of plants growing on the surface as this is built up above water level and the drainage improves. The record of such changes in the character of the vegetation will be preserved in the peat beds. These will be irregular in structure, and, if mature enough, the upper layers will be more thoroughly decomposed than any of the others, since they will be most completely aërated.

Such beds will normally increase in depth until the surface gets so far above the water level that wasting goes on as fast as deposition; then, unless some change in the supply of water occurs, no more peat will be formed. If, however, for any reason, such as increased rainfall or obstruction of the drainage by fallen timber, the groundwater level rises again, a new period of peat accumulation begins, and the structure of the peat deposited is changed according to the type of plants that the new conditions establish. Hence, beds of peat built up under such conditions show heterogeneous structure in which the changes in the water level are recorded in variations in the kind as well as in the degree of preservation of the vegetable matter laid down and preserved.

If it be assumed that the remains of trees and other woody plants indicate the lowest level of the soil water possible for peat formation, a number of woody layers in a given bed of peat indicates an equal number of approaches to this maximum unfavorable stage. Also, beds of moss and shrub remains usually indicate less favorable conditions than do beds of grasslike plants.

\section{PEAT FORMATION ON SUBSIDING COASTAL AREAS.}

It may be considered demonstrated from the foregoing that the remains of plants, preserved as they grew but below that level of the water at which the species can live and grow, indicate with certainty either that the water level has risen since they were alive or that the land surface below the deposit has sunk.

If the given area is near the continental margin, and the groundwater level is affected by the sea water, significant changes of level may often be attributed to movements of the ocean bottom and the adjacent land. The evidences of the operation of such a cause are very clear when remains of plants, to which even a small amount of salt water is known to be fatal, are found submerged below the sea. In many localities stumps and roots of trees, associated with deposits of peat built up by fresh-water plants, are now buried below sea level by later salt-water deposits, and some such remains are even found in the seaward side of the present ocean beach.

$661^{\circ}-$ Bull. $16-11-3$ 
With the assumption that the existence of such conditions shows that at least portions of the coastal plain have actually sunk, the effects of such subsidence on the formation of peat may be considered. The first effects of the subsidence will be to modify the drainage of the region in which it is taking place by checking the outflow of water from the mouths of the valleys that reach to or below sea level. This stoppage will increase the wetness of the wet parts of the region of subsidence by so much as the water is beld back upon them by the inflowing tidal waters. After a time a reaction of this increase of water in the soil upon the vegetation should be evident and should be recorded in contemporary peat beds. If the subsidence is rapid enough to cause the water level to rise faster than peat is formed, the character of the vegetation preserved in the peat should vary to show this condition; more aquatic forms should appear in the upper than in the lower layers. When the rate of growth more nearly equals that of subsidence, the resulting peat should be more uniform in structure; the principal apparent changes should be those marking the transition from fresh to salt water conditions when the tide finally overflows the area of peat deposition. However, no sharp line of division may exist, since under the assumed conditions there may be a considerable deposit of the remains of plants that tolerate brackish water. The more durable parts of these are very similar in structure and appearance to those of species growing only in fresh water.

If the rate of the subsidence exactly equals that of the growth of the peat, the same kinds of plants should theoretically continue indefinitely to form the bulk of the peat. Actually, however, because of erosion and the effects of storms, after the surface of the peat has been brought near the high-tide level, salt water is likely to cover it with increasing frequency during storms and spring tides, so that salt-marsh conditions gradually develop.

\section{SALT-MARSH PEAT.}

Salt-marsh peat deposits and those made in areas overflowed by salt water are generally at once distinguishable from those formed under usual fresh-water conditions. The former contain a large amount of finely divided mineral matter, usually sufficient to give them a noticeably grayish color when dry, and gritty feel when crushed between the teeth. On parts of the ocean shores exposed to strong wave and current action, the mineral matter is gathered up by the sea water from the shallows and settles on the areas of overflow, wherever the motion of the water is arrested. 


\section{RELATION OF FORMATION TO TIDAL LEVEL.}

It may be said at this point that but little vegetable matter accumulates between the average low and high tide marks. This is due partly to the constant motion of the water and partly to the very sparse vegetation between the zone near low water where the common eel grass lives, and that of the surface of the salt marshes on which salt water stands only during the high tides. If peat occurs between these, it must have been formed by plants growing at or above the usual level of the tides, and must indicate subsidence to the extent of its thickness, or more, if the structure of the peat is such as to indicate fresh-water origin. If then the section of a bed of peat in a salt marsh shows that it has been built up to a thickness of several feet by plants such as are now found on the surface of the marsh at or slightly above the average high-tide level, the formation of the material has evidently gone on at that level, and on a substratum that was subsiding at the same rate as the upbuilding which gave conditions of plant growth that were the same throughout the whole period. If plant débris had accumulated faster than the bottom subsided, fresh-water plants would have supplanted the salt-marsh flora as soon as the surface strata had been built above the tide; if the bottom had sunk faster than the rate of upbuilding, plant remains would have given place to mud and silt.

By a similar consideration of the possible conditions surrounding the growth of plants at and near the high-tide level, it will be possible to obtain records of irregular periods of subsidence, and of slight oscillations of the plain forming the continental margin. These periods affect the quantity and quality of the peat formations in the region in proportion to the length of time which they continue. In some observed cases where salt marshes have protecting beaches between them and the sea, the destruction of the barrier may permit freer inflow of the tides and suddenly modify the peat-forming flora. Such effects, however, would be small in character and extent in relation to the whole coast and would not cover very wide areas nor considerable depths.

\section{ECONOMIC VALUE OF SALT-MARSH PEAT.}

Economic importance attaches to the invasion of salt waters, heavily laden with silty mineral matter, into areas in which ordinary peat has been formed. The peat that is developed after the saltmarsh plants appear is usually too high in ash to make satisfactory fuel. In general the beds of peat resulting from salt-marsh conditions, as outlined above, can have only local use and will furnish very low-grade fuel. They may probably be used as sources of power gas, 
although even for such use trouble is likely to occur from the high ash content and the fusion of the mineral matter into slag and clinker in the gas producers.

\section{PEAT FORMATION ABOVE FILLED DEPRESSIONS.}

The plains formed by bogs filling depressions are often so wet that peat formation continues above the original level of the water in the depression. In such places the plant associations establish themselves in accordance with the laws which have already been discussed. The ones best adapted to the existing environment invade and hold the area as long as conditions remain suitable for them, and peat formation goes on until the water no longer rises sufficiently to prevent desiccation and oxidation of the plant débris as it accumulates.

The effects of prolonged drought upon peat formation in such places are the same as in other situations, and are such as follow the lowering of the water level and the penetration of the air into the accumulated vegetable matter. These two factors permit the entrance of organisms producing decay which, with the air, disintegrate and blacken, or carbonize, peat, reduce its bulk and lower its surface. This is particularly true around the margins of the swamps where the peat is already thin and the drying most severe; in such places there is often a well-defined depression resulting from the alternating rise and fall of the water level due to seasonal and periodic fluctuations of rainfall and evaporation.

In any peat deposit, blackened, thoroughly decomposed layers, either with or without woody matter, may be taken to indicate a period of low-water level or drought. If such layers recur at various levels they show that the conditions have been repeated from time to time in the history of the deposit.

On the other hand, periods of unusual precipitation and moisture may be recorded in peat beds by poorly decomposed and fibrous strata of plant remains, or, if long continued so that the water permanently rises, by an entire change in the kind of material present in the contemporaneous strata.

\section{LATERAL GROWTH OF PEAT BEDS.}

Incidental to the growth of peat, there may be so much interference with the drainage that swamp conditions may spread laterally and cover with peat a part or all of the plain surrounding the depression, or they may even push up well-defined slopes where climatic conditions are especially favorable for the formation of peat. Discussing the possibilities still further, it may be said that on very broad, flat plains or on gentle slopes, in regions of heavy rainfall and high atmospheric humidity, the lateral spread of the peat, as a swamp increases in diameter, will at length react on the vegetation of the 
most poorly drained part because in that place the water level will rise in proportion as the water fails to drain away. This rise in water level will make conditions less favorable for plant growth, and peat will not accumulate as fast as in the surrounding areas, and thus a pond may be formed. Later, since the accumulated water in such places is usually very dark colored and only slightly transparent, thus preventing the growth of aquatic plants below its surface, the area. covered by water will increase as the peat is built up around the margin.

Such ponds should not be confused with the many small, deep tarns in the middle of small swamps and peat bogs, as these are manifestly the open water in the unfilled part of a depression. In the former type the water in the lake will be no deeper than the peat surrounding it, if it is as deep, whereas in the latter it may be much deeper.

\section{RATE OF PEAT FORMATION.}

No data of value relative to the rate at which peat is formed in the United States have been obtained, but there are indications that the rate varies greatly even in the same locality.

\section{GENERAL CONCLUSIONS RELATIVE TO THE FORMATION OF PEAT.}

Many factors may operate to change the character of the dominant types of vegetation from which peat beds may originate. These factors may also affect the resulting peat, under the varying conditions of climate existing over the great areas of the United States in which peat may be found. The resulting material must evidently vary quite as much from the operation of external causes as from the form of the land surface upon which it is built up.

This fact emphasizes the necessity of considering in detail the possibilities of origin of the substance in any given deposit before deciding to use it for any given purpose, in order to find how much of the entire amount is available for the desired use.

\section{PRACTICAL APPLICATION OF THE PRINCIPLES OF PEAT FORMA- TION.}

Aside from the purely scientific interest attaching to the study of the origin of peat is the consideration of the practical and economic utilization of individual deposits. In fact, only by knowing under what general laws the substance is developed can statement be made as to whether a given deposit of peat can be used profitably for certain special purposes. To illustrate, after brief preliminary tests, with a properly constructed sampling tool, the laws governing the accumulation of peat can be applied to any bog with sufficient precision to determine to which general class it belongs, and whether it may be drained to the bottom. 
Filled depressions can not be drained lower than the bottom of the existing outlet, except at great expense, or under very unusual conditions, so that any peat deposit of this type can be more cheaply worked without attempting drainage.

Where the structure of the peat, as determined by preliminary tests, shows that it has been built up layer upon layer, on a flat area, it can manifestly be drained to the very bottom of the deposit, and by beginning at the outlet, or lower end, can be drained by easy stages, as utilization progresses.

Application of the same laws to the structure of bogs will demonstrate that the peat of mature bogs in filled depressions is never of the same structure from top to bottom, since it has been formed by plants growing partly below and partly above water level. Moreover, the lower strata of the peat are of much greater fineness than the upper and are almost, if not quite, free from fibrous matter of all sorts, and are not adapted for any use requiring a large proportion of fiber. The latter will be found only in that part of the peat formed above, or immediately below, the water level, and will be at most only a few feet thick.

On the other hand, built-up bogs may be composed of the same sort of material for the greater part of their thickness, since the ground water level of the deposit may always have been in a definite relation to the surface of the peat. It is generally true that such bogs rarely exceed 15 feet in depth even when they cover very wide areas, and they are much more likely to include woody layers containing stumps and roots of trees than those of the other type.

The same general statements are applicable to deposits formed by the subsidence of the bottom on which they are built, with the additional assertion that such deposits contain a large percentage of silt where they lie below tide level, and hence are of low fuel value. 


\section{PHYSICAL AND CHEMICAL PROPERTIES OF PEAT AS RELATED TO ITS FUEL VALUE.}

\section{PHYSICAL PROPERTIES.}

Peat as it is found in undrained bogs is a mixture of water and of partly decayed and disintegrated vegetable matter of varied origin. The amount of water present is generally sufficient to saturate or supersaturate the vegetable material and constitutes from 85 to 95 per cent or even more of the weight of the mixture.

Even in drained bogs a short distance away from the ditches the water content seldom falls below 80 per cent, as the rain falling on the surface is quickly absorbed by the mass of the peat, through which it drains very slowly. The slow movement of water to the ditches in peat beds is shown by the fact that for a considerable distance above the water level in the ditches, or even when no water is standing in them, water can usually be squeezed from the material taken from their walls.

Aside from this generally high water content, peat is exceedingly variable, so that scarcely any two deposits contain material which is exactly similar in all of its physical properties. These properties also normally vary in peat from different regions. Material from the north may be quite dissimilar in appearance and other physical properties from that farther south, east, or west, because not only are the kinds of plants from which it was derived different, but also the climatic effects on their accumulated remains during deposition. It also must be apparent from the discussion of the ways in which peat is formed, that peat in bogs of distinct types in the same region must differ physically because the conditions of accumulation and the original vegetable matter must be different. Considering the matter still further, it may be shown that the upper layers of peat in a given deposit are often distinct in many of their properties from those below them, and in the bogs that fill depressions are practically always so.

The considerable variation in the properties of peat is due to many causes, the most important of which have been briefly discussed. Although this variability is unimportant to those who propose to prepare peat for fuel by any of the simpler methods, it must be carefully considered by all who intend to use the material for special purposes or processes because of the relatively small quantity of the required kind of material that may be found in a given peat deposit. Not only must the limited quantity be taken into account, but when fiber or similar material is sought for the 
manufacture of certain kinds of products there must be considered, also, the quantity and probable condition of the fiber and the proportion thereof that can be used as compared with the material to be excavated and handled to recover the usable part. By no means of least importance, also, is the cost of production and the value of the final product when compared with that obtained from other substances already in use.

\section{COLOR.}

In color peat ranges from light-yellowish or straw tints through various shades of yellowish brown, reddish brown, and dark brown to jet black. All of these colors are darker when the peat is wet, but the lighter shades usually change to black or dark brown after the peat is macerated and exposed to the air. The color sometimes darkens immediately after the freshly cut sample comes in contact with the air and before it dries to any appreciable extent.

In general, the top strata of a given deposit that has a low water level will be black or dark colored, whereas those below the water level will be lighter in color, but in a built-up deposit there may be darkcolored strata interbedded with or lying below lighter ones.

It is seemingly true that all beds of peat to which the air has had access have been blackened or at least darkened in color, and it is only in such beds as have been dried out to the bottom and thoroughly aerated that a progressive darkening from the top to the bottom is found. The blackening is due to the oxidizing of the more complex organic compounds to simpler ones and the liberation of certain gaseous constituents of the vegetable matter, largely by biochemical activities of low organisms, chiefly plants. The oxidation tends to concentrate the carbon of the plant débris in its simpler dark-colored or black compounds, which give the color to the resulting mass.

Peat that is greenish when wet or that is gray, rusty, or spotted with white when dry, or that is unduly heavy, owes these characteristics to the presence of mineral matter and is probably unsuited for fuel for ordinary purposes. Rarely, however, do appearance and color of peat, even in the dry state, indicate whether or not it contains mineral matter enough to render it useless, except when silt and sand grains are present in sufficient numbers to be seen on close inspection of the dry sample. Such material should be looked upon with suspicion and carefully tested before using. A report from Mexico, where fuel is high priced, states that peat that has been washed to free it from sand is marketed with profit.

TEXTURE.

The texture naturally depends upon the kinds of plants from which the peat is formed and the conditions under which their remains have accumulated. If the original vegetation was largely trees and shrubs growing slightly above the level of the water, the peat is woody. If 
the growing plants were of grass-like structure with tough, fibrous leaves, stems, and roots built into a compact turf near the water level, the peat derived from them is fibrous and generally poorly decomposed. If such materials have accumulated much above the preserving effect of the water, the fibrous structure may be lost and the whole be uniformly of fine grain. Grass and sedge peat, in shallow deposits in those parts of the country where there are prolonged summer droughts, are often so thoroughly decomposed as to be almost without fibrous matter, except such as is furnished by the roots of plants growing upon the surface of the bog.

Mosses, including Sphagnum, the so-called peat moss, are without fibrous tissues of any sort, although their stems are somewhat durable under ordinary bog conditions, so that true moss peat, even when poorly decomposed, does not furnish fibrous material. Peat of this sort is of rare occurrence, however, and the mixed moss and sedge peat of the northern and northeastern parts of the United States often has considerable tough, fibrous matter derived from cotton grasses, Eriophorum, and other sedges.

The water plants, because of their lack of fibrous and durable tissues and of the conditions under which they grow and decay, form a structureless, cheesy substance, lacking both wood and fiber, except where there is an admixture of drift material from land plants, as sometimes happens. The bottom layers of filled bogs, therefore, are made up of soft, oozy peat, and are worthless as sources of fiber for any purpose, but, conversely, may make better fuel than more fibrous types.

It is apparent, then, that the texture and uniformity of peat in a given deposit depend upon (i) the kind of bog, whether filled or built up; (2) the general types of plants whose remains have been incorporated in the peat; (3) the completeness of their disintegration, which is in large measure controlled by the position of the groundwater level relative to the surface during the formation of the deposit. The disintegration is indicated in general by the shade of coloration, the more thoroughly disintegrated material being the darker.

Variability in the texture of peat, as has been indicated elsewhere, is the rule, even in parts of the same bog. Bogs of very moist regions, like those of the northern and northeastern parts of the United States, are less likely to show large variations than are those occurring where periods of heavy rainfall alternate with droughts. In the latter regions there are frequent changes in the conditions of growth of the vegetation, and in the conditions attendant upon the decay of the resulting collections of débris. Thus the peat beds of the South and the Middle West, having been formed under the last-named conditions, are likely to be more woody and less fibrous, as well as much more thoroughly decomposed, than those of similar types found elsewhere in this country. 


\section{COMPOSITION.}

For purposes of this discussion, the solid material found in peat beds may be considered as regards origin to be of two sorts-organic and inorganic. The first includes such material as has been accumulated by the life processes of plant and animal organisms, the second includes extraneous mineral matter present as impurities and generally not directly traceable to the activities of organisms. Each of these groups may be subdivided into two others-soluble and insoluble material. Group 1 may be subdivided still further into carbonaceous matter and mineral matter, the former being combustible and the latter incombustible and constituting the ash-forming substances of the peat.

The carbonaceous or combustible portion of peat is chiefly of vegetable origin. Doubtless, however, the more durable parts of many small animals, especially insects and crustaceans, enter into the composition of types of peat formed below water level, and sometimes may be present in sufficient quantities to give to the smoke from burning peat a distinct trace of the characteristic odor of burning chitin.

The purely vegetable constituents of peats are generally in various stages of disintegration and division as the result of chemical decomposition and physical maceration of the original plant tissues from which they have been derived. A part of this comminution is purely mechanical, the result of the action of wind, water, and other forces on the material before it reached the place of final deposition; some of it results from combined mechanical and chemical action, and some appears to come from chemical action of air and water. Much of it is due to biochemical agencies, as many kinds of animals and of plants, including the bacteria and fungi, as well as the roots and other underground organs of higher plants, play some part in the reduction of the highly complex plant material to the structureless pulp of well-decomposed peat. In the disintegration due to the chemical agencies actual changes of composition occur in the chemical compounds of the plant tissues concerned. A part of their constituents form new and simpler compounds, some of which are soluble and some are gaseous. The soluble ones are taken up by the water, to which they impart a distinct color and often an acid reaction; the gases escape into the air, either imperceptibly or in the form of bubbles, or are absorbed by or dissolved in the water.

As would be expected, it seems generally true that the herbaceous plants and the softer and less woody parts of other plants are most easily broken up, and their fragments enter largely into the composition of the finer matter of peat beds. On the other hand, woody and fibrous tissues are often found to contribute abundantly to such material, but some of the algæ and mosses seem very little subject to disintegration, although of exceedingly delicate texture. As is gen- 
erally known, well-preserved roots, stumps, and boles of trees, and, to a less degree, of shrubs, are common in peat beds. In all cases, however, peat that has been exposed in a moist condition to the air, and has been subjected to the invasion of the soil fungi and bacteria and the attacks of low types of animals, is most nearly structureless; that which has been continuously covered by or saturated with water often contains very fragile and delicate plant organs preserved entire.

The mineral matter that has been segregated in peat beds by organisms varies greatly in form and quantity. Of the total dry weight, the purest peat contains only 2 or 3 per cent in the form of mineral matter, although such a small proportion is unusual, and from this minimum we find every gradation to pure mineral soil. In those deposits in which the quantity of mineral matter is small, it has usually been collected and deposited by the plants of which the peat has been formed and by the animals associated with them; that is, it is all of organic origin. The assumption can not be made without investigation that where a large amount of mineral matter is found it has not been concentrated by the same sort of agents, because in limestone regions much calcareous matter is secreted from the ground waters by water plants (especially by Chara and more minute algæ) and deposited with the carbonaceous matter, or in excess of it in some cases. In addition, many types of plants growing in the water or in wet places deposit considerable quantities of silica in their cell walls. The diatoms, very minute water plants often enormously abundant in lakes and ponds, the scouring rushes or horsetails, Equisetum, grasses and sedges, and many of the higher plants are examples of this type. Many kinds of plants are also known to collect as crystals in the walls and cavities of their cells and tissues more or less mineral matter of other kinds than those mentioned. Animals contribute bones, teeth, and shells varying in size and composition from the calcareous bones of the gigantic extinct elephants, the mastodon and the mammoth, to the minute siliceous shells of microscopic water animals.

The mineral matter of peat, which can not be considered as of organic origin, is derived from two principal sources. It is either brought in by the water or blown in from the surrounding land. The water-transported material is carried to the peat either in suspension or in solution. In general, the amount of deposition from suspension is much greater and of much more importance than that from solution, because it may be considered to include not only finely divided mineral matter transported by waves and currents, but the coarser rock fragments floating about supported by ice masses. Stones and pebbles, as well as the finer sands, silts, and muds, are thus borne into peat beds and left at times of high water, and in all deposits subject to overflow from streams, lakes, or the ocean, a greater or less quantity of such material will be found. 
What might be important sources of fuel supply are often rendered unfit for use for this purpose by the great amount of incombustible matter brought to them by some small stream, or their prospective value is greatly lessened by the presence of stones, which limit the use of machinery.

The dissolved mineral substances brought to peat beds are of less importance than the kinds considered, but if they are sufficiently abundant they serve as sources of supply for their precipitation by organisms, as already mentioned; or they may be chemically precipitated in the peat as insoluble substances, or be concentrated by the evaporation of the water from the surface of the peat, and thus become important impurities. Iron sulphide, often found in peat, is an example of a chemically precipitated substance. The ferrous sulphate and the salts of magnesium and calcium which accumulate in peat subject to overflow by spring and pond waters rich in mineral matter or lying above beds of marl may also be taken as illustrations of concentration due to evaporation. Much of the mineral matter brought to peat in solution is retained because only the water evaporates, and appears in the ash after the peat is burned; hence the peat in regions where the ground water is mineralized, as where limestone predominates, is likely to have more ash than that of areas of pure water such as occur in granitic regions.

The material brought to peat beds by the wind is chiefly fine dust. Such material constitutes an important part of the ash in peat along the border of the great plains region, but is practically lacking in peat from the moister parts of the United States. Along the shores of the ocean and the Great Lakes, where bogs are formed in hollows between lines of sand dunes, sand is often blown into the peat during storms, and peat deposits of this type may contain much sand.

\section{WATER-HOLDING CAPACITY.}

From what has already been said, it is apparent that peat has great capacity for taking up and holding water. In fact, the bogs of Europe and especially of Ireland often become greatly swollen during rainy seasons and sometimes burst and flood the surrounding country with pasty peat and water.

The water present in peat appears to be held by the plant remains in three ways, two of which are mechanical. Of the mechanically held water a part only is removable by pressure or other mechanical means. Prolonged trials made by many competent experimenters show that only a relatively small per cent of the water can be pressed from peat having at the outset 90 per cent moisture, that is, about the quantity found in peat as it lies in the bog. The remainder of the included water resists the greatest obtainable hydraulic pressure and the best centrifugal machines, and can be removed only by evaporation. If the quantity present originally is below 90 per cent, 
the percentage removable by pressure is correspondingly reduced. In other words, the removal of the water that can be pressed from peat does not reduce its water content much below 70 per cent, and the rest can be driven off only by heat, derived either from the sun and air or, more expensively, from an artificial source. This residual water is largely held in the cell walls and the minute cavities of the cells of the plant remains. It is clearly not held in chemical combination, as it can be entirely removed by gentle heat without destroying the nature and structure of the peat. After drying under proper conditions, the peat will again take up water and will assume its former appearance and condition; drying destroys the cementing compounds in the peat, however, and peat that has been once dried out, even if again thoroughly wet, will not make good machine-peat bricks.

The quantity of water thus held in peat varies somewhat, being less in black, thoroughly decomposed types than in the more fibrous brown ones, but the variation does not seem to be very large, and does not warrant the attempt to use pressure for completely removing water from any kind of peat. Thorough maceration or grinding also has the effect of rendering the water more free in its movement in the peat. This effect is probably due to increased uniformity of texture thus produced and not to breaking up the cells of the plant remains, as these are exceedingly minute and would not be much affected by the coarse machinery commonly used for grinding peat.

After thorough maceration and puddling, if the peat mass is allowed to dry slowly to an air-dry condition, it contracts in bulk and dries into a hard and firm substance that absorbs very little water even if thoroughly immersed. Untreated peat, on the other hand, dries into a loosely aggregated mass, which takes up water readily and is very friable and easily broken up in either wet or dry states.

Peat that has been dried below the air-dry condition quickly absorbs moisture from the air until it is again air dry, and its moisture content then varies with the relative amount of moisture in the air, so that air-dried peat contains a lower percentage of water in a dry climate than in a moist one, or in dry weather than in wet.

WEIGHT, DENSITY, AND SPECIFIC GRAVITY.

The different types of peat, as is indicated by their differences in structure and appearance, vary considerably in weight for a given unit of volume. They also vary in specific gravity; that is, their weight compared with that of an equal bulk of pure water which is taken as unity. The actual specific gravity of plant fiber, and of peat substance derived from it, is greater than unity; hence these materials free from air and other included buoyant matter would sink when placed in water. Under ordinary circumstances, however, 
because of the many open spaces and air-containing cavities in peat, the specific gravity, as obtained, is generally much less than unity. The figures determined for the dried peat substances range from about 0.1 for very fibrous, light-colored, and poorly decomposed moss peat to 1.06 for the heavy, compact, fine-grained, thoroughly decomposed black kinds, which, when dry, are almost as hard and black as bituminous coal. The darker brown, fibrous, and partly decomposed types are intermediate in character, and their specific gravity varies from 0.25 to 0.70 , or even more, if it happens that there is much included mineral matter.

The actual dry weights of these grades per cubic foot are, for the lighter and undecomposed fibrous kinds of moss and sedge peats, 7 to 16 pounds. For the brown and dark brown and more thoroughly disintegrated types the weight ranges from about 15 to 45 pounds per cubic foot. The dense, black, nonfibrous kinds that are thoroughly decomposed weigh from about 40 to more than 60 pounds per cubic foot of dry matter. These weights will be increased if the ash content rises above 15 per cent of the total weight of the dry peat, as the mineral matter of the ash has a high specific gravity. Therefore, before any other tests are made, peats that are very heavy and compact when dry should be examined to see if they do not contain too much ash for fuel purposes.

In order to get the true weight of a cubic foot of peat, the mass weighed should be as compact as possible without compression, since if the dry material be in the form of lumps or of disintegrated fibers, air spaces will take up a considerable part of the measure, and the weight obtained will be too small.

It may be noted therefore that the fibrous, light-colored, and poorly decomposed peats are light in weight when compared with the darker homogeneous, and more thoroughly decomposed kinds, and make more bulky and less easily transported and stored fuel and require much more thorough maceration to reduce them to a satisfactory condition for general use.

RELATIONS OF THE PHYSICAL CONDITION OF INCLUDED VEgETABLE MATTER TO EXPLOITATION.

The availability of a given peat deposit for certain definite prospective uses depends much upon the physical condition of the plant remains contained in the peat. Thus, if the peat is to be used for making paper or stable litter there should preferably be a large amount of well-preserved, fibrous matter available, whereas fine-grained, structureless, compact peat, so desirable for fuel, must be rejected. If the peat contains layers of well-preserved woody plant structures, especially roots and logs, the cost of preparing the bog for working is increased and its actual exploitation is rendered costly and slow 
unless powerful machinery be used. Peat containing much tough, fibrous matter is often difficult to grind in the usual type of peat machine because the knives become clogged by the fibers. Poorly disintegrated grassy and mossy peat is not suitable for most types of briquetting machines, because the briquets made from it are very light in weight and particularly likely to break up into thin plates when handled or when in the fire. Therefore, it is very desirable and even essential to learn as much as possible of the physical properties that are necessary to insure success in some chosen field of exploitation. A quality of peat which is adapted to the use should then be sought.

\section{CLASSIFICATION BY PHYSICAL CHARACTERS.}

It is quite evident from what has already been written that a classification of peats may be based upon purely physical properties, but when such classification is attempted it is difficult to draw sharp lines, so that a number of systems of characterizing peat are in common use. In most of these a compound terminology combining color, structure, and weight is used, but a quite different terminology is also used, which characterizes the material according to the kind of vegetation that is most conspicuously preserved in it or is found growing on the surface.

In this connection muck should be mentioned. The term "muck" is frequently used as distinct from peat to characterize peaty soils high in mineral matter, but in general it is applied by farmers of all parts of the country to swamp soils which, by their color, indicate a considerable, or high, per cent of organic matter, whether they are pure vegetable substances or not. In fact, the word "peat" is often unknown, except as a book word, in districts in which there are good peat beds of considerable extent, muck being the only name given such deposits.

Johnson ${ }^{a}$ gives the following classification of peats cited from a German writer:

(a) Turfy peat.-Consisting of slightly decomposed mosses and other peat-producing plants, having a yellow or yellowish-brown color, very soft, spongy, and elastic; specific gravity, 0.11 to 0.26 , the full English cubic foot weighing from 7 to 16 pounds.

(b) Fibrous peat.-Unripe peat which is brown or black in color, less elastic than turfy peat, the fibers either of moss, grass, roots, leaves, or wood, distinguishable by the eye, but brittle and easily broken; specific gravity 0.24 to 0.67 , the full cubic foot weighing, accordingly, from 15 to 42 pounds.

(c) Earthy peat.-Nearly or altogether destitute of fibrous structure, drying to earthlike masses which break with more or less difficulty, giving lusterless surfaces of fracture; specific gravity, 0.41 to 0.90 , the full cubic foot weighing from 25 to 56 pounds.

(d) Pitchy peat.-Dense; when dry, hard; often resisting the blows of a hammer, breaking with a smooth, sometimes lustrous fracture into sharp-angled pieces; specific gravity, 0.62 to 1.03 , the full cubic foot weighing from 38 to 65 pounds. 


\section{CHEMICAL PROPERTIES.}

\section{GENERAL COMPOSITION.}

Primarily, the organic materials from which peat originates are two-cellulose, or ordinary vegetable substance, and lignin, or woody matter. Both of these are complicated chemical compounds of the solid element carbon and the gases oxygen and hydrogen, and as found in plant tissues contain also mineral substances in considerable variety. They are often mixed with lesser quantities of other organic compounds which have been formed in the course of the activities of the living plants, such as resins, fatty and waxy bodies, and others which contain nitrogen, the inert gaseous element of air.

During the decomposition of these substances, which, as already pointed out, is largely accomplished by the activities of fungi, bacteria, and other organisms, new and simpler but still complicated substances are formed. The latter have never been exhaustively studied, although from time to time some of the more generally distributed groups of such compounds have been investigated. Several substances possessing acid properties that have been isolated from peat have been named. In this class are humic, ulmic, geic, crenic, pectic, and other acids; humin, ulmin, etc., are names given to other types of substances known to occur in peat, but difficult to obtain from it. By some writers these compounds are all classed together under the comprehensive name of humus. The plant organs composed of pure cellulose seem to be least affected by decomposition. Thus fine rootlets, epidermal cells of herbs, etc., often occur well preserved in peats from which all other structures have disappeared.

It is generally understood by chemists, however, that the above names do not correspond to single compounds, but rather to groups of related bodies which possess similar chemical properties. Bituminous and resinous matters are also found under natural conditions in some types of peat, especially in such as are thoroughly decomposed and blackened, most often under conditions that lead to the conclusion that they are concentration and not decomposition products.

During the processes of decomposition of vegetable matter, as they ordinarily go on in a peat bog, a part of the gaseous elements oxygen and hydrogen, together with a part of the carbon, is liberated from the less resistant organic compounds in the form of gases. Of these gases, carbon dioxide $\left(\mathrm{CO}_{2}\right)$, made up of carbon and oxygen, and marsh gas or methane $\left(\mathrm{CH}_{4}\right)$, a simple compound of carbon and hydrogen, are those most frequently observed. Together with nitrogen, and less often hydrogen-sulphide, the gases referred to form the bubbles of gas so abundantly given off when vegetable matter undergoing decay under water is disturbed, and by their formation and escape they reduce the proportion of oxygen to the carbon. Hence the more completely decomposed peats have a higher percentage of 
carbon and less oxygen and hydrogen than those in which the vegetable matter is more nearly in its original state. This is well shown in the tables of analyses (see p.186) made by the United States Geological Surver.

\section{CHEMICAL COMPOSITION OF THE ASH.}

As the ash of peat is extremely variable in quantity and in origin, so also it varies greatly in chemical composition. When the ash exceeds from 3 to 8 per cent of the dry weight the excess may commonly be attributed to the action of water or wind or both.

The quantity of ash directly traceable to the plants varies, however, according to the kinds of plants from which the peat originated, its state of decomposition, and the quantity of mineral matter carried in solution in the water with which it is saturated. Thus peat formed from trees and other woody plants will generally have a higher normal percentage of ash than that derived from grasses and similar plants. Such peat in turn will be somewhat richer in silica, calcium compounds, and other mineral matter than that in which mosses are the principal sources of the original plant material.

As the peat loses its more volatile constituents the proportion of mineral matter or ash will, as is clear, steadily increase by reason of the concentration of the solid constituents. Chemical analysis has also demonstrated that in regions where the soil waters contain much mineral matter in solution plants of a given species contain a higher percentage of ash than those of the same species grown where the water has less soluble matter. Thus in limestone regions the ash of most plants is found to contain more lime, or calcium sulphate, than occurs in the same species in regions of granitic rocks.

As a rule the mineral matter of extraneous origin which is found in peat ash is largely silica in the form of sand and silt, or is alumina and silica in the form of clay. It may, however, be principally calcium carbonate or sulphate where these minerals are abundant in the rocks or in the derived soil and soil water. Iron is not infrequently abundant in the peat as organic compounds, humates, etc., or as the sulphate, sulphide, carbonate, or oxide. Ferrous sulphate is sometimes abundant in peat beds formed where the water supply is chiefly derived from springs, and indicates its presence by giving off strongly acid fumes when the peat is burned and by imparting a whitish or greenish coating to the partly dried peat. All iron compounds give to the ashes of the peat a rusty or reddish color. As already noted above, the silica or the calcium carbonate in pond-formed peat may be largely of organic origin.

The following analyses ${ }^{a}$ of ashes of peat from Connecticut bogs show their variable character. 
Analyses of ashes of peat from Connecticut bogs.

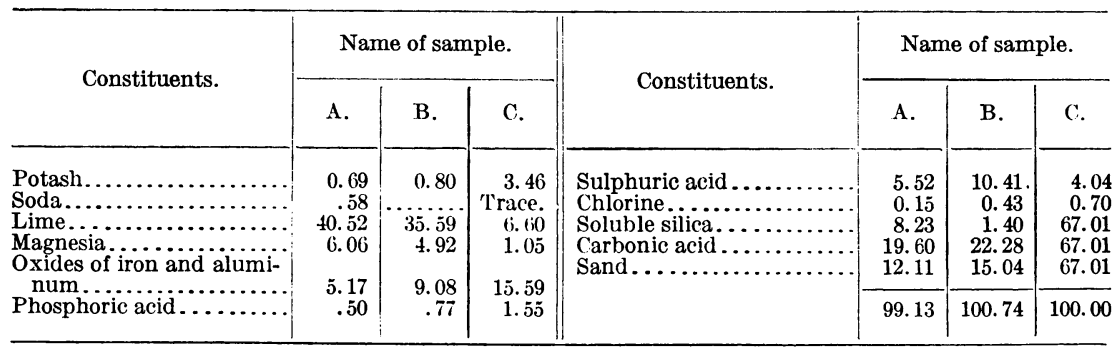

The range of the components compiled by the same author from various sources, chiefly European, is as follows:

Variations and averages in composition of peat ashes.

\begin{tabular}{|c|c|c|c|c|c|c|}
\hline \multirow{2}{*}{ Chemical compound. } & \multicolumn{2}{|c|}{ Minimum. } & \multicolumn{2}{|c|}{ Maximum. } & \multicolumn{2}{|c|}{ Average. } \\
\hline & l'er cent. & $\begin{array}{l}\text { Pounds } \\
\text { per ton. }\end{array}$ & Per cent. & $\begin{array}{l}\text { Pounds } \\
\text { per ton. }\end{array}$ & Per cent. & $\begin{array}{l}\text { Pounds } \\
\text { per ton. }\end{array}$ \\
\hline 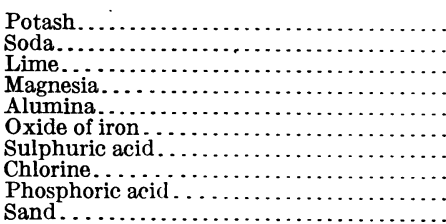 & $\begin{array}{l}0.05 \\
\text { None. } \\
4.72 \\
\text { None. } \\
.90 \\
\text { None. } \\
\text { None. } \\
\text { None. } \\
\text { None. } \\
.99\end{array}$ & $\begin{array}{r}1.0 \\
.0 \\
94.4 \\
.0 \\
18.0 \\
.0 \\
.0 \\
.0 \\
.0 \\
19.8\end{array}$ & $\begin{array}{r}3.64 \\
5.73 \\
58.38 \\
24.39 \\
20.50 \\
73.33 \\
37.40 \\
6.50 \\
6.29 \\
56.97\end{array}$ & $\begin{array}{r}72.8 \\
114.6 \\
1,167.6 \\
487.8 \\
410.0 \\
1,466.6 \\
748.0 \\
130.0 \\
125.8 \\
1,139.4\end{array}$ & $\begin{array}{r}0.89 \\
.83 \\
24.00 \\
3.20 \\
5.78 \\
18.70 \\
7.50 \\
.60 \\
2.56 \\
25.50\end{array}$ & $\begin{array}{r}17.8 \\
16.6 \\
480.0 \\
64.0 \\
115.6 \\
374.0 \\
150.0 \\
12.0 \\
51.2 \\
510.0\end{array}$ \\
\hline
\end{tabular}

It should be noted that in peats of low ash content the percentage of constitutents of agricultural value will generally be higher than in those having much ash, because such peat is derived from nearly pure vegetable matter in which there is a degree of concentration of potash and phosphoric-acid salts which does not exist in soil waters or in the finely divided mineral matter borne about in suspension in lakes and streams or in the air.

RELATION OF ASH TO FUel VALUE.

The quantity of ash determines within certain limits the value of peat for commercial fuel purposes, because the analyses accompanying this report (pp. 186-203) clearly show that the fuel value is decreased nearly in direct proportion to the increase in the amount of ash within these limits.

This is due theoretically to the following reasons: The ash displaces a definite amount of combustible matter so that a given weight of peat with much ash contains less actual substance from which heat can be generated than the same weight of purer material. The ash requires and uses up heat to raise and maintain its own temperature to that of the surrounding combustibles. Heat energy is also used to bring about many of the chemical changes that the fire may cause in the 
ash constituents. In the latter respect silica and other substances chemically unchanged by heat produce no effect.

The maximum quantity of ash usually considered allowable in peat that is to be sold for fuel on a commercial scale is somewhat arbitrarily placed by some writers at 25 per cent of the total dry weight and by others at 20 per cent. Peat with less than 5 per cent ash is regarded by the Irish authorities as good, that having from 5 to 10 per cent as moderately good, and that having from 10 to 25 per cent as bad. The Swedish standards are as follows: Low, 2 per cent; average, 5 per cent; comparatively high, 8 per cent; high, 11 per cent; very high, 14 per cent.

These limits are fixed because the calorific value of material with more than 20 per cent ash is assumed to be too low for commercial use. Below this limit, however, peat of high ash content is often found which exceeds in its theoretical fuel value, as shown by calorimeter tests, peat with a much smaller percentage. Peat with a proportion of ash much greater than 20 per cent may doubtless be used without detriment for the generation of producer gas than for burning as ordinary fuel.

Enthusiastic advocates of the use of peat fuel have made some absurd claims regarding the value of peat compared with other kinds of fuel now in common use. The basis for all adequate fuel comparisons, however, must be chemical analyses and calorimetric determinations, followed where possible by actual working tests conducted under standard conditions by impartial and well-trained engineers.

It should be pointed out, on the other hand, that all tests are of relative rather than absolute value; they form a reliable foundation upon which to base judgments, and therefore are justified and of immeasurably greater value for practical operations than mere opinions derived from superficial personal observation and experience.

PROXIMATE AND ULTIMATE ANALYSES.

There are two kinds of experimental work for determining the relative value of fuels of the same or different kinds: (1) the chemical and fuel analyses of small samples, and (2) test runs made with large quantities under conditions reproducing as closely as possible those under which the fuel is used commercially.

Chemical analyses of fuel are of two kinds, proximate and ultimate. In the former the moisture or free water contained in the fuel, the volatile matter, including chemically combined water and the hydrocarbons, the nonvolatile or fixed carbon, and the ash are determined under approximately fixed conditions. The included water is first driven off by heating a carefully weighed sample of the material at about the temperature of boiling water, the heating being continued until repeated weighings show no further loss of weight. If the substance contains much very volatile matter the water is often removed 
by heating under reduced pressure or by exposure to dry air at a low temperature (about $100^{\circ} \mathrm{F}$.). In making the analyses of peat that accompany this report it was found necessary to take these precautions.

The volatile matter, chiefly hydrocarbons, is next driven off from the sample in the form of permanent gases and liquids by raising the temperature enough to insure the decomposition of the fuel and the vaporization of the newly formed compounds of carbon and hydrogen, care being taken to exclude the air so that the residue of carbon does not take fire. After the evolution of the gases has ceased, as shown by the dying out of the flame above the dish in which the heating is done, the carbon residue and dish are cooled and again weighed. The difference in weight from that previously found shows the quantity of the volatile matter; the weight of the residue is that of the coke.

The coke is once more strongly heated in a plentiful supply of air until all traces of the black color of the carbon disappear, leaving only the ash. The difference between the weight of the coke and that of the ash is fixed carbon. The weighings are always made after the dish and the substance contained in it are cold. In such analyses it is apparent that no effort is made to find out what substances are present, the whole operation being on a small scale similar to the processes going on in any fire box while combustion is taking place.

In ultimate analyses, on the other hand, the substance is broken up into its constituent elements by proper chemical processes, and the amount of each is determined as exactly as possible. The methods employed are somewhat complicated and require great care and special chemical knowledge, and need not be described here. The results of such work are much more definite than those of the other class and state exactly the proportions of the elements that are present in the substance under examination. In ultimate analyses of fuels it is not usual to fully analyze the ash.

DETERMINATION OF CALORIFIC VALUE.

Besides these two kinds of chemical analyses the theoretical calorific or heat value of fuels is determined by direct experiment, or by calculation from the ultimate analysis. The results of either method are expressed in thermal or heat units.

A thermal unit is the quantity of heat required to raise the temperature of a given weight of a selected substance a specified amount. The thermal units in general use among physicists, engineers, and others are the British and the French or continental. The British thermal unit (B. t. u.) is the quantity of heat required to raise the temperature of a pound of water $1^{\circ} \mathrm{F}$. The French unit (calorie) is based on the centigrade thermometer scale and the metric system 
of weights. The gram calorie, or small calorie (cal.), is the amount of heat required to raise the temperature of 1 gram of water $1^{\circ} \mathrm{C}$., and the kilogram calorie, or large calorie (Cal.), is the amount of heat required to raise the temperature of 1 kilogram of water $1^{\circ} \mathrm{C}$. Another thermal unit sometimes used is the pound calorie, the amount of heat required to raise the temperature of 1 pound of water $1^{\circ} \mathrm{C}$.

The calorific value of a fuel is measured by the power of a given weight of the fuel to heat a given weight of water. Manifestly, 1 gram of a fuel will heat 1 gram of water to just the same degree that 1 pound of the fuel will heat 1 pound of water. Hence if the weights of fuel burned and of water heated are expressed in the same units, the relation between the British and the French thermal units becomes that of the thermometric scales. In other words, if grams (or kilograms) of fuel are burned to heat grams (or kilograms) of water, the gram (or kilogram) calories thus determined may be converted to British thermal units per pound by multiplying by 1.8 , because a centigrade degree is 1.8 times as large as a Fahrenheit degree.

If, however, a constant weight (for instance, $1 \mathrm{lb}$.) of fuel be used, and the large calorie (the amount of heat necessary to raise the temperature of $1 \mathrm{~kg}$. of water $1^{\circ} \mathrm{C}$.) be compared with the British thermal unit (the amount of heat required to raise $1 \mathrm{lb}$. of water $1^{\circ} \mathrm{F}$.), account must be taken not only of the different thermometric scales, but of the kilogram being 2.2 times the weight of the pound; hence the number of large calories in 1 pound of fuel is equal to $1.8 \times 2.2=3.96$ times the number of British thermal units.

The calorific value of a given fuel may be determined directly from an average sample by the use of a calorimeter, or by calculation from the ultimate analysis. The calorimeter is a carefully constructed instrument, in one type of which a small quantity of the finely powdered fuel to be tested is completely burned in a closed metal vessel or bomb, entirely surrounded by water, which absorbs the heat generated by the combustion. Complete combustion is insured by the addition of pure oxygen gas or oxygen-bearing chemicals to the sample in the bomb. The resulting rise in temperature is measured by an accurate, finely graduated thermometer. To prevent temperature changes due to outside influences, the whole apparatus is protected when in use by a heavy nonconducting covering, ${ }^{a}$ and is used in a uniformly heated, closed room.

The calorific value of a given peat sample, stated in terms of the theoretically dry peat, may be reduced to that of any desired water content or percentage of moisture between 0 and 30 per cent, sufficiently near for ordinary commercial use, by deducting 1 per cent

$a$ For a description of the methods used in chemical and calorimetric work on fuels in the chemical laboratory of the technologic branch of the United States Geological Survey and in the chemical laboratory of the Bureau of Mines, the reader is referred to Technical Paper 8 of the bureau. 
from the theoretical calorific value for each per cent of moisture assumed to be present. Conversely, if the thermal value of peat with a given percentage of moisture is known, the thermal value of the same peat on the theoretically dry basis can be calculated. In practice this is reduced to a formula as follows:

$$
\begin{gathered}
\text { Calorific value as analyzed } \\
100-\text { percentage of water } \\
\text { found by analysis }
\end{gathered} \times 100=\begin{gathered}
\text { Calorific value of the } \\
\text { moisture-free peat. }
\end{gathered}
$$

The calorific value of a fuel of which an ultimate analysis has been made may be obtained by the use of formulas in which the percentages of the heat-giving elements of the compound under examination are properly combined with fuel values of the pure elements. The latter have been so often determined that they are accurately known and may be used as constants.

To secure uniformity of statement in comparing fuel values, many analyses have been published showing the number of heat units obtainable from different kinds of fuel under theoretical conditions. Such statements are often misleading to the general reader, especially when they are given in terms of the water-and-ash-free substance, or as if the fuel were entirely made up of combustibles - a purely hypothetical condition which makes the efficiency of the fuel appear too high. On this basis, adopted to secure the uniformity of statement that is essential for accurate comparison of fuels of the same kind, the error is not uniformly distributed when comparisons are made of widely varying classes of fuels, because those which always have high percentages of ash and water may be given false values by recalculating them. On the other hand, there are other kinds of fuel which are always low in ash and contain smaller percentages of water and their analyses show but little change when recalculated.

For these reasons the following calorific values of mineral fuels are all chosen to indicate as nearly as possible their fuel value in the condition in which they are found in the market. The determinations were made at the chemical laboratories of the technologic branch of the United States Geological Survey. They are from samples carefully taken from carload lots of commercially well-known coals and other substances which were sent to the fuel-testing plants of the survey for experimental and testing work.

The peat samples were analyzed at the same laboratories and by the same methods as the coals. The method of collecting the peat samples was slightly modified for different field seasons, but in general the samples analyzed were taken at 2 -foot intervals from several rather widely separated test holes extending from top to bottom of the deposit. The samples were sufficiently well mixed to insure that each was an average of the deposit. The collections were made with a sampling tool devised by the writer. This tool permits 
the taking of pure samples at any desired depth, and has proved so generally useful and accurate that it is described on pages 71 and 72 .

In the early part of the work samples were sent to the laboratory in a wet state, but the difficulty of obtaining water-tight containers of the right size led to the adoption of the plan of collecting a large sample for the usual analyses in a cloth bag. A small sample from which the water content of the peat at the time of its collection could be determined was also collected in a 4-ounce bottle, provided with a suitable mailing case. The sample in the bag soon dries down to a low percentage of moisture and can then be mailed without difficulty.

It is evident that analyses made from samples taken in this way are of more general value than those made from carefully selected materials or from those which have been taken from single stations or beds.

Calorific value of the common types of fuel compared with air-dried peat.

. COMMON TYPES OF FUEL.

\begin{tabular}{|c|c|c|c|c|c|c|c|}
\hline \multirow{2}{*}{$\begin{array}{l}\text { Lab. } \\
\text { No. }\end{array}$} & \multirow{2}{*}{ Type of fuel. } & \multirow{2}{*}{ Locality. } & \multirow{2}{*}{$\mathrm{H}_{2} \mathrm{O}$. } & \multirow{2}{*}{ Ash. } & \multirow{2}{*}{ Sulphur. } & \multicolumn{2}{|c|}{ Heating value. } \\
\hline & & & & & & Calories. & B. t. u. \\
\hline 3216 & Graphitic anthracite.. & Cranston, R. I. & 2.41 & 19.06 & 0.07 & 6,109 & 10,996 \\
\hline a 519 & Coke.................. & Mixed coke...... & 6.55 & 12.86 & .97 & 6,870 & 12,366 \\
\hline & Anthracite......... & St. Nicholas, Pa.. & 2.30 & 13.39 & 1.05 & 6,975 & 12,523 \\
\hline 4287 & Semido.............. & Blacksburg, Va.. & 4.80 & 17.64 & .84 & 6,645 & 11,961 \\
\hline 5829 & 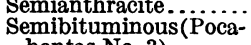 & $\begin{array}{l}\text { Spadra, Ark.......... } \\
\text { Ennis, W. Va....... }\end{array}$ & $\begin{array}{l}5.19 \\
3.67\end{array}$ & $\begin{array}{r}14.01 \\
6.55\end{array}$ & $\begin{array}{r}2.05 \\
.46\end{array}$ & $\begin{array}{l}6,922 \\
7,939\end{array}$ & $\begin{array}{l}12,460 \\
14,290\end{array}$ \\
\hline 4609 & $\begin{array}{l}\text { hontas No. 3). } \\
\text { Bituminous } \\
\text { burgh). }\end{array}$ & Connellsville, $\mathrm{Pa}$. & 5.13 & 8.71 & .86 & 7,525 & 13,365 \\
\hline 2020 & Bituminous (Illinois).. & Zeigler, Ill.... & 10.72 & 9.36 & .52 & 6,492 & 11,686 \\
\hline 1779 & $\ldots$ do......................... & La Salle, Ill... & 12.39 & 8.92 & 3.92 & 6,333 & 11,399 \\
\hline 3396 & $\begin{array}{l}\text { Bituminous . (Wyo- } \\
\text { ming). }\end{array}$ & Hanna, Wyo... & 12.40 & 6.77 & .26 & 5,948 & 10,706 \\
\hline $\begin{array}{l}2734 \\
2243\end{array}$ & $\begin{array}{l}\text { Lignite (Texas) ......... } \\
\text { Lignite (North Dakota) }\end{array}$ & $\begin{array}{l}\text { Olsen, Tex.......... } \\
\text { Wilton, N. Dak..... }\end{array}$ & $\begin{array}{l}31.06 \\
35.96\end{array}$ & $\begin{array}{l}7.88 \\
7.75\end{array}$ & $\begin{array}{r}.99 \\
1.15\end{array}$ & $\begin{array}{l}4,372 \\
3,927\end{array}$ & $\begin{array}{l}7,870 \\
7,069\end{array}$ \\
\hline
\end{tabular}

$a$ Test number.

AIR-DRIED PEAT.

\begin{tabular}{|c|c|c|c|c|c|c|c|c|}
\hline \multirow{3}{*}{$\begin{array}{l}\text { Lab. } \\
\text { No. }\end{array}$} & \multirow{3}{*}{ Kind of peat. } & \multirow{3}{*}{ Locality. } & \multirow{3}{*}{ Water. } & \multirow{3}{*}{ Ash. } & \multirow{3}{*}{ Sulphur. } & \multicolumn{3}{|c|}{ Heating value. } \\
\hline & & & & & & \multirow{2}{*}{ Calories. } & \multicolumn{2}{|c|}{ B.t. u. } \\
\hline & & & & & & & $\underset{\text { dried. }}{\text { Air }}$ & $\begin{array}{l}\text { Water } \\
\text { free. }\end{array}$ \\
\hline 6576 & Brown, fibrous. & Fremont, N. H. & 6.34 & 7.93 & 0.63 & 5,161 & 9,290 & 9,920 \\
\hline 6722 & 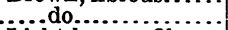 & Hamburg, Mich. & 7.50 & 6.55 & .28 & 5,050 & 9,090 & 10,026 \\
\hline 6572 & Light-brown, fibrous & Rochester, N. H. & 11.64 & 4.06 & .22 & 5,042 & 9,083 & 10,280 \\
\hline 6191 & Dark-brown........... & Westport, Conn & 12.70 & 4.12 & .24 & 4,772 & 8,590 & 9,839 \\
\hline 6580 & Brown, structureless & New Durham, N. H. & 6.06 & 17.92 & .88 & 4,415 & 7,947 & 8,460 \\
\hline 6203 & Brown.............. & New Fairfield, Conn. & 9.63 & 7.93 & .46 & 4,367 & 7,861 & 8,698 \\
\hline 6193 & Brown, fibrous...... & Westport, Conn..... & 19.69 & 3.23 & .19 & 4,273 & 7,691 & 9,578 \\
\hline 6198 & Brown......... & Kent, Conn..... & 12.10 & 7.22 & .83 & 4,269 & 7,684 & 8,743 \\
\hline 6398 & Brown, fibrous. & Cicero, N. Y... & 14.57 & 7.42 & .25 & 4,209 & 7,576 & 8,869 \\
\hline 6436 & Brown......... & Black Lake, N. Y... & 8.68 & 16.61 & .93 & 4,179 & 7,522 & 8,237 \\
\hline 6279 & Brown, fibrous & La Martine, Wis.... & 9.95 & 16. 77 & .79 & 4,149 & 7,468 & 8,293 \\
\hline 6555 & Salt marsh... & Kittery, Me.......... & 13.50 & 12.04 & 1.94 & 4,066 & 7,319 & 8,462 \\
\hline 6571 & Black.......... & Greenland, N. H... & 6.62 & 24.11 & 1.01 & 3,992 & 7,186 & 7,695 \\
\hline 6290 & Light-brown, struc- & Waupaca, Wis.... & 6.62 & 24.44 & .65 & 3,872 & 6,070 & 7,465 \\
\hline 6278 & Brown, fibrous...... & Madison, Wis..... & 8.99 & 18. 77 & .38 & 3,857 & 6,943 & 7,628 \\
\hline 6199 & Brown, sandy.. & Kent, Conn & 9.06 & 36.06 & 1.46 & 3,291 & 5,924 & 5,924 \\
\hline & Black.............. & & 6.52 & 28.50 & .57 & 2,867 & 5,161 & 5,521 \\
\hline
\end{tabular}




\section{CHARACTERISTICS DETERMINING FUEL VALUE.}

The characteristics determining fuel value have already been indicated in part; the most important are ash and water content, degree of decomposition, density, and color. The effects of ash and water are to lower the heating value nearly in proportion to the amounts in which they are present. In general, also, it may be said that peat that is coarse in texture and fibrous or woody in structure is less valuable for fuel than the finer-grained types which are compact and dark colored when dry. This is readily demonstrated by comparing the theoretical heating value in the series of peat analyses given on page 53 , and is due in some degree to the concentration of the fuel element carbon as the original chemical compounds of the peat become more and more completely broken up.

The ideal fuel should maintain a steady and efficient fire, and be capable of easy control, with small attention and without developing smoke or offensive and injurious gases. It must not have too much ash and must not produce clinkers and slag that will clog the fuel bed and fuse to the grate bars or fire box, nor give off compounds that corrode the boiler or other metal work with which they come in contact. In addition, it must be cheap, efficient, and transportable.

Natural gas is the nearest approach to this ideal occuring in nature, and where it has been found has proven to be the best fuel known.

\section{COMPARATIVE FUEL VALUE OF PEAT IN DIFFERING CONDITIONS.}

\section{FRESHLY DUG.}

Freshly dug peat from an undrained deposit consists of from 85 to 90 or even 95 per cent of water, 8 to 13 or even as little as 3 per cent of carbonaceous materials, and a widely variable percentage of incombustible matter or ash. Freshly dug, wet peat, therefore, has such small heating value that it can not be made to burn until it is at least partly dry, reaching its highest value as a fuel only when the water has entirely disappeared. Peat with enough water present to feel wet to the touch will burn in a strong draft, but the.intensity of the heat as indicated by the temperature is low compared with that of the perfectly dry substance, because most of the heat developed by the combustion is rendered latent in evaporating water from the particles of peat near those that are burning.

\section{DRIED.}

The maximum temperature developed by the combustion of perfectly dry peat of good quality under the most suitable conditions of draft and combustion chamber is very high, being over $4,000^{\circ} \mathrm{F}$. $\left(2,200^{\circ}\right.$ C. $)$. This temperature is lowered by the presence of even small amounts of water or by ash, hence the desirability of having the peat as dry as possible when the highest temperatures attainable by its use are necessary. The drying of peat that is to be stored before 
use, with the hope of increasing its efficiency below the "air-dry" stage of 12 or 15 per cent to 25 per cent moisture content, is useless and a needless expense; if so dried, it soon reabsorbs water from the air, just as wood and other vegetable matter do when kiln dried.

The water content of air-dry peat varies considerably in a given locality according to the season, and in different parts of the country, on account of variations in the relative humidity of the air, there will be an even wider variation, the water content of air-dry peat being constantly higher in the moist and cool regions, where there is a high relative humidity, than in the drier and warmer ones. The lower limit of moisture in the central United States will probably be at least 8 per cent; the highest limit will probably be along the coast of New England, where it is not far from 25 per cent, or about that of the European countries.

\section{EFFECT OF EXPOSURE TO AIR.}

The weight of a cubic foot of the heavier and denser qualities of peat, when freshly cut from undrained beds, may be as much as 70 or 75 pounds to the cubic foot, but after a few days of exposure to the air its water content will be reduced by at least one-half of its original amount. Continued drying in the sun and wind will finally lower it to from 8 to 25 per cent of the weight of the mass, within which limits it remains permanently, as indicated in the preceding paragraph.

Accompanying the loss of water there is a great shrinkage in bulk, and the block may be reduced to a fourth of its original volume in drying. The weight of a full cubic foot of air-dry cut peat ranges from about 10 pounds for very light kinds to over 60 pounds for the black, thoroughly decomposed kinds.

CONDITIONS OF IGNITION.

The lighter, more fibrous kinds of peat ignite when heated in the air at about $400^{\circ} \mathrm{F}$. $\left(200^{\circ} \mathrm{C}\right.$.) and burn with a red, smoky flame. The burning is accompanied by a characteristic biting or acrid odor and grayish or whitish smoke, arising from the destructive gasification of the poorly carbonized organic matter of which the peat is composed.

Black, pitchy or denser kinds of peat do not ignite as readily, burn less rapidly, and often need a higher temperature to induce combustion than do the other types. This is so well recognized in European countries where peat is used that a supply of the light, fibrous material from the top of the peat beds is always cut for use as kindling and for starting quick fires; the denser kinds from the deeper parts of the deposit are used for general purposes.

CHARACTER AND EFFECT OF ASH.

Unless a peat has a high per cent of ash, the quantity resulting from burning it is small. In any case, the ash is light in weight and pow- 
dery in texture and generally does not fuse into clinkers or slag, even in a strong fire. When the surface of a peat fire is covered by ashes, or the draft is cut off, the fire smolders as long as there is any unconsumed peat left, and may be rekindled at any time by renewing the supply of air. The relatively large amount of oxygen present in the fuel itself probably supports combustion under these circumstances, some of it being liberated from the fuel by the heat. This may also account for the fact that peat fires require less draft than those of other fuels.

\section{AIR-DRIED PEAT COMPARED WITH COAL.}

According to European authorities, the heating value of air-dried cut peat is small as compared with that of coal, being only a little more than one-half as much; expressed more definitely, it ranges from fiveeights to five-ninths as much, or in the ratio of $1: 1.6$ or $1: 1.8$. Reference to the tables of analyses (pp. 186 to 203) will show that the fuel value of the United States peats has a comparatively high range. To obtain the same evaporating effect, from 8 to 10 or even as much as 18 times the volume of peat in the crude, air-dry state must be used as of good coal. It is necessary, therefore, to provide plenty of room for transporting, storing, and firing if the fuel is used in this form.

The deficiencies of peat thus prepared were recognized at an early stage in its use for power production, and several methods and many machines have been devised for compacting it, thereby increasing its efficiency and lasting qualities as fuel, and making it more easily transported and stored.

In spite of its manifest disadvantages in the more bulky and crudely prepared forms, such as hand-cut, air-dried sods or blocks, peat in compacted forms is well liked by those who have used it. It is reported to be an admirably adapted fuel for all domestic purposes, as it is easily kindled, burns freely when the drafts are open, yields a quickly developed and intense heat, is light and easily handled, and is very clean, giving neither soot, dust, nor any other form of dirt. Fires fed with it are easy to keep, regulate, and control, and quickly produce enough heat at all times for any special purpose. When used in heating stoves and furnaces it also gives satisfaction, furnishing a mild but sufficient heat, although success with it for these purposes depends seemingly as much on the experience and judgment of the individual who has charge of the fire, the way in which it is handled, and the kind of grate and fire box used as on the fuel itself.

\section{USE OF PEAT FUEL IN EUROPE.}

In European countries where peat is used largely for domestic fuel special stoves for it have been designed and sold, although these do 
not appear to have any very general use, as the common report made by those who have investigated the matter is that the peat is usually burned in the same stoves as other fuels. The best results from using peat would probably be had by more frequent firing, with less draft and smaller grate openings, and for power generation by having larger and longer fire boxes than are used with coal. For open grates peat is an ideal fuel, and for this purpose alone it should command a large sale, as it is in many respects superior to wood and coal.

\section{EFFICIENCY OF PEAT FUEL FOR STEAM GENERATION.}

The efficiency of this fuel in comparison with others is at once questioned when its use for the generation of steam under boilers in manufacturing establishments and power and lighting plants is proposed. If trial by the owners of such establishments demonstrates that the same money spent for any other fuel will give a larger quantity of steam, or more heat units than will peat, or will insure a more readily obtained and certain supply or even one more in favor with the men who handle it, the probabilities are that the other fuels will be given preference and used exclusively. For these reasons peatfuel manufacturers will have to make the best possible showing by producing a fuel that is cheaper and more convenient to use and very efficient as compared with types already on the market. They must also be able to provide an abundant and steady supply the year round if they expect it to be generally used for power purposes, as it must be if large investments in peat fuel are to be profitable.

\section{CaIORIfic VALUE OF PEAT FUEL.}

Taking up briefly the calorific value of peat fuel, the tables below should be examined carefully, as they enable a comparison of the value of peat prepared in several commercial ways to be made with that of other kinds of fuel in common use.

It should be remembered in this connection, however, that unless the peat is heated enough to drive off some of the volatile matter, thereby increasing the proportion of carbon present, the theoretical heating value - that is, the number of heat units per pound-is practically the same whether the peat is cut, pressed, or briquetted. When artificial heating is resorted to and carried on at sufficiently high temperatures to partly char the peat previous to or during briquetting, or when a bituminous or resinous binder is used in the process of making the briquets, the calorific value may be much increased. However, in the first case there is a loss of weight of the material proportionate to the gain in fuel value, and in the second the binder may furnish the additional heat units at a high cost. Probably 
both factors must be considered to account for the differences which are apparent in the following table: ${ }^{a}$

Calorific values of peat and other fuels.

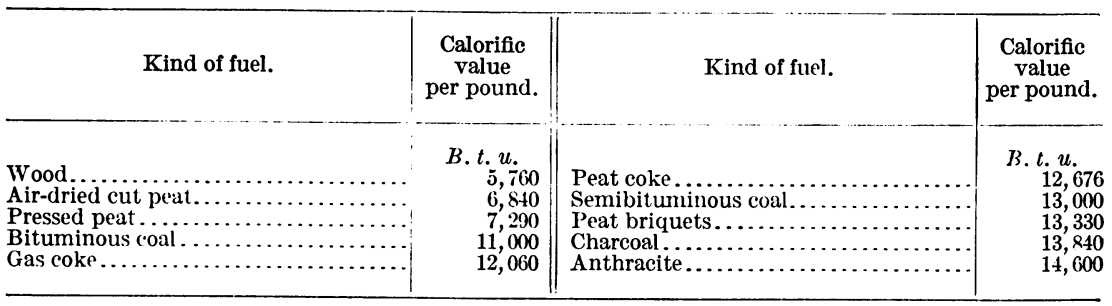

The following analyses are of peat from the same part of a deposit and were made independently; the calorific value is on the ash-andmoisture-free basis. ${ }^{b}$

Calorific value of peat prepared in different ways.

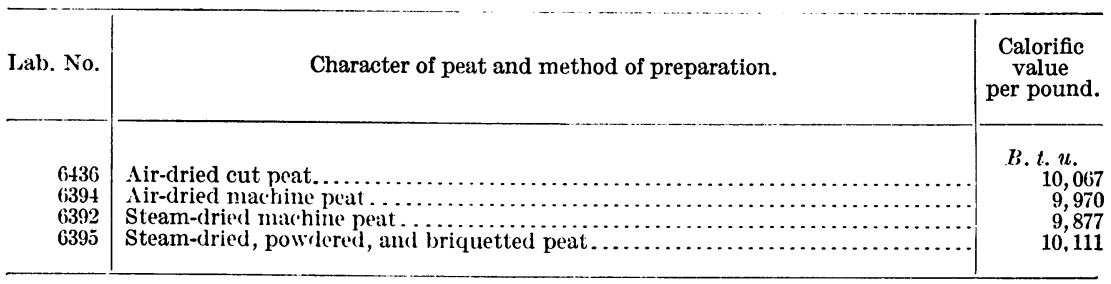

The slight variations obtained in the determinations probably are due to differences in the quantity of ash present, this varying more than 1 per cent in the different samples, as is very often the case in different collections of the same material. The analyses show conclusively that the untreated peat analyzed has almost exactly the same theoretical heating value as that which has been dried by steam heat and briquetted without binder or heat in an open-mold briquetting press.

\section{CONCLUSIONS.}

The foregoing indicates that briquetting alone does not increase the heating value of a given weight of peat, but, as is shown below, it does give more heat units for a given volume, and therefore improves the efficiency of the fuel for commercial uses.

The effects of the presence of ash and moisture on the calorific value of peat have already been discussed. Of more importance still are the tables of analyses given on page 53, since they were all made by the United States Geological Survey, and show the calorific value of the fuels cited in their commercial condition.

These tables clearly demonstrate that peat is a better fuel than wood or the lignites with which it is compared, and at its best is not 
much inferior to some grades of commercially important coals, although generally considerably poorer. The best peat has about 75 per cent of the heating value of anthracites and about 80 per cent of that of the Illinois coals, or from 85 to nearly 90 per cent of that of the Rhode Island and Wyoming samples; the poorest of the peats with high ash and moisture content are only about half as valuable as the best of the coals and are commonly rated as 55 to 65 per cent as valuable as the poorest coals. These comparisons are made on a strictly commercial basis, the peat being air dried and the other fuels in the state in which they were received from the mines.

The following table shows the effect of the moisture and ash on good and poor peats:

Comparative calorific value of peat with various amounts of ash and water.

\begin{tabular}{|r|r|r||r|r|r|}
\hline Ash. & Water. & $\begin{array}{c}\text { Calorific } \\
\text { value } \\
\text { per pound. }\end{array}$ & Ash. & Water. & $\begin{array}{c}\text { Calorific } \\
\text { value } \\
\text { per pound. }\end{array}$ \\
\cline { 2 - 2 } & Per cent. & B.t.u. & Per cent. & Per cent. & B.t.u. $u$ \\
Free. & Free. & 10,726 & 10 & Free. & 9,653 \\
4 & Free. & 10,297 & 20 & Free. & 8,581 \\
4 & 11 & 9,117 & 10 & 15 & 8,045 \\
4 & 15 & 8,688 & 10 & 20 & 7,508 \\
4 & 25 & 7,615 & 20 & 15 & 6,973 \\
4 & 30 & 7,079 & 20 & 20 & 6,436 \\
4 & 50 & 4,934 & & & \\
\hline
\end{tabular}

The statement should be emphasized that peat which has been dried below the air-dry condition, but not charred, will soon absorb moisture enough from the air to give it about the amount of water which it would have had if air dried at first. The percentage of water thus hygroscopically absorbed from the air is less for very dense black peat than for the more fibrous brown kinds, but to continue the drying of any type lower than about 15 per cent, with the expectation that it will remain fixed there, is useless. Peat thus dried below the critical percentage of moisture to secure greater efficiency for special purposes must therefore be used immediately if any advantage is to be gained by the operation; storage, even for a short time, permits water to be reabsorbed from the air.

If the peat is heated sufficiently to carbonize or char it, as may be done by artificial drying at high temperatures, it loses to a large degree its property of absorbing moisture from the air.

\section{CHEMICAL EFFECTS OF ARTIFICIAL DRYING. •}

The commonly used method of drying peat for fuel is by exposure to the air, either in the sunshine or under shelter, but as this process, on account of changeable weather conditions, is a slow and somewhat uncertain way of getting results, many artificial drying systems have been proposed or actually tried. At this point in the dis- 
cussion, however, the chemical effects are to be considered rather than the processes of drying.

There seems to be a slight chemical change in peat that is dried in the air without heat owing, in part at least, to the contact of the oxygen of the air with the peat as it is drying. The most obvious evidence of change is the blackening of the peat while it is still wet, especially after it has been thoroughly macerated; the discoloration often begins as soon as the peat is cut. Whether there is any change in weight accompanying the change of color from brown to black has not been determined.

Various observers have noted that peat loses in weight when heated at about the boiling point of water, and some have supposed this loss to be due in part to the distillation of combustible gases. It seems more probable, however, that a part of the chemically combined water of the complicated compounds making up the peat is driven off at these lower temperatures and that little if any combustible gas escapes.

Bornstein ${ }^{a}$ reports that brown peat with 17 per cent of water, when distilled in a retort closed at one end, gave water at $100^{\circ} \mathrm{C}$. $\left(212^{\circ} \mathrm{F}.\right)$, gas at $250^{\circ} \mathrm{C} .\left(482^{\circ} \mathrm{F}.\right)$, tar at $325^{\circ} \mathrm{C} .\left(617^{\circ} \mathrm{F}.\right)$, and combustible gases at $400^{\circ} \mathrm{C} .\left(752^{\circ} \mathrm{F}\right.$.).

If the material used was representative, little gaseous matter of value is driven off from peat until heating is carried well above the boiling point of water. The elimination of incombustible gases at about $500^{\circ} \mathrm{F}$. and the use of higher temperatures for drying, although reducing the weight of the substance to some extent, should undoubtedly increase the calorific value by so much as the carbon is increased in proportion to the other constituents. Clearly, therefore, artificial drying may decrease the weight of the peat treated, but it will also increase the fuel value. The latter cause, as noted above, operates to give the high fuel value to peat briquetted after artificial drying.

\section{PRACTICAL OR ECONOMIC CALORIFIC VALUE AND EVAPORATIVE EFFECT OF PEAT.}

The economic calorific effect of a fuel used under most favorable circumstances in practice may be expressed in the number of units of weight of water that can be raised from the freezing to the boiling point of water and converted into steam by the heat developed by the combustion of a single corresponding unit of the given fuel. The units of weight used are the gram (or kilogram) or the pound, according as the metric or the English system of weights prevails. The practical calorific value of any fuel is manifestly to be derived from the previously ascertained theoretical heating value stated in 
thermal units, if the number of these units required to convert a unit weight of water at the boiling point into steam of the same temperature be known. This value has been found to be 536 calories, and as the number of heat units required to raise a given body of water from the freezing to the boiling point under normal atmospheric pressure is practically always the same (100 calories or $180 \mathrm{~B}$. t. u.), the evaporative effect of a pound of peat may be ascertained by dividing its heating value stated in calories by 536, or, if stated in British thermal units, by 965 . The result will be the number of pounds of water that the combustion of a pound of peat will convert into steam after the boiling point is reached. This amount will be reduced, however, by the number of heat units lost in raising the temperature of the water to the boiling point; it will also be reduced through the inefficiency of the boilers used. In practice the reduction will vary from a fourth to a third of the whole as determined above, so that the practical calorific value expressed in pounds may be from twothirds to three-quarters the evaporative effect.

The following table cited from Ryan ${ }^{a}$ shows the comparative economic calorific value of several types of fuel:

Average economic heating effects of ordinary fuels of European origin.

\begin{tabular}{|c|c|c|c|}
\hline Kind of fuel. & $\begin{array}{l}\text { Quantity } \\
\text { of water } \\
\text { evaporated } \\
\text { per pound } \\
\text { of fuel. }\end{array}$ & Kind of fuel. & $\begin{array}{l}\text { Quantity } \\
\text { of water } \\
\text { evaporated } \\
\text { per pound } \\
\text { of fuel. }\end{array}$ \\
\hline 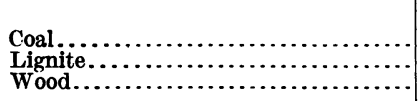 & $\begin{array}{r}\text { Pounds. } \\
6.5 \\
4.5 \\
3.5\end{array}$ & $\begin{array}{l}\text { Peat } \ldots \ldots \ldots \ldots \\
\text { Machine peat } \ldots \ldots \ldots \\
\end{array}$ & $\begin{array}{r}\text { Pounds. } \\
3.5 \\
4.8\end{array}$ \\
\hline
\end{tabular}

Lyons $^{b}$ gives the theoretical evaporative effect of Indiana peat, as compared with coal from the same State, as follows:

Evaporative effect of Indiana peat and coal.

\begin{tabular}{|c|c|c|c|c|}
\hline & \multirow{2}{*}{$\begin{array}{l}\text { Number of } \\
\text { samples } \\
\text { analyzed. }\end{array}$} & \multicolumn{3}{|c|}{$\begin{array}{l}\text { Evaporative effect (pounds of } \\
\text { water per pound of fuel). }\end{array}$} \\
\hline & & Maximum. & Minimum. & Average. \\
\hline $\begin{array}{l}\text { Coal................. } \\
\text { Peat............ }\end{array}$ & $\begin{array}{l}20 \\
29\end{array}$ & $\begin{array}{l}13.4 \\
10.8\end{array}$ & $\begin{array}{r}12.1 \\
4.7\end{array}$ & $\begin{array}{r}12.8 \\
8.0\end{array}$ \\
\hline
\end{tabular}

The following table has been compiled from fuel tests made by the United States Geological Survey $^{c}$ at St. Louis, Mo. The data were

a Ryan, H., Econ. Proc. Royal Dublin Soc., vol. 1, pt. 13, 1908, p. 468.

$b$ Lyons, R. E., Thirty-first Ann. Rept. Ind. Dept. Geology and Nat. Hist., 1906, p. 102.

c U. S. Geol. Survey Bull, No. 332, 
obtained from actual boiler tests, and the number of pounds of water evaporated at $212^{\circ} \mathrm{F}$. per pound of fuel used was calculated separately for each test.

Fuel tests made by the United States Geological Survey at St. Louis, 1906-\%.

\begin{tabular}{|c|c|c|c|c|c|}
\hline \multirow{2}{*}{$\begin{array}{l}\text { Test } \\
\text { No. }\end{array}$} & \multirow{2}{*}{ Source of fuel. } & \multirow{2}{*}{ Type of fuel. } & \multicolumn{2}{|c|}{$\begin{array}{l}\text { Pounds of water evap- } \\
\text { orated at } 212^{\circ} \mathrm{F} \text {., per } \\
\text { pound of }-\end{array}$} & \multirow{2}{*}{$\begin{array}{l}\text { Percentage } \\
\text { of water in } \\
\text { fuel as } \\
\text { fired. }\end{array}$} \\
\hline & & & $\begin{array}{l}\text { Dry fuel } \\
\text { used. }\end{array}$ & $\begin{array}{l}\text { Fuel as } \\
\text { fired. }\end{array}$ & \\
\hline 386 & Florida. & Compressed or machine peat. & 6.04 & 5.00 & 17.21 \\
\hline 410 & Alabama. & Bituminous coal............... & 9.00 & 8.69 & 3.43 \\
\hline 294 & Arkansas. & $\ldots$ do...$\ldots \ldots \ldots \ldots$ & 8.84 & 8.35 & 5.55 \\
\hline 340 & .....do.... & Lignite.............. & 5.86 & 3.59 & 38.75 \\
\hline 420 & Illinois.. & Bituminous coal... & 8.40 & 7.67 & 8.72 \\
\hline 432 & Indiana. & ....do............. & 8.60 & 8.02 & 12.79 \\
\hline 311 & Kansas... & ....do............. & 7.88 & 7.23 & 8.28 \\
\hline 462 & Kentucky. & ....do.......... & 8.61 & 7.92 & 8.04 \\
\hline 486 & Missouri... & [...do $\ldots \ldots \ldots \ldots \ldots \ldots \ldots \ldots \ldots$ & 5.66 & 6.36 & 4.51 \\
\hline 469 & Ohio.......... & .....do..... & 9.28 & 8.90 & 4.10 \\
\hline 467 & Pennsylvania. & ....do..... & 10.04 & 9.65 & 3.90 \\
\hline 510 & ....do......... & ....do............... & 8.92 & 8.46 & 5.15 \\
\hline 401 & Rhode Island. & Graphitic anthracite.................... & 4.93 & 4.81 & 2.33 \\
\hline 291 & Texas....... & 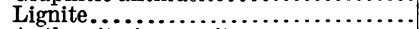 & 6.90 & 4.40 & 36.27 \\
\hline 476 & Virginia..... & Anthracite (pea coal) $\ldots \ldots \ldots \ldots \ldots \ldots$ & 7.83 & 7.46 & 4.73 \\
\hline 290 & Washington & Subbituminous coal.............. & 7.44 & 6.25 & 15.96 \\
\hline
\end{tabular}

This comparison includes only a single specimen of peat, used for a comparatively short time, and of necessity prevents the reaching of any general conclusions of value, but the confirmation which it gives to other estimates of the relative value of peat is striking. The coal samples used for the tests were generally run-of-mine, carload lots, shipped under the inspection of the United States Geological Survey, and tested under known conditions.

The table shows that slightly more than 60 per cent as much water per pound was evaporated from the peat as from the best sample of bituminous coal citel, when considered on the water-free basis, and 51.8 per cent as much per pound when compared "as fired." On the other hand, the figures are 90.7 and 75.5 per cent when comparison is made with the poorest of the bituminous coals or, for the average of the 10 samples listed, 70 per cent for the water-free fuels, and 61.5 per cent for the fuels as fired.

The peat gave better results than the graphitic anthracite from Rhode Island, which evaporated only 81.4 per cent as much water on the dry and 96 per cent as much on the "as fired" basis. Compared with the pea-size Virginia anthracite, the peat was 77 per cent as valuable "as fired." The subbituminous coal from Washington evaporated about 20 per cent more water than the peat in each form of statement.

In the case of the iignites, the sample from Texas was 13 per cent better as dry fuel, but its large percentage of moisture reduced its value to 88 per cent of that of the peat as fired; that from Arkansas 
had 97 per cent of the value of the peat on the dry basis and about 72 per cent as fired.

The peat used was of good quality, as shown by the accompanying proximate analysis:

Proximate chemical analysis of Florida No. 1 peat.

[Used in steaming test 386.]

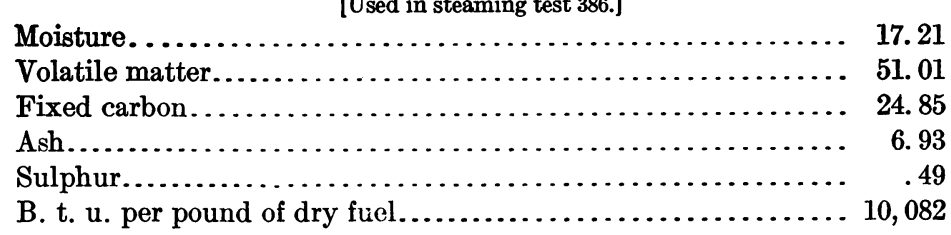

In a preliminary report ${ }^{a}$ of the steaming test with peat on which this discussion is based, the statement is made that "No difficulty was encountered in keeping the boiler up to its rated capacity, and in fact during the four hours' run the percentage of rated horsepower of the boiler developed was 113.2. The amount of peat burned per indicated horsepower hour at the steam engine was 5.66 pounds, and per electrical horsepower hour at the switchboard was 6.98 pounds. The principal difficulty in the utilization of peat under boilers appears to be the frequency with which it must be fired. On account of the lightness of the material and also on account of its rapid combustion the fireman was kept at work almost constantly during the test."

\section{IMPROVEMENTS PROBABLE.}

There are strong probabilities that with more experience with peat fuel, and consequent better adjustment of the drafts and slight modification of the fire box, the difficulties mentioned above would have been largely obviated, and at the same time a somewhat smaller consumption of fuel would have been obtained with no material decrease in the efficiency of the boiler. These probabilities are strongly supported by the statements of users of peat who have given it prolonged trial for boiler use; they state that it requires much less draft than coal. A fire of peat is claimed to raise steam in a boiler in about one-half the time taken by a coal fire; the fire is said to be lasting, nearly or quite smokeless and to make a very light, powdery ash, which does not fuse readily, if at all, so that there are no clinkers produced. Further claim is made that no unconsumed fuel is left as cinders either in the fire box or in the ash pit. Because the combustion is complete, no soot is deposited, and by reason of the small percentage of sulphur present in the fresh-water peats, scaling and other forms of corrosion of grate bars, fire box, and boiler are reduced to a minimum; the boiler flues are generally left entirely without any

a U. S. Geol. Survey Bull. No. 290, p. 135. (Now out of print.)

$661^{\circ}-$ Bull. $16-11-5$ 
form of deposit except, in rather unusual cases, a small quantity of very powdery ash. The lightness of the peat makes it the most easily handled of all solid fuels, and it can be placed on the fire exactly where needed.

\section{ACTION OF VOLATILE HYDROCARBONS.}

As has been noted, the volatile hydrocarbons of peat are not driven off as black smoke, as are those of bituminous coal, but are consumed in the fire box above the fuel bed, thus quickly giving a high temperature; by this means steam is generated rapidly and the supply is maintained by the slower combustion of the fixed carbon of the fuel bed. The actual efficiency of peat when properly fired in a welldesigned fire box, as compared with the theoretical calorific value, is apparently greater than would be expected, because of its ready ignition, complete combustion, as well as its freedom from cinders, clinkers, sparks, soot, smoke, and deposition of heat-absorbing compounds on the fire box and in the boiler flues. On the other hand, coal yields a large amount of ash and soot, which clog the flues, and corrosive gases, which cover the boiler and any metal surfaces with which they come in contact with a constantly thickening incrustation of rust; a considerable percentage of the good coal fails to burn, and the fusible character of the ash makes slag and clinkers a constant source of annoyance as well as loss of heat. These factors reduce the efficiency of most kinds of coal more than is commonly appreciated, because each lowers the steam-generating power of the fuel and lessens by so much its theoretical superiority over peat in ordinary boiler practice.

Even if the truth of these comparisons were not apparent, some sacrifices of heating value could seemingly be tolerated in view of the smokeless feature of peat combustion as compared with the constantly increasing losses of the public from damage to and defacement of property and probable injury to health directly traceable to the smoke of bituminous coal. 


\section{PREPaRATION AND MANUFACTURE OF PEAT FUEL.}

\section{ESSENTIAL PRELIMINARY CONSIDERATIONS.}

The preceding sections of this paper have discussed at length the occurrence and origin of peat and those of its qualities which appear to be of most importance relative to its value as fuel, and which need to be taken into account in making it into a marketable fuel on a large scale.

Before such production can be made commercially successful on any scale, however, other factors than those pertaining solely to the properties of peat and its fitness for specific use must be considered. Some of these are presented here as preliminary to the more technical part of the paper, because the success or failure of all attempts to make any product from peat must be based upon them, and because they are so often overlooked or deliberately ignored by those about to enter upon or promote the manufacture of peat products. The need of such a discussion is emphasized by a glance at the history of the numerous attempts at peat-fuel manufacture that have been made in the United States during the last 50 years. Large sums of money, aggregating many hundreds of thousands of dollars, have been spent upon such ventures, yet practically no financial returns have been received from them by their supporters.

These facts are so well known in some sections of the country where there are numerous peat deposits that a large part of the conservative investing public can no longer be interested in any enterprise based on peat utilization, no matter how attractively it may be presented. This section of the report is designed to show that causes which are avoidable have been chiefly responsible for the losses and failures of peat enterprises of the past-not a lack of desirable qualities existing primarily in the peat itself and in the products made from it.

\section{ERRORS THAT HAVE CAUSED PAST FAILURES.}

To state the matter simply, the study of unsuccessful peat-fuel plants in this country, and an analysis of their history, emphasizes the fact that a number of important matters must be taken into account before any peat bog can be made the source of a paying business, even when the peat is of good quality, and can be shown to be 
valuable fuel if rightly treated. It seems clearly obvious from such examination that much of the lack of success observed has been due to failure to take such factors into account, to ignorance of their existence, or to too great optimism when they were under consideration.

IGNORANCE AND INEXPERIENCE.

The most important single group of such errors may be charged, perhaps, to ignorance and inexperience. Ignorance is not excusable, however, since there is a very considerable mass of literature in nearly every European language, which details at length records of the theoretical and business experience gained during more than a hundred years of experiments. Although these experimental data have been gathered under economic conditions differing somewhat from those in America, the difference is not so great that the results can not be made applicable here; to entirely overlook or throw them aside is to invite failure when success might almost as easily be attained. For example, much greater progress could be made in a given time by taking the best types of European machinery and processes for manufacturing peat and improving them than by beginning anew and working out similar ones independently. Large sums of money and much disappointment would also be saved.

FAULTY ENGINEERING.

Many of the difficulties which have been encountered in peat utilization in the United States, as well as some of the failures, may be attributed to what may be termed "faulty engineering." Under this head may be grouped mistakes made in choosing sites for the erection of plants; poor planning and erection; unwise selection of the kind of product to be made and the way to make it; the choice of inefficient machinery by which it is to be made; and even in imperfect prospecting, surveying, and proving up peat bogs.

There have also come to the attention of the writer many cases in which certain fundamental business considerations seemingly have been ignored or overlooked, thus predestining the ultimate collapse of the enterprises.

As the results of overlooking or neglecting these factors have been observed in many parts of the country, persons who, without previous experience, are considering investment in some form of peat utilization, may be helped by a brief statement of some of the economic and related principles that must govern the founding and successful growth of any business that has the use of peat as a basis. Attention may in this way be directed to some of the dangers of loss which may be encountered as the result of inexperience. 


\section{FACTORS GOVERNING PROFITABIE UTILIZATION OF PEAT DEPOSITS.}

\section{MARKET.}

One of the first objections which is raised against the use of peat for fuel is the one made by economists and others that the country is already so well supplied with good fuel in other forms, such as wood, coal, oil, and gas, that there will be no sale for peat; they contend, a priori, that there will be no market for peat fuel; hence investigation of its possibilities is useless. The market is rightly considered to be the most important factor and the one upon which the fate of any peat development must hinge, for unless the product of an industry finds a ready sale at prices which will meet all costs, maintain the the plant, and give a profit on the capital invested, there can be no permanence to it-in fact, no industry.

At first thought, any desirable type of fuel, would seemingly find a ready sale at good prices, but more careful consideration will raise the question as to whether a substance like peat, which is quite unknown and untried in most American fuel markets, will be accepted by any number of buyers until they have learned by experience that it may be depended upon. Experience shows that most people are conservative in adopting new materials in place of those which they have long known and have found satisfactory. The conclusion may be drawn, therefore, that the market for any form of peat, as for other new materials, must generally be won by slow and persistent effort, in which a first-rate product, skillful manufacture, careful advertising, and constant demonstration must be combined.

The important markets for fuel are located in the larger towns and cities; hence a peat-fuel factory should be situated where one or more large centers of population and manufacture can be worked up for a market. It must be remembered, however, that the fuel trade in such places is thoroughly and closely organized, and therefore opposition must be expected to any new and independent product. This opposition, if effective, will result in reduced sales, in lower prices, and obviously in smaller profits during the stage while competition from these agencies is active.

A good market, then, generally must be built up. Not less than five years after peat fuel is put on a given market would probably be needed for it to find its proper place among other fuels. At the end of the period peat could hardly be expected to form more than 10 per cent of the entire quantity of fuel used for all purposes in the region surrounding the proposed plant.

Conversely, time is needed in all new manufacturing enterprises to get the plant to a stage where its efficiency permits other than slow and expensive production. This period of development ought to be 
the time when a market is being secured and established so that the product as fast as it can be made will be taken at fair prices, and so that as soon as a full and satisfactory output is attained the whole of it can be sold with profit.

So far as can be seen at present, or can be judged from European experience, it will not be feasible to send peat fuel long distances by rail. Indeed, the closer to a good market that it can be produced, the more certain will be the chances of success. The abundance and prices of other kinds of fuel, the means of transportation, the attitude of the transportation companies, the conservatism of the population, and the way in which the peat is prepared will all be factors in determining the maximum distance that can be reached by a given peatfuel factory. This maximum distance will presumably be less than 50 miles for a long time after the factory has reached a productive stage.

The market within this radius can be secured only by making a uniform product with enough good qualities to displace fuels which have been known long before the time of its introduction. The peat must be fairly and honestly shown to be really desirable, and the more honestly the demonstration is made the more profitable will be the final outcome.

\section{TRANSPORTATION FACILITIES.}

It will probably not be possible for a long time in the future to utilize as a source of fuel peat bogs that are unfavorably located in respect to lines of railroad already built, or to water routes, such as rivers, lakes, and canals. The possible exception lies in bogs which may be utilized by producer-gas plants where the peat is converted into electric energy at the bog, or into fuel gas that may be conveyed by pipe lines to the places where it is to be used. Both of these uses are quite practicable, but are likely to be slowly developed, because of the conservatism of capital in taking up entirely new lines of investment.

It is important, therefore, to be assured that good transportation lines to the site chosen for a peat-fuel plant are already in existence, or will be before the plant is built. The cost of every item is so much increased where teaming is necessary, that, except on a very small scale, a plant can not be established and brought to a successful production with this sort of transportation. The limit to which the finished peat fuel can be drawn by horses and sold at a profit is easily determined when the cost of production is added to other charges, including the cost of men and teams, and subtracted from the selling price. Failure to secure steam or water transportation to the factory has obviously been the cause of failure of a very considerable number of peat-fuel plants, either before they were fully developed or soon afterwards. 
Closely connected with the factors which have been mentioned is that of choice of location of a bog on which to establish peat operations. Too much importance can scarcely be attached to this, as the success of the enterprise depends not so much upon the quantity of peat to be manufactured as upon the cost of production and marketing as compared with the price at which sales can be made. Clearly, therefore, a small, favorably located bog is preferable for experimental exploitation to a large one remote from market, transportation lines, and cheap labor supply.

The margin of profit on the finished product of any type of peatfuel plant will be so small, because of the low price at which it must be sold in competition with coal and wood, that no extra charges should be placed on its production by a choice of location that will entail a high cost for labor and maintenance, and slow, uncertain, and expensive transportation to market. The greed that urges the promotors of projected enterprises to get the largest possible quantity of raw material may blind them to the handicaps caused by its location, and thus bring the entire investment to a disastrous end.

\section{AVAILABLE CAPITAL AND QUANTITY OF PEAT.}

An estimate of the life of the plant, its size, and consequently the amount of money invested, must be determined by the total quantity of good peat in the bog selected for exploitation; hence an approximately accurate knowledge of how much peat can be had is essential before other plans are made, especially if the deposit is of small area and depth. If it is very large, the need of care in this respect is not so great as when the quantity is clearly limited; in all cases, however, sufficiently exact tests should be made to insure the fact that the projected investment is justified by the quantity of good raw material available.

The prosperity of the enterprise and the returns from the investment will depend upon the salability of the output and the reputation which it wins among fuel consumers. These, in turn, must be based upon the quality of the peat, its fuel value, structure, ash content, and the kind of fuel that it makes. In considerable measure, also, some of these factors control the cost of production, because upon them depends the ease and consequent cheapness with which the peat can be dug and made ready for market.

PRACTICAL METHOD OF COMPUTATION.

The quantity of peat in a given deposit may be determined with sufficient accuracy for practical purposes by finding its total area 
and average depth, and assuming that at least 200 tons of air-dry machine peat can be made per acre for each foot in depth. Some heavy types of peat will yield more than this, and the figure is seemingly conservative for American peats, which in practice generally give a dense, heavy product.

SMALLEST WORKABIE SIZE OF BOF.

So many erroneous ideas have been expressed as to the lower limit of size of bogs that may be used for making peat fuel that the following illustration is cited to show that in Europe bogs of small size are used even where considerable investments are made. At Skabersjö, Sweden, a producer-gas plant equipped for generating electricity, and costing several thousands of dollars, has been erected at a peat deposit 37 acres in area and averaging 5 feet deep. The life of the plant is estimated at 30 years at the present rate of consumption of fuel, of which there is estimated to be 44,500 tons available. There are other bogs in the neighborhood which may be used after the one now in use is exhausted, but none is of great size. The plant develops 300 horsepower.

The illustration mentioned indicates that small deposits of peat of small average depth will justify exploitation if the plans formed are not too ambitious, as the annual production of 1,000 or 1,500 tons of peat fuel can be assured for a long period of years from such bogs as the one cited. Such a quantity may be sufficient to furnish all that will be taken by a good-sized community for several years after a plant is built. It should also be taken into account that a number of years would probably elapse before so large an output could be made by the plant or be taken by local markets.

There are many small towns in the northern United States near which are sufficiently large beds of peat to supply electric current for many years for lighting and other uses. Likewise, power for factories and mines-where now the fuel used is coal shipped by rail from distant mines-might be cheaply obtained from near-by peat beds.

The physical properties of the peat beds under consideration should be such that the raw material may be easily dug and easily and rapidly put into the desired form of product with the chosen machinery. If condensed or machine peat to be shipped from bog to market by rail is the product decided upon, the peat should not be very fibrous or woody. These qualities, however, do not reduce its value so much for local use, except as stumps and other remains of trees increase the cost of digging, which in most cases will be small per ton of final product. 


\section{METHODS OF PROSPECTING PEAT BOGS AND ESTIMATING THEIR CONTENTS.}

Peat beds of large area and considerable average depth are rather rare in the United States, and where they do occur are often so located with respect to lines of transportation or to markets that they could not be used at present except for the production of gas for power generation. Bogs of this class need little careful prospecting, as the quantity of peat in them is very large, and ordinary errors in the relation of the estimated quantity to that actually present may be disregarded when a quantity of material sufficient to warrant exploitation is known to be present.

There is greater need of carefully testing bogs of small area, and the cost of doing this is relatively small. After the area has been found by an ordinary land survey, a series of parallel, uniformly spaced lines should be laid out at right angles to the long axis of the bog and entirely across its surface. Along the lines test holes to the bottom of the deposit should be made to determine its variations in depth. The intervals between the holes should be of the same length, and in final proving up should be dug as deep as possible with a spade or post-hole digger. An earth auger with an open spiral or a ship auger of similar construction may be welded to a section of half-inch gas pipe, and used for sounding the depth and for taking from below the surface samples for chemical analysis. If the tool is to be used often, 3 or 4 foot lengths of pipe, provided at one end with a carefully fitted coupling and at the other with a thread which fits the coupling, will be found convenient. The coupling may be fastened to the pipe by a pin which prevents its unscrewing from that piece when another section is joined to it.

The chief objection to the use of the auger lies in the fact that in deep deposits the sample taken at a considerable depth may be stripped from the auger as it is drawn up and may be replaced by the material through which it is drawn, so that the origin of the sample may be doubtful.

A much more exact tool is one devised by the author and used by him with great satisfaction for several seasons. The essential part of this tool is a stout brass tube about a foot long and seven-eighths of an inch in inside diameter. The lower edge of the tube is sharpened, and inside the upper end is.closely fitted and riveted a shoulder or ring of brass one-sixteenth of an inch thick to serve as a stop for the piston and catch. Inside the cylinder is a brass piston of threefourths inch rod accurately fitting the opening in the upper part of the tube and bushed out at the lower end by a ring of brass to fit the cylinder. This lower end of the piston is slotted on one side, and in the slot is fastened a brass spring catch which automatically locks 
when the piston is drawn up and out of the cylinder. Ametal peg driven through a hole in the piston at the proper distance from its upper end and at right angles to its long axis prevents its being pushed out of the cylinder at the outlet end. The whole tool can be quickly and firmly fastened to a rod of gas pipe by a screw thread in the upper end of the piston. When used, this tool is pushed down into the peat the required distance, with the plunger filling the cylinder. A sample is taken by drawing up the rod and the attached piston until the catch is heard to lock at the top of the cylinder, after which the cylinder is pushed down into the peat about its own length. This action fills it unless the peat is very wet or very hard. After it is full it may be drawn to the surface without danger of loss or of mixing with the overlying material: The inclosed sample may then be pushed from the cylinder by unlocking and pushing in the piston. By using this tool carefully and thoroughly the depth and character of any peat bed may be accurately learned with a relatively small expenditure of time and labor. Only by digging with a shovel, however, can be had the large-sized samples that ought to be used in final tests. The large samples are more satisfactory for examination and may give more characteristic results than those taken with the testing tool described.

BOGS LYING BELOW THE GROUND-WATER LEVEL OR CONTAINING MARL.

Small and medium sized bogs which fill deep depressions below the ground-water level, like lake basins, may be expected to have open water or a layer of very watery peat below the thick, firm turf that forms the upper 3 or 4 feet of the bog upon which large trees may grow. Where such watery deposits occur they must be examined with unusual care, because the amount of water may occupy so much of the basin that the peat could not be worked profitably. In one such basin in Michigan, where the turf supported a growth of trees and was so strong that a railroad was built upon it entirely across the basin, more than 60,000 cubic yards of earth were used to give the track stability after the traffic had become so heavy that the turf would no longer support the weight of the grade, tracks, and train. Manifestly, this bulk of earth would fill only a small part of the space occupied by water and watery peat in that basin which hasty or inefficient testing would have determined to be filled with compact peat.

The possible occurrence of marl should also be watched for in basins the upper levels of which have good peat beds. This precaution should be taken especially in those parts of Wisconsin, Michigan, Iowa, Illinois, and Indiana, where the ground water, as shown by its hardness, contains much lime and where marl deposits are of frequent occurrence. Such deposits are often covered with peat to the depth of several feet and may also be interbedded with it. If an auger or 
ordinary sounding rod is used in testing such deposits the marl may not be found because, as indicated above, the peat of the top strata may replace it in the auger and lead to the conclusion that the entire deposit is of peat and that a much larger quantity is available than really exists. Beds of soft, fine clay underlying peat in basins may be equally deceptive.

APPROXIMATE DETERMINATION OF PRODUCTIVENESS.

If a close approximation of the actual quantity of air-dried machine peat which a bog contains is desired, a considerable number of measured cubic yards should be dug from different parts of the deposit and from different depths and each of these macerated separately. After thorough drying by exposure to the air for some weeks the resulting blocks should be weighed; the average of the series will give the number of pounds of marketable material per cubic yard, and this multiplied into the number of cubic yards in the entire deposit and reduced to tons will give approximately the total weight of the entire available mass of peat. The more thoroughly the sample cubic yards are distributed over the entire area and depth of the bog, the more valuable the data obtained will be. In making estimates and the tests upon which they are based, the turf and the poorly decomposed top stratum of peat for a foot, more or less, below the surface is not usually included.

It is perhaps worth while to point out here the urgent necessity of having all surveying and testing work done thoroughly and by competent men, as money expended on these determinations gives information without which it is impossible to proceed with any certainty to the making of investments; lack of knowledge or a wrong estimate may lead to overconfidence and serious financial loss, or to entire failure.

\section{CHEMICAL TESTS.}

The use and kinds of chemical tests have already been discussed, but for persons who may wish to know how to make preliminary examinations of peat for themselves the following directions are given. The recommendation is made that any preliminary tests be confirmed before the peat is utilized for commercial purposes. Analyses by a competent chemist who has the proper apparatus and laboratory equipment to do the work accurately and inexpensively are the most satisfactory.

The equipment needed for such preliminary tests as need to be made are: (1) Some form of weighing apparatus that will give a reasonable degree of accuracy. If the scale is not sensitive, a large sample of peat must be tested. (2) Some form of metal or earthen vessel in which the peat can be weighed and burned. For this purpose a small 
pressed metal cup will answer. Before using, it should be thoroughly heated to burn or melt off any substances that would later be lost in this way. (3) A stove or burner in which a clear, smokeless fire can be kept up; a gas stove is ideal for the purpose. (4) Metal tongs or forceps for use in handling the cup when it is hot.

The testing of peat as fuel begins with the air-dried material, although if the quantity of water the peat contains in the bog is desired, this can be ascertained by taking a sample just as it is dug and keeping it in a tightly closed glass fruit jar until the desired tests can be made.

To find the percentage of water in the peat, a sample is removed from the storage jar to the clean, dry cup, which should be weighed as accurately as possible beforehand and the weight recorded. The combined weight of the sample and cup is next ascertained and the weight of the peat obtained by difference. The cup containing the sample may then be placed on a hot steam radiator or in the top of a vessel of boiling water and dried until there is no longer loss of weight after repeated weighings. The difference between the original weight and the last is the amount of water evaporated. By the same method, the percentage of water in an air-dried sample can be found, the drying being hastened by thoroughly pulverizing the peat before it is weighed. In drying samples in these operations care must be taken not to heat the peat much above the boiling point of water on account of the ease with which some of the volatile matter is driven off, causing too great a loss of weight.

After the water is all driven off (a state indicated by no loss of weight when the sample is reheated) and after the weight of the sample is correctly noted, the residue should be set on fire and carefully burned, stirring with a clean wire being resorted to to make combustion complete. When the ash is nearly white, and no unconsumed particles can be seen, the dish should be allowed to stand till cold and the ash and dish weighed. The weight of the dish subtracted from the weight of the ash and the dish is the weight of the ash. Peat with less than 5 per cent of ash is rated as good for fuel; that with from 5 to 10 per cent, medium good; and that with more than 20 per cent is generally considered too high in ash to be of any value for commercial exploitation, except for use in a good gas producer or in some local manufacturing enterprise.

If it is desired to know the quantity of coke that a given peat sample will yield, the sample should be weighed in a cup with a loosely fitting cover, and the cup and sample placed in a flame or a clear fire and heated to redness until gas ceases to come off. The gas will take fire around the cover, and as long as it burns the heating should be continued. As soon as the gas is all driven off, the cup, tightly covered, should be cooled and weighed again. The difference in weight is the 
weight of the volatile matter, including the water in the peat, and the residue is the coke, which is the fixed carbon plus the ash.

The denisity of a given peat may be determined by cutting out a block of such shape that it can be exactly measured and comparing its weight with that of the same number of cubic inches of water. If the block is made to contain an exact number of cubic inches, the operation will be easier. A cubic inch of water at $60^{\circ} \mathrm{F}$., the ordinary temperature of the air at which weighings are made, weighs $252 \frac{1}{2}$ grains.

In most large cities cheap laboratory appliances can be bought, and these will serve for making the required tests. In the same cities, too, will be found commercial testing laboratories where satisfactory fueltesting work is done at reasonable rates. Practically all of the educational institutions with courses in mechanical engineering or technical chemistry also have good equipment for making fuel analyses. The essential elements to be obtained for comparison are the ash content and the theoretical fuel value expressed in calories or in British thermal units (B. t. u.).

MECHANICAL TESTS.

According to observation and experience an examination into the mechanical structure and qualities of peat is of more value than a chemical analysis. This is especially true when the material has been selected for a single specialized use requiring a large outlay of money for a properly equipped plant. The importance of carefully investigating the deficiencies of peat, as well as its good qualities for the intended use, is emphasized and should not be overlooked. The defects, the cost and difficulty of handling, the large percentage of water and waste matter as compared with that of usable material, and other qualities of similar nature must be investigated. The more specific the proposed use the more thorough and complete should be the preliminary investigations. As a part of such tests the selected machinery should be tried under conditions as nearly as possible like those of the factory, with large samples of the chosen peat. The samples should be of not less than a ton in weight and of larger size when they can be had, and the tests should be made before any plans for installation of a permanent nature are developed.

Samples used in such tests should be carefully collected, so that they include material from well-separated parts of the bog and from as deep below the surface as the peat can be reached with the usual tools for digging. The costs of these tests may seem excessive, but in the end are justified by the results obtained, whether satisfactory or not. If the peat thus tested turns out to be unsuited for the purposes for which it was chosen, the expense is especially justified. 
When such tests are made it is probably more satisfactory to send the material to the factory of the makers of the machinery, where installation is complete and skilled labor is available, rather than to try to set up the machinery temporarily at the bog; by the former course more valuable results will be obtained at much less cost. The tests should be made under the inspection of some competent and disinterested observer who is retained to guard the rights of both parties concerned.

The great importance of thus trying machinery and peat together before erection of the plant has been fully demonstrated in this country. In at least two instances more than $\$ 100,000$ have been spent in the development of elaborate peat-fuel plants which were never successfully operated. The reason for their failure was that the machinery which had been installed could not manufacture the peat available into the desired product or any other that could be sold at a profit in accessible markets. Other examples less impressive might easily be cited in which lack of success seems clearly referable to the omission of thorough preliminary testing.

\section{SOURCE AND PERCENTAGE OF ASH.}

Peat containing a large quantity of ash is not as good fuel as that containing a less percentage, because the former type gives less heat for a given unit of weight. The ash of peat deposits, as noted above, is derived from the mineral matter gathered by the growing plants that have built up the peat. Mineral matter may also be brought in by the water by which the plant remains have been protected and preserved from decay, or may be blown in by the winds. The mineral matter derived from the water is carried either in solution or in suspension and may reach the peat continually with the water or be supplied intermittently by overflow from the ocean tides, lakes, streams, rain rills, or springs.

When peat deposits are being tested those in which the peat is grayish or greenish, or contains whitish or red streaks and spots when dry, or shows shining specks of mica, or is gritty when ground between the teeth, may be classed as of poor quality for fuel unless their analyses prove otherwise. In such deposits the ash content is generally found to be high.

Peat beds that lie in salt marshes, in the flood plains of brooks and rivers, in deltas of streams, or on terraces or slopes watered by springs whose waters are perceptibly mineralized, seldom pay for testing unless in a region where all kinds of fuel are scarce. All of these types of peat beds are certain to be somewhat deteriorated by mineral matter; hence the peat has its fuel value and its possible market value lowered by the presence of too much ash. 
In certain parts of the country peat beds in basins, even when no important streams enter them, are sometimes found to be rich in ash. This condition is caused by the presence of plants that concentrate in their cells or tissues or on their leaves and stems some of the minerals brought in by springs or other sources of water supply. The minerals are left on the bottom with other débris at the end of the cycle of growth of the plants. Calcium, magnesium, silicon, and iron compounds are thus segregated from lake waters and become part of the ash of peat.

The effects of the action of waves and currents on sandy or muddy lake shores also must be considered as a source of mineral matter in peat beds exposed to the wash of these sediment-transporting agents. Consequently peat on the banks of lakes having wide stretches of exposed sandy and muddy shores must be tested very thoroughly before using it for commercial purposes.

On the wind-swept plains of the States west of the Mississippi much fine mineral matter in the form of dust is blown into low places, where it is left and becomes a part of any peat deposit which may exist there. The supply of wind-blown dust is fairly constant from year to year, and doubtless the peat beds of Iowa, the Dakotas, and of western Minnesota will be found to have a high percentage of ash, a considerable part of which may be traced to dust.

\section{PREPARATION OF THE BOG FOR USE.}

In making the preliminary examination of a bog the quantity and kind of vegetation on the surface of the deposit should be carefully noted. If trees and shrubs are present, their kind, size, and relative abundance should be observed. The presence and frequency of roots, stumps, and buried logs should also be determined at the same time. Where trees are present and their buried remains are abundant the cost of getting the ground ready for digging the peat will be very materially greater than in a grass-covered bog. On the other hand, the wood may be sold or used for fuel at the plant, and the work of clearing may be done at times when weather or other conditions are unfavorable for production, thus keeping the force of laborers at work. It is also apparent that only a small area will be used at a time, and that the preliminary work will, therefore, be distributed over a long period, so that its cost per ton of peat produced will usually be so small as to be insignificant.

When all things are taken into account, however, and a choice of bogs can be made, that which has many buried logs and stumps should be avoided. If the woody material is confined closely to the surface layers, little account should be taken of it, because it is easily removed. The deposit below such layers is often more decomposed and compact than where trees have not yet become established. 


\section{DRAINAGE OF BOG.}

In European countries, where peat is dug extensively by hand, the general practice is to plan and carry out an elaborate system of drainage, so that the water content of the peat is perceptibly lowered before digging is begun. Aside from the greater convenience in digging insured by drainage, the water content is lowered to a considerable extent, although not so much nor so rapidly as would be expected, because of the water-holding powers of the peat.

Drainage becomes of importance, however, whenever the greatest economy of handling the wet peat is sought, as it should always be if dug by hand. Reference to the table giving the relation of the percentage of water in peat to its weight (p. 110) will show that, if the water content of a given weight of peat is reduced from 90 per cent to 80 per cent, its weight will be decreased 50 per cent, or one-half. Hence by lowering the water 10 per cent only one-half the weight of wet peat that would have to be dug before the reduction has to be dug out and handled for a given weight of finished product.

Drainage may be unnecessary, or even undesirable, where the peat is to be dug and transported from the bog to the factory by machinery, especially if it is to be dug by dredges, loaded on scows, and towed in them across the water-filled openings already made to the factory. It would be still less desirable to drain where the peat is to be dug and moved from the bog to the factory by powerful rotary pumps, such as are employed on the "sand-sucker" dredges so often used to improve waterways and harbors in the United States.

Before draining is decided upon as a policy in any given instance the possibility of draining the deposit must be determined. Although this could seemingly best be determined by taking levels, there is an important relation between the structure of the deposit and drainage possibilities which, if observed, will be of much assistance and may render surveying unnecessary. Bogs of the built-up type-that is, those which show a uniformity of structure or the presence from bottom to top of the remains of such plants as always grow near or slightly above the ground-water level-can be drained to the bottom or as deep as such structure is found.

On the other hand, peat that fills basins formerly occupied by ponds and lakes can be drained only for a short distance below the surface, or not at all, except at great expense, as the outlet must sometimes be lowered for a long distance. An attempt to drain peat beds of this type more than a few feet by surface ditching will, therefore, be unsuccessful, and peat will generally be most easily and most cheaply worked without any attempt at draining unless diking and pumping are adopted. Deposits of this class, as they lie chiefly below the water level and can not be drained, must manifestly be worked almost entirely by machinery, unless the water is kept down by 
pumping or by sinking tubular drainage wells to porous beds in the ground below the basin, as may sometimes be done.

In bogs filling basins ditches should not be cut from the shoreward margin to open water in the interior of the marsh without very careful leveling across the surface, because not uncommonly the surface of the water in the pond is higher than that in the marginal area and water will flow from the pond and not into it.

That utilization of peat bogs in the United States under existing economic conditions necessitates drainage remains to be proved. Where digging by hand has been tried it has been very slow and expensive and has been an important contributory cause in the final failure of the plants adopting the system. If draining is decided upon, levels must be taken carefully to determine the direction and fall of the surface, and surveys must be made of the distance to the nearest main established stream. After these data have been collected draining will proceed much more cheaply and more satisfactorily if excavation is begun at the outlet end of the bog and continued as development progresses toward the higher parts. Such a course will make the system of drains as simple and short as possible and will reduce thereby the cost of the work, and by keeping them wet will also protect the undeveloped parts of the bog from loss by fire and injury from freezing. Where machine peat is to be made from a drained bog the ditches must be provided with dams to hold the water in them during the winter, as freezing injures the cohesiveness of the drier parts of peat beds more than it does those that are kept very wet.

\section{CHOICE OF SITE FOR THE PLANT.}

The choice of a site for the plant would seem to be a simple matter and not of sufficient importance to merit much discussion, but when it is remembered that from 80 to 90 per cent of the material brought to the plant is water (and therefore waste) it becomes evident that by reducing the distance of the average haul of the wet peat a material saving in the cost of this transportation and production will be made. The permanent buildings of the plant, therefore, should be so placed in relation to the bog to be worked that the raw wet peat will reach the grinding machinery by the shortest and most direct route; from the grinding machinery it should be taken as directly to the drying grounds or sheds.

An ideal arrangement, especially in the manufacture of machine peat, is to have no fixed buildings, but to have the movable machinery always at the side of the openings from which the peat is taken, and to pass the peat directly from the mechanical excavator to the pulping machinery and thence to a part of the bog near by that is laid out as drying ground. To insure such mobility of plant, the machinery $661^{\circ}-$ Bull. $16-11 \longrightarrow 6$ 
may be mounted on a strong car and moved on iron rails or upon rollers or broad-wheeled trucks; the engine is used to run the plant and as a locomotive. This is the common practice in many parts of Europe. The plant is much the same temporary sort of an arrangement as a portable sawmill or thrashing outfit. The most recent practice in Germany, Canada, and the United States is to combine digging, macerating, and spreading machinery into a single selfpropelling plant which is supported on a single platform with or without rails.

However, in some cases it will be desirable to place the machinery on solid ground, because there are difficulties in moving peat machinery of large capacity from place to place on the soft and unstable surface of the wet peat. If the moving of the wet peat is the ruling consideration, the plant ought to be placed as near as possible to the bog, the necessity of a firm foundation and convenient approaches and drying ground being also observed; the hauls necessary to get the freshly dug peat to the buildings should average as short as possible during the life of the plant. The best location would ordinarily be about midway of one of the long sides of the deposit.

If, however, more satisfactory transportation arrangements can be made, a more stable supply of labor assured, or better drying ground obtained at some point other than the one indicated, these practical matters should determine the selection of the site.

LAYING OUT THE PLANT.

Several factories in the United States have been built for making peat fuel in which, seemingly, no thought or care has been given to laying out the plant so as to secure the greatest efficiency from the machinery and economy in the details of production. This is evidently a radical defect in such plants, if the highest financial returns are sought, as these are dependent upon successfully solving the following problem, stated in terms of the unit of production. The problem in peat-fuel manufacture is so to handle a ton of wet peat (containing 90 per cent of water, nearly all of which is useless) as it is dug from the undrained bog that the approximately 225 to 250 pounds of salable materials (containing 12 to 20 per cent of water)which will be obtained from it can be sold in the open market at a price that will pay for the digging, preparation for sale, and cost of selling, and, in addition, maintain the plant and equipment and return a profit on the investment. The handling of many tons of this wet raw material and the production of a large amount of marketable fuel only complicates matters if the unit of quantity is made at a loss, and manifestly any saving in the course of proper preparation will help to give a favorable solution of the problem. 
The machinery should be so arranged in the building that its best operation requires the least possible labor and supervision and that the various processes through which the peat must be put will become automatic or go on with the minimum amount of human labor and attention. Careful study should be given to the entire course of production and whenever simple and efficient machinery can be substituted for manual labor, it should be introduced, if possible.

The fact must not be lost sight of, however, that a product of such low selling price as peat is much more likely to be manufactured profitably if the machinery used is simple and the processes through which it is made ready for sale are few and direct than if complicated and high-priced machines and numerous operations are required.

\section{SELECTION OF PROCESSES AND MACHINERY.}

The process by which a given peat bed can be utilized to the best advantage and with the greatest profit depends, among other factors, upon the quality of peat, the kind of market which can be reached, and the amount of capital which is available for the purpose. Not all kinds of peat will make good briquets, even with the best machinery, and it would be a needless expense to erect a large and expensive plant in a region of limited population, or where coal or other fuels are very cheap. It would obviously also be a poor policy to choose a process which would need a large investment of capital when an equally salable type of fuel, whether actually as good or not, could be made with a much smaller investment. It should be remembered that there is no such thing as a really secret process for making peat fuel, that when the time comes for selection the number of available processes is not large, and that all such processes have often been described by European authors or by others discussing the use of peat in Europe.

It should be the chief concern of the purchasing agent before any decision is reached to learn everything possible about the progress of peat-fuel production in Europe, and especially in Germany and Sweden, where, for more than a century, experienced men with keen, well-trained minds and ample facilities have been studying the possibilities of the substance and have been testing ways in which they have thought it could be most cheaply and readily made into an efficient and salable product.

After obtaining this information a careful examination should be made of the kinds of machinery now on the market as the practical result of the world's experience. That type should be chosen which has proven most efficient and successful in actual operation under con- 
ditions similar to those under which the proposed plant is to operate. With so many available types that have been thoroughly tested by commercial use it is not advisable to adopt new and untried processes and machinery for a plant that must be made financially successful from the start.

However, after machinery embodying the latest European knowledge has been tried, modification and adaptation to the conditions of production which experience has brought to light may seem advisable. Such work can be done much more satisfactorily after a preliminary test than at an earlier time before any practical knowledge had been gained. Indeed, it seems that much more real progress would be made by American inventors in developing machinery for manufacturing peat fuel if they started with the best European types as the basis of their plans rather than with an attempt to start from the beginning.

\section{CHARACTER OF THE PLANT.}

The size of the prospective operations, the process of manufacture chosen, and the amount of capital to be spent will govern to some extent the necessary expenditures for buildings and machinery. Aside from these factors, however, expediency and the actual needs of the business should govern the character of the buildings.

The permanent buildings needed for a factory making machine peat are few and can be of the simplest and cheapest construction consistent with durability for the expected life of the plant. All that is actually required is sheds for the protection of the boiler, engine, and grinding machinery and for drying and storing the peat. As production is limited to the warm months, heating and lighting in the winter do not have to be considered. This fact may also be taken into account in the construction.

In Europe many establishments making peat fuel have no permanent buildings, except for storage, as the machinery is all movable and is given temporary housing at the places on the bog where it is in use. Each peat machine makes a certain number of tons per day and the plant is added to by the purchase of new units as the need for increased output arises. The same would be true if self-propelling automatic machines were used instead of the standard older types.

If peat briquets are to be made, somewhat larger and more substantial buildings must be erected, because more machinery of heavier construction must be housed; yet even for the briquet plant the buildings may be built as cheaply and roughly as sawmills. The chief requirements are that the roofs keep out the rain and that the foundations for the presses, boilers, drivers, and engines be of sufficient strength. A simple, inexpensive, compact, and well-arranged 
plant of moderate capacity, increased unit by unit, is much more advisable than large and costly buildings containing small equipment.

Peat-coke, or charcoal manufacture combined with the recovery of by-products, requires a heavier investment for buildings to house the much greater quantity of apparatus necessary, and these must be of good construction, because the plant will be operated the entire year. Practically the same statement applies to the buildings that would be needed for utilizing peat for gas production. Even for for such uses, however, care may be exercised to keep down the outlay of construction by making the necessary buildings simple and inexpensive. Some of the buildings which have been erected for peat-fuel factories are monuments to the dreams of their builders.

\section{WORKING CAPITAL.}

The preceding sections show that a considerable number of factors must be taken into account preliminary to operating a peat-fuel manufactory. One of the most important is a definite and full provision for working capital for the maintenance and running expenses of the plant for the time that will surely be needed to develop it to a state of efficient production and to build up and establish a market for its output.

An examination of the history of the attempts to start peat-fuel operations in this country seems plainly to show that many of them have failed because of insufficient working capital. Money enough generally has been provided for actual building and partial or complete equipment of factories, but the projectors apparently have been so certain of success that they have deemed it sufficient to plan to produce peat fuel, and to build and more or less fully equip their plant therefor. Beyond this, they have often seemed to expect that the anticipated product would make and market itself with so much profit that necessary additional equipment could be had, dividends on the original investment paid, and the production continued indefinitely with increasing impetus.

This is not the usual result of an attempt to introduce a new and practically untried and unknown article that competes with one that has been long in use and that is acknowledged to be superior in some respects. In the cases under consideration, when the investors did not immediately realize their anticipated profits, they lost faith and refused to furnish additional money, often before their plants had advanced to a stage where commercial manufacture was possible. Such a result might have been foreseen in some cases and should have been provided for in all, as frequently is done in other kinds of business, by reserving a certain part of the funds at hand for carrying on the business through its period of experimental production. If 
such action had been taken, and later the necessity had arisen for increased facilities for production, the money for them would have been available.

To make no provision for working capital must be looked upon as a most serious error in business policy, and the conclusion seems warranted that those who start and promote enterprises for peat utilization in the United States at present without such provision are inviting the same troubles that have beset their predecessors, and can expect no greater success.

\section{CAPITALIZATION.}

The capitalization of peat enterprises, as stated in the preliminary literature issued by their promoters, has varied greatly. At least one reported an authorized capital of $\$ 20,000,000$. Obviously, however, certain definite matters control the sums of money which must be provided to establish a plant for using peat and to bring it to a successful stage of production, and these are here considered. In general, it may be said that large capitalization is neither needed nor desirable for most forms of peat utilization, but it is important, as has been noted above, to have reserve capital for use during the critical periods of the proposed factory. The amount of capital actually needed will differ for different products and for different ways of making the same products; it will be governed also by the proposed quantity of output, the size and kind of buildings to be erected, and other factors which do not need to be taken up here. The simpler processes of peat-fuel making on a moderate scale can be undertaken and carried on with success on a small capital. Some of the more complicated operations, such as making peat coke and by-products, or those peat products requiring heavier machines, more manipulation and labor, and stronger and more expensive buildings, must be liberally supported with money or credit if any returns are to be derived from them.

A much greater amount of capital must be assured and actually paid in, as required, to bring to a commercially productive and independent stage a plant that is equipped with machinery invented to exploit some new way of treating peat than would be needed to do an equivalent amount of development with machinery that is already on the market and has proved satisfactory in actual manufacture of the product which it was designed to make. This statement is warranted by the experience of many of the more aggressively advertised experiments in peat development which have been made in America and Europe. These experiments have invariably taken much more money and time to bring to a state of completion than their inventors anticipated; and some, after all, have failed. 


\section{EXPERIMENTAL WORK IN NEW PLANTS.}

The past uncounted waste of time and money in this country in what is called experimentation demands a brief notice. Experimentation has generally signified the random use of the whole or a part of a plant and its force of laborers for the purpose of testing some of the ideas of the man in charge or of some of his associates, in the hope that the process or machinery in use may be advantageously supplanted. The futility and waste lie more in the way in which the work is generally carried out than in the ideas themselves. Usually experimentation of this sort is attempted without the appliances for exact methods and without the originator having any clearly developed plans as to what is needed or how the work is to be conducted; yet it calls for much energy and money, and in the end counts for nothing. If the same amount of work and funds were used to raise the efficiency of the working force and of the machinery already in use, much of the experimenting would be entirely unnecessary. Sometimes the men who propose the changes are entirely without experience and training, or have only elementary knowledge, and the work which they do is nearly all lost. It appears certain that the men who have come nearest to success or have had the greatest success in making peat fuel have done so by avoiding as much as possible the expense of the sort of experiments described. They have developed their plants to profitable production by learning in practice from day to day the peculiarities of the substance with which they worked and the conditions required for making the best product possible with the machinery and process which they had chosen.

It must not be understood that properly controlled and carefully planned experiments may not lead to valuable results in the making of products from peat, but in so far as this work is done by inexperienced and untrained men, and diverts time, money, energy, and work needed to improve the commercial operation of the plant, it is a source of injury and positive loss, and may destroy what would otherwise be a profitable business.

It may be said in closing this discussion that in the writer's judgment the adoption of untried machinery for peat manufacture should always be considered as a purely experimental or speculative investment, especially if only working plans and calculations are submitted as the basis of the proposed plant. Only that machinery which has been actually used and has shown what it will do under approximately commercial conditions should be the basis of a factory from which it is necessary to get quick financial returns.

It has been the history of the development of all mechanical and chemical processes that they have developed slowly and by repeated and often costly failures. The more thoroughly and completely 
the processes are dependent for success upon the proper operation of a number of machines working in harmony for long periods of time the longer the period of development must be. In the history of peat-fuel enterprises in Europe this fact is emphasized again and again. At the present writing announcements are made of the reduction to a commercially possible stage of two important nearly continuous processes for utilizing peat. These processes have been before the public for a number of years as theoretically valuable, as demonstrated by laboratory experiments, but only now have they been sufficiently worked out in the details of the machinery needed for turning out the finished product on a scale and at a price that warrants the erection of the large plants required; the latest authentic information indicates that these have yet to be built.

\section{CUT PEAT.}

In Ireland, England, Denmark, Germany, and the other countries of Europe where peat is a common domestic fuel the simplest and most ancient method of preparation is still most commonly used. In Ireland, where nearly all of the fuel consumed by the country people is peat, no other process of preparing it has ever been used to any appreciable extent. Within a few years, however, the Department of Agriculture and Technical Education has established several temporary experiment stations for the purpose of introducing to the people the treatment of peat and its manufacture into fuel by simple machinery, most of which is of German origin.

The preparation of cut peat and the equipment for making it are so simple that the owners of small peat deposits can easily make fuel for home consumption. On this account a somewhat detailed description of the methods of procedure is given here, aithough the product is such that probably it can have only a very limited use in the United States.

After the surface of the part of the bog that is to be used is cleared, it is drained to the nearest watercourse by a ditch of good size. Into this main ditch are led a number of smaller ditches of sufficient capacity to lower the general water level in the peat at least 2 or 3 feet.

The part of the field to be worked is then chosen and more carefully cleared and leveled, so that its surface may be used as a drying ground. If this area is selected near the margin of the main ditch, it will be more easily and cheaply drained than if it is at a greater distance, because the water will already be lowered there, and the transverse ditches when dug will be as short as possible. Such small transverse ditches on the drying ground are made about a foot wide and with enough slope to the bottom to carry off the water that collects in them; they are generally placed from 30 to 60 feet apart. 
If the bog can not be drained cheaply by ditching, an opening may be made near the place selected for beginning work. The water can be pumped from this opening from time to time as it accumulates and can be conducted away from the immediate vicinity of the hole and the drying grounds. Care should be taken not to let water into such a hole by digging into the sands below the peat.

The tools used for making cut peat in different European countries are somewhat different in size and shape, but they are always of the simplest form and construction and differ only slightly from those used in ordinary ditching and digging. In Ireland, the most important special tool is the slane, a stout narrow spade having the length and width of the bricks to be cut. It has a narrow sharp steel lug welded on one side of the point of the blade and at right angles thereto. Some types of spades used for peat cutting in Germany have two of these lugs, one in the middle of the blade and the other at one side, so that two bricks can be cut at once. The size of the bricks varies in different countries according to the purposes for which they are to be used, the moisture conditions under which they must be dried, and the density and structure of the peat. The usual range is from 8 or 10 to 18 inches in length, and from 4 to 7 inches in width by 3 to 6 inches in thickness, when the bricks are freshly cut and wet.

The men generally work in pairs, a digger and a tender. The turf is first removed from a strip at the end of the ground prepared for digging and the peat below dug out in the form of bricks of as nearly uniform size as possible, and placed to one side. The tender picks them up, loads them on a car or wheelbarrow, wheels them to the drying ground, and lays them out for drying. As soon as the peat has been removed from a depth twice the length of the spade, or, more often, to the depth of the ditch bottoms, a new cut is started, the digger working in the trench to make the horizontal cuts, which are the last ones to be made. The vertical cuts are made with a straight spade or spadelike knife, the operator first making the wall cut at the length of the block from the last cut. The cuts forming the sides of the blocks are then made the width of the block apart; the horizontal cuts are made from the trench, and determine the thickness of the block.

If the peat is very thoroughly decomposed and structureless, the blocks may possibly be cut with the long axes vertical, using the slane, but where stratification is well marked or the peat fibrous this way of cutting causes the blocks to be easily broken along the lines of bedding; hence in most cases the length of the block is cut parallel to the planes of bedding. The slane may be used to cut the bricks out after the first vertical cut is made along the wall, especially where the peat is dense enough to be cut easily. 
After the blocks are taken to the drying ground they are stood on edge, with narrow spaces between them, and allowed to dry and drain for some days; in some countries they are turned during this time. In Ireland, as soon as they are firm enough to be handled they are "footed," or stood on end, generally seven in a small circle and two others crossed on top of the group. After a week or two, in good drying weather (or longer in bad weather), the blocks are "refooted" by turning them and combining two piles into one. In about four weeks they are ready to be removed and stacked. The bricks are piled in an open manner so that the air can circulate freely through the piles, and the peat is often left in these stacks until needed for use, the top being protected by a thatch or by a shed roof. If dried too rapidly, the product cracks and is brittle, and in this country stacking to check the drying may have to be resorted to in less than four weeks. In different countries the methods of piling the still moist peat blocks vary somewhat, but any open form that gives free access of the air to as much of the block as possible will serve. Where lumber is cheap, racks similar to those used in brickyards may be used to advantage for the preliminary drying and will hasten it by some weeks.

Peat blocks of the sizes given weigh from about half a pound to a pound and a half when they are air dry or contain from 15 to 30 per cent of moisture.

The cost of producing peat in this form varies with the cost of labor and the skill of the laborers who do the work. In Continental Europe, where this sort of work is usually paid for by the piece, the men getting a fixed price per thousand bricks in each of the processes of digging, spreading, etc., the fuel is made at from 50 cents to about $\$ 1.75$ per ton of air-dry peat bricks. The efficiency and price of labor and the different ways of handling the product are the only apparent reasons why the price should greatly vary. Cutting and drying peat for fuel should be done as early in the season as possible, because the product dries much more quickly in spring and early summer than later, and when the gathering is put off till August the peat may not get thoroughly dry before winter.

Cut peat is the poorest form of peat fuel, as it is bulky, friable, and burns up rapidly with considerable waste when thoroughly dry. In general, this kind of fuel may be considered as unfitted for American fuel markets; its chief use, if any, will be in the homes of its producers. The dark-colored, thoroughly disintegrated peats make the best cut bricks, and the light-brown, fibrous kinds the poorest, except for kindling.

In some parts of Europe, however, cut peat is still used to a considerable extent, even in the towns. Where it is made on a large scale machines are used to dig the peat, as these give the advantage 
of producing large blocks quickly, even from undrained and undrainable bogs which could hardly be worked by hand.

The essential part of such machines, which differ mainly in the details of construction and not in principle, is a series of three vertical iron or steel plates edged with steel knives. These plates are arranged in the form of a bottomless box from which one side has been removed and are supported and moved by simple machinery. The knives are forced into the peat to the desired depth by a strong rack and pinion operated by a crank turned by hand. The column of peat thus formed is cut off and supported at the bottom by a horizontal knife that is forced across the bottom of the box formed by the three vertical knife-edged plates. The horizontal knife is operated by a powerful lever worked from the surface. The column of peat, held up by the horizontal knife, is then raised by reversing the motion of the crank, and as it is brought above the surface it is cut into bricks with a spade, just as when cut by hand.

Some machines of this type will cut peat to a depth of more than 20 feet. They usually can be operated by two men; one raises and lowers the cutting apparatus and the other cuts up and loads the peat on barrows or cars, in which it is wheeled to the drying grounds. Where the peat is cut from considerable depths by large and heavy machines, three or four men may be needed to each machine. Peatcutting machines of this sort are strongly built, but may be moved from point to point on the surface of the bog as digging progresses. The guide for the knife can be moved so that a trench several feet wide can be cut without changing the position of the whole machine.

\section{MACHINE PEAT.}

\section{GENERAL STATEMENT.}

The term "machine peat" following German practice, has so generally come into use to designate peat that after being dug has been treated to a process of grinding or macerating and pressing before forming it into bricks that it is used here. Terms which are nearly or quite equivalent are press peat, pressed peat, condensed peat, machine-formed peat, and wet-process peat, so called in the United States to distinguish it from briquetted peat, which is thoroughly dried before being formed into blocks by great pressure in a briquetting press.

Cut peat as a fuel that is to be used, or even produced, on any considerable scale has well-marked defects, such as lack of uniformity, firmness, and density, small fuel value per unit of volume, and a high percentage of water frequently found in it even after prolonged drying. These defects led to early efforts to work the raw material into a more compact and durable form which would dry more thor- 
oughly and quickly and would be more dense and therefore easier to to transport. In general the earliest experiments in this direction were made to improve the quality of the very fibrous kinds of peat. So much was gained by even the crudest treatment that gradually in the more progressive peat regions all types of peat were treated in this way, and cut peat was only sparingly made by the larger enterprises. By the effects of the mechanical treatment mentioned above, the plant remains in the peat are reduced to a fine pulp, and their water-retaining capacity is lowered considerably; hence peat that has been thoroughly ground and mixed dries more quickly and forms denser fuel than that untreated. Within limits the more thorough the grinding and pulping and the more quickly the drying takes place, the more compact is the resulting fuel and the better its quality.

In theory, at least, when peat has been thoroughly macerated, a block of it is soon covered by a thin coating of a colloidal or gluelike material, which becomes nearly waterproof on drying, but which is sufficiently porous to allow moisture to pass through it from the inside of the brick. Possibly also this coating, when wet by rain, absorbs enough water to close up the minute openings which exist in the surface when it is dry, and thus prevent further absorption. Hence after a heavy rain properly ground machine peat is nearly as dry as it was before, whereas cut peat takes in a large amount of water and if the rain is prolonged may be much disintegrated. At the same time the contraction of the outer layers of the brick as they dry out exerts a certain pressure on the water contained in the interior, and thus probably forces it out toward the moister side, which in this case is always the one lying on the ground or on which the brick is supported.

\section{METHODS IN USE FOR MACERATING PEAT WITHOUT SPECIAL MACHINERY.}

There are two quite distinct processes used for macerating peat without special machinery: First, that in which enough water is added to the peat before it is macerated to make it into a soft paste, which, after treatment, is often decidedly liquid. This pulp is usually formed into bricks after it is spread on the drying ground. The forming is done either by hand, whence the name hand turf sometimes given the product, or by turning the pulpinto molds. Less often the macerated peat is spread in a layer on the drying ground and cut into the required shape with special tools, the bricks thus formed separating through contraction as they dry.

By the second method the peat is ground with practically the same amount of water that it contained when dug and is forced from the orifice of the grinding machine in one or more continuous prismatic or cylindrical strands, which are cut into bricks as they emerge from the machine; some types of machines form the peat pulp into balls; 
others perforate the bricks to facilitate drying. The product is machine peat in the usually accepted sense of the term, and the principal variations in its manufacture are all found in the details of construction of macerating machines and in drying the peat.

The simplest and most primitive modification of the first process, as used in Ireland and in other parts of Europe where no capital is available, is the following: The coarse, fibrous top layers of the peat are thrown into the hole made by the previous season's work. If sufficient water is already in the hole, the coarse peat is thoroughly mixed by trampling with that of finer texture in the hole, until the mass is of uniformly fine grained and pasty consistency. After this mixing is completed the ground peat is taken to the drying ground and spread in a layer from 8 to 12 inches thick, and the bricks are marked off by hand as the spreading proceeds. Only slightly more complicated than this simple process, is the use of wooden troughs for holding the peat and water while the maceration is going on, or the substitution of the feet of horses for those of men for mixing the peat and water.

In larger enterprises with some capital the peat is ground and mixed with water by machinery, a simple form of which is made by placing in the trough a rotating axis, to which are attached spirally-arranged knives and which is turned by horse or steam power. The peat and water are thrown into the upper end of the trough and mixed and reduced to a slurry while being moved forward by the revolution of the knives. At the outlet end the slurry is removed in cars or barrows to the drying field and is sometimes turned into sets of wooden or metal molds, in which the sections have the dimensions of the bricks to be made.

The mass of peat is tamped into the molds and smoothed off, and after a short time, the surplus water having drained away, the bricks are easily removed and are then laid out on the drying ground to drain and dry, after which the procedure is the same as in drying cut peat.

In Denmark and Sweden, where women and children are hired to do the work of turning and piling on the bricks on the drying ground, the cost of producing this type of peat on a large scale varies from $\$ 1.25$ to more than $\$ 1.50$ per ton.

The manufacture of peat fuel by any of the various modifications of the above-mentioned processes does not seem feasible in the United States except on a small scale, since the hand labor required is considerable, and the product is no better and quite as expensive to make as the better-known machine-formed peat, which is taking its place abroad.

Machine peat, as the name is commonly understood, is made by grinding the peat with about the same amount of moisture that it contains in the bog and cutting it into bricks as it issues from the 
outlet of the grinding machine in a thoroughly macerated condition, but sufficiently stiff to retain its form.

REASONS FOR EXTENDED DISCUSSION OF METHOD OF MANUFACTURE.

This method of manufacturing peat into fuel by machinery is somewhat thoroughly discussed here because it is so widely applicable to all kinds of peat, whether well or poorly decomposed, fibrous or compact, light-colored or dark. The equipment needed for successfully carrying on the process is modest, and the investment of capital small compared with that required for the more elaborate coking and briquetting processes. The experience needed for using the method is also much less than with either of the others. The discussion seems to be warranted also by the fact that many trustworthy observers report that it is the only way yet found in Europe for making peat fuel for general purposes and in quantities at a profit, except at a few plants referred to under briquetting and coking (pp. 120-139).

The opponents of this method of making peat into salable fuel say that it leaves much to be desired, not only mechanically but in the quality of the product, which for some purposes is not an ideal fuel. The product is, however, solid, tough, and of rather high specific weight. Where it has failed to give satisfaction under boilers in the United States the cause has been faulty construction of the fire boxes. In Amsterdam, Holland, machine peat sells at a retail price equivalent to $\$ 5.80$ for the lighter grades and $\$ 6.30$ for heavier grades, when coal may be bought at about $\$ 4$ per ton. Evidently, when people are accustomed to it and know how to get the best results from its use, machine peat has decided advantages for domestic use.

\section{EARLY PEAT PRESSES.}

The manufacture of machine peat began in Europe at least as early as 1820 , when crude wooden machines were in use in Saxony. The use of similar machines was reported shortly afterwards in England and Ireland.

These early machines really attempted to form the peat into blocks and to squeeze the water from it at the same time by powerful screw presses. These failed to give very satisfactory results, however, and hydraulic presses were afterwards tested, both alone and in combination with macerating apparatus. The machinery was slow in action, expensive to run and maintain, and the results, after repeated trials with many types of presses, so uniformly unsuccessful financially that the idea of pressing the water from the peat was reluctantly abandoned. The reports on these machines show that the best and most powerful presses rarely reduced the moisture content below 65 to 75 per cent and gave a very small daily output. Besides these difficulties, the drying of peat by pressure resulted in forcing the finer 
and more completely disintegrated parts of the peat with the water into and through the cloth used to retain the peat in the press. The pores of the cloth were thus stopped so completely after a short time that water could be forced through it with difficulty or not at all; sometimes, also, the peat would expand again after the pressure was taken off.

At the present time there is a revival of interest in this country in the possibilities of using great pressure, vacuum pumps, sieves, and similar devices for drying wet peat. Those inventors who are attempting to develop processes depending on these and like principles will learn what to avoid by a careful study of the types of peat presses developed by German experimenters and abandoned in the middle of the last century, as described in the older standard European peat manuals.

\section{ESSENTIAL PROCESSES.}

In considering the development and construction of a factory for making machine peat, the following processes must be provided for: Digging the peat, transportation to the machine, grinding, removal to the drying grounds or sheds, care during drying, and, usually, subsequent stacking and storage. If, as is often the case in Europe, the peat machine is placed on the bog at or near the opening from which the peat is dug, the second process is eliminated, as the material may be dug and placed in the machine by one operation, either by hand, by a dredge bucket, or by a mechanical digger and elevator. Digging, macerating, and spreading form a continuous, automatic operation in the latest types of self-propelling, portable plants now being tested in America and Europe.

\section{DESCRIPTION OF PEAT MACHINE.}

The peat machine, or mill, is the important part of the plant, and should be the focus of all the other parts. Especial attention should be given to the importance of having each stage of the manufacture as nearly continuous with the one before it as possible.

The peat machine has been developed rather slowly and the best models are of strong and simple construction. In principle and form the latest types are much like the pug mill or grinding machine for plastic clay. Some of the experimental plants in the United States have used ordinary brick or tile makers' pug mills, with very slight changes, to grind peat, especially that with little fibrous matter, and have found them well suited for the purpose.

The earliest German peat machines of this type of construction appeared about 1860 and were vertical iron cylinders, in the upper part of which knives, fastened to a slowly revolving axis, cut and ground the peat. It was then subjected to pressure by a revolving 
screw at the lower part of the cylinder and forced through a rectangular tube, opening at the side of the machine. This shaped the mass, which as it issued from the opening was received on movable boards and cut into bricks by hand. This type of machine worked well with structureless peat, but its operation was slow and the knives soon became clogged when fibrous peat was introduced into the cylinder. The type has gradually given place to one having a horizontal iron cylinder and a swiftly rotating axis armed with spirally arranged knives and flanges. These act as screws to press the peat forward to the constricted outlet end of the cylinder, while they are mixing and macerating it, and in passing through them the peat is reduced to a fine-grained or structureless, homogeneous pulp.

\section{TYPES OF MACHINES.}

The most recently devised and efficient form of this class of machines has a hopper for receiving the peat at the inlet end, doors in the outer casing, by which all working parts can be easily reached, and a device for cutting the strand of peat pulp into bricks of uniform length as it issues from the orifice. In some models the vertical body is still retained, in others there is a combination of vertical and horizontal cylinders. In some machines the knives are separate from the screw flanges, but mounted on the same shaft with them; in others the flanges of the screw are sharpened and work against stationary knives set fast in the cast-iron walls of the cylinder; still others have both fixed and movable knives, the cutting edges of which work together like the blades of a scissors; a few models have been built and placed on the market, with two knife-armed shafts revolving in opposite directions. Many types of peat machines have been patented in the United States, but few of them have ever been really used, and most of them follow European models.

European manufacturers make peat machines in all sizes. The smallest are run by the power furnished by a single horse, and with the help of a few men turn out 3 or more tons (air-dry weight) of peat bricks per day. The largest must be equipped with powerful engines and accessories and require the services of from 15 to 25 men and boys to dig the peat and handle the 60,000 to 80,000 peat bricks, amounting when dry to 50 or more tons of fuel, made in a successful day's run.

\section{DESIRABLE QUALITIES OF MACHINES.}

In all of these variations in the form of peat machines, the purpose is to reduce quickly and effectively to a fine pulp all of the coarse matter found in the peat. This also must be done with the fewest possible delays from breakage of parts of the machine or from clogging caused by the fibers of the peat winding around the shaft or the 
knives, or from pieces of wood or even of stone becoming fast in their passage through the machine.

The possibilities of such obstructions require strong and heavy construction and easy accessibility of all working parts so that they can be quickly cleaned when clogged, and replaced when broken. The best peat machine to purchase is the one which will most rapidly and completely grind the greatest quantity of peat in a given time with the least power and attention and will produce a uniformly wellmacerated pulp from all types of peat that are suitable for fuel. Such a machine should be strong and simple, and its parts should be capable of being quickly and easily reached and adjusted when necessary. In most of the peat machines now in use the grinding parts are made so that their angle of setting can be changed according to the kind of peat that is to be manufactured-a most necessary improvement where peat is as variable in structure as it is in the United States.

Many models of peat machines of the type just described are manufactured in various European countries, and a few excellent ones are advertised as manufactured in the United States; from among them all a form to meet almost every need can be found.

The principal types of European peat machines of modern construction are fully described and illustrated in a recent publication of the Canada Department of Mines ${ }^{a}$ to which the reader is referred for further details. Reference to the catalogues of the manufacturers in this country and Europe is also suggested.

The most efficient of the machines now in use, under favorable conditions of operation, reduce by about one-third the bulk of a mass of wet peat as it passes through them. This is done partly by squeezing out a portion of the water, but more of the condensation is caused by crushing the fibrous and woody structures, and by releasing included gases during the maceration and kneading that the peat receives while in the machines. There is little true compression, as the pressure exerted on the peat is not sufficient to remove much of the water from it, and because the peat is not confined, such pressure as is brought to bear upon it only causes it to move forward in the cylinder and flow freely from the outlet.

\section{METHODS OF MOUNTING MACHINES.}

Peat machines are mounted in several different ways. Some designed to be used on the bog are placed on timber platforms, either on rollers or trucks; others are mounted on cars, together with the boilers and engines used for running them, and the whole plant takes up little space and is very portable, so that it can be moved

$a$ Nystrom, E., Peat and lignite; their manufacture and uses in Europe; Canada Department of Mines, Mines Branch, 1908.

$661^{\circ}-$ Bull. $16-11-7$ 
about wherever rails can be laid. This kind of mounting has been extended by the use of broad-tired iron or wooden wheels, or movable roller platforms such as are common on agricultural machinery in the United States; thus the entire plant becomes as mobile as a thrashing machine, the main factor being the weight of the larger sizes of peat machines. This weight, if properly distributed, is no insuperable matter, and in Canada in 1911 the largest size of peat machine is reported as successfully tried on a trackless self-moving portable plant. The practice of using movable rails, however, is satisfactory in most places, and as rails are used constantly for transporting the macerated peat or the finished peat bricks from machine to drying grounds and thence to storage or shipping point, they are always available.

\section{DIGGING MACHINERY.}

Until recently but little machinery has been used for digging the peat, which is the initial task of actual peat fuel production. By far the larger percentage of peat made into fuel in European countries is still dug by hand labor. Within the past few years, however, as larger machines and plants have been built, prominent makers of peat machinery have been constructing mechanical diggers operated by steam or electric power.

Power digging machines, so far as descriptions have been received, are either of the form of the hand-power machines already described (pp. 88-89) but of larger size, or of the chain-and-bucket type. The latter, although effective in peat of the more completely decomposed kinds, can not be satisfactorily used where stumps and other poorly decomposed tree remains are abundant, as they sometimes are, unless the machines are of very strong construction. The most recent models of this type of digging machinery developed in Europe are reported to be satisfactory. They have the advantage over other forms of diggers of mixing the peat from different beds, thus securing a homogeneous product.

DIPPER DREDGES.

In general, the dipper dredge, or its land equivalent, the steam shovel, would seemingly be more satisfactory and give better and more continuous service than the chain-and-bucket digger. Both have already been tried successfully in the United States in peat operations and are still in use at several plants where peat is produced.

The statement has been made that the dipper dredge can not be used because of the danger of including material from below the peat, but this, of course, is merely an operating detail, which can readily be provided for. This form of machinery will probably be much more freely used in this country as a peat industry develops than it has 
been in Europe, as digging machines of some kind will be a practical necessity in the United States, whatever the type of material produced. It will always be necessary to dig a much larger weight of peat than will be sold. Thus a machine that can produce 50 tons of salable fuel in a day's run, if it is to be kept up to its capacity, must be provided with approximately 10 times as much raw material because the latter is about 90 per cent water and other waste. If the macerating machine is not kept busy, the productive part of the plant will be idle some of the time. To dig and move the required amount of wet peat by hand labor would mean a high labor cost, which could hardly be tolerated under existing economic conditions. Even in small plants where the excavating machinery would be idle part of the time its use will probably be found more economical and satisfactory than dependence on hand digging.

AUGER DIGGING MACHINES.

Many years ago in Canada a scow was equipped with very large augers, which, on being driven into the peat, dug it out of the bog and elevated it, making a canal as the digging progressed. Recently, in one of the experimental portable plants devised in the United States, augers of much smaller size and of different form have been used to excavate and macerate peat. Their use is reported to be satisfactory.

\section{MECHANICAI, CONVEYERS AND ELEVATORS.}

All of the large peat machines manufactured in Europe are provided with mechanical conveyers and elevators, generally of the belt or chain-and-bucket type, and sufficiently long to reach from the bottom of the excavation to the hopper of the machine when the latter is placed near the opening in the bog. The peat as it is dug is thrown on the elevator, conveyed to the machine, and dropped into the hopper; thus time and labor are saved. The conveyers are usually operated and adjusted as a part of the peat machine, being placed either at one end or at one of the sides, and the same engine runs both.

If the peat machine is permanently placed in a building, the elevator may still be used, or it may be discarded, as the cars loaded with peat can be drawn up an inclined plane to a bin placed in a loft above the machine, and the wet peat can be fed from the bin by a gravity chute.

TRANSPORTATION OF WET PEAT.

TRAMCARS.

Machinery for transporting to the drying grounds the peat bricks, after the peat has been ground and formed in the mill, has been more thoroughly developed than that for digging, and several types have been more or less fully worked out by different makers. 
These are, first, tramcars running on tracks temporarily laid on the surface of the bog, and pushed by men or drawn back and forth by horses or cables, or, in the United States, by electric or gasoline locomotives. Generally the cars used for this purpose have some form of open wooden or iron rack so that a number of tiers of wooden pallets full of the wet bricks can be loaded onto them, but where the peat is spread on the ground, wooden or iron dump cars are used. The tracks are usually laid out in such a way that the loaded cars go out to the drying grounds one way and return another, and that part of the grounds farthest from the machine is first covered. By systematic and careful planning, the tracks can be so laid that the number of men employed and the number of cars used for moving the wet peat bricks to the drying ground will be reduced to a minimum.

CABLE AND CARS.

In Sweden a system of cable transportation has been successfully developed by which the cars are drawn out and back by moving cables kept in motion by the engine running the peat machine. The track is movable and is laid out in the form of a rectangle with round corners. This arrangement reduces the number of men employed by as many as are elsewhere required to move the cars, one only being needed at the machine to fasten the clutch of the outgoing cars to the cable and to release those returning empty. The men who do the unloading attend to stopping and starting the cars at the drying ground. Obviously the cables in this system are adjustable and can be moved with the tracks as certain parts of the drying grounds are filled and others come into use. Provision has also been made for temporarily anchoring the pulleys through which the cables run. This system is in successful operation at the demonstration plant of the Canadian Government at Alfred, Ontario, and is reported to decrease materially the cost of handling the peat. In connection with this cable system, the peat is generally run directly from the peat machine into iron cars without bricking. Thence it is taken to the drying ground and there spread into a flat sheet and marked off into bricks by a device called a "field press." This is in effect a heavy sledlike platform with a number of thin knives extending out behind, which mark off the peat longitudinally as it is spread and compacted by the passage of the slanting platform; the crosscutting is done by hand. The platform is slightly higher in front than behind and has an opening at the front end into which the peat is turned from the cars. The platform is moved in only one direction, away from the opening in the bog, and the motive power is a special cable operated from the engine; when it has been drawn the length of the drying ground in one direction it is placed on a specially built car and moved back the length of the drying ground 
for a new start. By using this machine and the cables the number of men employed is reduced and the cost of handling the bricks materially lessened; the very considerable investment for pallets on which to handle the bricks may also be avoided entirely. This plan has been adopted at Alfred, Ontario, and is very effective and successful there. The peat bricks, after they have become dry and firm enough to handle, are turned and subsequently are stacked in small conical piles, and when sufficiently dry are removed from the drying grounds to the storage sheds or to cars on which they are shipped. The peat bricks are carried to the cars on barrows or light cars provided with racks, some of which are so built that their load can easily be dumped. Elsewhere the cars are simply platforms on which may be placed several handbarrows into which the peat bricks have been loaded as soon as dry.

\section{CONVEYERS.}

Another successful means of peat transportation is movable mechanical conveyers leading from the machine to the drying grounds and back. Such conveyers can be used in places where cars and tracks can not, but they are expensive to install and maintain-at least as made by the foreign manufacturers. The extensive use of various kinds of conveyers for many purposes about factories in the United States makes it seem probable that similar use of them could be made in transporting the loaded pallets of peat bricks to the drying grounds and in returning empty ones. It is also probable that some form of belt conveyer might be made to serve the same purpose.

CHAIN CONVEYERS.

An even simpler plan has been used in Florida. The peat is first ground and thoroughly reduced to a pulp; then, without being formed into bricks, it is conveyed by a common belt conveyer in a long movable trough to the drying ground and spread in a sheet about 8 inches thick by a specially devised spreader. This spreader is a wooden scraper mounted on wheels and drawn by a cable. The peat is not marked off into bricks, but as it dries and contracts it breaks into prismatic pieces, which are easily dried and handled. If, as was done at Orlando, Fla., the peat is piled in heaps after grinding, it dries slowly and must be cut into blocks before it can be used to advantage. This operation materially increases the cost of production.

AERIAL CABLES.

In a plant now being installed in Ireland for making ammonia from peat, cars or buckets moved by an elaborate system of overhead aerial cables are being used to carry the peat from the bog to the plant. This system is expensive but very satisfactory after it is once in operation. 
CENTRIFUGAL AND VACUUM PUMPS.

When thoroughly macerated and sufficiently fluid peat is to be dried by spreading, it could probably be pumped from the machine to the drying grounds through iron pipes with flexible connections by centrifugal or vacuum pumps and spread by mechanical means.

\section{DRYING ON RACKS.}

A certain amount of time is gained in drying the peat on racks, as the bricks give up their water somewhat more rapidly when placed above the ground than when lying on it; they also need less attention and require much less space for drying ground; there is, moreover, less likelihood of considerable loss from rain. On the other hand, a larger number of pallets are required; these materially increase the first cost and add to the cost of maintaining the racks.

\section{DRYING ON THE GROUND.}

If the plan is chosen of drying the peat on the cleared surface of the bog, or of laying it out to dry on higher ground, a good sized area should be made ready by clearing off bushes and leveling, so that ample space will be provided; for if the output is 50,000 or more bricks of peat a day, a large area will be covered at the end of a short time. If too little space is allotted for this purpose, the entire plant may be kept idle just when all other conditions are most favorable for production. It may be said that in suitable weather the bricks are dry enough to remove from the pallets after a few days' exposure and may then be piled in small open piles or spread out on the ground and the pallets used again. If the peat is spread directly on the bog surface and formed into bricks by marking, it must be turned over at least once before piling. The best practice in air drying calls for storing the peat in covered piles when it still contains from 50 to 60 per cent of moisture. Peat so stored dries into tough hard fuel.

\section{advantages of a COMPaCt PLANT.}

The advantages gained by confining all operations as closely as possible to the surface of the bog must not be overlooked. If grinding, handling, and drying operations are all kept as near as practicable to the place where excavating is going on and the finished product is all that is moved away, the waste, chiefly water, is left on the bog and the moving of the greater part thereof is avoided.

In making plans for equipment it is cleariy better to install a small complete plant, with only necessary buildings of cheap construction, than to equip inadequately a large plant housed in expensive structures. It should be kept constantly in mind that the output of a 
well-arranged small plant can be practically doubled by duplicating a part of the machinery, but that a small output from a large machine, with too little power and too few accessories, can be obtained only at a considerably greater cost per ton than from the more complete installation.

\section{REQUIREMENTS FOR A COMMERCIAL PLANT.}

In planning to make air-dried machine peat on a commercial scale the following factors must be regarded as essential to success:

(1) Railroad or other cheap transportation from the plant to the expected market.

(2) A good-sized area of peat of workable thickness.

(3) Machinery for excavating the peat.

(4) A peat machine of approved and thoroughly tried pattern.

(5) Cars and portable tracks or suitable mechanical conveyers for moving the wet peat from the openings in the bog to the machine, from the machine to the drying grounds or racks, and thence to the storage sheds, or to cars for final shipment. The self-propelling portable plants that combine digging, macerating, and spreading machinery simplify or eliminate (3), (4), and (5).

(6) Ground space, cleared and leveled, for drying the prepared peat, and if the peat is formed into bricks at the machine, pallets enough to move the possible output of the machine for several days; room for storing under cover unsold finished product must also be provided.

\section{COST OF PLANT.}

The investment necessary for equipping a plant for making machine peat manifestly will be governed by the output of fuel contemplated, the number, size, and kind of buildings which are projected, the amount of equipment to be provided for digging and transportation, and the method of drying-whether on the ground or on racks. If the plan of spreading on the ground be adopted, and the peat be formed into bricks by cross marking the peat layer after it has been spread from movable troughs, much of the cost of tramways, cars, and pallets will be avoided. Although this plan is in use, it has not been fully described, and details will have to be worked out experimentally which will necessarily detract from its value when immediate production must be assured.

ESTIMATED COST OF PLANTS EQUIPPED WITH AMERICAN MACHINERY.

The following tables of costs have been furnished by manufacturers of peat machinery, and are for the season of 1909. The estimated cost of a peat-fuel plant, fully equipped with machinery made in the United States, the fuel to be dried in the air, and the average out- 
put to be 50 tons of finished product per day, will be from $\$ 20,000$ to $\$ 25,000$, as follows:

Estimated cost of plant for a bog that can not be drained.

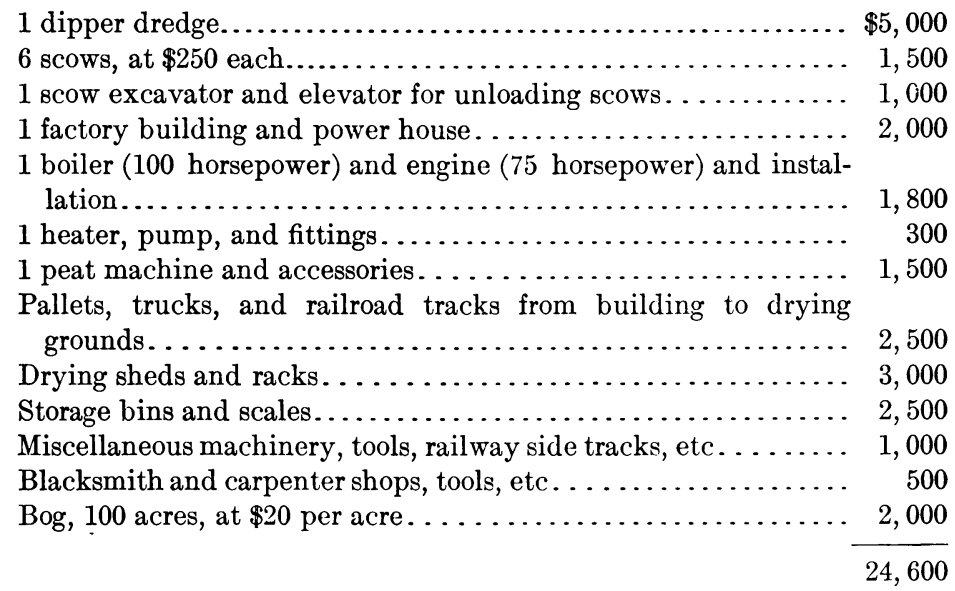

Such a plant could be increased to 100-tons daily capacity at a small additional outlay.

For a bog that is or can be drained, and has a comparatively level bottom, the dredge could be replaced by a forward-end or side continuous-bucket excavator costing $\$ 3,500$.

Tracks and hopper-dump tram cars for this equipment would cost about the same as scows, and a pump and power to run it would be needed to keep the excavation clear of water.

A plant with an estimated capacity of 25 tons of finished peat fuel per day will cost about one-third less than one of 50 tons capacity.

A portable plant with estimated capacity of 20 tons of finished product per day can be installed for from $\$ 5,000$ to $\$ 7,500$. The peat machine, boiler, engine, and digging machinery for this size plant are all installed on a large, broad truck running on a portable wide-gauge track. The costs are divided as follows:

Estimated cost of a portable plant.

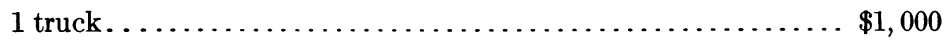

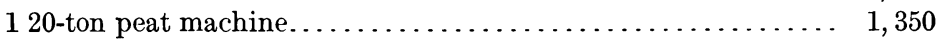

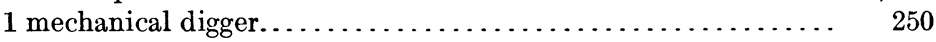

1 boiler and engine . . . . . . . . . . . . . . . . . . . . . . $\quad 750$

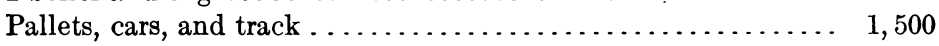

Miscellaneous tools and equipment.................. $\quad 250$

1 drainage pump and power...................... $\quad 250$

5,350

These estimates are for maximum cost, and can doubtless be reduced in many ways by taking advantage of local conditions. Trackless 
self-propelling combined digging, macerating, and spreading machines, capacity from 20 to 75 tons per day, are estimated to cost from $\$ 5,000$ to $\$ 25,000$ each.

COST OF PLANTS EQUIPPED WITH EUROPEAN MACHINERY.

European machinery is generally of simple and strong construction, and in the countries where it is manufactured the cost is low, but the high tariff on machinery and the other charges incidental to its importation into the United States much increase the original price. If German machinery of this type- that which is most often quotedis sought, the mark (24 cents) must be more than doubled in value and should be reckoned at about 60 cents. On this basis a complete movable plant, operated by steam, and including a traction engine and boiler of from 5 to 8 horsepower; a peat machine with a daily capacity of 30,000 peat bricks (about 15 short tons) per day, elevator belts, and other equipment for transmitting the power, cables, tramcars, and rails for moving the wet peat from the machine to the drying grounds and the dry peat to the storage sheds; and various smaller articles, all of which are listed at a total cost of 8,500 marks, would cost on the cars in New York about $\$ 5,000$. The peat machine alone with accessories, is quoted at 2,000 marks $(\$ 1,200)$. Besides the machinery, storage sheds and other structures would need to be provided. This class of plant would require hand digging, and 13 people would be necessary to attend the machine, dig and transport the peat, and work on the drying grounds.

A movable plant having double the above capacity and similar but more powerful equipment is listed, exclusive of the buildings, at 14,500 marks $(\$ 8,700)$. This plant requires a force of 16 men to carry on all of the operations, including digging, transporting, drying, and storing the peat.

Among the most recently announced European inventions for making machine peat is one tried in Germany during the summer of 1909 and improved the succeeding year. According to published descriptions, this is self-propelling, requires no tracks for drying grounds, is compactly and simply mounted, and while moving over the surface of the bog, which must be drained, it digs, machines, forms, and delivers the peat as bricks on the drying ground. The entire plant weighs about 3 tons (3,000 kilograms) and requires but one man to operate it. The motor, which has a pulling capacity of 20 tons, may be detached and used to draw cars filled with peat from the drying grounds to the storage bins. The cost at the factory in Germany is 13,000 marks, equal to about $\$ 7,500$ in New York on the above basis.

PRICE OF THE BOG.

Still another factor to be taken into account is the price of the bog to be utilized. Little discussion has been given this matter because 
undrained peat land in the greater part of the United States is held at a very low price per acre, often merely a nominal value being placed upon it. The question may arise, however, as to the maximum figure per acre that could be paid for the bog if the peat was to be dug and manufactured into fuel or other commercial product. If the peat is of good quality and has an average depth of 5 feet, at least 1,000 tons of air-dry peat fuel can presumably be made from each acre. Hence, if $\$ 50$ per acre is paid, the cost of the raw material will be 5 cents per ton; to this must be added the interest charges on the unused portions of the bog. These charges may be entirely offset by clearing and using a part of the bog for growing certain kinds of crops, as is often done in Germany. Apparently, however, good or even high prices can always be paid for suitable and accessible bogs without imposing too large a charge for raw material upon the finished product.

\section{WORKING CAPITAL.}

In planning the whole outlay for a peat-fuel plant, a certain part of the available sum should be reserved as working capital, the proportion to be determined by the probable future needs of the new business and the length of time before a maximum output can be expected from the plant.

\section{PROBABLE OUTPUT FROM A SMALL PLANT.}

During the season, from the middle of March to the middle of October, a peat machine of 25 tons daily capacity should make at least 3,000 tons of finished, dry fuel in nearly any part of the United States, and in favorable seasons the output might easily be 500 or 1,000 tons greater. In the south a longer season and larger output could be expected; at the extreme north the season would be shortened somewhat. The production of such a plant could be doubled by working two shifts of men daily.

Such a machine would be much easier to operate at its full capacity, and to provide with full accessory equipment, than one of double the output. Unless the market for the product is known exactly beforehand, planning on a small rather than on a large scale is doubtless much better. The small, well-planned, and thoroughly equipped plant can manifestly be more easily made successful from the outset than can a large and efficient machine, for which necessary accessories are planned in the future, but which, for the present, must be made to run with poor and insufficient equipment.

\section{COST OF MANUFACTURE.}

It is generally stated by those who discuss the question that machine peat may be prepared for use at a cost not exceeding $\$ 1$ per ton. Doubtless this is possible, if only the actual cost of handling 
be considered, as in Europe, where the cheapest labor is used in the manufacture of peat; the expense for labor in its preparation is generally stated to be below 75 cents per ton. If, however, the reports of test runs and of carefully managed companies be examined, it will be found that, even in Europe, when the entire cost of production is reckoned and the proper charges for raw material, management, selling, maintenance, interest, etc., are made, the estimated expense is often doubled. Hence it is not improbable that even under favorable conditions the entire cost of making fuel by this method will be more than $\$ 1.50$ per ton, and will often run as high as $\$ 2$ or more if all the details of the business are not closely watched. However, if the plants are carefully planned and fully equipped with all necessary machinery, so that slow and inefficient, and hence costly, hand labor is largely eliminated the price of production could probably be materially reduced below the usual European figures. In one instance in the United States, however, a report was made that the entire cost of digging by machinery, drying, and gathering was about 60 cents per ton of product, but the peat was not formed into bricks, but was spread and gathered by machinery. In another instance a cost of less than $\$ 1.50$ per ton of dry fuel is reported where the peat was dug by hand.

\section{SELLING PRICES.}

Eventually the real or supposed value of a product, the supply and demand, the cost of production and transportation, the competition of similar substances, and the extent to which it can be monopolized, are among the factors which settle its price in open market.

At present it is difficult, if not impossible, to predict the prices that machine peat will command in the United States when once it is an established staple in the fuel market. The small quantity that has already been made and sold has been eagerly taken at high prices, often seemingly out of curiosity, but after trial more has been asked for, and no complaints have been made as to the price. A recent report from one of the larger cities stated that a dealer in fuel had asserted that he could sell a number of thousands of tons of air-dry peat bricks at $\$ 4.50$ per ton if he could get them to sell. Five dollars per ton is frequently mentioned as the retail selling price, even in competition with cheap bituminous coal. In Canada the Department of Mines reported the demand for peat fuel in 1910 to greatly exceed the supply. That such a price will be maintained where the product is to be used for commercial boiler firing or for manufacturing purposes is hardly to be expected, but the wholesale selling price would probably fall to $\$ 3$ per ton or below. If, however, the cost of production is kept down as it should be and the production of fuel 
is large enough, the last-mentioned price offers a good percentage on the investment necessary to make the commodity. Where the manufacturer is so well placed that he can utilize his men and teams during unfavorable weather and after the producing season is over by conducting a retail business, he can command the highest price attainable in his market. This would apparently be good practice, as it would make feasible the employment of some of the men for the entire year.

\section{LENGTH OF OPERATING SEASON.}

The estimate of the length of the operating season is based on climatic conditions. The work should be started as early in the season as the frost and water will permit the peat to be dug, and carried on until hard frosts become frequent. In Florida, where the temperature rarely sinks below the freezing point, the winter, being a dry season, is the best time for making peat fuel. As one proceeds northward less and less of the winter season is available, until in northern New England, New York, Michigan, Wisconsin, and Minnesota, peat production, where air drying is used, will be confined to spring and summer-possibly six months, or five north of $45^{\circ}$ north latitude. At London, Ontario, the average for several years has been 100 days when peat powder could be gathered from the surface of the bog by a suction collector. The end of the season comes abruptly when frosts are heavy enough to freeze the wet peat bricks, as freezing renders very wet machine peat porous and friable and effectually prevents it from becoming hard and compact.

\section{COMPARISON WITH OTHER INDUSTRIES.}

The facts enumerated above form the basis for some of the objections most frequently urged against attempting the manufacture of air-dried machine peat as a profitable business venture. Summarized, they are that the season of manufacture is short; that rainy and damp weather check operations or suspend them entirely; and that the plant and the working force will be employed only a part of the year, and then somewhat irregularly. Manifestly, however, many successful industries are equally handicapped, and just as good reasons exist for discontinuing the beet-sugar industry, lumbering, the ilarvesting of ice, brickmaking, and other enterprises, most of which require much larger original investment.

\section{THE LABOR QUESTION.}

In Europe a considerable part of the labor employed in peat-fuel manufacture comes from near-by farms during periods of slack work, so that the working force is constantly changing as one man or 
another returns to his regular occupation. Such a system may not come into existence in the United States, yet possibly it will, if the need for it arises, and it may provide the labor necessary for carrying on peat-fuel production. During periods when the weather might be too cold, too moist, or too threatening to permit regular work, a part of the men could be clearing and leveling the surface of the bog, extracting stumps and logs, and constructing necessary ditches. Even in damp weather wet peat bricks, if protected from actual rain, give up some moisture to the air, so that drying is never actually suspended. By increasing the area of the drying grounds or the number of racks the making and spreading of peat bricks could go on, even when, otherwise, it would be suspended because the bricks produced could not be cared for. If this work can be successfully done in the very moist climate of Ireland, of the region around the Baltic Sea, and even of Iceland, it must be possible in the much drier climate of the United States, where not only is the amount of moisture in the air less, but the seasons are longer and the average temperature of the air several degrees higher-all favoring conditions.

ARTIFICIAL DRYING.

A system of artificial drying is an ideal of those who have been working on the problem of the sure production of a large amount of peat fuel in a given time from a single plant. Even recently the statement has been made that no considerable quantity of peat fuel could be produced in North America unless artificial drying could be assured, and more than one attempt has been and doubtless will be made in the United States to develop plants so planned that the raw wet peat as it is taken from the bog can be put in at one end of a series of machines and turned out at the other as a dry, marketable fuel, the process being continuous and taking but a few hours. Mechanically, the plan presents no great difficulties and may be worked out in a number of different ways, especially if large capital is available.

THE PRACTICAL PROBLEM.

Relative to drying machine peat, the problem to be solved might be said to be how to take the wet bricks from the machine and dry them by artificial heat without handling until the product was ready to be shipped. A drying chamber of sufficient size and heated to the right temperature would seem to furnish a speedy solution of this problem, but for the following incontestable facts: If the outside of the peat bricks is dried rapidly before the water inside has had a chance to evaporate, and the moisture inside is prevented 
from escaping, the bricks shrink, warp, and crack, and become very much more brittle than if dried slowly. The result is an unsatisfactory product. If the drying is permitted to go on slowly the size of the drying chamber must be increased sufficiently to accommodate the entire output for the number of days that the drying is prolonged, and the number of conveyors or pallets and racks needed to support the bricks must be proportionately increased, so that the investment necessary must be much augmented. The greater size of the chamber needed also increases the cost of heating and moving the air by which the drying is accomplished. Solution of the problem is still further complicated by the fact that the peat makes the best product if machined very wet. The bricks seem to be less likely to crack under ordinary conditions of drying and to be harder, denser, and tougher after drying if the peat from which they are formed contains from 80 to 90 per cent of water; in addition grinding goes on more satisfactorily and smoothly, and with less consumption of power. Complications arise, however, from the fact that the higher the percentage of water in the bricks, the more heat is required to dry them, and the limit is soon passed beyond which more heat units are required to dry the peat than the fuel obtained will give if entirely burned under the best attainable conditions.

Stating the case in another form, a pound of good, perfectly dry peat will evaporate 6 pounds of water in a boiler after the boilerwater temperature has been raised to $212^{\circ} \mathrm{F}$. This quantity is nearly double that given by good European authorities, but as it is based on a carefully conducted boiler test made at the Government fuel-testing plant at St. Louis, Mo., it may be used as a maximum in order to present the problem as favorably as possible. A ton of peat bricks containing 85 per cent of water consists of 1,700 pounds of water and 300 pounds of completely dry fuel. Therefore, if the water could be evaporated from the peat under as favorable conditions as are found in a boiler, enough fuel would be obtained to convert into steam 100 pounds more water than must be evaporated, or less than 17 pounds; more fuel than this would be needed to raise the temperature of the peat and the contained water to $212^{\circ} \mathrm{F}$. It is evident, therefore, that the complete artificial drying of peat by a process that requires a direct consumption of fuel for the purpose must in itself use more heat units than are yielded by the product, and all of the power and labor involved in preparing the bricks and in handling them after drying must be paid for at a loss. If a large proportion of the heat used is waste from other operations, or if the fuel is such as can not be used in any other way, the problem is quite different; but the above statement holds true, and the cost in heat units will be the same, even if they are not used for any other purpose. 
WASTE HEAT MUST BE UTILIZED.

It is apparent, therefore, that any process for preparing peat fuel that involves artificially drying to the air-dried state peat containing any considerable percentage of water must be regarded as financially impracticable, unless the heat used is available as a waste product of some other operations. The processes and machinery used for drying products that have a higher selling price than peat fuel, such as heated rollers, vacuum evaporators and presses, are not applicable, since the small margin of profit would all be used up in the costs of operation and maintenance of the complicated and expensive machinery required.

Peat that has been dried by exposure to the air until it contains less than 50 per cent of moisture may possibly be dried for fuel, by artificial heat, on a commercial scale, to the air-dried state, by some of the simpler and more efficient types of driers used in other industries, because the certain and rapid completion of the drying at that stage may offset the cost of the fuel used and of the additional handling and plant required.

It is less practicable to artificially dry peat with a high water content down to 50 or 60 per cent moisture, because the much greater weight of water to be handled and evaporated in proportion to the quantity of product to be recovered requires much more heat than is needed to reduce the moisture from 50 per cent to the air-dried state. In the eastern United States the amount of moisture in completely air-dried peat rarely exceeds 15 per cent and may be as low as 6 or 8 per cent; it varies as the moisture in the air varies.

From the facts given and also from the requirement that all costs in any system of artificial drying must be borne by the product, it is apparent that the problem of artificially drying peat is decidedly complex and can be worked out only by those who have had special training and experience in designing and building drying machinery for similar purposes and fully appreciate the difficulties involved in this class of work. Any plan to be successfully incorporated in machinery for completely freeing freshly dug peat from its high percentage of water must provide for the utilization of large quantities of waste heat or of fuel that has no other economic uses.

WEIGHT OF WATER TO BE EVAPORATED IN DRYING TO VARIOUS PERCENTAGES OF MOISTURE.

The table following shows the weight of water that must be evaporated from a ton of peat as its water content is lowered, by 10 per cent stages, from 90 per cent to 10 per cent. 
Weight of water evaporated from a ton of peat as its water content is lowered, by 10 per cent stages, from 90 per cent to 10 per cent.

\begin{tabular}{|c|c|c|c|c|c|}
\hline $\begin{array}{c}\text { Percentage } \\
\text { of water in } \\
\text { peat. }\end{array}$ & $\begin{array}{l}\text { Total } \\
\text { dry-peat } \\
\text { content. }\end{array}$ & $\begin{array}{l}\text { Water } \\
\text { content. }\end{array}$ & $\begin{array}{c}\text { Water } \\
\text { evaporated } \\
\text { for each } 10 \\
\text { per cent } \\
\text { reduction. }\end{array}$ & $\begin{array}{l}\text { Residue } \\
\text { left for } \\
\text { each } 10 \\
\text { per cent } \\
\text { reduction. }\end{array}$ & $\begin{array}{c}\text { Total } \\
\text { amount of } \\
\text { water } \\
\text { evaporated. }\end{array}$ \\
\hline $\begin{array}{l}90 \\
80 \\
70 \\
60 \\
50 \\
40 \\
30 \\
20 \\
10\end{array}$ & $\begin{array}{l}\text { Pounds. } \\
200 \\
200 \\
200 \\
200 \\
200 \\
200 \\
200 \\
200 \\
200\end{array}$ & $\begin{array}{r}\text { Pounds. } \\
1,800.0 \\
800.0 \\
466.7 \\
300.0 \\
200.0 \\
133.3 \\
85.7 \\
50.0 \\
22.2\end{array}$ & $\begin{array}{r}\text { Pounds. } \\
3,000.0 \\
333.3 \\
166.7 \\
100.0 \\
66.7 \\
47.6 \\
35.7 \\
27.8\end{array}$ & $\begin{array}{r}\text { Pounds. } \\
2.000 .0 \\
1,000.0 \\
666.7 \\
500.0 \\
400.0 \\
333.3 \\
285.7 \\
250.0 \\
222.2\end{array}$ & $\begin{array}{c}\text { Pounds. } \\
\ldots \ldots \ldots 0.0 \\
1,000.0 \\
1,333.3 \\
1,500.0 \\
1,600.0 \\
1,666.7 \\
1,714.3 \\
1,750.0 \\
1,777.8\end{array}$ \\
\hline
\end{tabular}

It will be seen from the above table and the accompanying figure (fig. 1) that eight-ninths of the water in a ton of wet peat is evaporated

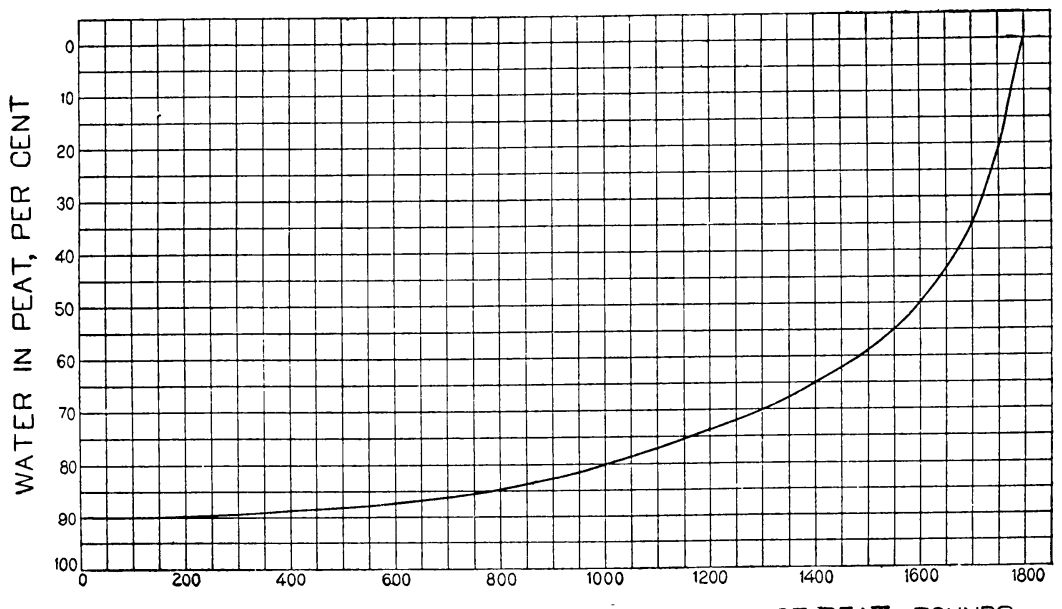

WEIGHT OF WATER EVAPORATED FROM 1 TON OF PEAT, POUNDS

Figure 1.-Relation between weight and moisture content of peat.

in reducing the water from 90 per cent to 50 per cent, whereas 1,000 pounds, or five-ninths of the whole, disappears in reducing it from 90 per cent to 80 per cent.

It is manifest, also, that only 250 pounds of peat containing 20 per cent of water will be left as the result of all the processes and labor by which a finished product is made from the ton of wet material.

\section{PEAT POWDER.}

There seems to be a much greater possibility of artificially drying peat in the form of powder or small fragments than as machineformed bricks, because such material can be handled in much smaller space and more rapidly and cheaply than can the bricks. The small 
particles also dry more quickly and are not injured by warping, cracking, or by becoming brittle. The peat will dry more rapidly if thoroughly macerated before it is put into the dryer than if it is used as dug.

Although the fundamental factors involved in drying peat by artificial heat are not much more favorable for producing peat powder than peat bricks, the possibility of making the continuous process a commercial success seems considerably greater for the powder than for the bricks. This opinion is held because the cost of equipment can be made considerably less, heat can be applied more directly, and the expenses for handling the product in powdered form can be reduced materially at all stages after it leaves the peat machine. Moreover, the production of dry peat as powder can be assured at any season of the year, as freezing would scarcely injure it at any step of its preparation. In fact, the powdery condition induced in all types of peat by continued freezing and thawing would then be desirable and would naturally be adopted as one of the preliminary stages of the process.

Because peat is readily reduced to a powdered form, has a larger percentage of volatile matter than coal, and burns with a hot flame, it is well adapted for use in powder burners. For this purpose the peat does not need to be crushed as fine as coal because of its more porous structure, which permits the penetration of air, thus insuring complete combustion. It also ignites at a lower temperature than coal.

\section{METHODS AND ADVANTAGES OF USE OF POWDERED FUEL.}

It is well known among users of fuel that various types of familiar materials are now burned as powder by the use of specially designed blast burners. Sawdust and powdered coal have been used for a number of years in burners of this type, and most satisfactory reports have been made by the users. The claims are made that the combustion with this form of firing is so complete that there is no black smoke from coal, that the efficiency of the fuel is increased, and that much less attention is required than when firing is done in the ordinary way. The use of powdered coal has passed beyond the experimental stage in Portland cement manufacture and in firing boilers in Europe and the United States. Manufacturers of the improved forms of powder burners claim, for a given type of coal, an increase of from 15 to 20 per cent in efficiency over common grate firing, and facts seem to warrant the claims.

Such burners can be regulated for automatic fuel feed, for furnishing the proper amount of air, and for blowing the fuel into the fire box, where it burns almost exactly like a gas.

$661^{\circ}-$ Bull. $16-11-8$ 


\section{EUROPEAN TESTS.}

A report of tests made in Sweden in 1907 of peat powder burned in burners of this type is here quoted as cited by Nystrom: ${ }^{a}$

The fuel is very easily ignited in the fire box, but no danger of self-ignition, which is often the case with other powdered and somewhat moist fuels, need be feared.

The combustion of the fuel can be easily regulated so that the ash is always free from any unburned particles of carbon, and so that the carbon and hydrocarbons in the fuel will be at once completely burned to carbon dioxide and water, thus giving the highest temperature with either a weak or a strong oxidizing flame (the former with just enough air for the combustion and the latter with excess of air). The combustion can also be so regulated that a producer gas with only a small percentage of carbon dioxide and of comparatively high temperature (light-red heat) is formed. This hot gas is then carried to the furnace room proper, where it is burned to carbon dioxide and water, there giving the highest temperature. This producer gas can be used for reduction, or in reheating furnaces where the heated material must be kept from oxidation, and then afterwards burned in other furnaces.

The change from oxidizing to reducing flame, or vice versa, can be very easily and quickly made.

The quantity of the fuel and the required amount of air can at any time and in either of the above cases be exactly regulated as required, and in case no change is required no attendance is necessary after the valves are once regulated [in the special type of burner examined].

The powder gives the highest temperature which can be employed in furnaces with a considerably less consumption than can be obtained with any other of the solid fuels, and it can be used for the melting of glass, cast iron, steel, soft iron, and other metals. The right temperature is more quickly obtained through the combustion of the powder than by the older methods.

Furnaces for using this fuel are considerably cheaper to erect than those designed for the use of other fuels.

Capt. Ernst Wallgren, chief peat engineer of the Swedish Government, in an official report of tests made by him in 1910 and preceding years at the Ekelund plant at Bäck, Sweden, states in substance:

(1) Peat powder could be produced at this factory in commercial quantities if the plant were run for a full season at its present estimated annual capacity of 10,000 metric tons at a maximum cost of 8.50 kroner $(\$ 2.30)$ a metric ton $(2,204$ pounds), all charges included.

(2) This cost could be reduced by increasing the size of the plant and the output or by making contemplated changes in equipment.

(3) The peat powder when burned by the method used at Bäck was equal in fuel value to the best English coal, ton for ton.

(4) This discovery makes Sweden independent of other countries for fuel supplies for industrial uses.

These reports and those that have come independently from Canada, ${ }^{b}$ where peat powder is used to a limited extent for boiler firing, show clearly that this type of fuel is an especially desirable one, which needs more extended and careful exarnination, so that it may

\footnotetext{
$a$ Nystrom, E., Peat and lignite; their manufacture and uses in Europe, Canada Department of Kines, Mines Branch, 1908, pp. 171-172.

$b$ See also Can. Dept, Mines, Mines Branch, Bull. No. 4, 2d ed., 1910, pp. 19 and 31 to 44.
} 
have a greater use for cement manufacture and steam production generally if it proves to be as valuable as the reports indicate. The peat for making peat powder by the system mentioned (Ekelund's) is dug, machined, spread on the bog, cut into bricks, and dried by exposure to the air to 50 per cent water content. The bricks are then crushed and the powder dried in drying furnaces.

\section{SPECIAL GATHERING SYSTEMS.}

For the preparation of peat in the powdered form a system of gathering the peat as air-dried powder by a special type of collector has been developed in Canada. The cleared and smooth surface of the bog is lightly stirred by harrowing, and after a few hours' exposure to the wind and sun the thin layer becomes dried to 30 per cent or less of moisture. The dry particles are then gathered by a pneumatic collector operated on the same principle as the exhaust carpet cleaners that are now so generally used. The collector is operated electrically and runs on rails, which can be moved whenever necessary. The peat, with its low percentage of moisture, is taken to the plant in the cars that receive it from the collector; there it is screened and its moisture content still further lowered by artificial drying, after which the powder is ready for use. It is shipped in bags and may be stored without deteriorating. The statement is made that each collector on a favorable day will gather from 40 to 50 tons of air-dried peat powder from a drained and well-prepared bog.

Although this method of drying peat powder is manifestly open to the same objection as any form of drying out of doors, it is equally clear that by increasing the number of collectors and the area of the surface from which the air-dried material can be gathered in favorable weather great quantities of air-dried powder may be stored for complete drying during rainy days or during the winter, especially if the peat is produced in quantities. ${ }^{a}$

This dry material could be stored either in permanent and strong storage bins, constructed for the purpose, or in large stock piles,

$a$ Another system of producing air-dry peat powder was invented in Canada. It is now in use there at the peat-briquet plant of the inventor and in the United States at two factories producing peat for fertilizer uses. The simple and efficient machinery used consists of three separate machines-a digger and spreader, a scraper, and a collector. Each of these is mounted on broad roller wheels and driven by electric motors, to which current is supplied from a central generator through trailing, insulated wires.

The digger and spreader, although mounted and working together are distinct machines. The digger, a plow-like disk revolving at one side of the machine, cuts the peat to a depth of 12 to 18 inches and delivers it to a belt conveyor. This draws it across the front of the machine and up a chute projecting from the side opposite the digging disk. At the upper end of the chute is a rapidly revolving propeller-shaped fan, which tears the peat into bits and scatters it broadcast over the surface of the bog, which is stripped of all vegetation before being used as drying ground. The powdered peat dries in a few hours and is scraped into windrows by the scraper which at the same time rolls the surface, thus preparing it for the next spreading. The windrows are made near portable tramways at the sides of the drying fields, and the peat is mechanically loaded on tram cars by a simple loading machine and drawn by an electric locomotive to the storage piles or sheds, after which drying is completed by artificial heat. This system must be used on dry drained bogs. 
which, although they might become wet and frozen on the outside, would remain dry and free from frost a short distance below the surface, because penetration of the mass by either water or cold would be very slow, owing to the insulating and nonabsorbent qualities of the material.

\section{COST OF EQUIPMENT.}

The cost of erecting and fitting out a plant for making peat powder is estimated by the inventor of the Swedish process mentioned to be about $\$ 100,000$ for a plant having an output of 20,000 tons per year. This amount includes the cost of the peat deposit; the cost of manufacture is given as less than $\$ 2.35$ per ton.

No figures are available for publication regarding the cost of a factory using the Canadian processes and equipment, but the cost of production is said to be less than $\$ 1.50$ per ton. The process obviously can be used only during the warmer months of the year.

\section{TYPES OF DRYING MACHINES.}

In Europe, lignite, or brown coal, is dried by artificial heat before it is briquetted. Two types of driers have been developed and are now used for this purpose - the steam plate and the rotary, the latter being the more recent and the more efficient.

In the steam-plate system the powdered lignite is dried on hollow cast-iron plates heated by steam from the engines or from the briquetting presses of the plant. The plates are 16.5 feet in diameter and are supported one above the other in a series of twenty or more, with intervening spaces. A central shaft bears a series of arms which, when the shaft is turned, constantly stir the material that is being dried. Provision is made for hastening the drying by changing the air as often as it becomes saturated with moisture. In such driers the water of the lignite is reduced from 30 to 40 per cent or more to 12 to 18 per cent, which is the content most suitable for briquetting this material.

In the best European type of rotary drier the essential part is a large boiler-plate cylinder inclined at an angle of $7^{\circ}$, supported by and turned on trunnions. A large number of 4-inch tubes run from end to end of the cylinder and through these the material to be dried passes. It is fed in at the upper end and dried by the heat of the steam that is turned through the trunnions into the space around the tubes. The steam is supplied from the exhaust from the engines and briquetting presses. The powder dries during its passage through the tubes, and is mixed, as the cylinder revolves, by cleats or baffle-irons fastened to the inside of the tubes. Such driers have been used to some extent for drying peat, and if the moisture content were not too high could be used in the production of peat powder for fuel, for briquetting, or for fertilizer filler. 
In the United States a number of novel machines for drying peat have been invented and installed in factories for the manufacture of peat briquets, but as none of the plants are now operating, the machines seemingly failed to do what was expected of them. In the manufacture of peat powder for fertilizer filler, however, driers of the rotary type, originally designed for drying clay, shale, and materials used in brick, cement, and fertilizer making before they are ground, have been used for some years to complete the drying of peat that has been partly air dried.

Two forms of rotary driers are used for drying peat in the United States-single-shell and double-shell. Both types are long cylindrical tubes made of iron or steel plates bolted together as in boiler construction. The tubes vary in length and diameter according to their estimated capacity for drying. They are mounted in a slightly inclined position, and are supported and rotated by friction rollers or geared wheels placed near either end.

At the higher or inlet end, if single-shell driers, the cylinder is generally placed directly against the open end of the combustion chamber of a furnace, and the lower end opens directly into a brick chamber that is closely connected with the smokestack. The cylinder is therefore a part of the flue through which the products of combustion pass from the furnace to the air. Usually there is an exhaust or a blowing fan to increase the combustion or hasten the passage of hot gases through the tube.

Narrow iron shelves, projecting at an angle inward and running, either spirally or otherwise, the entire length of the tube, are securely bolted to the inside of the shell. These shelves carry the peat from the bottom to the top of the cylinder and allow it to fall again to the bottom through the current of heated gases and air, thus assuring more rapid and thorough drying than would be possible if the inside of the cylinder were smooth.

The material to be dried enters at the higher end of the drier at the hottest part and is slowly carried to the lower and cool end by the rotation. It ultimately falls into the receiving chamber as a dry powder. Peat so dried contains less than 10 per cent of moisture.

The efficiency of such a drier depends on the relationship between the quantity of water to be evaporated and the quantity of heat units which must be made available to convert the water into vapor. To attain the highest efficiency, the heat generated in the furnace should all be absorbed by the material that is being dried, and the gases and air passing through the drier should leave it cold.

In practice, however, driers are often much overheated, which results in great losses of heat through radiation from the overheated shell and the high temperature of the gases leaving the tube. The remedy is to use longer cylinders of larger diameter, and to reduce 
the moisture content of the peat as much as possible by air drying before putting it in the drier.

A double-shell drier, as the name implies, has two cylinders, one securely fastened concentrically inside the other, with a space between them. The hot gases from a furnace enter the inner tube of the drier at one end. In the same end the material to be dried is placed in the chamber between the inner and outer shells. After traversing the length of the inner tube the gases enter and pass through the outer one and are deprived of the rest of their heat by contact with the substance being dried. The circulation is maintained by exhaust fans at the outlet end. As the heated gases pass twice through the length of the cylinder, more time is allowed them to give up their heat to the substance being dried. A double-tube drier should, therefore, be more efficient, and give a greater amount of dry product per unit of fuel consumed than a single-tube drier.

As the price obtained for the product of the driers is considerably more than that which could be obtained for the same material if it were to be used as fuel, a somewhat greater outlay can be borne in preparing it for market; but experience has demonstrated, as would be expected, that the more the water in peat is reduced before putting the peat into the drier the lower the cost of production becomes. Presumably, therefore, by using some of the types of driers developed for drying tankage, garbage, and other similar materials, peat, in the form of a powder that has been partly air dried can be dried to a moisture content of from 10 to 15 per cent with profit, especially if a part or all of the heat used be derived from stack gases or exhaust steam.

\section{PEAT BRIQUETS.}

\section{ADVANTAGES OF BRIQUETTING.}

Manifestly peat powder can not be burned economically in an ordinary fire box or stove, because it packs so that no air can get through it, or it falls through the grates if stirred. Such fuel is also open to the objections that are urged against.other forms of peat fuel, and is costly to transport as compared with coal. To avoid these difficulties the proposal has been made to shape the dry powder into briquets by the use of specially designed briquetting presses. In Europe, where peat is commonly used, and where for a considerable time lignite and poor grades of coal have been put on the market in briquetted form, and have found ready and constantly increasing sales, it is not surprising that peat should have been briquetted at an early date.

\section{PROPERTIES.}

Peat, when briquetted, makes a most attractive type of fuel, as the briquets are uniform in size, may be of cylindrical, ovoid, pris- 
matic, pillow, or other shape, and often have a highly glazed black surface. The briquets are clean to handle; they are also compact and dense, so that they occupy less space, and are more easily transported and stored than the same weight of the same peat could be if in any of the other forms described. They burn less rapidly than cut or machine peat, and hence give less trouble in firing for power production than do other kinds of peat fuel.

It has been pointed out, however, that peat briquets are likely to crack and crumble when handled roughly, and to break down in the fire into a powder, whereas machine-peat bricks burn like a piece of good coal, or wood, without falling apart. The briquets are also easily wet by rain, and are quickly disintegrated by exposure to storms; therefore they must be stored under cover and shipped by rail in weatherproof cars.

\section{METHODS OF MANUFACTURE.}

In the parts of Europe where peat briquets are made the peat is cut or dug from the bog and is allowed to dry in the air until the water is reduced to about 40 per cent. The peat is then powdered and dried artificially to about 15 per cent moisture, after which it is briquetted or stored for future briquetting.

The Canadian method of drying peat on the surface of the bog in a thin layer and picking up the dry material at frequent intervals with a vacuum dust collector does away with most of the cost of drying and subsequent handling, so that after a brief exposure to artificial heat it can be satisfactorily briquetted. The process was primarily designed by its inventors to produce at the lowest cost air-dried peat for making briquets.

\section{TYPES OF PRESSES.}

The essential part of a plant for making peat briquets is the briquetting press. Such presses are of two general types-the open and the closed mold. In the open-mold type the dry peat powder is introduced into a straight tube, or mold, of circular or other shaped cross section, and compressed by a tightly fitting piston that exerts a pressure of from 18,000 to 30,000 pounds per square inch. Sufficient resistance is offered by the friction of the peat on the sides of the tube to press it into a solid block or briquet, while at the same time the air is forced from the peat. With each stroke of the piston a new charge of peat enters the mold and a finished briquet leaves the outlet end; the briquets already made act as a cushion and, in fact, form the bottom of the mold. The friction is sufficient in presses constructed on this principle to raise the temperature of the mass enough to release some of the tarry compounds of the peat, 
and these cover the sides of the briquets with a highly polished glaze. A chief objection to this form of press is said to be that the constant heating and friction produce great wear on the molds, and the plates forming them must be removed every few days and reground, so that after a comparatively short life they have to be renewed.

The number of briquets that can be made with such a machine manifestly depends upon the number of strokes of the plunger to the minute. For briquetting lignite, this may be as low as 80 or as high as 130; thus the number of briquets made in a minute lies between these limits. The output of peat briquets is usually about 100 a minute, because the peat powder is sometimes blown from the mold if the press is run at greater speed.

In briquetting presses of the closed-mold type various forms of rollers and plates, or plungers and wheels or plates, or even special forms of crown wheels, have been employed for the two halves or parts of the molds. The advantage claimed for presses of this type is their greater rapidity and durability, but mechanical difficulties are encountered in getting sufficient pressure to make solid briquets and in keeping the two halves of the mold in exact adjustment. This form of press is sometimes used when a binder of pitch or other resinous or tarry matter is used to cement the particles of fuel together to make the briquets less breakable when handled or burned.

European briquetting presses of the open-mold type are made in three sizes-a small size, turning out from 16.5 to 22 tons of finished briquets in 24 hours; a medium size, having a capacity of 33 to 44 tons in 24 hours; and a large size, which makes from 44 to 55 tons in 24 hours.

To produce a ton of peat briquets costs considerably more than to produce a ton of machine peat because of the greater power required, the artificial drying, and the additional expenses for stronger buildings and more complicated and powerful machinery.

\section{TREATMENT OF PEAT PRELIMINARY TO BRIQUETTING.}

All European factories for making peat briquets are reported to use cut peat of the more compact kinds as raw material, because it can be ground more quickly and thoroughly than the tougher machine peat. The peat is treated exactly as if it were to be used as the cut product, until the water is reduced by evaporation to 40 or 50 per cent; it is then taken to the plant and ground while still moist so as to avoid the dust and resistance to the mill which result from grinding with less water. It is then screened. The drying is finished in a dryer, and the dry powder is either briquetted immediately or stored. If ground when too dry, considerable loss occurs from the finer particles flying about as dust, the presence of which in air is annoying and dangerous to the workman, and under certain conditions may cause disastrous 
explosions. The dry peat is also hard to grind and rapidly wears the milling machinery.

There is no record either in Europe or America of a successful plant for making peat briquets by a continuous process that dries the peat wholly by artificial heat.

COST OF PLANTS.

European briquetting presses of 50 tons capacity in 24 hours, which is the size most often considered, need engines of about 100 horsepower, operated by high-pressure steam; in the best equipped European plants the steam is superheated to about $665^{\circ} \mathrm{F}$. and the boiler pressure is carried at about 150 pounds. The exhaust steam from the engines is used in the driers, at about 30 pounds pressure, and is returned to the boilers after condensation under about the same pressure.

A briquetting plant, fully equipped with the best types of German machinery, including a drier, will cost two to three times as much as a plant for making cut and machine peat, even if only a single press with a capacity of about 50 tons per day is contemplated.

At least three distinct presses for briquetting peat have been invented and tried on a factory scale in Canada. Two are of the closedmold type, although working on very different principles; the third employs an open mold. The peat used for these plants was dried as much as possible on the surface of the bog, but the final drying was done in specially designed rotary driers.

The essential details of these plants have been described by $\mathrm{Ny}-$ strom. $^{a}$ Of these plants only one was operated in 1908, and no figures as to the cost of installation or of the production of the briquets are available. Two of them made a small output in 1910. Several forms of presses of American construction for briquetting coal and lignite, and some designed for peat, have been developed and are on the market, and probably these could be installed at somewhat lower cost than any which have been made abroad. It is doubtful, however, whether a bog can be purchased, proper buildings erected for housing the machinery and the finished briquets, and the necessary machinery bought for digging, grinding, drying, and briquetting the peat for an output of about 50 tons of briquets each 24 hours for less than $\$ 60,000$ to $\$ 75,000$, although estimates as low as $\$ 35,000$ have been made based on untried machinery.

The plan of drying the peat upon the surface of the bog and gathering it as a dry powder with a small amount of water, because a part of the cost of preparing the peat for briquetting is thus eliminated, should reduce the primary cost of the plant by a certain amount. It

$a$ Nystrom, E., Peat and lignite; their manufacture and uses in Europe. Canada Department of Mines, Mines Branch, 1908, pp. 148-157. 
is questionable, however, whether the cost of collecting machines and their installation would not be almost as great as that of the rotary driers which they would in part displace. Their operation by electric power might prove to be nearly as expensive as that of steam driers utilizing waste steam.

The operation of the briquetting part of a plant during the winter could be made possible by operating a number of the collecting machines during the favorable months of the drying season and storing in stock piles or storage bins the excess of dry peat as it was taken from the surface of the bog. If storage under cover were adopted, the construction of the necessary buildings would be an added charge.

The following statement, which shows the cost of a briquetting plant with an estimated output of 50 tons of peat briquets per day, is quoted from an estimate furnished by Mr. F. H. Mason, ${ }^{a}$ when United States consul general in Berlin, Germany:

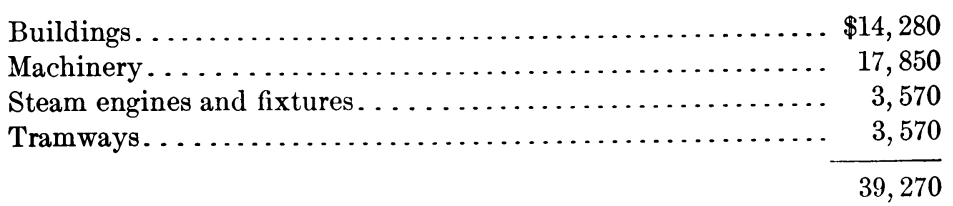

These figures are approximate only and will have to be considerably modified to meet present conditions.

The American agent of one of the leading German builders of briquetting plants furnished the following estimates for a peat briquetting plant having an estimated capacity of 40,000 kilograms (about 44 short tons) of finished briquets in 24 hours:

The complete mechanical plant, which costs 201,000 marks $(\$ 48,240)$ in Germany, includes two large steam boilers, necessary engines, conveyers, elevators, electrical generators and motors, a rotary drier, a powerful press, sieves, and the numerous other items of machinery needed to carry on successfully the rather complicated processes that seem required to produce marketable peat briquets steadily and in quantity. The duties, trans-Atlanitc freight, and other charges to which foreign machinery importations are subject more than double the list prices, so that the mark must be reckoned as equivalent to 60 cents; thus the estimated cost of this machinery becomes about $\$ 120,000$ when delivered to the American purchaser on the cars in New York.

Many of the items included in this list could doubtless be replaced at a less cost by those of American manufacture. To successfully install the briquetting press and drier, however, would require the importation of some of the other machinery designed to accompany 
them, so that it is probable that a briquetting plant of the capacity given above could scarcely be equipped for less than $\$ 70,000$ to $\$ 75,000$. To this amount must be added the cost of special digging machinery, buildings, railroad sidings, etc., which would mean a total investment probably exceeding $\$ 100,000$.

\section{COMPARATIVE COST OF BRIQUETS AND MACHINE PEAT.}

The cost per ton of making peat briquets must of necessity be greater than that of making machine peat, because a larger investment in plant is needed and this involves larger charges for interest and depreciation. The more complicated machinery requires more skillful and better-paid men, and the machinery requires greater power, and therefore a greater consumption of fuel. The wear on the briquetting presses is excessive, which makes the cost of maintenance high in comparison with that of the more simple peat machine, and the cost of artificial drying, of grinding the peat, and of briquetting must also be taken into consideration. In view of all these factors, and the added cost of digging and partially air drying the peat and of getting it to the briquetting machinery, peat briquets can probably not be made under American conditions with any machinery now in use in Europe at much less than $\$ 3$ per ton, and conditions would have to be excellent if this price were not exceeded.

What can be done with peat briquetting machinery and plants of American design and construction now in process of development or installation can not be predicted at this time.

\section{COMPARATIVE FUEL EFFICIENCY.}

Naturally, the inquiry will be made whether the added expense of equipment and the greater cost of making peat briquets is justified by a corresponding increase in the efficiency of the fuel. Seemingly it is not, because the cost of production is at least one-third greater than for machine peat, whereas, according to Nystrom, ${ }^{a}$ the heating value is increased only about 15 per cent. Actual analyses of peat from the same deposit at Black Lake, N. Y., and prepared in different ways, are given below. The samples were taken at random from considerable quantities of similar material which had been given identical treatment, but possibly gathered at different times; that is, the samples were not prepared especially for these analyses. 
Analyses of peat to show the effect of method of preparation on heating value of a given peat.

\begin{tabular}{|c|c|c|c|c|c|c|c|c|}
\hline \multirow{2}{*}{$\begin{array}{l}\text { Lab. } \\
\text { No. }\end{array}$} & \multirow{2}{*}{ Character of fue!. } & \multirow{2}{*}{$\begin{array}{l}\text { Mois- } \\
\text { ture. }\end{array}$} & \multirow{2}{*}{$\begin{array}{c}\text { Volatile } \\
\text { com- } \\
\text { bustible. }\end{array}$} & \multirow{2}{*}{$\begin{array}{l}\text { Fixed } \\
\text { carbon. }\end{array}$} & \multirow{2}{*}{ Ash. } & \multirow{2}{*}{$\begin{array}{l}\text { Sul- } \\
\text { phur. }\end{array}$} & \multicolumn{2}{|c|}{ Heating value. } \\
\hline & & & & & & & Calories. & B. t. u. \\
\hline 6436 & $\begin{array}{l}\text { Raw peat: } \\
\quad \text { Air dried.................... } \\
\quad \text { Moisture free............. }\end{array}$ & 8.68 & $\begin{array}{l}50.92 \\
55.77\end{array}$ & $\begin{array}{l}23.79 \\
26.04\end{array}$ & $\begin{array}{l}16.61 \\
18.19\end{array}$ & $\begin{array}{l}0.99 \\
1.08\end{array}$ & $\begin{array}{l}4,179 \\
4,576\end{array}$ & $\begin{array}{l}7,522 \\
8,237\end{array}$ \\
\hline 6394 & 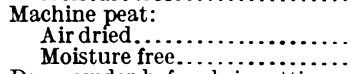 & 9.33 & $\begin{array}{l}49.85 \\
54.97\end{array}$ & 23.35 & $\begin{array}{l}17.47 \\
19.26\end{array}$ & $\begin{array}{l}.89 \\
.98\end{array}$ & $\begin{array}{l}4,055 \\
4,472\end{array}$ & $\begin{array}{l}7,299 \\
8,050\end{array}$ \\
\hline 6392 & 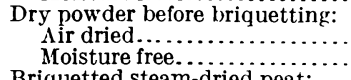 & 7.37 & $\begin{array}{l}52.03 \\
56.17\end{array}$ & $\begin{array}{l}22.74 \\
24.53\end{array}$ & $\begin{array}{l}17.86 \\
19.30\end{array}$ & $\begin{array}{r}.96 \\
1.03\end{array}$ & $\begin{array}{l}4,102 \\
4,428\end{array}$ & $\begin{array}{l}7,384 \\
7,971\end{array}$ \\
\hline 6395 & 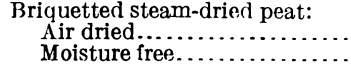 & 8. 00 & $\begin{array}{l}52.19 \\
56.73\end{array}$ & $\begin{array}{l}22.44 \\
24.39\end{array}$ & $\begin{array}{l}17.37 \\
18.88\end{array}$ & $\begin{array}{l}1.16 \\
1.27\end{array}$ & $\begin{array}{l}4,193 \\
4,557\end{array}$ & $\begin{array}{l}7,547 \\
8,203\end{array}$ \\
\hline
\end{tabular}

$\Lambda$ verage heating value of dry peat, 8,115 B. t. $u$.

This table indicates that the differences in the number of heat units obtained from the different samples are slight, and it is difficult to see that any appreciable change has been made by the various kinds of treatment. Equal variations might occur in the same number of samples of peat collected from a single stratum at the same time but analyzed separately. Therefore, except for the greater compactness and hardness obtained, there is no justification for incurring the cost of briquetting. However, a larger series of more carefully collected samples may show greater variation than is here indicated; or if drying or briquetting at high temperatures is adopted so that some of the lighter volatile combustibles are driven from the peat, a somewhat higher thermal value may be obtained. Clearly, however, briquetting as a rule increases the number of heat units per unit of volume and not per unit of weight; that is, the peat is made more compact, so that it can be transported and stored in smaller space and burned in smaller fire boxes than if prepared in other ways. Whether the advantages thus obtained are sufficient to justify the additional costs of building a plant and of making the briquets on a commercial scale must be demonstrated by actual operations.

\section{ELECTRIC PROCESSES FOR DRYING PEAT.}

The fundamental plan of electric processes for drying peat is to pass electric currents, either direct or alternating, through the wet peat, with the idea of liberating the water by breaking up the cells and fibers of the vegetable remains in the peat. The most thoroughly advertised of these processes was one developed in England and embodied in two plants, one at Kilberry, near Athy, in the county of Kildare, Ireland, and the other near Eaton Rapids, Mich. Although both of these plants were well supported by capital and equipped 
with unusual thoroughness, both were complete failures. The peat was dug by a "grab" dredge or shovel and dumped into cars which took it to the factory. Here it was thrown on an endless belt, by which it was elevated to the hopper of what was called by the inventor a "hydro-extractor," a form of press that squeezed out part of the water. From the base of the hydro-extractor the peat passed between the plates of the electrolyzer, and a powerful alternating electric current was passed into it for some time. The peat thus electrolyzed was forced into another hydro-extractor, or eliminator, placed below the electrolyzer, and in this the water liberated by the passage of the electric current was forced out. From this press it was carried by a bucket conveyor to the top of a large slab, where it was crushed by four heavy rollers, each weighing a ton, and thence the crushed, electrified, and pressed peat passed to a molding machine with six dies, which formed it into bricks and deposited these on a revolving table. The bricks were then removed from the table by a scraper to cars which carried them to drying sheds, where the drying was finished by contact with the air as in ordinary air drying.

The material thus obtained was called electro-peat coal, which, like many of the other names applied to peat products, was a misnomer, because in reality it was no different from, if as good as, ordinary machine peat, and in no way resembled coal.

The more extensively advertised electric processes seemingly have been based upon the supposition that the electric discharge into the wet peat would burst the cells of the plant remains in it, and the water could then be quickly pressed out; but such a result does not seem to have been attained to an extent warranting the treatment. The theoretical consideration of the matter leads to the conclusion that no such effect can be produced, because the differences between the conductivity of the water and of the saturated vegetable matter constituting the walls of the cells is very slight, if any exists, and upon such differences the supposed effectiveness of the electric charge must be based. The heat energy derived by converting the electric energy through the resistance offered by the water and peat is obtained at a cost from ten to fifteen times as great as by direct firing.

\section{WET CARBONIZATION.}

\section{UNDERLYING PRINCIPLES.}

In 1904 and the following years Dr. M. Ekenberg, of London, England, conducted a lengthy series of experiments on what has been called the "wet carbonization" of peat. As the term indicates, the wet peat is subjected to temperatures slightly above $300^{\circ} \mathrm{F}$. $\left(150^{\circ}-\right.$ $155^{\circ}$ C.), which drive off a part of the lighter hydrocarbons if the heated mass be kept at ordinary pressure. During the heating, how- 
ever, a pressure of about 150 pounds to the square inch is maintained by the pump which forces the wet peat into the carbonizing apparatus, so that the process really consists of superheating wet peat in a closed receptacle under pressure of about 10 atmospheres. Such pressure is quite enough to prevent any steam from forming at the temperature at which heating is carried on, so that there is no loss of heat units from this source and no volatilization of the hydrocarbon compounds of the peat.

\section{PROCESS OF TREATMENT.}

After digging, the wet peat is thoroughly macerated in a special form of peat machine located on the bog. The machine delivers the peat as a finely divided pulp to dumping cars, which convey it to the plant, and there it is stored in a large tank until used.

The wet-carbonizing furnace, the essential feature of the process as it was developed in an experimental plant in Sweden, consists of a series of 52 iron pipes, some 36 feet long, all heated from a fire box at one end of the series. Each tube is double; the smaller inner tube has on its outside a screw flange which, when the tube is turned, moves the peat through the space between the tubes. The inner tube is open at both ends, and at its free end is connected with the corresponding ends of all of the rest of the series. Each of the larger outer tubes is connected with a common inlet, through which the wet peat is forced by a specially designed pump. At the end opposite the inlet the large tube projects into the fire box and is exposed for half its length to the direct heat of the fire.

The peat pumped into the common inlet is forced through the outer tubes by the pressure of the pump and the screw flanges of the inner revolving tube, and then, wet and hot, into the open end of the inner tubes and through these to the outlet.

The economy of heat effected by having only that half of the length of the tubes heated that is remote from the inlet is manifest when one considers that the cool material coming into the outer tube takes the heat from the hot material going out through the inner tube. Thus the cool material is hot when it reaches the directly heated part of the system, and the outgoing material gives up a considerable portion of its heat before it reaches the outlet.

From the carbonizer the peat is conveyed to a special type of filter press, which reduces the water to about 55 per cent, according to Nystrom, or, according to later reports, to about 10 per cent, from the original 85 to 90 per cent. The material from the filter press is dried artificially and briquetted.

PROPERTIES OF PEAT AFTER TREATMENT.

The peat becomes blackened, loses its structural peculiarities, becomes fine grained, and, it is stated, readily gives up under moderate 
pressure a considerably larger percentage of water than untreated peat. It is reported that a form of coking takes place, the extent of which is governed by the temperature used during the treatment, the use of higher temperatures giving more complete carbonization. If this is true, as the blackening of the peat would indicate, apparently the matter driven off must be absorbed either by the peat itself or by the water which it contains, as no gases are developed during the process. It is evident, however, that at the temperature reported $\left(300^{\circ} \mathrm{F}\right.$.) the process of coking is not carried very far, because only at considerably higher temperatures are volatile carbonaceous matters driven off by dry distillation.

The exact nature of the changes that take place is immaterial to this discussion, however, since the important fact is that a definite change is effected by the treatment which makes possible the quick drying of the peat by artificial heat and pressure. From available reports the process, when it is fully developed, will seemingly be commercially useful and will enable those who adopt it not only to extend the season of operations to early winter, but to produce very hard, heavy, and black briquets closely resembling coal in appearance and, volume for volume, having about the same fuel value as bituminous coal of ordinary grades.

\section{COST OF BRIQUETS BY THIS PROCESS.}

The cost of manufacture, including all charges for digging and grinding the peat and transporting it to the factory, and for carbonizing, drying, and briqueting, interest, depreciation, and administration, is estimated, from the results obtained at the experimental plant in Sweden, to be $\$ 2$ to $\$ 2.25$ a ton of finished briquets. The smaller cost is estimated for an output of 20,000 to 30,000 tons in a year of about 200 working days. The English company owning the patents covering the processes and machinery estimates that the briquets can be made in a factory turning out 100 tons of briquets a day, under European labor conditions, for about $\$ 1.50$ a ton, after the machinery now being experimented with shall have been fully perfected.

\section{COST OF PLANT.}

The cost of a plant fully equipped with briqueting presses, carbonizers, and all other accessories is estimated by the inventor at about $\$ 160,000$; or, if production is to be 30,000 tons of briquets a year, at about $\$ 225,000$, at European prices for machinery, structural work, and labor.

\section{CLAIMS OF INVENTOR.}

The inventor claims for this method of treatment that-

(1) The manufacture is independent of weather conditions.

(2) The work can be carried on equally well night and day. 
(3) Undrained bogs can be worked without difficulty.

(4) All the processes of treatment may be completed and the briquets made in two hours after the peat is dug.

(5) The fuel produced is always of the same quality. The water content may be as low as desired.

(6) The number of men required for a plant with an output of 100 tons a day is small compared with that needed for the same output of machine peat, as only from 18 to 24 men are needed, chiefly to watch and care for the machinery.

(7) Since the process is continuous and may be carried on independent of weather conditions, an abundant supply of labor can be had without difficulty, because the men will be assured steady work.

\section{PROSPECTIVE VALUE OF PROCESS.}

The various unbiased reports which have been made concerning this way of treating peat lead to the conclusion that it is one of the most promising that has yet been discovered, and if the treatment and machinery are not too costly it may yet become the basis of a successful continuous-process, peat-drying, and briquetting industry. No reports have yet appeared, however, showing that the method has been applied in a successful commercial plant, and for that reason the process must still be considered as experimental, some of the important details needing development and embodiment in machinery.

\section{FUEL PRODUCTS DERIVED FROM THE DISTILLATION OF PEAT.}

\section{PEAT CHARCOAL.}

Early in the eighteenth century a crude process of making charcoal from peat was in use in several European countries, and presumably cut peat was made into charcoal at an earlier date in districts where wood was scarce.

The simplest way of making charcoal from peat is that of the charcoal burners of Europe, who made a circular, dome-shaped heap by piling cut-peat bricks in regular courses around a pole, at the base of which a small quantity of dry fuel was placed to start combustion. A fluelike space, through which the dry fuel was ignited and air was admitted, led to the outside of the heap. A small space around the central pole formed a chimney for gas and smoke as needed, and various inlets for air were made through the sides of the structure. The heap of bricks was covered with a layer of brush, outside of which was placed a layer of earth, varying in thickness gradually from about 1 foot at the bottom to half as much at the top.

After the fire was well started the chimney opening in the top of the heap was closed, and the combustion was then carefully watched by a man of experience who regulated the supply of air so 
as to prevent too complete combustion and yet keep the fire from going out. When the coking was judged to be complete, all openings were closed by damp earth, the fire was allowed to die out, and the mass was permitted to cool thoroughly before the heap was opened. The yield of charcoal recovered by this method was generally from 30 to 40 per cent of the original weight of the peat.

In some parts of Europe the peat was piled in long, narrow pits about 1 yard wide and 20 yards long. The heaps so made were converted into charcoal in much the same manner as were the smaller ones. In Sweden, peat charcoal was made to some extent in kilns of iron or masonry. Peat was piled in these to a considerable height above the mouth and a fire started at the bottom and allowed to burn until the mass had settled down to the level of the top, when a layer of green rushes or brush was spread over the mouth and quickly covered with wet clay. This brought the combustion to an end and after the kiln was cooled the charcoal was removed.

PEAT COKE.

EARLY ATTEMPTS AT MANUFACTURE.

The crude method of making charcoal from peat piled in heaps was improved as early as the first half of the eighteenth century, when Lange developed a special furnace consisting of a vertical cylindrical iron furnace, conical at the top, and partly closed at the bottom by an iron plate in which was a barred opening. The plate rested on a stone base in which was an arch or fire box closed by a tightly fitting iron door.

The furnace was filled from the top with peat bricks and combustion was started in the mass by building a fire in the stone fire box. When the lower part of the peat was burning freely, the door was closed and the fire allowed to smolder until the peat was coked; then the furnace was filled to the top again and the process of burning continued. After a number of chargings, the furnace became filled with burning coke. Then the opening was closed and all air was shut off until the coke was cold. This furnace gave a small output of porous and friable coke and after a time its use was abandoned.

In still another type of furnace, developed in Germany, the firing was done from the top, the gases developed during coking being drawn down through the mass of peat and out of the furnace by pumps attached to pipes leading from the bottom of the furnace. The purpose of this arrangement was to prevent loss from crushing, because by its use the brittle charcoal was formed above the undecomposed peat, and did not have to bear the weight of the latter.

None of these ways of making coke and charcoal from peat proved very remunerative, however, in spite of every care to reduce waste. The cost of production measured by fuel consumed in making the $661^{\circ}-$ Bull. $16-11-9$ 
coke was large and the output was small and generally of unsatisfactory quality.

The fact that good peat coke or charcoal had all of the desirable qualities of wood charcoal and fully as high calorific value made it a useful and salable fuel, especially as wood charcoal became less abundant and more costly.

\section{DRY DISTILLATION IN RETORTS.}

The facts cited above led to continued experimentation, and as early as 1786 coke was produced by dry distillation of peat in retorts heated from the outside; the heavier volatile hydrocarbon compounds like tar were condensed and saved and the noncondensing gases were used for fuel or illuminating purposes.

From 1786 until the present time many European inventors and some Americans have worked upon processes for coking peat in retorts with more or less complete recovery of the useful chemical substances that by condensation and redistillation at different temperatures may be derived from the liquid products of the decomposition of the peat. These efforts have been concentrated upon making hard, firm peat coke which should be at least as good as good charcoal, or even as hard as coke made from coal, and upon saving all of the volatile products that could be made into marketable chemical compounds without too great expense.

THE ZIEGLER PEAT-COKING PROCESS.

In the last decade of the nineteenth century a method of coking peat in retorts was worked out and patented by Dr. Martin Ziegler, a German chemist and inventor. In this method the permanent gases derived from the dry distillation of peat are used for heating the retorts in which the coking is done, and for other operations about the plant. The system also provides for the use of the same retorts continuously, and for the recovery in a most practical way of all marketable chemical compounds as by-products. Three plants of commercial size using this system have been erected in Europe; the first at Oldenburg, Germany; the second at Redkino, Russia, by the Russian Government in 1901, and the third at Beuerberg, Bavaria, in 1904. The last-named plant embodies many improvements, and at the time of its construction was the most complete establishment for making coke and by-products from peat that had then been developed. Each of these plants is built on the unit system, each unit consisting of two vertical retorts about 40 feet high and elliptical in cross section. The lower half of each retort is of fire brick and the upper half of cast iron, covered with thin fire bricks, and the two halves are inclosed in a fire-brick shell. Between the two shells are horizontal fire flues. The whole structure is inclosed by a covering of common brick to prevent loss of heat through radia- 
tion. The retorts rest on a cast-iron base and taper down to hoppers, each with two openings, closed by air-tight doors, through which the peat coke can be removed as often as desired. In practice the coke is drawn off once an hour into iron cars with air-tight covers and is kept in the cars till cool. The tops of the retorts have heavy castiron doors, to which are attached feed boxes with gas-tight covers, opening. inward. By this provision new fuel can be introduced whenever necessary without interfering with the operation of the retorts, so that coking is continuous. The volatile matter is drawn off through pipes in the upper half of the retorts by suction fans and led to condensing chambers; there it gives up a part of its heat to concentrate solutions and dry some of the by-products, the tar and tar water being removed by condensation. The uncondensed gases are returned to the combustion chambers to serve as fuel.

The hot gases from the fires, having a temperature of more than $1,800^{\circ} \mathrm{F}$. $\left(1,000^{\circ} \mathrm{C}\right.$.), are drawn through the fire-brick flues in the walls inclosing the retorts, and thence to a main flue connected both with drying chambers, in which the drying of the peat bricks is completed, and with the chimney.

As indicated above, the heat of the gases leaving the retorts is used to concentrate and dry out part of the by-products by being drawn under the vessels containing them. The by-products plant is in a separate building, and as the essentials of the processes used in it are described on pages 131-132, details regarding it are unnecessary at this point.

Besides the retorts in which the peat is thoroughly coked at the Beuerberg plant, each pair of these is directly connected with a circular retort for making half coke or "semicoke," from low grades of peat by using the heat of the waste combustion gases from the coking retorts. These gases, because they have no free oxygen, and hence can not set fire to the peat, are conducted from the collecting flue of the coking retorts directly into the halfcoke ovens, and are hot enough to thoroughly carbonize the peat without driving off all of the tarry compounds. The resulting product is not as hard and firm as the peat coke, and is lower in carbon and richer in hydrogen, but it makes excellent fuel for heating, as it burns with a long bright flame. ${ }^{a}$ The Ziegler plant at Redkino, Russia, is reported to have manufactured this product for fuel for locomotives on the railways of the country, and 1 pound of it is said to have evaporated 6.63 pounds of water in a stationary boiler and 5.76 pounds in a locomotive boiker. $^{b}$

\footnotetext{
a Nystrom, E., Peat and lignite; their manufacture and uses in Europe. Can. Dept. Mines, Mines Branch, 1908, pp. 181-183.

$b$ After running for some months with seeming success, the Beuerberg plant was closed, and has not been operated since. Among the reasons given for the failure of the plant was the great difficulty, except at prohibitive cost, of drying the large quantity of machine peat bricks before they were placed in the retorts.
} 
RECOVERY OF BY-PRODUCTS.

A good quality of coke can be made from dense, thoroughly decomposed peat that has been machined and air dried, but the coke must be manufactured under favorable conditions of market and on a large scale, and, if the best financial returns are expected, the coking must be accompanied by the recovery and profitable sale of the chemical by-products and the utilization of the noncondensible gases as fuel for heating the retorts and for drying the peat preliminary to coking.

By such treatment there can be obtained from peat the following useful substances:

(1) Coke, or charcoal, the nonvolatile part of the peat, consisting of the fixed carbon and the ash or incombustible mineral solids.

(2) Tar, a mixture of the more readily condensed hydrocarbon compounds formed by the destruction of the complex organic substances in the peat.

(3) Tar water, or, as it is sometimes called, gas water, a solution of a number of the lighter, less easily condensed organic compounds in the water originally present in the peat or formed by the decomposition of original hydrogen compounds.

(4) Fixed gases, a considerable part of the volatile matter given off by peat heated in a retort, which before purification form a mixture of elementary and compound gases, some of which are combustible. The yield of gas varies considerably for different kinds of peat, the less decomposed giving the largest quantity and poorest quality.

PROPERTIES OF PEAT COKE.

Coke made from peat differs much in purity and hardness, depending on the kind of peat, the thoroughness with which the peat is macerated before coking, and the extent to which the volatile matters are driven off. The best peat coke is black and has the luster of jet, or it may be even of graphite color; it is hard and compact, but retains the original structure of the macerated peat. Such peat coke is quite as strong as good, hardwood charcoal, and may even surpass the latter in resistance to crushing.

The percentages of sulphur and phosphorus are usually very low, and if the peat was good the ash content is also low. Burned under the proper conditions the coke gives practically the same temperature as good charcoal, about $4,300^{\circ} \mathrm{F} .\left(2,380^{\circ} \mathrm{C}.\right)$; it has practically the same calorific power $(12,000$ to 14,000 B. t. u. per pound). Peat coke has been used in making gunpowder, in purifying water and solutions containing organic matter, in smelting and refining metals, in the manufacture and hardening of steel, and, to some extent, in making calcium carbide. Obviously, if it can stand the pressure of tall blast furnaces, it may replace charcoal in the manufacture 
of charcoal iron, and the statement is made that retort-made peat coke is already replacing charcoal for this use to some extent in northern Europe. It may also be used wherever an efficient, smokeless fuel is desired, or in industries where such fuel is necessary.

The poorer grades of peat and those higher in ash are sometimes made into "half coke," a charcoal-like product in which some of the volatile matter is left. This has about 65 per cent of pure carbon, compared with more than 90 per cent in the thoroughly coked material. The amount of coke that can be obtained from a given weight of peat depends upon the thoroughness of the coking and the intensity of the heat. About 33 per cent of good coke is obtained by the Ziegler process of coking in retorts, and as high as 45 or 50 per cent of salable half coke may be had.

PROPERTIES AND DERIVATIVES OF TAR.

The quantity of tar that may be recovered from the distillation of peat in coking retorts is somewhat variable, but rarely exceeds 4 or 4.5 per cent of the dry weight of the peat used, and may run as low as 1.5 or 2 per cent.

Peat tar is a black, viscid liquid having a strong, smoky odor, often acrid and disagreeable. It may be used in the crude state as a wood preservative, or may be converted into a variety of commercially valuable substances by redistillation at various temperatures. The most important products of such treatment are light oil, heavy oil, wax, creosote, and asphalt.

METHODS OF RECOVERING TAR AND OF PURIFYING TAR DERIVATIVES.

In the Ziegler process the tar is condensed in a receiver which may be placed in the ground near the retorts. The tar is separated from the water condensed with it by heating the mixture in large open vessels to the melting point of the tar by the use of steam heat. The tar collects in a layer on top of the water, and after cooling may be removed to another tank, where the operation is repeated. The last traces of any ammonia still left in the tar are washed out with dilute sulphuric acid.

After the tar has been sufficiently freed from tar water and ammonia it is placed in a large cast-iron retort and melted with a small amount of a dilute solution of sodium hydroxide. It is then distilled slowly until all of the water and some of the light oils have been liberated. After the water ceases to pass off from the retort, the distillate is collected in a second receiver and heating continued until about 10 per cent of the amount of the tar has passed over. The product is then removed, the heat is increased, and the distillation allowed to proceed until crude, heavy oil, mixed with paraffin wax, has collected in the receiver to an amount equal, approximately, to 33 per cent of the tar taken. The hot tar residue is then dipped from 
the retort and molded into blocks of asphaltum, and the crude mixture of paraffin and heavy oils is placed in tanks having valves at various heights on the sides. The mixture is stored in cold underground storerooms until the wax separates from the oil and becomes solid. The valves in the containers are then opened, one at a time, beginning at the top, and the oil pressed out from the openings and added to the crude oil already collected. The final residue of heavy oil which serves as lubricating oil is removed from the wax by pressing it cold. The wax is allowed to accumulate until enough is on hand to pay for its purification, after which it is melted, filtered through felt, and after some further purification molded into candles or other salable form.

The crude oils, which are said to be identical with petroleum in properties and appearance, are refined by adding enough caustic soda to separate the creosote and similar compounds from the oil. The soda is added to the oil in definite proportions, depending on the amount of creosote found by analysis, and the mixture of oil and reagent is agitated for an hour or more to insure complete union of the creosote and soda. The tank in which this reaction is carried on has valves at intervals down the sides. After the stirring is completed the mixture is allowed to stand for several hours until the oil and creosote solution separate.

After the separation is completed the oils are drawn off into a lead-lined vat, 5 parts of concentrated acid for each 100 parts of oil are added, and the mixture is stirred for about an hour to remove certain organic impurities. The oil that separates from the acid is drawn off from the top, again treated with caustic soda, and then distilled in an iron or copper retort. The first oil obtained is usually yellowish, and this portion is saved separately. The colorless distillate is run into barrels; when the specific gravity of the distillate reaches 0.83 , the receiver is again changed and the heavy oils that have an average specific gravity of 0.85 are collected. The residue left in the retort at the end of the distillation consists of tar and sodium hydroxide, or, if the heating be carried far enough and all the volatile matter be driven off, only carbon in the form of graphite remains. This can be converted into carbons for electric lights.

Creosote and resin compounds may be obtained from the soda residue collected during the purification of the oils by placing the residue in a proper vessel and adding sulphuric acid until no more oil separates. This oil forms a distinct layer above the acid, and may be drawn off into another vessel, where it is washed with water. A strong solution of caustic soda is added in the proportion of 1 part of solution to 10 parts of oil, until about 70 per cent of the oil has boiled over. The residue left in the retort is crude sodium resinate, which may be used in making lampblack or gas carbon. If the crude creosote 
resulting from this treatment is to be further purified, the processes described must be repeated several times. As such purification pays only when conducted on a large scale, the crude creosote obtained from small plants can best be utilized by treating it with finely powdered and sifted slaked lime. The product is a crude calcium creosote compound that can be sold for disinfecting purposes.

The tars obtained at the Beuerberg coking plant in Bavaria (Ziegler process) are said to have been converted into a soaplike product which makes excellent axle grease by adding lime and resin oil to the tar. This disposition of the tarry material is simpler and requires much less apparatus than the process described above, and if the product can be sold in sufficient quantities makes the disposal of the tar a relatively easy matter.

\section{DERIVATIVES FROM TAR WATER.}

The character of the derivatives from tar water depends to some extent on the kind of peat; the less decomposed, fibrous kinds yield more methyl alcohol and acetic acid and less ammonia than the darker colored, thoroughly decomposed, and structureless kinds, which contain more combined nitrogen. The tar water from the condensers is practically a dilute watery solution of ammonia salts, acetic and other organic acids, and wood alcohol, together with smaller quantities of finely divided tarry matter.

In recovering these substances on a commercial scale several methods are in use. By one of them the tar is removed by filtering through a charcoal filter, the clear filtrate is made alkaline with calcium hydrate, and filtered again through a fine cloth. This separates the bases (from which aniline and other organic compounds may be obtained) from the filtrate, containing the acetic acid compounds, ammonia, and methyl alcohol.

This filtrate is then placed in a retort and the ammonia and methyl alcohol, together with much of the water, are distilled over into a receiver. As the distillation proceeds the heat causes certain tarry substances to separate from the residue in the retort, and these have to be removed as fast as formed, so that they will not decompose and discolor the solutions on further heating. The latter part of the distillation, after the residue, which is principally calcium acetate, becomes concentrated, is carried on at low temperature, and is accompanied by constant stirring of the solution, so as to prevent any decomposition of the acetate.

The liquid containing the ammonia and methyl alcohol is neutralized with sulphuric acid, filtered to remove impurities, and again distilled to obtain the methyl alcohol, which is further purified and concentrated by redistillation and by passing the distillate over layers of quicklime to remove the water. After the methyl alcohol 
has all been driven off, the residue, which contains the ammonia in the form of ammonium sulphate, is filtered again and slowly evaporated in an open iron vessel until the salt begins to crystallize. The temperature is then decreased and the liquid stirred vigorously until the ammonium sulphate is thoroughly dry.

The recovery of these three compounds (ammonia, wood alcohol, and acetic acid) may be accomplished on a very large scale by modifications of the processes described, including the use of towers through which the gases from the coking retorts are passed, and in which they are brought in contact first with sulphuric acid to fix the ammonia and then with milk of lime to remove the acetic acid. The materials obtained are purified and concentrated as previously described. The most recent practice, however, eliminates the towers.

PERMANENT GASES FROM COKING RETORTS.

As with the other by-products discussed, the volume and composition of the uncondensible part of the distillates from peat-coking retorts vary with the kind of peat used, the amount of water present, and the temperatures at which the coking is carried on.

As the present discussion relates to the by-products recoverable from coking ovens, the figures furnished by the Ziegler peat-coking plants in operation in Germany are valuable and instructive. In a test run at the plant at Oldenburg, in which 576 tons of peat were used, the noncondensible gases were found to be 57.3 per cent of the whole product, and of this quantity about 20 per cent was air, leaving 37 per cent, or 213.4 tons, as the amount available for use.

The uncondensed gases before purification were found, according to official reports cited by Nystrom ${ }^{a}$ to have the following composition:

Analysis of uncondensed gases from retorts at the plant at Oldenburg, Germany.

\begin{tabular}{|c|c|c|}
\hline Gas. & Weight. & Volume. \\
\hline 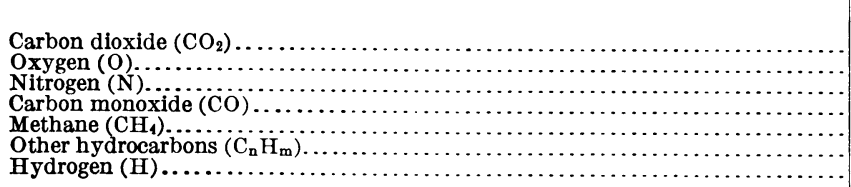 & $\begin{array}{r}\text { Per cent. } \\
48.8 \\
2.8 \\
25.5 \\
9.7 \\
9.6 \\
1.7 \\
1.9\end{array}$ & $\begin{array}{r}\text { Per cent. } \\
27.4 \\
2.2 \\
22.5 \\
8.6 \\
14.8 \\
1.0 \\
23.6\end{array}$ \\
\hline
\end{tabular}

This gas had a calorific value of 322 British thermal units per cubic foot.

$a$ Nystrom, E., Peat and lignite; their manufacture and uses in Furope: Can. Dept. Mines, Mines Branch, 1907, p. 180. 
A later report, from the Ziegler peat-coking plant at Beuerberg, gives the composition of the gases obtained there as follows:

Analysis of uncondensed gases from retorts at the plant at Beuerberg, Germany.

\begin{tabular}{|c|c|}
\hline Gas. & Volume. \\
\hline 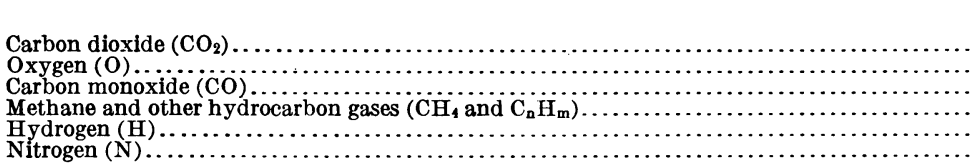 & $\begin{array}{r}\text { Per cent. } \\
15.5 \\
1.1 \\
20.4 \\
12.4 \\
28.6 \\
21.9\end{array}$ \\
\hline
\end{tabular}

This is a better fuel gas than the first one, as it contains a lower percentage of carbon dioxide and more carbon monoxide and hydrogen.

Properties.-Of the gases found by these analyses, carbon dioxide, oxygen, and nitrogen are not inflammable, although the oxygen aids in the combustion of the fuel gases present. Carbon monoxide and hydrogen give heat but nonluminous flames so that they are not available for illuminating purposes when pure, unless incandescent burners of the Welsbach type are used. The methane and other hydrocarbon gases given in the analyses, however, burn with a bright light, and may be termed illuminants. The illuminating power of the peat gas depends on the percentage of illuminants in the gas, and this, in turn, is largely governed by the intensity of the heat developed in the coking retorts and the degree to which the coking is carried.

Volume per unit of peat.-The volume of gas derived from coking peat is quite variable, but in experimental work 100 pounds of dry peat are reported by Ryan ${ }^{a}$ to yield from 475 to 519 cubic feet of illuminating gas, when treated in a retort, whereas other writers report 300 to 430 cubic feet from the same weight of peat. The volume of gas obtained from ovens of the Ziegler pattern is reported to have been, in one test, 6,650 cubic feet of gas to the metric ton $(2,204$ pounds) of dry machine peat coked, or about 300 cubic feet from 100 pounds of peat.

Uses.-The noncondensible gases obtained in the ways described are, in part, combustible, and may be used for illuminating or for fuel. If they are to be used for lighting, they must be purified by removing carbon dioxide and other impurities or diluents, and, as a rule, enriched by the addition of some of the hydrocarbon compounds obtained by heating the tars in retorts. The peat gas may be used as a source of power by burning it under steam boilers or

$a$ Ryan, Hugh, Reports upon the Irish peat industries, pt. 2: Econ. Proc. Roy. Soc. Dublin, vol. 1, pt. 13, pp. 519, 520 . 
in the cylinders of internal-combustion engines. It may be used for heating the coking retorts, for generating the heat or power needed for handling and drying the peat, and for any other purpose in the process of making peat coke and recovering by-products. The actual value of this gas for the uses given is estimated by Dr. Ziegler to be fully 25 per cent of the value of the coke obtained, and with it and the waste heat from the retorts he carried on all of the operations about his plants, after the coking operation was once started, including the manufacture of peat charcoal or "half coke" from the poorer grades of peat.

QUANTITY OF BY-PRODUCTS OBTAINED FROM COKING PEAT.

Thenius, as cited by Ryan ${ }^{a}$ obtained from good air-dried peat the following by-products:

Percentage and weight of by-products per ton of air-dried peat.

\begin{tabular}{|c|c|c|c|c|c|}
\hline Substances. & $\begin{array}{l}\text { Percent- } \\
\text { age. }\end{array}$ & $\begin{array}{l}\text { Pounds } \\
\text { per ton. }\end{array}$ & Substances. & $\begin{array}{l}\text { Percent- } \\
\text { age. }\end{array}$ & $\begin{array}{l}\text { Pounds } \\
\text { per ton. }\end{array}$ \\
\hline 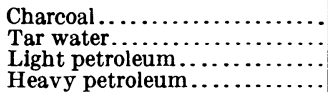 & $\begin{array}{r}35.34 \\
40.00 \\
1.76 \\
2.56\end{array}$ & $\begin{array}{r}706.8 \\
800.0 \\
35.2 \\
51.2\end{array}$ & $\begin{array}{l}\text { Asphalt } \ldots \ldots \ldots \ldots \\
\text { Creosote } \ldots \ldots \ldots \\
\text { Gas and loss } \ldots \ldots \ldots \ldots \ldots \\
\end{array}$ & $\begin{array}{r}1.56 \\
1.08 \\
15.63\end{array}$ & $\begin{array}{r}31.2 \\
21.6 \\
312.6\end{array}$ \\
\hline $\begin{array}{l}\text { Lubricating oil. } \\
\text { Paraffin wax...................... }\end{array}$ & $\begin{array}{r}1.77 \\
.30\end{array}$ & $\begin{array}{r}35.4 \\
6.0\end{array}$ & & 100.00 & $2,000.0$ \\
\hline
\end{tabular}

From 100 pounds of dry peat tar the same investigator reports the following as obtained by distillation:

Products of distillation from 100 pounds of dry peat tar.

\begin{tabular}{|c|c|c|c|c|c|}
\hline Substances. & Crude. & Purified. & Substances. & Crude. & Purified. \\
\hline 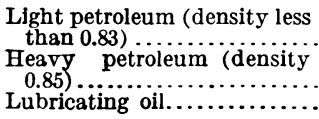 & $\begin{array}{r}\text { Pounds. } \\
16 \\
\\
30 \\
15\end{array}$ & $\begin{array}{r}\text { Pounds. } \\
12 \\
25 \\
15\end{array}$ & 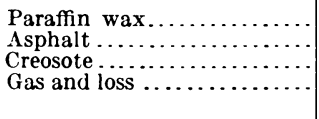 & $\begin{array}{c}12 \\
16 \\
11\end{array}$ & $\begin{array}{r}2 \\
16 \\
0 \\
23\end{array}$ \\
\hline
\end{tabular}

From 100 pounds of tar water there was also obtained:

Ammonium sulphate............................... 4.0

Methyl alcohol...................................... 2. 0

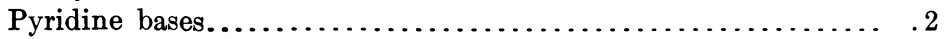

These figures, when reduced to pounds of the substances per short ton of peat ( 800 pounds of tar water can be obtained from a ton of peat), became:

Pounds.

Ammonium sulphate................................ 32.

Methyl alcohol..................................... 16.0

Pyridine bases ................................... 1.6

a Ryan, Hugh, Reports upon the Irish peat industries, pt. 2: Econ. Proc. Roy. Soc. Dublin, vol. I pt. 13, p. 516 . 
In addition, acetic acid can be recovered in the form of calcium or potassium acetate, equivalent to 12.6 pounds of the pure acid to a ton of dry peat.

The processes for the recovery of these compounds from the tar and the tar water have already been described, and although the necessary equipment is simple, the operations require high-priced supervision and skilled labor, as well as much heat from some cheap and convenient source. On account of the cost of these items and of maintaining the plant, very large quantities of crude materials must be treated to make profitable the recovery for commercial purposes of any or all of the substances mentioned as by-products.

Dr. Ziegler estimates that in actual practice in a well-equipped Ziegler plant, capable of coking 100 tons of air-dried machine peat each day of 24 hours, the total quantity and value of by-products will be as follows: $a$

Quantity and value of by-products from 100 tons of air-dried machine peat each day of 24 hours.

\begin{tabular}{|c|c|c|c|}
\hline Product. & Quantity. & Selling price per unit. & Value. \\
\hline 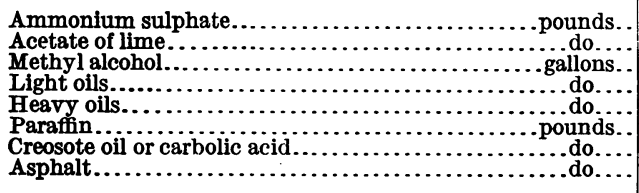 & $\begin{array}{r}900 \\
1,320 \\
65 \\
280 \\
95 \\
715 \\
3,100 \\
440\end{array}$ & $\begin{array}{r}\$ 3.07 \text { per } 100 \text { pounds... } \\
2.35 \text { per } 100 \text { pounds... } \\
.70 \text { per gallon........ } \\
.07 \frac{1}{2} \text { per gallon...... } \\
.07 \frac{1}{\text { per gallon...... }} \\
.03 \text { per pound....... } \\
.02 \frac{1}{\text { per per pound...... }} \\
.00 \frac{1}{2} \text { per pound...... }\end{array}$ & $\begin{array}{r}\$ 27.63 \\
31.02 \\
45.50 \\
21.00 \\
7.12 \\
26.81 \\
69.75 \\
2.20\end{array}$ \\
\hline educt $10 \mathrm{p}$ & & & $\begin{array}{r}231.03 \\
23.10\end{array}$ \\
\hline Total... & & & 207.93 \\
\hline
\end{tabular}

This total value of the by-products may be subtracted from the cost of producing the peat coke, which, after the deduction has been made, is given as $\$ 1.74$ to $\$ 3.05$, depending on the cost of producing the machine peat and delivering it to the coking retorts. The cost of making the coke includes all proper charges for plant, labor, maintenance, etc. As the price received for the best quality of peat coke in Germany ${ }^{b}$ is $\$ 13.20$ (55 marks), or even more, per ton, and for the poorer grades $\$ 6$ to $\$ 9$ (27 to 36 marks) per ton, the margin of profit for the investment of capital is excellent in that country, especially with large plants operated for the recovery of by-products. Whether the opportunities are as good in the United States, where there is a great iron industry and an active demand for the chemical substances made as by-products of peat-coke manufacturing, can be shown only by the actual development of a plant.

a Nystrom, E., Peat and lignite; their manufacture and uses in Europe, Can. Dept. Mines, Mines Branch, 1908, p. 186.

$b$ Nystrom, E., Peat and lignite; their manufacture and uses in Europe, Can. Dept. Mines, Mines Branch, 1908, p. 181. 
COST OF PLANT FOR MAKING PEAT COKE AND RECOVERING BY-PRODUCTs.

Each additional process adds to the initial expense of a plant, and it is to be expected that any system of coking peat will involve a large preliminary investment for retorts and other equipment, as well as for buildings, which must be larger and more substantial than those for briquetting in order to accommodate the apparatus necessary for conducting operations on a profitable scale.

The estimated cost of a four-oven plant built according to the plans of the Ziegler system and capable of coking 35,000 tons of air-dried peat per year, or about 100 tons of peat per day of 24 hours, is given by Dr. O. K. Zwingenberger, of New York, formerly agent for the United States for the company controlling the Ziegler patents, as $\$ 160,000$. Of this amount $\$ 100,000$ is for building and equipping the plant and the remainder for necessary working capital. The figures are based on American prices for materials and labor.

As only about one-third of the weight of the peat charged into the ovens is recovered as coke, or less than one-half if the main product is "half coke," a small plant, handling but a few thousand tons of air-dried peat in a year, would manifestly be operated at a disadvantage. Such a plant could hardly prove profitable, even if the by-products were all recovered and sold on the best possible basis, because as many costly operations and high-priced men are needed in a small plant as in a large one.

\section{MANUfACtURE OF PEAT COKE IN THE UNITED STATES.}

That peat coke would find a ready market in this country in the regions where iron ores are mined seems probable, however, as it could be profitably used there to produce high-grade charcoal iron. The manufacture of such iron is now carried on in northern Michigan and the adjacent regions at a great cost for the hardwood lumber that is converted into charcoal, although in the same territory, and especially in Minnesota, there are extensive beds of peat that have never been used for any purpose. There should also be a good market for the product as fuel in large cities and in parts of the country where anthracite is high-priced or unobtainable.

A single small plant making peat charcoal for fuel was in operation at New Haven, Conn., for several years, but the output was small and the quality of the original peat was poor, so that the product had only a small local market. Other systems for making peat coke have been advertised as originating in the United States, but so far as can be learned only one of them has yet actually been embodied in a working plant. A plant for making peat coke has been reported in operation in southern California, but no account of it has been received and no report can be made as to its operations. In fact, 
so far as is known at this writing, the Ziegler system is the only peat-coking system so far worked out in a full-sized plant that has operated successfully from a financial point of view, except that at Elizabethfehn, Germany, designed by Dr. W. Wielandt, of which no detailed description has been received.

Peat coke should be produced in the United States by a plant equipped for the recovery of by-products and handling 100 tons of air-dried machine peat per day, at a cost of from $\$ 3$ to $\$ 3.50$ per ton of coke, if the by-products are sold at current rates. Included in this estimate are fair charges for digging and air drying the peat, for machinery, and for all other charges that should be borne by the plant.

The price at which the coke can be sold will probably vary, according to the quality of the coke, the locality in which it is made, the purposes for which it is to be used, etc., but it should about equal that of charcoal, or $\$ 6$ to $\$ 12$ or more per ton. As the price of charcoal will continue to advance with the exhaustion of the available wood supply, there is a good prospect for an equivalent increase in the probable price of peat coke, because peat coke can be used not simply as a substitute for charcoal but, if of the best grade, as a superior article.

The experience gained by those who have attempted to make peat coke in Europe points clearly to the fact that the operation is not commercially successful unless the peat is of the best quality and the coking is conducted in such a way as to utilize the heat of the gases from the retorts for various purposes throughout the plant. If the coking is to be profitable the condensible distillates should be saved and made into a series of salable chemical by-products.

The amount of capital needed for developing a proper plant for making peat coke is so large that the investment is scarcely justified unless a preliminary attempt is made not only to find a market for the coke, but to learn where, in what quantities, and at what prices the by-products can be sold and, if possible, to have at least a part of the output sold conditionally.

\section{MANUFACTURE OF GAS FROM PEAT.}

\section{HISTORY.}

A few years ago it was predicted that with the rapid introduction of improvements in lighting by electricity the use of gas for illuminating purposes would decrease. Almost at the same time, however, came entirely new forms of gas burners, in which the light is derived from the incandescence of the oxides of certain rare metals, instead of from that of the carbon particles in the flame itself. In these burners the gas is completely burned and the oxides, in the form of a porous 
mantle, are intensely heated. Much less gas is used than with the old patterns of burners, and much more light is obtained. In addition the cost of gas was decreased by improved methods of manufacture, so that the price of gaslight, for the candlepower obtainable, became much cheaper than ever before.

Accompanying the improvements by which gas could be furnished to the consumer at lower prices came also the invention and popularizing of correctly designed burners, stoves, and other apparatus for using gas as a domestic fuel and for the generation of steam power. The convenience, cleanliness, and efficiency of the fuel more than offset its somewhat greater cost for these uses as compared with wood or coal at the prices that those fuels bring in many localities.

In still another direction there has been a great advance in the use of gaseous fuel. This advance has gone on so rapidly that only mechanical engineers especially interested in power development realize the rate at which the change is taking place. This is the development of engines in which the energy of the fuel is converted into power by its ignition and sudden expansion in the cylinders of the engines.

Besides these important advances in the use of gas, improvements in generators and gas producers, and investigation of the properties of gases derived from many kinds of fuel have demonstrated that gas can be profitably made from fuels that have long been regarded as practically worthless. With these improvements there have been modifications of the gas engine that make practicable the use of the poorest grades of producer gas. In view of all these facts, the possibility of using peat for the manufacture of gas becomes an important topic for investigation in regions where coal is not found and peat is abundant.

It has already been shown that gas of good quality is obtained when peat is heated in retorts and that this gas can be used for fuel and, after purification and enrichment, for lighting. Doubtless, also, it would without enrichment provide ample light if burned in incandescent types of burners.

\section{ILLUMINATING GAS.}

REQUIREMENTS FOR SUCCESSFUL PRODUCTION.

Excellent illuminating gas may be prepared from peat by distilling it in cast-iron retorts heated from the outside. To secure satisfactory commercial results, however, the retorts for making a given quantity of gas must be larger for peat than for coal, and the outlet pipes must be of larger diameter because the peat gives off large quantities of gas quickly; the condensing apparatus also must be more efficient than that required for coal gas, because of the greater proportion of watery and tarry products.

The distillation of peat for illuminating-gas manufacture must be carried on at a red heat, or higher, in order to decompose the heavier 
hydrocarbons into permanent gases that will furnish substances to brighten the flame when the gas is burned. To maintain this high temperature, the fire boxes of the retorts must be larger than for making gas from coal, and more fuel must be burned to continue the necessary decomposition of the tars.

If distillation is carried on at temperatures that are too low, the gas contains much carbon dioxide and gives a colorless flame when burned; the percentage of carbon dioxide may reach 25 to 30 per cent and even more if the peat used is not thoroughly dry when it is put into the retort. The evaporation of the water present lowers the temperature of the gases formed so much that the carbon dioxide developed is not decomposed.

\section{COMPOSITION.}

The composition of peat gas is reported to vary considerably, being dependent upon the temperature of distillation, the character of the peat, the quantity of water in the peat, and the method of distilling.

Ryan ${ }^{a}$ gives the following tables as indicating the average composition of peat gas:

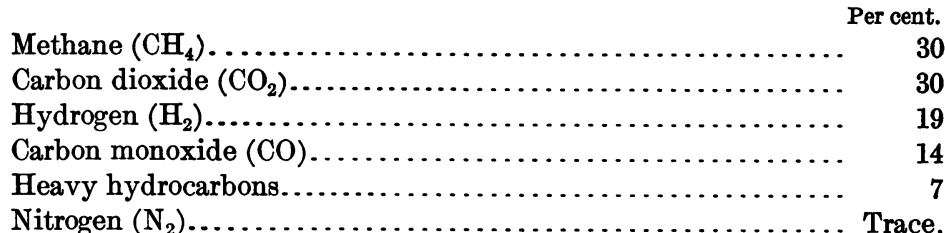

The gas after it has been purified by the removal of the carbon dioxide shows the following composition:

Methane $\left(\mathrm{CH}_{4}\right)$

Per cent.

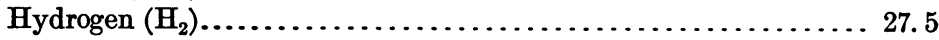

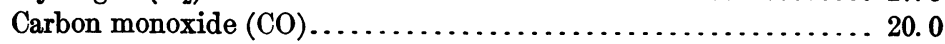

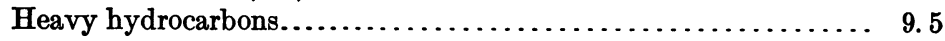

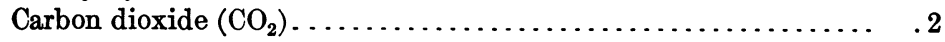

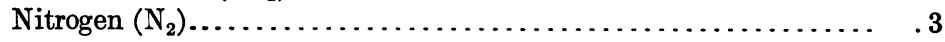

The carbon dioxide is removed by slaked lime, and the necessity of using a large quantity of lime, compared with what is necessary for coal gas, has operated against the use of peat as a source of illuminating gas.

Peat gas may also contain sulphur compounds and considerable ammonia, the proportion of the former depends upon the proportion of sulphur in the peat, and of the latter upon the percentage of combined nitrogen in the peat and the temperature at which distillation is carried on. The proportion of nitrogen that combines with hydrogen to form ammonia is much larger at low than at high temperatures.

a Ryan, Hugh, Reports upon the Irish peat industries, Pt. II: Econ. Proc. Roy. Soc., Dublin, vol. 1, pt. 13, pp. 520-521. 
The quantity of sulphur compounds in gas distilled from fresh-water peat will nearly always be considerably lower than in coal gas, because such peat contains less sulphur than coal; but peat that has been subjected to the action of salt water is likely to have a relatively high percentage of sulphur, and this will appear in the gas derived from it.

\section{QUANTITY OF GAS PER UNIT OF PEAT.}

The yield of gas from a pound of peat in a given time is reported to be greater than that obtainable from a pound of coal in the same time, so that fewer retorts are needed for a stated production of gas. The volume of gas obtainable from good, properly dried peat by the use of well-designed and well-constructed retorts and of temperatures high enough to decompose the tars, is almost equal to that yielded by English cannel coals under equally good conditions, the peat giving from 8,900 to 10,400 cubic feet per ton of 2,000 pounds, and Newcastle coal giving about 11,400 cubic feet per ton.

Peat gas is heavier and denser than coal gas, hence it must be burned under greater pressure if coal-gas burners are used for it, or if burned without pressure the openings in the burners must be made larger to get as good results.

\section{CAUSES OF FAILURE IN PAST EXPERIMENTS.}

It is apparent from the facts recited that experimental runs with peat as a source of gas in retorts made for generating gas from coal, and by men familiar only with the manufacture of coal gas, would yield results of negative value and a very unsatisfactory product. The history of the attempted commercial use of peat for the production of illuminating gas on a large scale is principally a record of such attempts and of failures resulting from them. They have been carried on in Europe principally, but on a small scale attempts were made to use peat for illuminating-gas production in parts of New England, New York, and New Jersey about fifty years ago. The results were reported satisfactory, although, as the use of peat for the purpose was not continued, it seems probable that there was a technical failure, due, in part at least, to a lack of appreciation of the underlying principles as outlined above. From 1894 to 1896 peat gas was made at the works of the Cambridge Gaslight Company, Cambridge, Mass., under patents of W. F. Brown, but the process was finally abandoned on account of the cost and poor quality of the cut peat used.

\section{PRESENT STATUS OF GAS MANUFACTURE.}

The use of coal is so much more general now than when the experiments were made of which definite reports have given, that it would 
be difficult to secure their repetition. No localities where peat is now used as a source of illuminating gas in Europe are reported in the latest advices from the countries where such use has been attempted, so that it may be safely assumed that, in spite of the practicability of making illuminating gas from peat, it is not now used for the purpose on a commercial scale; that it might be so used in properly designed and constructed plants in regions remote from supplies of suitable coal and where peat is common is clearly indicated.

\section{WATER GAS.}

In recent years a type of gas known as water gas and enriched or carbureted water gas has been used extensively for illuminating purposes. This gas is obtained by bringing steam into contact with incandescent carbon in the form of coke. The steam is decomposed and its oxygen unites with the carbon to form carbon monoxide, leaving the hydrogen free. The mixture of carbon monoxide and hydrogen burns with an intensely hot but slightly luminous flame. To give this gas, which is nearly identical with the gas from some forms of gas producers, illuminating elements, the heavier hydrocarbons are added to it. A common method of enriching water gas is by injecting naphtha or gasoline into it. The enriched gas gives a bright flame of good candlepower. It is the type of illuminating gas supplied in many cities of the United States, as it can be made at much less cost than that obtained by the destructive distillation of coal. Peat, although used to make producer gas, does not seem to have been tested for making the carbureted water gas, but such use is evidently possible.

\section{FUEL GAS.}

Gas is now much used as a source of heat for power and other purposes, and is rapidly growing in favor for such uses, because of its high efficiency, cleanliness, and the ease and cheapness with which it is handled.

It is apparent from what has already been said regarding the quality and quantity of gas to be had as a by-product of peat distillation or of coking operations that the subject should prove attractive to the engineer seeking a cheap and unutilized fuel as a source of power and fuel gas. Moreover, it is known, from the unqualified statements of trustworthy, unprejudiced, and competent observers, that peat is being given a thorough trial for power-gas production in several European countries where there is an increasing need for fuel for manufacturing industries. In Sweden and Germany this use has passed to the commercial stage of development.

$$
661^{\circ}-\text { Bull. } 16-11-10
$$




\section{PRODUCER GAS.}

The generation of gas for burning under boilers and for direct use in gas engines places few of the limitations on the process or the gas that are inherent in the manufacture of gas for lighting. The main object is to get as much as possible of the heat energy from the original fuel in the form of inflammable gas, yield and uniform composition being more important than the thermal value to the unit of volume or the proportion of inert gas present. For these reasons the use of retorts has been abandoned as too costly for manufacturing gas for fuel and power purposes. In their place have been substituted gas producers in which the fuel elements of the combustibles, the carbon, both fixed and volatile, and the hydrogen are all used, the entire body of fuel being converted into permanent gas and ashes. The process of making gas in a gas producer differs from that of making illuminating gas in that a part of the fuel is burned inside of the producer to furnish the heat necessary for gasification and in that no fixed carbon or coke remains.

Used in this way there is a loss of fuel to the extent that heat units are required to bring about the chemical changes necessary to reduce the solid compounds of the fuel to permanent gases that have the power of combining with the oxygen of the air and thus developing heat. In the gasification of fuel in retorts the loss of heat units is even greater than in the gas producer.

The gas producer differs from a common furnace in that less oxygen is admitted to the combustion chamber and the fuel bed is thicker. In an ordinary furnace the effort is made to have the fuel elements take up all of the oxygen possible, and air is furnished in excess of the supply needed for complete combustion in order that the energy of the fuel may be converted rapidly into heat. In the gas producer only sufficient oxygen is supplied to completely satisfy enough of the carbon and hydrogen units of the fuel to convert the rest of it into permanent gases; in other words, in the gas producer the combustion of the greater part of the fuel is incomplete.

Producer gas, therefore, is obtained by gradually converting solid fuel to the gaseous state by the heat given off from the complete combustion of a part of the fuel. The character and composition of the resulting gas is quite variable, according to the kind of fuel and the type of gas producer used.

\section{DESCRIPTION OF GAS PRODUCER.}

The simplest form of gas producer for power-gas generation is a vertical cylinder of iron or masonry, lined with fire brick, having a grate near the bottom, an opening in the top for charging fuel, a smaller opening near the top for the outlet of the gas, and one near the bottom for the admission of air. Openings are also provided at 
various heights on the sides, through which the interior may be reached for poking the fuel bed, inspecting and cleaning the interior, making repairs, and removing ashes. To prevent the entrance of air except through the proper openings, which are covered by gastight doors, the bottom of the producer is placed in a shallow tank of water, into which the ashes and refuse fall, and the charging opening is generally a small chamber, guarded by gas-tight doors at the bottom and top, which prevents the escape of the gas and the ingress of air while the producer is being recharged.

SCRUBBERS AND REGENERATORS.

Simple gas producers such as described above furnish uncleansed gas, which contains so much dust and other foreign matter that it is unsatisfactory for use, especially in gas engines. Power-gas producers are therefore provided with apparatus for cleansing the gas, known as scrubbers, through which the gas passes after leaving the producer. The scrubber in its simplest form is a cylindrical chamber filled with some porous material like coke or shavings, which is kept constantly wet. The gas, in passing through this wet material, leaves behind most of the solid and liquid impurities it contains.

In addition to the scrubber, many gas producers have attachments for preheating the air admitted for combustion, so that it enters the fire at a temperature sufficiently high to prevent cooling of the fuel. Such attachments make use of the heat of the off-going gases, and are called regenerators.

\section{THEORY OF GAS FORMATION IN A GAS PRODUCER. ${ }^{a}$}

When such a gas producer as that described is in operation, there is at the bottom an inert layer of ashes to protect the grate. Above this layer is the part of the fuel bed where combustion is complete and the temperature highest. Still higher in the thick fuel bed is a zone of incandescent carbon or coke from which the volatile matter has already been driven; at the top is the layer of fuel most recently added, from which the heavier gases and volatile matters are being driven, or distilled, by the heat from below.

Clearly, the gas from the layer of complete combustion must pass up through the layers above it; if the combustion is properly regulated, all of the carbon of the fuel in the lowest layers will be converted into carbon dioxide as expressed by the chemical equation

$$
\mathrm{C}_{2}+2 \mathrm{O}_{2}=2 \mathrm{CO}_{2} \text {. }
$$

The nitrogen of the air used is inert, and hence is not taken into account in the equation. The carbon dioxide, on reaching the layer of

a For a more complete discussion of the theory of the formation of gas in gas producers, see Bull. 7, Bureau of Mines. 1911. $58 \mathrm{pp}$. 
incandescent coke, gives up a part of its oxygen to the hot carbon, converting each carbon molecule thus attacked into two molecules of carbon monoxide; at the same time two molecules of the carbon dioxide are reduced to carbon monoxide, according to the chemical equation

$$
2 \mathrm{CO}_{2}+\mathrm{C}_{2}=4 \mathrm{CO} \text {. }
$$

As all of the combustibles in the fuel at the bottom of the producer are united with oxygen, only the ash remains, and the residue of coke from the incandescent layer settles down or is poked down to be completely gasified.

If the fuel used in this way were charcoal or coke-that is, pure carbon and ash-the producer gas would be a mixture of carbon monoxide and nitrogen, the simplest form of producer gas obtainable. The high price of the purer carbonaceous fuels has led to the use of other fuels to furnish the carbon, and to the use of steam, an oxygen and hydrogen compound, to supply part of the oxygen needed in the gas producer. The gas resulting from the decomposition of the steam by the incandescent carbon is a mixture of carbon monoxide, hydrogen, and nitrogen, as shown by the following equation:

$$
\mathrm{C}_{2}+\mathrm{H}_{2} \mathrm{O}+\mathrm{CO}_{2}+x \mathrm{~N}=3 \mathrm{CO}+\mathrm{H}_{2}+x \mathrm{~N} \text {. }
$$

The nitrogen is merely a diluent, and the quantity in the gas depends upon the quantity of air used in proportion to that of steam.

The decomposition of the steam, however, requires much heat, and if too much steam is used the temperature is soon lowered below that at which the decomposition will go on. It is therefore necessary to keep the quantity of steam introduced small in proportion to the quantity of air used, or to turn the steam intermittently into the producer. It is evident that the gas thus generated is identical with water gas, except for the nitrogen present.

\section{TYPES OF GAS PRODUCERS.}

The form of producer in most general use for generating gas for the development of power, especially in gas engines, is that supplying gas directly to the engine, which draws the air and steam through the fuel bed by means of the suction stroke of the piston. The suction producer, as it is termed, has been largely restricted to the use of anthracite, coke, charcoal, and other fuels containing a low percentage of tarry compounds. When bituminous fuels are used these tarry compounds are likely to be carried over with the fixed gases into the engine and, condensing there, clog the valves, pipes, and other working parts, despite scrubbing apparatus. Recent improvements in methods of scrubbing, however, have so modified 
the older practice as to make the use of fuels rich in volatiles comparatively free from such accidents, and their use in the suction type of producer is increasing.

The pressure gas producer is so designed that the air and steam necessary to develop the gas are forced into the fuel bed under enough pressure to drive the gases generated through the fuel bed and scrubbing apparatus into a gas holder. The gas is thus generated independently of the piston stroke of the engine, and may be thoroughly cleansed of tars and ash before it is used. For this reason the pressure type of gas producer is well fitted for using bituminous coal, lignite, and peat. This type of producer was first used in this country to generate gas for fuel in connection with metallurgical operations, and later was adapted to the needs of large power plants, anthracite being until recently the fuel chiefly used. The down-draft or inverted-draft gas producer, in which the heavier products of distillation are all decomposed and changed into simple permanent gases, constitutes a third type and seems to be the one most successfully used in Europe for peat gasification. In power-gas producers of this type the heated gases, rich in vaporized hydrocarbons, tars, and heavy gases, are drawn by exhaust fans from the top of the producer, where they accumulate above the freshly added fuel, down through the fuel bed. In the fuel bed, by contact with the heated carbon, they are converted into carbon monoxide and hydrogen, which, after cleansing, can be either stored in receivers or used in engines.

The use of air-dried peat in the down-draft gas producer brought out the fact that the variable water content of the fuel made difficult the keeping of the fire in the proper place at the top of the fuel bed. This trouble has been obviated by the construction of the double-zone gas producer, in which fires are maintained at both the top and the bottom of the fuel bed, and the air blast is turned in at the top or the bottom as conditions require. The gas outlet is in the side of the generator, the gas produced being withdrawn from between the two combustion zones.

\section{USE OF PEAT IN GAS PRODUCERS IN EUROPE.}

The commercial use of peat in gas producers as a source of both fuel and power gas seems to be successful in Germany and Sweden, fuel gas made from peat having for many years been in use in metallurgical operations, in brick and glass making, and in lime burning.

Gas producers for making power gas from peat are now advertised by several manufacturers of gas engines in Europe, and, as has been previously noted, there seems to be no reasonable doubt that such producers are in successful commercial operation in the countries 
mentioned. New plants for utilizing this fuel are annually added to those already at work, and in 1910 it was reported that large electric power plants using peat for fuel in gas producers were running in Sweden, Germany, Italy, and England. ${ }^{a}$

\section{PRODUCER GAS COMPARED WITH OTHER COMMERCIAL GASES.}

Producer gas, as shown by the following table, is poor in the compounds giving illumination and comparatively rich in the inert gases, carbon dioxide and nitrogen. The presence of these diluents seems unavoidable, and reduces materially the number of heat units per cubic foot of the mixed gases.

Composition and heating value of commercial gases.

\begin{tabular}{|c|c|c|c|c|c|c|c|c|c|}
\hline Character of gas. & $\mathrm{H}_{2}$. & $\mathrm{CH}_{4}$. & $\mathrm{C}_{2} \mathrm{H}_{4}$. & $\mathrm{N}_{2}$. & co. & $\mathrm{O}_{2}$. & $\mathrm{CO}_{2}$. & $\begin{array}{l}\text { B.t.u. } \\
\text { per cu. } \\
\text { foot. }\end{array}$ & Authority. \\
\hline Natural gas(Pittsburgh) & 3.0 & 92.0 & 3.0 & 2.0 & & & & 978.0 & \\
\hline Oil gas...................... & 32.0 & 48.0 & 16.5 & 3.0 & & .5 & & 846.0 & \\
\hline Coal illum & 46.0 & 40.0 & 5.0 & 2.0 & 6.0 & .5 & .5 & 646.0 & Wyer, S. S., Treatise on \\
\hline Coke-oven gas............ & 50.0 & 36.0 & 4.0 & 2.0 & 6.0 &. .5 & 1.5 & 603.0 & producer gas and gas \\
\hline $\begin{array}{l}\text { Carbureted water gas... } \\
\text { Water gas. }\end{array}$ & 40.0 & 25.0 & 8.5 & 4.0 & 19.0 & .5 & 3.0 & 575.0 & producers, p. 50 . \\
\hline $\begin{array}{l}\text { Water gas...................... } \\
\text { Producer gas from }\end{array}$ & 48.0 & 2.0 & & 5.5 & 38.0 & .5 & 6.0 & & \\
\hline Anthracite coal..... & 20.0 & & & 49.5 & 25.0 & .5 & 5.0 & 144.0 & \\
\hline Coke.... & 11.1 & .2 & 1 & 57.5 & 21.9 & & 9.2 & 120.6 & U. S. G. S. Bull. 332, \\
\hline Bituminous coal.... & 15.6 & 1.9 & .4 & 52.0 & 20.9 & .0 & 9.2 & 156.1 & $\begin{array}{l}\text { U. S. G. S. Bull. 332, } \\
\text { p. } 452 \text {, average } 24-\text { day }\end{array}$ \\
\hline Do.. & 15.0 & 2.2 & .5 & 53.2 & 19.2 & & 9.9 & 151.0 & U. S. G. S. Bull. 332, \\
\hline Lignite.. & 15.4 & 2.6 & .4 & 51.8 & 18.8 & .2 & 10.8 & 154.8 & U. S. G. S. Bull. 332, \\
\hline Florida peat........ & 18.5 & 2.2 & .4 & 45.5 & 21.0 & & 12.4 & 175.2 & U. S. G. S. Bull. 322, \\
\hline Massachusetts peat. & 13.9 & 2.1 & & 51.0 & 22.5 & & 10.5 & 166.1 & U. S. G. S. Bull. 290, \\
\hline North Carolina peat. & 10.19 & .4 & .06 & 60.8 & 16.9 & .4 & 10.9 & 109.7 & 1 test down-draft pro- \\
\hline Swedish peat... & 8.5 & 4.4 & .5 & 53.7 & 26.0 & & 6.9 & & Kerr, W. A., Peat and \\
\hline Do.. & 6.3 & 5.6 & .9 & 57.6 & 10.0 & .5 & 9.7 & 132.0 & $\begin{array}{l}\text { Nystrom, E., Peat and } \\
\text { lignite, p. } 222 \text {, aver- } \\
\text { age } 10 \text { tests. }\end{array}$ \\
\hline Blast-furnace gas.. & 1.0 & & & 60.0 & 27.5 & & 11.5 & 91.0 & $\begin{array}{l}\text { Wyer, S. S., Treatise on } \\
\text { producer gas and gas } \\
\text { producers. }\end{array}$ \\
\hline
\end{tabular}

The value of these gases, when their energy is converted into power by means of properly designed and constructed gas engines, is not decreased in direct proportion to the decrease in the number of heat units, as would seem to be the case on inspection. Indeed, it was proven some years ago by the researches of Lencaushez and others that when used in correctly designed engines a very poor gas was nearly as efficient as a much richer one, the chief difference being that larger engines were required to develop the same horsepower with poor gas than with rich gas. Thus it is $\operatorname{stated}^{b}$ that 
a certain engine using ordinary coal or illuminating gas developed 80 horsepower, and with blast-furnace gas 67 horsepower, a difference of 16 per cent only, whereas the calorific values of the gases were about 600 British thermal units and 120 British thermal units, respectively, to the cubic foot, or a ratio of 5 to 1 . Wyer ${ }^{a}$ also points out the same fact, on the authority of one of the large manufacturers of gas engines. He states that "an engine that will develop 100 horsepower with natural gas will give only about 80 horsepower with producer gas, a loss of 20 per cent. With a 200-horsepower engine this loss will be about 15 per cent, and with sizes above 300 horsepower it would be about 10 per cent." He does not point out, however, that the calorific value of natural gas is 978 British thermal units per cubic foot and of producer gas from anthracite coal only 144 British thermal units per cubic foot, according to figures cited by him, or about one-seventh as great. Thus the loss in power is not at all commensurate with the relative heating values of the two kinds of gas, the poor gas being much more efficient than the rich one, even in an engine designed for using the better gas.

The principle brought out by these statements has been found to be of such general application that gas engineers confidently predict that the power gas of the near future will be producer gas having a heat value of about 100 British thermal units per cubic foot. The development of the power necessary for operating the great steelmaking and manufacturing plant at Gary, Ind., by means of gas engines using blast-furnace gas entirely, shows how certain is the trend in the direction of the use of gases of low thermal efficiency.

Producer gas was generated from many kinds of low-grade and refuse coals at the fuel-testing plants of the United States Geological Survey at St. Louis, Norfolk, and Pittsburgh, and in the reports ${ }^{b}$ of the operations of these plants will be found full accounts of the work done and the impressive and valuable results obtained.

VOLUME OF PRODUCER GAS OBTAINED FROM PEAT.

The quantity of producer gas to be obtained from peat is large, and depends, as has been stated, on the quality of the peat and the form of the producer. Thus, Kerr, ${ }^{c}$ quoting from R. Aakermann, states that in Sweden the quantity of gas generated from 100 kilograms (220.4 pounds) of peat was 252 cubic meters ( 8,900 cubic feet), or about 80,000 cubic feet per ton of 2,000 pounds. The composition of this gas is given in the preceding table. Nystrom, ${ }^{d}$ on the other

$a$ Wyer, S. S., Producer gas and gas producers, 2 d ed., 1907, p. 229.

$b$ U. S. Geol. Survey Bulls. Nos. 290 and 332; Prof. Paper No. 48. See also Bulls. Nos. 7, 9, and 13, Bureau of Mines.

c Kerr, W. A., Peat and its products, p. 84.

$d$ Nystrom, E., Peat and lignite; their manufacture and use in Europe: Canada Department of Mines Mines Branch, 1908, p. 227. 
hand, states that 48,000 cubic feet of gas were obtained per ton of water-free peat substance, the gas having a calorific value of 152 British thermal units per cubic foot. Ryan ${ }^{a}$ reports that 100 cubic yards of gas, with a calorific value of 150 British thermal units per cubic foot, were yielded by 100 pounds of peat containing 26 per cent of water, or 54,000 cubic feet per short ton, in a Koerting suction gas producer, and that a Ziegler pressure gas producer is capable of affording 180 cubic yards of producer gas, having a calorific value of 135 British thermal units per cubic foot, from 100 pounds of average peat, or 97,200 cubic feet per ton. These figures are incorporated in the following table for purposes of reference:

Yield and calorific value of producer gas per ton of peat.

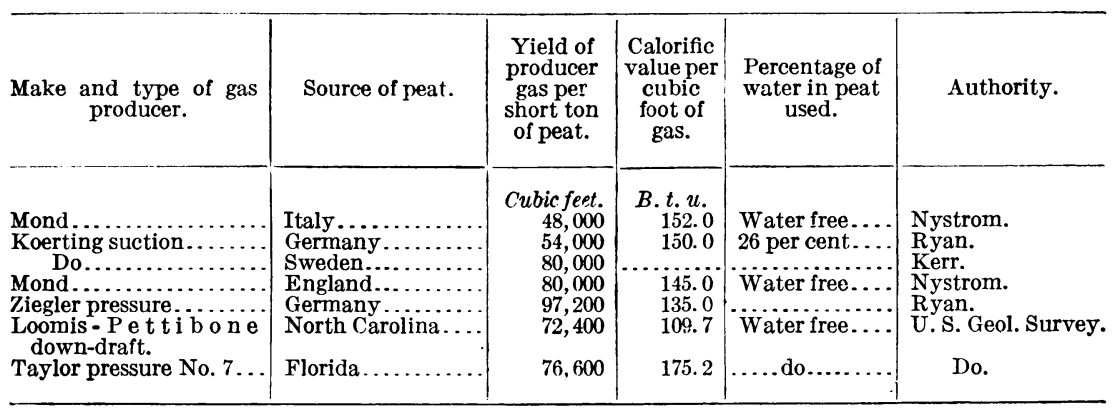

CALORIFIC VALUE OF PRODUCER GAS.

The calorific value of producer gas derived from peat is approximately the same as that from coal. Nystrom ${ }^{b}$ reports the following results of a number of carefully conducted tests made in different parts of Europe to find the calorific value per cubic foot of producer gas obtained from peat:

Calorific value of producer gas derived from European peat.

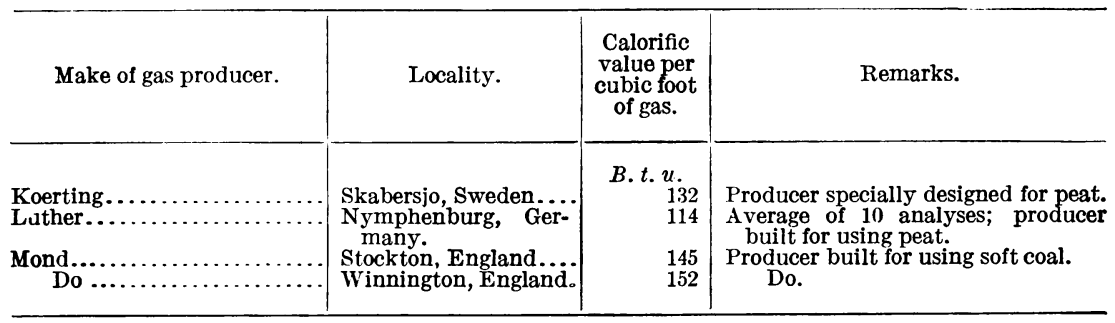

In the United States, records of only a small number of experiments with peat in gas producers are available, and seemingly very few such tests have been made. The two experimental runs made in

a Ryan, Hugh, Reports upon the Irish peat industries, Pt. II: Econ. Proc. Roy. Soc., Dublin, vol. 1, pt. 13 , pp. 524-526.

b Op. cit. 
1905 and 1906 at the fuel-testing plant of the United States Geological Survey at St. Louis, Mo., are of importance and interest not only because they were probably the first trials in this country of peat in a gas producer, but because they were made in a large pressure producer built to use anthracite. Unfortunately, in one of these tests the quantity of peat available was too small for a full test run, so that the results obtained must be considered incomplete.

In the first of these tests air-dried machine peat from near Halifax, Mass., was used. The average calorific value of the gas was 166 British thermal units per cubic foot. In the second test, of fifty hours' duration, air-dried machine peat from near Orlando, Fla., was used. The average calorific value of the gas was 175 British thermal units per cubic foot.

A third test was made in a down-draft producer designed for bituminous fuels, at the fuel-testing plant of the United States Geological Survey at Pittsburgh, in January, 1909, with air-dried machine peat from North Carolina. The average calorific value of the gas was 109.7 British thermal units per cubic foot, about the average value of the gas obtained from coal in this type of producer.

In order to show that these values are not materially different from those of producer gas developed from bituminous coal in the same gas producer and under the same test conditions, the first two values may be compared with those obtained from tests with this fuel made at the St. Louis fuel-testing plant during the same year.

Thermal value of producer gas made from bituminous coal.

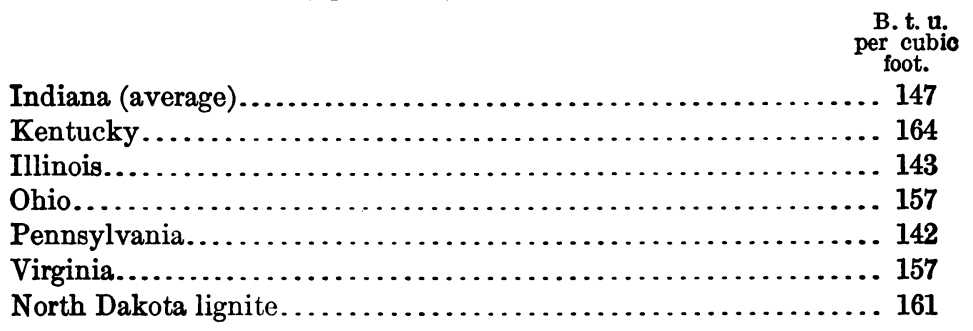

The calorific value per cubic foot of standard gas obtained from fifty-six producer-gas tests with bituminous coal, made from January 1, 1906, to March 1, 1907, with the same gas producer, were: ${ }^{a}$ Average, 151 British thermal units; maximum, 171.6 British thermal units; minimum, 122.5 British thermal units. From these results it is apparent that none of the coals gave as rich a producer gas as the Florida peat, and that the gas from the Massachusetts peat was better than the average of that made from the fifty-six samples of coal tested. 
It follows from these comparisons that the types of American peat and those of foreign peat here cited were as good fuel in the gas producer as the kinds of coal tested, so far as the calorific value of the gas is concerned.

Another significant fact brought out by the tests made by the United States Geological Survey was that the single full test run made with peat as fuel in the gas producer gave results that surpassed, in the horsepower developed, those obtained from the best of the kinds of coal used in boiler tests. The same results were obtained in the shorter run in which Massachusetts peat was used. That is, more power was developed from a ton of peat converted into producer gas and used in a gas engine than a ton of any kind of coal gave in the steam engine during the entire series of boiler tests conducted under standard test conditions.

Although too much emphasis must not be laid on the results of a single experimental run or on two tests, manifestly the value of peat as fuel is greatly increased by the use of a gas producer. In the two cases cited, under rigid test conditions in a gas producer designed for a very different sort of fuel, the peat, with a calorific value ratio to bituminous coal of $1: 1.8$, gave more power by being gasified and then used in a gas engine than an equal weight of coal did by being used under a boiler to generate steam for a steam engine.

GAS-PRODUCER TESTS BY THE UNITED STATES GEOLOGICAL SURVEY.

The following is an account of the method of proceaure in tests of peat as a source of producer gas in the only complete trial of this fuel yet made by the United States Geological Survey. The account includes, however, the results obtained from both Massachusetts and Florida samples.

MASSACHUSETTS NO. 1.

Peat briquets from a bog near Halifax, Plymouth County, Mass. They were furnished by Prof. C. L. Norton, of the Massachusetts Institute of Technology, Boston, Mass., and shipped under the supervision of Mr. J. S. Burrows. The sample consisted of a small amount (less than 5 tons) of peat which had been macerated and pressed into bricks and then dried, and it was impossible to run a test of sufficient length to eliminate the factor of uncertainty. It was demonstrated, however, that a satisfactory gas could be obtained and no trouble was experienced in manipulating the load, but owing to the small supply of peat it was necessary to make the foundation of the fuel bed out of another fuel-Illinois coal. Considering this fact, and that the amount of peat furnished made it possible to conduct a test of only nine hours' duration, it is possible that the results as given below are somewhat erroneous. The figures are given for what they are worth, as they furnish an approximate idea of the possibilities of peat fuel in the gas producer, although they can not be regarded as official results. It is impossible to tell exactly what portion of the gas was due to Illinois coal and what portion to the peat alone. 
The results of the tests of Massachusetts peat were as follows:

Producer-gas test-Test 97; Massachusetts No. 1.

A verage electrical horsepower 200.0

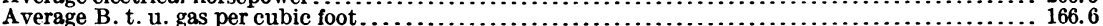

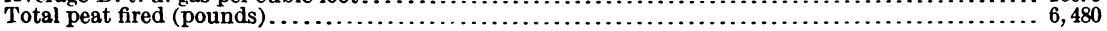

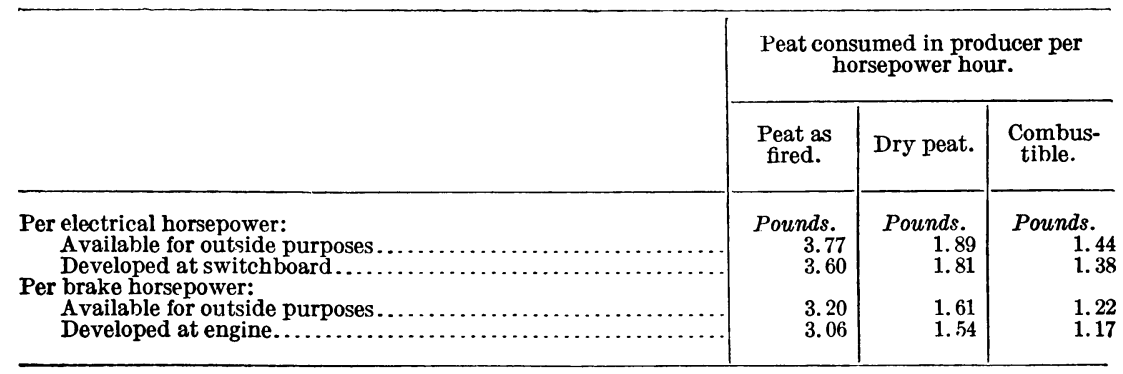

ANALYSES.

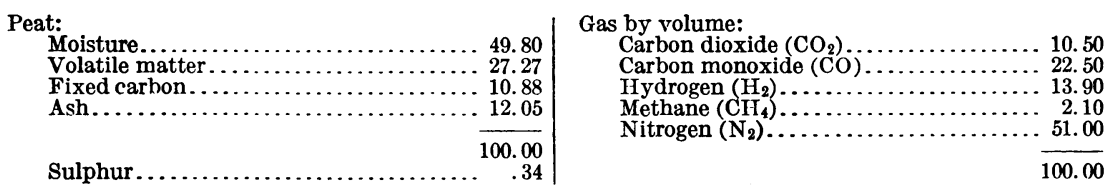

FIORIDA NO. 1.

In connection with this test of a small quantity of Massachusetts peat, it is deemed advisable to refer briefly to a more elaborate test of peat bricks obtained from a bog located near Orlando, Orange County, Fla., on the Seaboard Air Line Railway, and designated Florida No. 1. The following notes are from Bulletin 332 of the United States Geological Survey:

This sample consisted of machined peat, made by a commercial process and sun dried, and was used in steaming test 386 and producer-gas test 117. By the process mentioned the peat first passes through a condenser, which disintegrates the material and destroys the fiber. From the condenser the peat is elevated to a molding machine, consisting of a cylinder and two vertical molding wheels. Through the cylinder passes a vertical shaft, to which are attached revolving arms set in a screw form. Between these arms are set perforated plates. The peat, passing into the top of the cylinder, is forced down through the plates to the molding wheel. From the molding wheel the bricks, which are 8 by 4 by $2 \frac{1}{2}$ inches, are dropped on boards or pallets, which are being continuously pushed under the machine by a link-belt carrier. These pallets, containing 6 bricks each, are loaded on wagons 50 to the load, and are hauled to the drying ground, where the bricks are allowed to lose from 60 to 75 per cent of their moisture content. The peat was furnished by the Orlando Water \& Light Co.

Two samples were taken for analysis. Sample 3268 is raw peat just as it comes from the bog and sample 3269 is one of the bricks as it came from the machine before delivery to the drying ground. 
Chemical analyses of Florida No. 1.

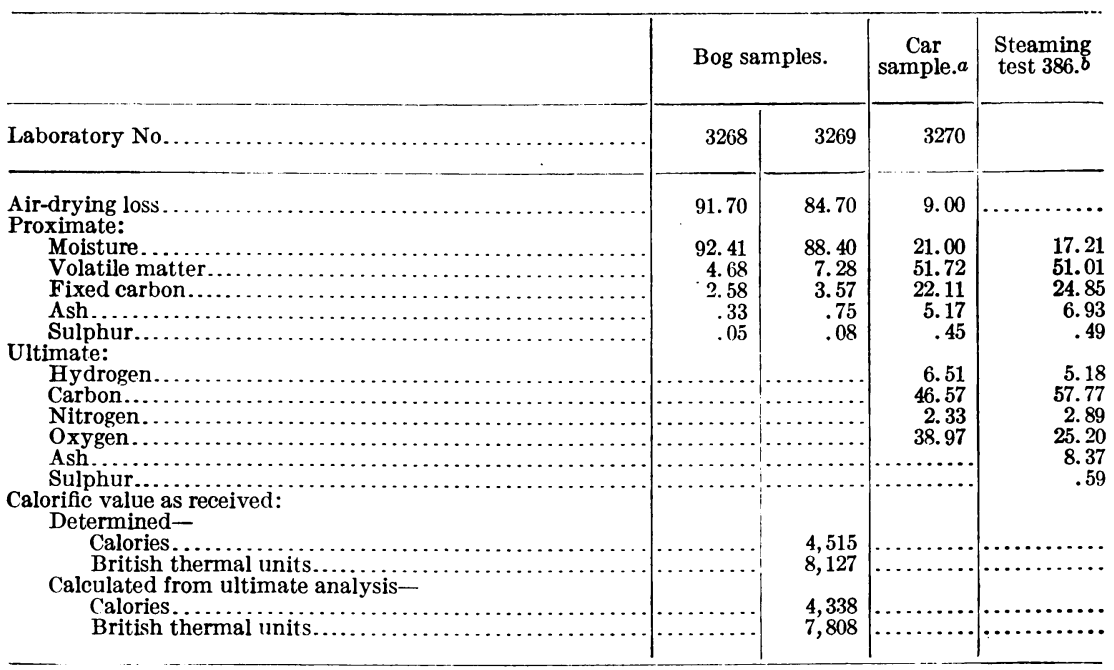

$a$ Figured from sample from producer-gas test 117.

$b$ Proximate analysis of fuel as fired; ultimate analysis of dry fuel figured from car sample.

In starting the producer-gas test (test 117) the fuel bed was built up entirely of the Florida peat and the usual preliminary run was conducted before the official test began. The total amount of peat consumed in the producer in the 50-hour run was 29,250 pounds, or 585 pounds per hour. The average calorific value of the gas produced was 175 British thermal units per cubic foot. During the entire run the average electrical horsepower developed at the switchboard was 205. The amount of peat used per electrical horsepower per hour available for outside purposes, including the estimated quantity required for the generation of the steam used in the operation of the producer, was 3.16 pounds, while 2.69 pounds were required per brake horsepower hour at the gas engine, available for outside purposes.

It should be stated that the peat bricks had been dried, and that the moisture content of those used averaged 21 per cent. The gas, as shown by the analysis, was rich in hydrogen and comparatively low in nitrogen. Following are the results of this test:

\section{Producer-gas test-Test 117; Florida No. 1.}

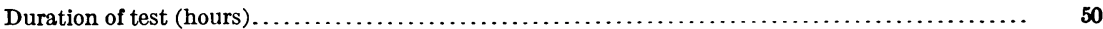

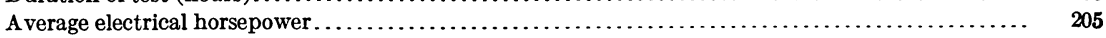

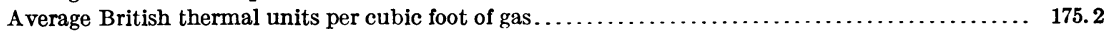

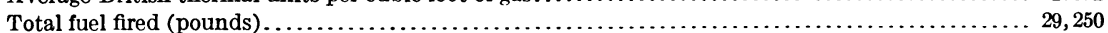

\begin{tabular}{|c|c|c|c|c|c|c|}
\hline & \multicolumn{3}{|c|}{$\begin{array}{l}\text { Peat consumed in producer } \\
\text { per horsepower hour. }\end{array}$} & \multicolumn{3}{|c|}{$\begin{array}{l}\text { Equivalent used by producer } \\
\text { plant. }\end{array}$} \\
\hline & $\begin{array}{l}\text { Peat as } \\
\text { fired. }\end{array}$ & $\begin{array}{l}\text { Dry } \\
\text { peat. }\end{array}$ & $\begin{array}{c}\text { Combus- } \\
\text { tible. }\end{array}$ & $\begin{array}{l}\text { Peat as } \\
\text { fired. }\end{array}$ & $\begin{array}{l}\text { Dry } \\
\text { peat. }\end{array}$ & $\begin{array}{c}\text { Combus- } \\
\text { tible. }\end{array}$ \\
\hline $\begin{array}{l}\text { Per electrical horsepower: } \\
\text { Commercially available...... } \\
\text { Developed at switchboard... } \\
\text { Per brake horsepower: }\end{array}$ & $\begin{array}{r}\text { Pounds. } \\
2.98 \\
2.85\end{array}$ & $\begin{array}{r}\text { Pounds. } \\
2.35 \\
2.25\end{array}$ & $\begin{array}{r}\text { Pounds. } \\
2.20 \\
2.11\end{array}$ & $\begin{array}{r}\text { Pounds. } \\
3.16 \\
3.03\end{array}$ & $\begin{array}{r}\text { Pounds. } \\
2.50 \\
2.39\end{array}$ & $\begin{array}{r}\text { Pounds. } \\
2.33 \\
2.24\end{array}$ \\
\hline $\begin{array}{l}\text { Per brake horsepower: } \\
\text { Commercially available...... } \\
\text { Developed at engine ........... }\end{array}$ & $\begin{array}{l}2.53 \\
2.43\end{array}$ & $\begin{array}{l}2.00 \\
1.92\end{array}$ & $\begin{array}{l}1.87 \\
1.79\end{array}$ & $\begin{array}{l}2.69 \\
2.57\end{array}$ & $\begin{array}{l}2.12 \\
2.03\end{array}$ & $\begin{array}{l}1.98 \\
1.90\end{array}$ \\
\hline
\end{tabular}


Carbon dioxide $\left(\mathrm{CO}_{2}\right)$.

Carbon monoxide (CO)

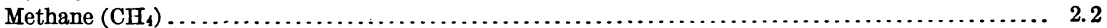

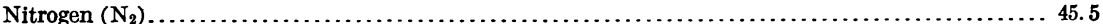

Ethylene $\left(\mathrm{C}_{2} \mathrm{H}_{4}\right)$.

From these reports and from others of a similar nature, based upon much more extended trials in Europe, the ideal way in which to utilize peat for the generation of power would appear to be to convert it into gas in some of the types of gas producers that have been adapted to the purpose and to use this in properly designed gas engines.

\section{PEAT AS FUEL IN THE GAS PRODUCER.}

Wet, unprepared peat is difficult material to handle in a gas producer, first, because it contains so much water that the temperature of a mass of it can with difficulty be raised high enough to generate a fuel gas without consuming more fuel than is warranted by the results, and, secondly, because the raw peat tends to form dense, impenetrable layers in the fuel bed of the producer, through which the gases generated can scarcely find their way.

On these accounts the feasibility of trying to use raw peat in existing types of gas producers, except in a purely experimental way, is doubtful. For elementary experiments, successful gas production will be much more probable if the peat is machined, formed into small bricks, thoroughly air dried, crushed into pieces with an average diameter of 1 inch, and then used in a down-draft or pressure gas producer, although a suction producer with centrifugal tar extractor might be successfully used. It does not seem to be essential to have the pieces of regular form, nor is it desirable to have them more than an inch or two in largest dimension. Experience shows that if the pieces are too large the gas passes through the fuel bed too rapidly for the carbon dioxide to be decomposed; but with usual forms of gas producers very unsatisfactory results will be obtained by using the peat in a powdery condition.

There seems little doubt that some of the heat of the off-going gas can be utilized for drying the peat, and also that peat with a higher percentage of water than the air-dry state may be successfully used in gas producers of the type in which an excess of steam under pressure is used, such as the Mond producers of the Power-Gas Corporation (Ltd.), of Stockton-on-Tees, England. This company announces that peat containing 60 to 70 per cent water can be utilized by their process, and that there are three large installations already in operation, one in England, one in Italy, and one in Germany. The Mond gas producer has been modified by Frank \& Caro, and by them it is claimed that peat with 40 to 60 per cent water may be used for fuel. 
The use of the heat of the producer gas to partially dry the peat, although possible, must be carried on in such a way that the process is automatic and continuous, and that the water driven off does not accumulate in undesirable places. Many suggestions and designs of machinery for this purpose have been made, but the present European practice seems to be to adhere to the use of crushed airdried machine peat.

The gas from peat gasified in ordinary gas producers contains much tar which should be removed in a tower scrubber with a spray of water, or in some of the more recently perfected types of scrubbers, because coke and other porous material used in ordinary scrubbers soon become saturated. The tar may all be decomposed, however, by using a down-draft producer, or as in the Koerting gas producer, by drawing the gases off at the top and conducting them by a special pipe to the zone of complete combustion, and thence up through the fuel bed. In such a producer the outlet for the producer gas is placed in the side of the producer at about the top of the incandescent layer.

\section{COST OF GAS-PRODUCER POWER PLANTS.}

For the following carefully prepared tables of cost of gas producers, producer-gas engines, and complete gas-producer power plants, the writer is indebted to R. H. Fernald, engineer of the Bureau of Mines, who had charge of the producer-gas investigations of the United States Geological Survey.

The following table gives the approximate price of suction, pressure, and down-draft gas producers of from 20 to 2,000 horsepower.

Approximate cost of suction, pressure, and down-druft gas producers of 20 to 2,000 horsepower.

\begin{tabular}{|c|c|c|c|c|c|c|c|}
\hline \multirow{2}{*}{$\begin{array}{l}\text { Horse- } \\
\text { power. }\end{array}$} & \multirow{2}{*}{$\begin{array}{l}\text { Cost of en- } \\
\text { gine and } \\
\text { auxiliaries } \\
\text { f. o. b. }\end{array}$} & \multirow{2}{*}{$\begin{array}{l}\text { Cost of } \\
\text { erection. }\end{array}$} & \multicolumn{2}{|c|}{ Foundation. } & \multirow{2}{*}{$\begin{array}{l}\text { Total cost } \\
\text { erected. }\end{array}$} & \multicolumn{2}{|c|}{ Cost per horsepower. } \\
\hline & & & $\begin{array}{l}\text { Cubic } \\
\text { feet. }\end{array}$ & Cost. & & F.o.b. & Total. \\
\hline 20 & & & & & $\$ 923$ & & $\$ 46.23$ \\
\hline 23 & $\cdots \cdots$ & & $\cdots$ & $\cdots \cdots$ & 1,050 & $\cdots$ & 42.00 \\
\hline 25 & $\begin{array}{r}\$ 650 \\
800\end{array}$ & & & & …... & $\begin{array}{r}\$ 26.00 \\
22.80\end{array}$ & $\cdots \cdots \cdots$ \\
\hline 50 & 1,000 & & & & & 20.00 & \\
\hline 60 & 1,360 & & & & & 22.70 & \\
\hline 60 & 1,100 & $\$ 150$ & 50 & $\$ 15$ & 1,265 & 18. 35 & 21. 10 \\
\hline 75 & 1,300 & $\cdots \cdot$ & & & & 17.35 & $\ldots \ldots \ldots \ldots$ \\
\hline 100 & 1,500 & $\ldots \ldots \ldots$ & - & & $\cdots$ & 15.00 & $\cdots$ \\
\hline 110 & 1,650 & & & & & 15.00 & $\cdots$ \\
\hline $\begin{array}{l}110 \\
150\end{array}$ & $\ddot{1}, \ddot{850}$ & & & & 1,900 & - & 16.30 \\
\hline 160 & & & 40 & 120 & 3,300 & & 20.60 \\
\hline 200 & 2,450 & & & & $\ldots \ldots$ & 12.25 & $\ldots \ldots$ \\
\hline 200 & 2,500 & & & .. & ...... & 12.50 & $\ldots \ldots \ldots$ \\
\hline 250 & 3,000 & $\cdots \cdots$ & $\cdots$ & & 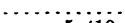 & 12.00 & $\because \cdots \cdots$ \\
\hline 300 & 4,300 & 960 & & 150 & 5,410 & 14.35 & 18.00 \\
\hline 1,000 & $\begin{array}{r}9,500 \\
18,300\end{array}$ & 3,100 & & & $\cdots \cdots$ & 18.30 & $\cdots \cdots$ \\
\hline 2,000 & 23,066 & 3,700 & 2,140 & 555 & 27,321 & 11.50 & 13.66 \\
\hline
\end{tabular}


The prices above are from quotations from various manufacturers, as is also true of the prices for the producer-gas engines below. It should be remembered that the cost of producer-gas engines is greater per rated power than the cost of engines of the same rating for natural or artificial gas.

Cost of producer-gas engines of 20 to 2,000 horsepower.

\begin{tabular}{|c|c|c|c|c|c|c|c|c|}
\hline \multirow[b]{2}{*}{$\begin{array}{l}\text { Horse- } \\
\text { power. }\end{array}$} & \multirow[b]{2}{*}{$\begin{array}{l}\text { Cost of en- } \\
\text { gine and } \\
\text { auxiliaries } \\
\text { f. } 0 . \text { b. }\end{array}$} & \multirow[b]{2}{*}{$\begin{array}{l}\text { Cost of } \\
\text { erection. }\end{array}$} & \multicolumn{2}{|c|}{ Foundation. } & \multirow[b]{2}{*}{$\begin{array}{c}\text { Total cost } \\
\text { erected. }\end{array}$} & \multicolumn{3}{|c|}{ Cost per horsepower. } \\
\hline & & & $\begin{array}{l}\text { Cubic } \\
\text { feet. }\end{array}$ & Cost. & & F.o.b. & $\begin{array}{l}\text { Erected, } \\
\text { excluding } \\
\text { founda- } \\
\text { tion. }\end{array}$ & $\begin{array}{l}\text { Erected, } \\
\text { including } \\
\text { founda- } \\
\text { tion. }\end{array}$ \\
\hline 20 & $\$ 1,100$ & $\cdots$ & & $\$ 50$ & $\$ 1,150$ & $\$ 55.00$ & & \\
\hline 55 & $\cdots \cdots$ & & 350 & ........... & 2,400 & …...... & & $\$ 43.70$ \\
\hline $\begin{array}{l}60 \\
60\end{array}$ & $\begin{array}{l}2,800 \\
2,900\end{array}$ & $\begin{array}{l}\ldots \ldots \\
\cdots \ldots\end{array}$ & 350 & $\begin{array}{l}105 \\
150\end{array}$ & $\begin{array}{l}\ldots \ldots \\
\cdots\end{array}$ & $\begin{array}{l}46.70 \\
48.40\end{array}$ & & $\cdots \cdots$ \\
\hline 75 & 3,610 & $\$ 175$ & 375 & 150 & 3,935 & 48.10 & $\$ 50.50$ & 52.40 \\
\hline $\begin{array}{l}80 \\
80\end{array}$ & 3,400 & $\cdots \cdots \cdots$ & $\cdots \cdot$ & $\cdots$ & 3,300 & 42 5 & $\ldots \ldots \ldots$ & 41.20 \\
\hline $\begin{array}{l}80 \\
80\end{array}$ & 3,250 & & & & $\mid \begin{array}{l}\cdots \\
\cdots \ldots \ldots\end{array}$ & $\begin{array}{l}42.50 \\
40.70\end{array}$ & & \\
\hline 80 & 3,830 & $\ldots$ & & & & 47.90 & $\ldots$ & \\
\hline 85 & 4,150 & $\cdots$ & & & $\ldots$. & 48.90 & $\ldots$ & ........ \\
\hline 85 & 3,550 & $\ldots$. & & & $\cdots$ & 41.80 & $\ldots$. & $\ldots \ldots$ \\
\hline 100 & 4,925 & & & & & 49.25 & ... & $\ldots \ldots$ \\
\hline 110 & 4,950 & & & 225 & & 45.00 & & $\ldots$ \\
\hline 110 & 4,960 & & & & & 45. 10 & $\ldots$ & ... \\
\hline 112 & 4,200 & & & & & 37.50 & $\ldots$ & ... \\
\hline 130 & 5,250 & & & ... & $\cdots \cdots$ & 40.40 & ........... & .... \\
\hline 135 & 6,600 & & & $\cdots$ & n........ & 48.80 & ........... & ........ \\
\hline 160 & 5,600 & $\because \because$ & & & …...... & 35.00 & 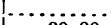 & $\cdots \cdots$ \\
\hline 160 & 6,100 & 150 & 2,000 & 520 & 6,770 & 38.10 & 39.00 & 42.30 \\
\hline 250 & 6,650 & 150 & 2,160 & 560 & 7,360 & 26.60 & 27.20 & 29.40 \\
\hline 400 & 12,000 & $\ldots \ldots \ldots$ & & $\cdots \cdot$ & $\ldots \ldots$ & 30.00 & $\begin{array}{lll}\cdots & \ldots\end{array}$ & . . . . . . . \\
\hline 400 & 12,800 & & & & $\cdots$ & 32.00 & $\ldots \ldots$ & $\ldots \ldots$ \\
\hline $\begin{array}{r}600 \\
1,000\end{array}$ & $\begin{array}{l}17,400 \\
33,750\end{array}$ & 300 & & & & $\begin{array}{l}29.00 \\
33.75\end{array}$ & 3400 & $\ldots$ \\
\hline 2,000 & 64,850 & 875 & 5,400 & 1,400 & 67,125 & 32.43 & 32.86 & 33.56 \\
\hline
\end{tabular}

Weight of producer gas-engines per horsepower: Average, 300 pounds; maximum, 425 pounds; minimum 134 pounds.

Cost per horsepower of producer-gas installations.

\begin{tabular}{|c|c|c|c|c|}
\hline \multirow{2}{*}{$\begin{array}{l}\text { Horse- } \\
\text { power. }\end{array}$} & \multicolumn{2}{|c|}{$\begin{array}{l}\text { Cost of gas producer } \\
\text { and engine. }\end{array}$} & \multicolumn{2}{|c|}{$\begin{array}{c}\text { Cost of complete } \\
\text { plant. }\end{array}$} \\
\hline & $\begin{array}{l}\text { Erected, } \\
\text { excluding } \\
\text { founda- } \\
\text { tions. }\end{array}$ & $\begin{array}{l}\text { Erected, } \\
\text { including } \\
\text { founda- } \\
\text { tions. }\end{array}$ & $\begin{array}{l}\text { Excluding } \\
\text { buildings.a }\end{array}$ & $\begin{array}{l}\text { Including } \\
\text { buildings. }\end{array}$ \\
\hline $\begin{array}{r}20 \\
25 \\
60 \\
75 \\
80 \\
110 \\
110 \\
125 \\
250 \\
500 \\
1,000 \\
2,000 \\
2,800 \\
4,000 \\
4,000 \\
4,800 \\
4,800 \\
5,500\end{array}$ & 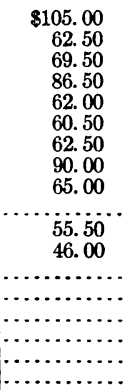 & 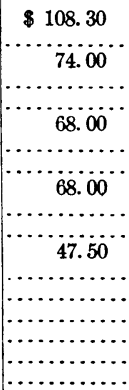 & 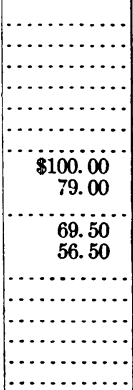 & 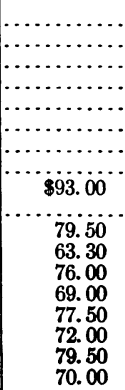 \\
\hline
\end{tabular}

$a$ Includes producer, engine, electric generator, and auxiliaries, all erected with suitable foundations. 
From the above it will be seen that the cost of a complete installation, with gas producers and producer-gas engines, is still somewhat more per horsepower than with boilers and steam engines, but seemingly the differences are decreasing. On the other hand, the cost of operating and maintaining a producer-gas plant is considerably less than for the steam plant of the same capacity, because the efficiency of the fuel is greater in the former. Less fuel and the ability to use the cheapest grades reduce the fuel bills, and labor charges are lower because less firing is needed, so that operating expenses may be decreased about 50 per cent. ${ }^{a}$

The chief matter of concern now is so to modify the types of gas producers used in this country that peat may be burned in them as successfully as in those used in Europe; the process of making producer gas is old and established, and engines for using the gas are already developed to a high state of efficiency and reliability.

\section{BY-PRODUCT GAS PRODUCERS.}

In Europe, where conservation and efficient utilization of natural resources have been practiced for many years, attention has been turned to the recovery of commercially valuable substances from the gases generated in gas producers and other apparatus for gasifying fuel without impairing the heat value of the gas, or of the other chief product of the distillation-for example, coke-if gas is not sought. Such secondary products are called by-products, and their recovery in charcoal, coke-making, or producer-gas plants may be of sufficient commercial importance to warrant the building of expensive equipment. The by-products obtained and obtainable depend upon the composition of the fuel distilled and the processes used to make the primary product, as well as upon the temperature at which gasification is carried on.

In general, it may be said that only three systems of by-product gas producers have been tried in Europe, two of which are still experimental. The Mond by-product gas producer for using bituminous coal is the oldest of these. This is designed to recover as ammonium sulphate a maximum proportion of the combined nitrogen in the fuel used. Ammonium sulphate, which finds a ready market for agricultural use is recovered in the producer by using large quantities of steam to keep the fuel at the lowest temperature at which the fuel gases can be given off. The ammonia was formerly made to unite with sulphuric acid in a special scrubbing tower, through which the gases from the gas producers were drawn by exhaust fans. The sulphuric acid towers have been entirely eliminated in the latest form of plant for recovering ammonia from Mond gas producers. The gas on 
leaving the producer is cooled somewhat by passing through a tubular regenerator into a rectangular washing chamber. There it is washed with water in the form of a fine spray and freed from dust and part of the contained tar. The cleansed gas then flows through an apparatus in which the ammonia in the gas combines with sulphuric acid to form ammonium sulphate; this, in dilute solution, is withdrawn periodically.

This form of gas producer is said to be successful for large plants, and is in operation in many places in England and in one (Wyandotte, Mich.) in the United States. The other two by-product gas producers are the Ziegler and the Frank-Caro, both designed for using peat. The Ziegler gas producer recovers other substances besides ammonium sulphate, whereas the Frank-Caro gas producer is reported to be an adaptation of the principle of the Mond gas producer for using peat with a relatively high percentage of water, 40 to 60 per cent being allowable.

In the case of the Mond gas producer, large installations, at least 2,000 horsepower, are required to make economically possible the operation of the special peat gas producers for the recovery of ammonia, and plants developing 1,000 horsepower or more are mentioned as necessary to make the Frank-Caro process of ammonia recovery a commercial success. Therefore it seems probable that, as at present understood, the peat gas producer for ordinary power plants does not yield enough salable by-products to make their recovery in a special plant feasible, although the peat may run high in combined nitrogen. But small gas producers for using peat fuel are entirely practicable if no attempt is made to recover by-products from the gas.

PEAT REQUIRED FOR PRODUCING A UNIT OF POWER IN THE GAS PRODUCER.

The available records of experiments with peat in gas producers and of authentic statements of commercial operations show that it requires from 2 to 3 pounds of dry peat to develop an electrical horsepower per hour, the exact quantity being dependent, among other things, upon the type of gas producer, the efficiency of the producergas engine, and the quality and amount of moisture and ash in the peat used.

In one test run, the details of which are not available for publication, the peat as put into the gas producer contained 27.8 per cent ash and 13.9 per cent moisture, yet only 4.11 pounds were consumed per hour for each commercially available electrical horsepower, or 3.5 pounds estimated as dry fuel. Stated in another way, 2 tons of airdried machine peat of a grade too high in ash to be considered within the limits of ordinary commercial use for boiler fuel would run a $661^{\circ}-$ Bull. $16=11-11$ 
100-horsepower plant for one 10-hour day, if the gas produced were used in a gas engine designed for this kind of gas. It may be said that the experiment cited was conducted under rigid test conditions, and although, because of probable and uncertain impoverishment of the gas through leakage, the details of the run can not be published, the figures quoted may be taken as the maximum for this type of producer and fuel.

\section{UTIIIZATION OF PRODUCER GAS FROM PEAT.}

Mention has been made of the use in European countries of producer gas as a fuel in certain industries. The energy of the peat may be economically and satisfactorily utilized as gas by using the proper forms of burners for firing ${ }^{a}$ steam boilers, ceramic kilns (brick, tile pottery, etc.), lime and cement kilns, metallurgical furnaces (forges, foundries, steel and ore roasters), and muffle and glass furnaces.

Peat fuel properly prepared is especially valuable for metallurgical work of all sorts, because it contains less sulphur than coal or coke. The same may be said of the gas derived from peat. However, beds of peat that have been subjected to the action of salt or brackish water, or to certain kinds of spring water, are exceptions to the general rule. These may have as much sulphur as many kinds of coal, and at least a part of the sulphur will appear in producer gas generated from such peat.

Gas producers for fuel gas are usually of the pressure type. The special use for which the gas is required should determine the form of the producer and the kind of scrubbing apparatus employed. The form of the producer and the scrubber must also be adapted to meet the peculiarities of peat if this substance is to be used for making fuel gas. In some cases where producer gas is required as fuel, no cleansing would be required, but the gas would be conducted directly from the producer to the burners. The form of the furnaces or kilns in which the use of peat gas is proposed and the manner of firing them will have to be adapted to the requirements of the product and of a gaseous fuel. Moreover, workmen must be trained specially in order to get the best practical results.

In general, it may be said that the attempt to develop plants for utilizing gas for fuel should be left to trained experts in gas engineering and to concerns with large capital, as much well-planned and carefully conducted experimental work will usually be needed before anything like the theoretical efficiency is obtained in actual practice from such processes and the plants using them. It should be said, however, that all or nearly all of the uses suggested as possible for producer gas as fuel have been tried on a commercial scale, and are 
embodied in plants now in operation in the United States or Europe. There seems to be no doubt, also, in view of the facts already stated, that a good quality of producer gas can be cheaply made from peat for any of these purposes, if properly designed and well-constructed gas producers are used at a place where a supply of peat is available.

\section{GENERAL CONCLUSIONS ON PEAT FUEL.}

FUEL VALUE.

The fuel value of peat as compared with that of coal and wood for firing boilers, furnaces, and stoves has already been discussed at length (pp. 52-64). The facts presented would seem to demonstrate that although plainly inferior to the best coal in the number of heat units yielded per pound consumed, nevertheless, if prepared in the ways commonly used in Europe peat fuel presents so many desirable qualities, such as freedom from smoke, cleanliness in handling, small ash content, complete and easily controlled combustion, and prospective low price, that there should be a good field for its introduction for manufacturing and domestic uses in those parts of the United States where peat naturally occurs in abundance.

\section{VTIIIZATION OF DEPOSITS.}

There are many small bogs in the peat-bearing regions of the country which, although too small to warrant the establishment of large plants for the production of fuel, could be utilized to furnish machine peat enough for boiler fuel for a single small factory for many years. They might also furnish the power to pump water and generate electricity for a small community for an equal length of time.

The principal matter to be borne in mind in preparing to exploit a peat deposit in such a way is that the simplest equipment which has proved it can yield the desired quantity of usable or salable fuel is the one most likely to give satisfactory returns either in fuel or money. Every added process of treatment beyond that which is necessary to put the peat into usable form for a specific purpose adds many times to the first cost of equipment and to the practical difficulties of making a product that can be sold for enough to pay the costs of preparation and of putting it on the market at a profit.

\section{PRODUCER-GAS PLANTS.}

The present state of knowledge seems strongly to indicate that large peat deposits can be most profitably utilized, and the largest percentage of the stored-up energy in them recovered as power, by converting the peat into producer gas and using this gas in properly 
designed gas engines. The power may be used by factories operated on the spot, or as electric energy may be used at a distance. Large plants, by using by-product gas producers and thus at least recovering as ammonium sulphate the ammonia that is formed during the destructive distillation of the peat, may be able from sales of the sulphate to pay a part of the expenses of the whole operation The by-products process, however, may not be feasible for gasproducer plants of small size, because the costs of installation, maintenance, and supervision are proportionately higher for small than for large plants, and the quantity of by-products obtainable from a small gas producer is not sufficient to keep a recovery plant in operation continuously.

Even without any by-products the use of producer gas presents so many advantages that wherever peat beds are to be used as sources of fuel for power installations of more than 100 horsepower, the possibilities of a producer-gas plant should be given serious consideration.

The producer-gas plant may also be readily adapted to metallurgical work, to firing kilns for brick, porcelain, lime, and probably for cement manufacturing. It might have a large use in roasting ores and, in a smaller way, in foundries and other iron-working plants, and in reheating and refining steel, copper, and other metals when fuel free from sulphur is required.

Even for boiler plants that could use peat fuel, a gas producer would be a most desirable adjunct, as it would permit the use of peat less carefully prepared and containing more water, and the economy would be greater than in any other way of firing.

\section{PEAT POWDER.}

Next to producer gas, peat powder is the most attractive form of fuel for firing boiler furnaces, for operating kilns of various sorts, and for the metallurgical operations mentioned. This form of peat fuel has not yet been so generally used in Europe as has producer gas, and not as much has been demonstrated commercially in regard to its value. The most recent reports are very favorable and indicate that peat powder can be cheaply produced and is as good fuel for boiler firing when properly prepared and fired as the same weight of good English coal.

\section{DOMESTIC USES.}

The steadiest and, in the aggregate, the greatest demand for peat fuel may be expected to come from small consumers who want a clean, easily handled, and cheap fuel that gives out a steady heat and yet responds quickly to changes of draft when burned in ordinary 
heating and cooking stoves. Doubtless in this way, as a supplementary and auxiliary fuel, much of the peat that is gathered for fuel will be used.

PEAT COKE.

Peat coke is the most efficient solid fuel derived from peat, but its high cost of preparation will doubtless limit its use even more than that of charcoal is now limited. Its value for all uses to which charcoal is now put should find it a ready and satisfactory market after it has once become known to the industries thatrequire such a product. 


\section{PEAT AS A RAW MATERIAL FOR PRODUCTS OTHER THAN FUEL.}

For many years the peat beds of Europe have been studied to see if the great quantities of partly decomposed, fibrous plant remains that are found in them, and that can be recovered seemingly at low cost, could not be made into articles of commercial value which would replace those now made from more expensive materials.

It must be borne in mind, however, that most kinds of vegetable raw materials are scarce in the countries of northern Europe where this experimental work has been carried on, and command a much higher price there than can be obtained for similar materials in the United States. There is, therefore, a much greater incentive to find substitutes or adulterants there than in this country, where potentially valuable vegetable substances are extravagantly used or allowed to go to waste. Material better than peat for some of the uses that have been proposed for it in Europe is at the present time wasted lavishly in some parts of the United States where peat is found, or in nearby territory.

\section{CHEMTCAL PRODUCTS.}

In discussing the manufacture of peat coke and peat gas in preceding sections, the possibility of obtaining a variety of chemical substances of commercial value was brought out. These materials are actually made on a commercial scale in Europe as by-products of peat-coke plants by condensing and redistilling the heavier gaseous products of distillation. In this country the same compounds are obtained as by-products of making charcoal, and to a rapidly increasing extent some of them are recovered from coal-coking plants and illuminating-gas and power-gas producers.

The recovery of chemical by-products from the destructive distillation of any fuel requires a carefully planned recovery plant, so designed and arranged that it will handle automatically, at the least possible expense, large volumes of liquids, containing a small percentage of salable material; to do this the greatest possible economy of heat and power must be effected. In addition, the cost of supervision and of skilled labor necessary for such recovery plants is considerably greater than for plants making less complicated products. For these reasons the manufacture of acetic acid 164 
and acetates, wood alcohol, formaldehyde, ammonia and its compounds, phenol and creosote compounds, and the products which can be derived from the tarry residues from peat distillation, such as illuminating and heavy oils, paraffin wax and asphaltum, can be profitably undertaken only at large plants, well designed and constructed, sufficiently capitalized, and properly managed.

It is significant that several plants erected in connection with large lumbering operations, for utilizing waste wood, by distilling the lighter compounds mentioned above, have not been successful. The reasons for failure have not been that the products were not in demand at good prices, or that there was any inherent difficulty in any of the processes, but that so far as could be learned, the margin of profit was so small, and the expenses of maintenance so great, that the owners preferred to close the plants and waste the materials which they attempted to save or to convert them to other uses.

There seems to be no question whatever, from the reports published, that all of the chemical compounds which have been mentioned can be profitably made from peat, and that there is a market for many of them in large and increasing quantities, but it seems assured, also, that they can be made with profit only in large and costly plants in which charcoal or coke is obtained from the peat as the principal product, or in those in which large quantities of peat are gasified to generate fuel or power gas.

\section{ALCOHOL.}

Within a few years there has been a revival of interest in a process by which ethyl or "grain" alcohol can be obtained from peat. It has long been known that cellulose could be broken down into sugar by proper chemical treatment, and that the sugar could be converted into alcohol by fermentation induced by yeasts, as in the ordinary production of alcohol from cereals and fruits.

The revival of this process was reported from Denmark, Sweden, and France, where experimental factories were established to test a newly discovered yeast, and from them came the reports that alcohol could be made from the coarser and less decomposed types of peat, at a total cost of between 45 and 50 cents per gallon. Later accounts state that the Danish plant has closed indefinitely without commercial operation.

The process of making alcohol from peat, therefore, is still in an experimental stage. It may never reach the point where it will be used in this country, as in many communities apples and other fruits rich in sugar and sugary waste of various kinds are allowed to decay in large quantities when, for a smaller cost than peat can be used, they might be converted into alcohol for fuel uses. 


\section{AMMMONIUM COMPOUNDS.}

\section{THE FRANK-CARO PROCESS. $a$}

The process of Frank and Caro for obtaining ammonium sulphate as a by-product incidental to the development of producer gas from peat has been mentioned in the discussion of producer gas. From 70 to 85 per cent of the combined nitrogen of the peat, often amounting to more than 2 per cent of its dry weight, is recovered by this process.

The peat, which may contain from 40 to 60 per cent of water, is superheated with an excess of steam in the drying zone of a Mond gas-producer, decomposing the nitrogenous compounds and converting part or all of them into ammonia. The steam and gases from the producer are conducted through pipes to washers and ammoniafixing apparatus, where the free ammonia in the gas is brought into intimate contact with sulphuric acid and converted into ammonium sulphate. The dilute solution is periodically drawn off at the bottom and concentrated by evaporation. It may be filtered and purified by crystallization. This process is reported by Caro ${ }^{b}$ to be in use at Sodingen, Germany, and at the large peat electric power station of the Hanover Colonization and Moor Improvement Co., at Schweger Moor, in northwestern Germany.

Ammonium sulphate has a rapidly increasing demand because of its high value as a constituent of the best types of fertilizers, and the cost of equipping a plant of sufficient size to profitably manufacture it from peat on a commercial scale is the chief factor to be considered by those contemplating its production.

\section{THE WOLTERECK PROCESS.}

By the Woltereck process, which is the discovery of Dr. H. Woltereck, of London, England, the discoverer claims to get a part of the nitrogen for the ammonia directly from the air and only a part from the peat. This claim is backed by the reports of a long series of carefully conducted laboratory and large-scale experiments, which have been worked out seemingly with great scientific accuracy and attention to detail. The assertion is made that when wet peat is burned in a specially constructed furnace at a temperature barely sufficient to keep the fire alive, some of the nitrogen of the moist air, constantly forced into the combustion zone of the furnace, forms ammonia by uniting with the hydrogen of the organic matter that is being decomposed. The gas from this wet combustion contains tar, tar water, and other distillates from the peat, besides the ammonia. In a large plant now in process of development in Ireland these 
gases are conveyed from the furnace to a scrubber that removes the tars without condensing the water, as this water would contain a part of the ammonia. From the tar scrubber the hot gases are sent to an alkali tower, where a hot solution of soda or milk of lime removes the acetic acid, as sodium or calcium acetates. The acid may be recovered by later treatment. The gas next passes to similar towers in which it is met by a fine spray of hot, dilute sulphuric acid, which combines with the ammonia to form ammonium sulphate, the chief object of the process. The acid is used until nearly or quite neutralized, when the solution of ammonium sulphate is drawn off to crystallizing vats, concentrated by evaporation, and purified by crystallization.

The process gives no fuel gas, as the temperature at which the peat is burned, $750^{\circ}$ to $950^{\circ} \mathrm{F}$. $\left(400^{\circ}\right.$ to $500^{\circ} \mathrm{C}$.) is too low to permit the formation of carbon monoxide or hydrogen. The process is consequently one purely of chemical manufacture, based on the formation of ammonia from the nitrogen of the air and of the peat itself, by the slow combustion of wet peat, the statement being made that peat with 75 per cent of water can be successfully used in this way.

The plant for manufacturing ammonium sulphate by this process must be of large size to be profitable, because, as in other chemical industries, the cost of production increases disproportionately as the output is decreased. The inventor of the process estimates a minimum production of 5 tons of ammonium sulphate from 100 tons of theoretically dry peat. The plant now being erected in Ireland, it is estimated, will manufacture at least 5,000 tons of ammonium sulphate per year when in operation, besides acetic acid, paraffin, and other chemical products of secondary importance. The cost of constructing the plant now being built will be approximately $£ 100,000$ $(\$ 500,000)$. If, however, the discovery is as stated, this investment is justified by the needs of the agricultural interests of the world, which are making constantly increasing demands for more sources of combined nitrogen suitable for fertilizing purposes.

NITRATES.

Peat has also been proposed as a means for the intensive production of nitrates on the following principle pointed out by Muntz and Laine. A culture bed of peat, watered with a dilute ( 0.75 per cent) solution of ammonium sulphate, then inoculated with nitrifying organisms and kept at a temperature of $38^{\circ} \mathrm{C}$, yields, after a time, nitrates to the amount of 0.82 per cent. By repeating the application of ammonium sulphate five times, the quantity of nitrates developed amounts to more than 4 per cent. This may be washed from the bed and purified. The peat may then be used for fuel or for distilla- 
tion. Whether this process is adapted to the commercial production of nitrates on a large scale is not yet demonstrated, but in view of the rare occurrence and limited supplies of these salts, so vitally important in agriculture, it presents possibilities of great importance if the facts relative to nitrogen fixation are as stated. The fact that all of the world's supply of grain alcohol is obtained by the action of microorganisms on sugar solutions, often of considerable dilution, points strongly to the conclusion that no great difficulty would be met in applying to commercial operations the principle stated by the authors quoted. If, however, the only change effected is to convert to a nitrate the nitrogen compound supplied to the peat from ammonia, the value of the process is questionable.

\section{DYE STUFFS.}

The well-known brown color of water flowing from peat deposits may be greatly increased in strength by adding alkaline substances to wet peat, as they dissolve some of the organic acid compounds. The resulting brown compounds can be again precipitated as insoluble substances that are said to give a permanent brown color and that could probably be utilized as dyes. The color can also be obtained in the form of a brown powder by adding an excess of acid to the alkaline solution first obtained and filtering.

\section{MATERIALS FOR TANNING.}

Tanning materials have been obtained in Europe from peat. It has long been known that peat, especially those types in which woody plants were abundant, contains tannic acid, tannin, and related substances in considerable quantity. The process of preparing the tanning material is thus described by Ryan: ${ }^{a}$

The powdered peat is treated with nitric acid in cemented cisterns until a small part of the product ceases to give brown fumes when boiled with an excess of nitric acid. The mash is then diluted with water and heated by a current of steam for several hours. A solution of stannous chloride is added, and the boiling is prolonged until the dark color of the solution has changed to a light brown, when the liquid is decanted from the precipitate and can be used directly for tanning hides.

Other chemical products that can be obtained are discussed in the sections of this bulletin relating to peat coke.

\section{PAPER.}

Peat containing much fibrous matter has been manufactured into paper, chiefly in a single factory established for the purpose at Capac, Mich. The machinery was invented in Europe, but has been brought to perfection in this plant, which was reported by the owners to be the only one in the world at the time it was erected. 
The product thus far manufactured is cardboard of a dark color but good quality, suitable for making boxes and for similar purposes. The raw material can be bleached, but seemingly the coloring matter of the peat is so durable as to render bleaching too expensive for commercial purposes.

In 1910 a small plant for making coarse brown paper from peat mixed with wood pulp and other paper stock was erected near Garrett, Ind. The product finds ready sale.

The chief objections to using peat as paper stock can be briefly stated as follows: There is much waste material, including water and mineral matter, which must be handled before it can be eliminated; peat is usually uneven in structure and texture; the fibrous matter is small in quantity, was originally poor in texture, and has been weakened by decay. Hence the peat fiber often has to be enriched with wood pulp or other paper stock to produce even poor grades of paper. The fiber is also difficult to bleach, so that only coarse brown papers and cardboard can be manuafctured. Most types of peat contain very little fiber and are too thoroughly decayed for use as paper stock, and it is probable that less than 10 per cent of the peat deposits of the United States are suitable for paper making.

Probably the only kind of bog that may be considered suitable for this purpose is one which has been built up from the bottom by successive layers of grasslike plants to a considerable depth and over a large area. Poorly decomposed moss peat, by the addition of a small percentage of paper stock, might be used for making some grades of paper. The bogs with a 3 or 4 foot stratum of mossy, fibrous, or woody peat at the top and structureless material below would be of small value for paper making, nor would those of small area be available, since the cost of equipping a paper mill is large.

Paper and pasteboard made from mixtures of varying quantities of peat fiber and wood pulp have been produced from time to time in several countries of Europe, where a considerable number of processes have been patented, but generally the manufacture has not been continued beyond the experimental stages because of the high costs of reducing the peat fiber to a condition suitable for use.

\section{WOVEN FABRICS.}

The stronger fibers from the more fibrous kinds of peat may be separated and cleansed from the surrounding material, and after treatment which renders them pliable they may be woven into fabrics. The most successful experimental use for this kind of cloth has been as blankets for horses and other live stock.

It has been reported recently from Europe, also, that the fiber obtained from the remains of the sedges that frequently grow in moss bogs is collected by hand as the peat is run through disinte- 
grating machinery, and is used for adulterating silk threads and fabrics, for which purpose it is in growing demand. After the material is sorted, or in the case of purer fibrous peat without such sorting, the entire mass is beaten up with water, after which the fibers are gathered by means of forks moved by an endless chain. The fibers are removed by the conveyor to large vats, in which they are washed with water, again collected, party dried, placed in hot acid solution, washed, and allowed to ferment, and then dried. The dust which still adheres to the fibers is next removed by proper screening, and the cleansed fibers are prepared for spinning. The cost of this material is about the same as that of hemp and flax, about twice that of jute, and only a little less than that of cotton, even in Germany, where it is produced.

\section{ARTIFICIAL WOOD.}

A material called "Heloxyl," closely resembling heavy paper, was made by compressing fibrous types of peat and hardening the resulting material by special treatment into sheets, blocks, and other forms for structural purposes. The material was light, compact, waterproof, and nonconductive of sound, vibrations, and heat, and could be made fireproof by the introduction of mineral matter; it was also readily glued, nailed, and painted, and because of these properties, as well as its strength and lightness, made good finishing material.

Artificial wood, made by mixing fibrous peat with certain mineral cements and compressing it, has also been made in a small way in Germany. The material can be molded into any desired form, is noncombustible or slow burning, does not absorb water, and is so tough and hard that it is said to make good and durable paving blocks and flooring, as well as a desirable substitute for wood in most of its ordinary uses.

\section{MATTRESSES AND SANITARY APPLIANCES.}

Moss peat and material which has been selected and cleansed of sticks and other coarse matter, or the roughly cleaned fibers derived from peat, may be made into mattresses and dressing for wounds.

The absorbent, deodorizing, and antiseptic properties of peat make it good material for these uses. The mattresses are said to be especially valuable for hospital use, since they are light in weight, resilient, soft, inodorous, and very cheap, so that they can be renewed at small cost.

The material used for dressing wounds needs more thorough preparation than that intended for mattresses, as it must be freed from all dirt and woody matter, and, on the whole, there is doubt whether it possesses sufficient superiority to substances now in general use for 
the same purpose to warrant trying to introduce it. In the form of fine powder it has been used with excellent results in dressing cuts, burns, and other wounds, and its many good features for such use merit investigation by American surgeons.

\section{MOSS IITTER AND MULL.}

A much more general use for the more fibrous kinds of peat in Europe is for bedding for stock, and in the form of powder or mull for various packing, absorbent, and deodorizing uses.

Moss or peat litter is hardly to be classed as a manufactured product, since the common processes of manufacture consist chiefly of cutting the peat into large blocks, spreading them on the bog to dry, gathering the peat blocks in a partly dried condition, and tearing these up by the use of simple machinery. The shredded material is passed through rotary screens to separate the finer material, or mull, then dried artificially and packed in bales. This material is capable of absorbing much larger amounts of moisture in proportion to its weight than any other substance in general use for stock bedding. It is a good deodorizer, and almost entirely prevents the decomposition of the nitrogenous and other organic substances for a considerable time. In addition, it is reported to be springy and durable and to keep the feet of the animals which stand on it in perfectly healthy condition.

At the present time a considerable quantity of this sort of litter is imported from Holland and other countries of northern and western Europe; in 1909 it amounted to something over 9,000 tons. It has been made for several years past at a single plant at Garrett, Ind., and the demand for the product of this establishment is rapidly increasing.

Many of the peat bogs of the northern United States are favorably situated for manufacturing this material, and the peat is admirably adapted for the use, judging from the imported product that has been examined by the writer. This substance is chiefly composed of poorly decomposed sphagnum moss and other herbaceous plants, and is of a light-brown color when dry.

\section{COST OF a PLANT.}

The cost of equipping and establishing a plant for making moss litter is not large when compared with that of the more complicated fuel-making plants, because the machinery is inexpensive and of considerably lighter construction. For larger plants some form of efficient artificial drier should be provided to complete the drying of the peat after it has dried as much as is possible on the surface of the bog. To dry the peat below 15 or 18 per cent of moisture before 
baling, however, will be entirely unnecessary, as when dried below this water content the peat will rapidly take up moisture until it contains as much as it can absorb from the air-from 10 to 20 per cent, according to the relative humidity of the air in the locality.

Following is a statement of the cost of a moderate-sized plant equipped with European machinery, but without drier or boiler and engine:

Cost of machinery for a peat moss litter and mull factory producing from 1 to 2 tons per hour.

\begin{tabular}{|c|c|c|}
\hline Description of machiner y.a & Weight. & $\begin{array}{c}\text { Net cost, } \\
\text { f. o. b. } \\
\text { New } \\
\text { York. }\end{array}$ \\
\hline \multirow{7}{*}{ 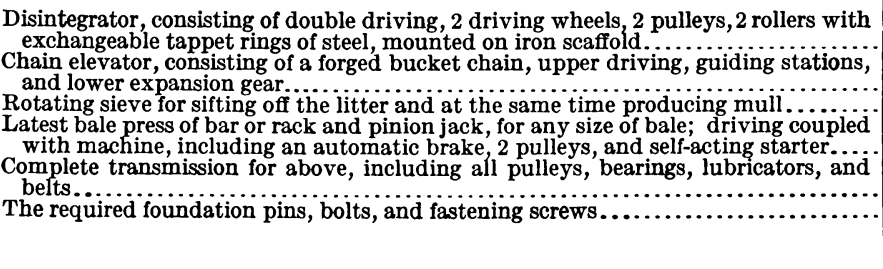 } & $\begin{array}{r}\text { Pounds. } \\
4,000\end{array}$ & \multirow{6}{*}{$\begin{array}{r}\$ 1,000 \\
675 \\
500 \\
\\
2,500 \\
1,200 \\
125\end{array}$} \\
\hline & \multirow{2}{*}{$\begin{array}{l}2,000 \\
1,500\end{array}$} & \\
\hline & & \\
\hline & 10,000 & \\
\hline & \multirow{2}{*}{$\begin{array}{r}2,500 \\
650\end{array}$} & \\
\hline & & \\
\hline & & 6,000 \\
\hline
\end{tabular}

$a$ For a full description of peat-litter plants see Nystrom, E., Peat and lignite; their manufacture and use in Europe: Canada Department of Mines, Mines Branch, 1908, p. 231.

\section{MARKETING AND USE.}

The litter, after preparation, is shipped in highly compressed burlap-covered bales, and brings a good price in the markets-generally a much better one than could be obtained as the result of the same expenditure of time in preparing the same weight of peat for fuel.

Peat litter should not only have a large use in city stables, but ought to be used in dairy barns, where its absorbent, deodorizing, and disinfecting properties would make it much more valuable than any material now commonly used for the purpose.

The mull, consisting of the finer parts of the peat screened out from the litter, is much used in those European countries where it is produced as an absorbent and cheap deodorizer. It is very satisfactory for use as a substitute for more expensive chemical substances or mixed with them for outhouses, earth closets, cesspools, etc., in places where comprehensive sewer systems have not been constructed.

On the whole, these products, simple as they are, and requiring no large outlay of capital, present the greatest possibilities for paying investment to owners of peat deposits of suitable character, because they are easily and cheaply made, are already on the market, and are favorably known to many dealers and consumers. 


\section{PACKING MATERIAL.}

Peat prepared in about the same way as the moss litter is largely used in Europe for packing fragile and perishable articles, and there seems no reason why it can not be used for the same purposes in this country, where much more expensive substances are now employed. This use should be extended to include the packing of eggs, fish, meats, and fruits, as is done in Europe, for cold storage. The antiseptic power of the peat adds to its value for this purpose. An exhaustive series of carefully planned experiments with the proposed packing material in various forms and with varying water content under American conditions is needed before any considerable investment for producing it on a commercial scale in the United States can be recommended. Peat moss (Sphagnum) is gathered and baled in considerable quantities in New Jersey, and to a less extent in New York, for packing and for florists' use.

\section{FERTILIZER FILLER.}

The most extensive and successful use of peat as the base of a commercial product sold in large quantities on the open market in this country is as "filler" in artificial or chemical fertilizers. This filler should not be regarded, however, as a harmful adulterant, but rather as a diluent, or in some cases as a necessary constituent of the mixture into which it is introduced, since it improves the whole, both mechanically and chemically; for the same purpose manufacturers use powdered graphite, coal dust, cinders, and ashes, sand, etc. The use of peat powder as filler also permits the use of many kinds of waste animal matter, rich in valuable nitrogenous compounds, which could not be used otherwise because they absorb water from the air and cake, or give off offensive odors, and soon decay, their valuable nitrogenous contents being dissipated as gases.

On the other hand, the peat adds to the total nitrogen of the completed fertilizer, so that an analysis shows a certain proportion of nitrogen, which is said by chemists not to be immediately available for plants, and as nitrogen is the most costly constituent of all fertilizers, this addition is objected to by some agricultural chemists. Recent experiments seem to show, however, that at least one-third of the nitrogen in even poorly decomposed peat is really immediately available for plants, hence part, at least, of the objections to this use of peat fall. The advocates of its use claim that it improves the mechanical texture and the odor of the mixtures in which it is used, and prevents the loss of nitrogen by checking the decomposition of its organic compounds and by absorbing any free ammonia developed; it also adds to the soil an amount of organic matter equivalent to the 
quantity of the peat used, the decomposition of which gives plant food and increases water-holding capacity. The black, well-decomposed kinds of peat from thoroughly drained bogs are most often used for this purpose; such soils often show great and lasting fertility, producing good crops year after year with little fertilization, thus showing that they have an abundance of plant food.

The processes of preparing peat filler are even simpler than those for peat litter. The peat is dug or plowed up and allowed to drain and become as nearly air-dry as may be, after which it is dried artificially, often in a rotary drier, to a low moisture content, ground into a powder, and shipped in bags or in bulk. The grinding may be done before the artificial drying. The blacker, more highly decomposed peats are most sought for this use because they generally contain a larger percentage of nitrogen than others.

To be well equipped for the production of peat fertilizer filler a plant should require as little manual labor as possible. The equipment should include machine diggers, cars, and portable tracks for transporting the peat to the stock piles or storage sheds, and mechanical conveyers for transferring the crude, partly dry peat from storage to the driers.

The commercial success of the entire operation may depend on the completeness of the mechanical arrangements connected with the drying plant. These, in such a plant, take the peat to the driers, receive it after drying, and remove it automatically to storage rooms or to cars for shipment.

Because of the varying conditions of drainage at the different plants producing peat filler, different methods of digging the peat and of treating it before artificial drying are used. At some plants hand labor is used exclusively to dig the peat from drained or partly drained deposits and to place it on tramcars by which it is removed immediately to stock piles.

At other plants operating on wet or undrained deposits the peat is dug by dredges floated in canals of their own excavation. As fast as the peat is dug it is either piled on the bog to drain, or on cars running on portable tracks along the bank of the canal, or on scows which are floated on the canal to the drying grounds or the factory for unloading.

On thoroughly drained bogs that are dry enough to permit cultivation the peat is sometimes plowed and harrowed before the upper layers are scraped up. Such treatment reduces the peat to powder and hastens drying materially. Every pound of water removed by evaporation induced by the wind and the heat of the sun reduces the amount of fuel needed in artificial drying. It is, therefore, where possible, a distinct advantage to treat the peat as described. 
A modification of the method of cultivation just described is in use at some peat-filler factories. The digging, spreading, and gathering machinery described in an earlier section (p. 113) is used to prepare and gather peat powder with less than 40 per cent of moisture from the drying fields a few hours after digging - a great advantage, as may be seen by reference to the table showing the relations of the weights and percentages of the water contained in peat (p. 110).

It is doubtful whether peat containing more than 50 per cent water can be dried with profit by artificial heat in the form of drier generally used, considering the prices generally received for the product.

A fully equipped plant for making peat into fertilizer filler probably costs more than a plant for making machine peat, but because of the established market a good product of sufficient weight and of high nitrogen content commands a ready sale at considerably higher prices than the peat would bring as fuel in the form of machine peat.

Peat fertilizer-filler plants were operated in 1910 in Florida, New Jersey, Massachusetts, Pennsylvania, Ohio, Indiana, Michigan, and Illinois.

\section{PEAT AS A FERTILIZER.}

Experiment has seemingly demonstrated that powdered black peat that is somewhat alkaline in its reactions may, if properly prepared, be used with much benefit as a fertilizer on soils lacking in organic matter. Such material has been put on the market as a lawn dressing, and is finding a ready sale. Peat for this use should have a high nitrogen content, and the organic matter should be in such form that plants can get it readily. Fibrous and brown peat have little, if any, value for this purpose, and should not be used where immediate results are expected. The experimental work which has been done on the fertilizing value of peat has been too limited to warrant final conclusions, but the experience of farmers for many generations seems to justify the use of peat as a fertilizer.

\section{CONCLUSIONS.}

Peat is available for any of the uses cited in this discussion and for some others which have not been considered here, but it can hardly be classed as a satisfactory raw material for making any of the more complicated products under the usual conditions existing in the United States, where other and established substances are already to be had in any desired quantity and at satisfactory prices. Moreover, these products are obtained from peat only by large investment of capital, and in most cases can not be manufactured before the plant has passed through a long experimental period, which must be properly provided for by a considerable reserve fund.

$661^{\circ}-$ Bull. $16-11-12$ 
The simpler products, peat litter, mull, mattresses, packing material, and peat-fertilizer filler, have a much greater chance of being quickly made profitable, because some of them are already on the market and present uses for which the peat is especially adapted. Moreover, the processes of preparation are simple, and the cost of equipment for their manufacture with tried machinery is so low that moderate expenditure will fully equip a plant for their manufacture, and a long experimental development is unnecessary.

It is apparent, therefore, that the more fibrous kinds of peat, where they are abundant in the United States, may be put to a number of profitable uses besides making them into fuel, while the black, plastic types have other possibilities, although they are not adapted to the same uses for which the first-mentioned type may be recommended. 


\section{AGRICULTURAL USES OF PEAT.}

The utilization of peat in agricultural operations is a topic of importance to the farmers of the regions of the United States where peat deposits are common, especially where reclamation by drainage is being undertaken, and this is beginning to be realized by those who are working on the problems involved in increasing the rate of yield and the diversity of farming operations. The subject of the proper value of peat and peat lands to agriculture is so important and so complicated that it can be fully discussed only after a great number of practical experiments on a large scale have been made to determine the availability of this sort of land for various kinds of crops under the wide range of temperature, of rainfall, and of types of peat that exists in the United States.

In Europe, partly because of the large areas of unproductive peat land in the agricultural countries, and partly because of the crowded condition of these countries, the qualities of peaty soils have been made for many years the subject of exhaustive and careful study by trained specialists.

These generally work under the auspices of a society made up of farmers, landholders, and others who are interested, and aided by definite appropriations of funds by the Government. The Government further aids in this important work by establishing and maintaining experiment stations at peat bogs, where the necessary experiments as to culture, drainage, and other phases of the problem are systematically carried out on such a scale that their practicability as well as their desirability may be determined. Government aid and supervision is given to plans for the colonization and development of large areas of marsh lands and in Germany a number of such colonies are now established.

No work of this sort has yet been attempted in the United States except at a few of the State agricultural experiment stations, where investigations of the value of peat as a fertilizer and as a soil for certain crops are now being carried on.

\section{PEAT SOILS.}

In its natural condition peat is too wet to be worked, and before any crop plant can be made to grow upon it the surface must be cleared and the water level lowered by effective ditching and draining. In 
general, after this has been accomplished, the surface layers of the peat are coarse in texture and often full of partly decayed stumps, roots, and other woody débris, which must be removed.

The coarse-textured peat dries out readily and affords only a small amount of plant food, so that after a short time, or during unfavorable seasons, crops fail. Often swamps are cleared, drained, and cultivated for a brief period at considerable expense and then abandoned because they are, as a rule, unproductive.

Aside from the coarseness of peat soils and their consequent poverty of moisture and plant food, an important cause of crop failure seems to be the attempt to grow crops not adapted to the soils. Extended observation in various parts of the country where peat soils are common seems to indicate that after one or two crops have been taken from newly cleared peat land of the common kind, grass is most likely to yield good crops for a number of years until the surface layers are blackened and disintegrated into a fine-grained, homogeneous mass. After this has been accomplished, various kinds of crops may be raised, but these, as a rule, should be such as can well endure cold nights and early frosts, and are not greatly injured by drought. Various truck crops, such as onions, lettuce, celery, cabbage, and other vegetables, seem to thrive on well-blackened peat and often yield very large returns.

Peat soils generally need mineral fertilizers, especially potash, because they contain little available mineral matter, and barnyard manure is often very effective in adding to their productiveness, both because it adds to the peat material which the latter lacks and because, seemingly, it promotes the decomposition of the peat by introducing the fungi and bacteria which cause decay and hasten humus formation.

In some parts of the country peat soils are among the most productive of any, yielding large crops year after year with no more care than is required to obtain inferior crops from other kinds of soils. In such places, however, the peat is of the thoroughly decomposed, black type, generally known as "muck"; the brown, fibrous kinds are seldom very fertile until they have been cultivated or exposed to weathering agents for some years.

\section{FERTILIZER.}

Muck, or peat, has long been used by farmers as an auxiliary fertilizing material, either directly applied to the land or applied in connection with other fertilizers, especially in composts with barnyard or stable manure. This practice is justified by the composition of peat, some kinds of which contain from 2 to 3 per cent of combined nitrogen, besides other organic matter, and when properly applied increase the humus in the soil and hence the water-holding power. 
To get the best results from peat for these purposes it should be dug and left on the bog for a time to dry out and disintegrate thoroughly. This not only gets rid of the water, but renders the peat more absorbent and in better form to be mixed with the soil. It seems also to make the nitrogenous matters more quickly available for the use of crops to which it is applied.

If dug wet and spread over the land in this condition the peat may dry into hard, tough lumps that for a long time are of no more value to the land than stones or blocks of wood. Aside from this, a ton of wet, freshly dug peat contains only about 225 pounds of usable material, and in this material there is not enough fertilizing substance to justify the labor of digging and hauling it. On the other hand, the dry material, which may be obtained by digging out the peat in the fall and letting it lie on the bog until the next fall, will yield excellent returns, especially if properly composted with coarse manure before being applied to the land.

The composting should be done in the ordinary way, by stacking the peat in thin layers alternating with those of stable refuse to a depth of several feet, and allowing the heap to stand for some months, turning over the whole at least once during the time. If the peat alone is used it should be applied liberally as dry as possible; it may be cheaply spread by a manure spreader. Such applications will improve the productiveness of many kinds of soils.

\section{ABSORBENT AND DISINFECTANT.}

The air-dried peat may be used to even better advantage as an absorbent of the valuable nitrogenous liquids of stables and barnyards, which ordinarily are allowed to go to waste. For this purpose the dried peat needs simply to be piled up under cover until used, when it may be spread over the barnyard in layers as needed. If used in the stables, it will not only act as an absorbent of liquids, but, since it checks decomposition and absorbs gases, will be more or less effective as a deodorizer.

Dry, powdery peat may also be used for all the purposes for which peat mull is recommended above, and it is greatly superior, for most of them, to lime, ashes, or the more expensive chemical compounds used for deodorizers and disinfectants. It is nearly an ideal material for use in earth closets and in other receptacles for moist waste organic matter, and has a value far in excess of the cost of gathering and preparing it.

\section{ITTER AND BEDDING FOR STOCK.}

Dry peat, if free from sticks and lumps, may be successfully used for bedding for all sorts of live stock, equalling for this purpose the more carefully prepared peat or moss litter, because it possesses all 
of the properties of the litter. When used for bedding the thoroughly dried peat should be packed firmly to the depth of 4 or 5 inches on the floor of the stalls or standing room, at the back of which a retaining cleat should be nailed; if well prepared and kept clean the litter will last without renewal for several months. It furnishes a standing room and bed which can not be excelled, being spongy, elastic, and absorbent, and keeping down the usual odors of the stable to a marked degree. Wet peat should not be used for this purpose.

\section{INSULATING MATERIAL.}

As dry, fibrous peat is a good nonconductor of heat, it may be used satisfactorily to protect water pipes from freezing. The peat is probably superior to straw and similar materials commonly used, because it is more durable and, if properly dried, more absorbent, hence would not lose its insulating properties so quickly when laid in a wet place. The only preparation needed is drying, and manifestly the tough, sponge-like turf, or uppermost layers of moss peat, would be especially desirable, because they afford large air spaces between the fibres, and thus give better protection than more compact material. Peat of this kind should also be good packing in refrigerators and icehouses and similar structures.

\section{STOCK FOOD.}

In Europe peat mull and peat litter prepared from moss and sedge peat have been used as the bases for the preparation of certain kinds of commercial stock foods. The chief ingredient in these preparations besides the peat is the uncrystallized residue, or molasses, from beet or other sugar factories. This molasses has a certain food value for fattening stock, but is difficult to feed because of its stickiness and liquid condition, and the peat is added to obviate these difficulties. Actual analyses, however, by reputable agricultural chemists, show that this material has a twofold use-it is eagerly eaten by the cattle, and thus stimulates them to eat more than they otherwise would of fattening food, and the peat itself adds a small amount of proteid substance to the food; the peat also neutralizes certain bad effects of the molasses, so that larger quantities may be eaten.

Although the weight of evidence gathered at agricultural experiment stations in the United States seems to show that condimental stock foods of the kinds usually sold are of the nature of stimulants, and do not give sufficient returns in actual gains in weight or condition of the animals to justify such use, the testimony as to the value of a mixture of molasses and peat mull as an addition to the ration of horses and other live stock seems conclusive. Reports of its beneficial 
effects have been issued from time to time through a number of years from various European countries and from the army veterinarians of Germany and England.

\section{PACKING MATERIAL.}

Air-dried peat can be used to advantage for packing eggs, fruit, and vegetables for storage either in bins, pits, cellars, or other receptacles, or in refrigerating plants.

The nonconducting properties of fibrous peat keep articles packed in it at an even temperature and prevent freezing. In addition peat prevents shrinking due to evaporation and quickly absorbs any water given off. Perishable articles packed in this material are not absolutely protected from decay, because the germs of the microscopic plants that cause decay are generally introduced before packing. Unaffected fruit, however, would not be spoiled by contact with that already inoculated, as is often the case in the usual methods of packing for storage, because peat is sufficiently antiseptic to prevent the growth of rot-producing fungi through it, and the reproducing bodies could not pass from point to point through it, as they do through air spaces.

Large quantities of peat powder or mull are sent annually to the Canary Islands from Europe for use in packing fruit for shipment, and the demand for the material for the purpose is growing. There seems no good reason why the same substance should not be tried in the United States in connection with the shipment for long distances of the more perishable fruits.

\section{PEAT ASHES.}

A question often is raised as to the value of peat ashes. In general, it may be said that they are not nearly so valuable as those obtained from wood, as they contain a disproportionately large percentage of silica and very little phosphoric acid or potash. The silica probably comes from fine silty sediments in the water in which the peat was formed, and has practically no value in plant growth although the most abundant constituent of most soils. The small proportion of other mineral constituents in peat ash can probably be attributed to the lack of the remains of woody plants, as the mosses and other herbaceous plants, which are the chief peat formers, do not usually accumulate as much mineral matter in their cell walls as do the shrubs and trees.

Therefore, while at times it may be advisable to burn over the surface of peat beds to remove quickly and cheaply the surface covering of vegetation, it is a great mistake to burn the peat for the sake of getting the ashes, as these are worthless for agricultural purposes in 
comparison with the high value of the peat itself for any of the uses that have been mentioned in this bulletin.

It is reported that peat with high ash in certain localities in Florida is burned in specially built furnaces to obtain the ashes for making polishing powders and scouring soaps, the ash containing a large amount of silica in the form of very minute shells of one-celled plants known as diatoms which are so small that they do not produce visible scratches on polished metal, yet so hard that they scour it.

\section{CONCLUSIONS.}

Peat land may be cultivated with profit if the right crops are chosen and the peat is sufficiently drained, decomposed, and fertilized. Many of the peat swamps in the northern part of the country are, however, of a type that will scarcely repay cultivation, since the peat is very poorly decomposed and would be a long time in reaching a state in which it could be safely used for most crops.

On the other hand, even poorly decomposed peat may be very profitably used in many ways on farms to increase the fertility of the land, and to add to its productiveness indirectly, by conserving and preserving other more salable articles, or by saving valuable waste matter which could not be kept except by its use. 


\section{TABLES OF ANALYSES.}

In the following tables all of the analyses of peat samples made by the United States Geological Survey from the beginning of the present investigation to July 1, 1909, are given for convenience of reference and comparison.

\section{COLLECTION OF SAMPLES.}

The samples from which these analyses have been made, except the samples from New York, Massachusetts, Michigan, New Hampshire, and North Carolina, were collected chiefly by field agents of the geological surveys of the States in which the peat was obtained, under the supervision of and in cooperation with the United States Geological Survey.

\section{METHODS OF COLLECTION.}

In the beginning, samples were collected with augers and placed in galvanized-iron and tin cans, such as were used for sending coal samples by mail to the fuel-testing laboratory of the survey, but it was found that the wet peat from many localities attacked the metal, and, after a relatively short time, etched holes in the sides and bottoms of the containers. This led to the use of glass bottles, after an unsatisfactory test of wooden mailing cases. The bottles finally chosen were ordinary wide-mouthed, 4-ounce size, with tightly fitted corks. Each bottle was rendered mailable by the use of a type of mailing case approved by the postal authorities. The bottles were small because they were used only for wet samples from which the approximate water content of the peat at the time of collection might be determined.

For the calorific and chemical analyses larger samples were always collected at the same time as the bottled samples. The larger samples were placed in stout cotton-cloth bags, about 6 inches wide by 9 inches long, provided with a tape for fastening the top. The samples were generally taken at intervals of 2 feet from the top to the bottom of the deposit, from at least three holes in widely separated parts of the deposit, and portions of each sample were put in a bag and in a bottle as they were collected and were given the same notebook number. Where the lower layers of a deposit showed much 
silt samples were sometimes rejected and not included with the material sent for analysis, although this was not the general rule. The bags and the wet samples contained in them before packing were more or less thoroughly dried by exposure to the air, after which they were labeled and sent, with proper identification cards, to the chemical laboratory for analysis. The samples, with the exception of those from Maine, ${ }^{a}$ most of which were taken with a ship auger, were collected with the sampling tube already described (pp. 71-72), which has proven very satisfactory for the purpose.

\section{ANALYTICAL METHODS.}

The general method used for the proximate analyses of peat samples was that which was adopted by the committee on coal analyses of the American Chemical Society. ${ }^{b}$ The Mahler bomb calorimeter was used for determining the calorific or thermal value, 2 grams of peat being taken instead of the 1 gram used in coal analyses. The peat was reduced to the air-dried state by warming it at a temperature of $35^{\circ} \mathrm{C}$. $\left(95^{\circ} \mathrm{F}\right.$.) in an oven so constructed that a current of warm, dry air passed over the powdered sample until it no longer showed loss of weight on repeated weighing. The time required for this thorough drying was usually from three to five days. ${ }^{c}$ The drying was conducted at a temperature used to prevent the loss of volatile combustible matter known to take place when peat is dried at the higher temperatures $\left(100^{\circ}\right.$ to $105^{\circ} \mathrm{C}$.) often used. Drying in ovens probably gives more uniform results than drying in the open air of the laboratory, because conditions of atmospheric humidity are more definitely controllable in an oven.

\section{MOISTURE.}

The difficulties in the way of collecting a peat sample, from any depth below the surface, with exactly the quantity of water that the peat contains at that depth have not all been surmounted, and it is doubtful if any of the samples give as high a percentage of water as they would if perfect collection were possible. The moisture analyses are useful, however, in showing that the water content of the samples collected is uniformly high and often above 90 per cent.

\section{CALORIFIC VALUE.}

As previously stated, the calorific value of the peat samples was determined with the Mahler bomb calorimeter. It is stated both in calories and British thermal units on both the air-dried and the 
water-free basis, the latter being derived from the former by calculation. (See pp. 51-52.)

No attempt is made in this report to discuss the analyses, which are published to give those who wish either to learn something of the value of peat for fuel in comparison with other substances now in use or to determine the comparative possibilities of the peat from some particular region or deposit. To such persons the tables have a distinct value, but, nevertheless, it should be remembered that before a given peat bed is exploited careful tests and analyses should be made of many samples, so that the uncertainty arising from the study of a single analysis can be eliminated. 


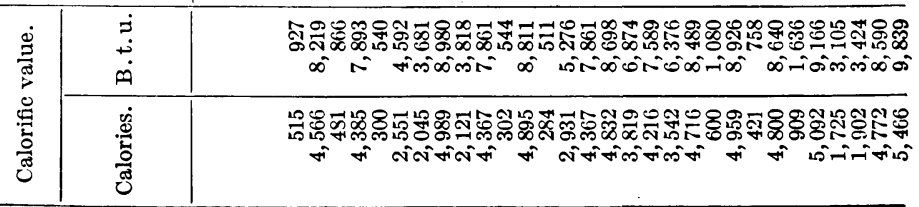

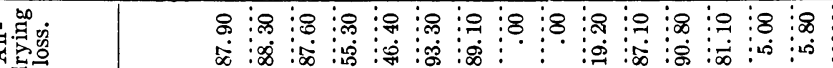

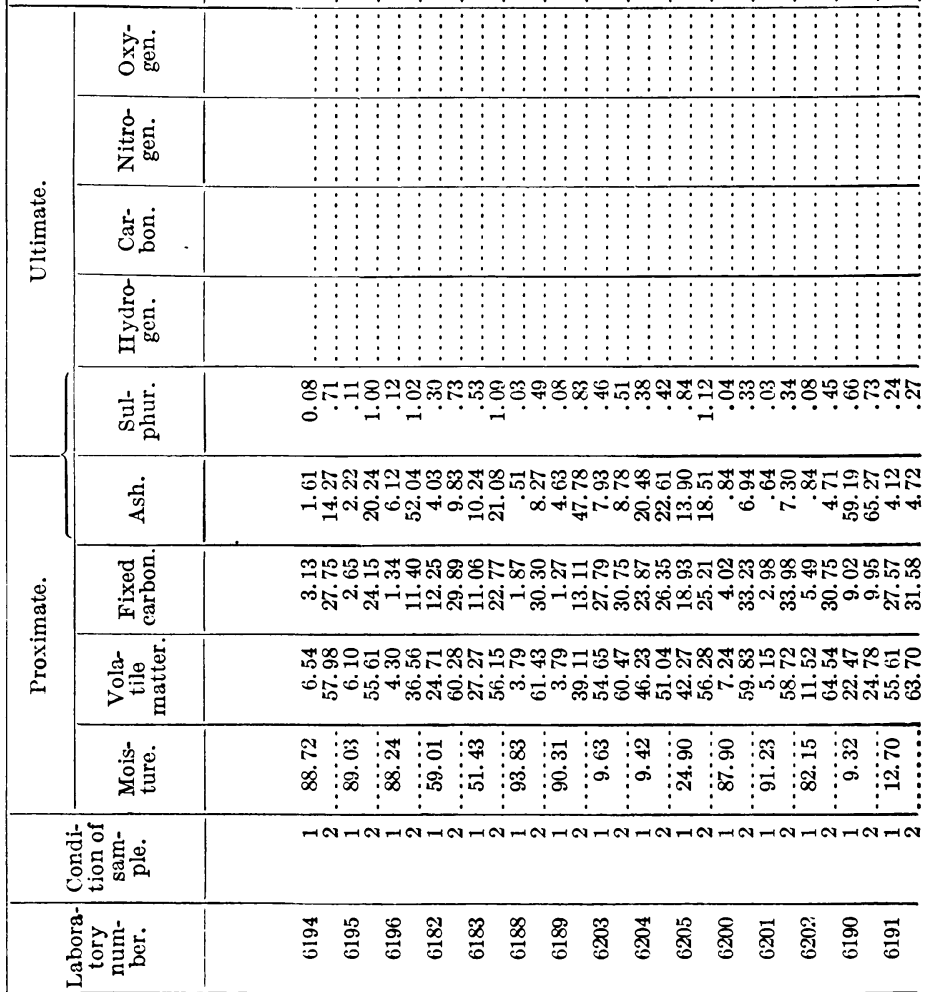

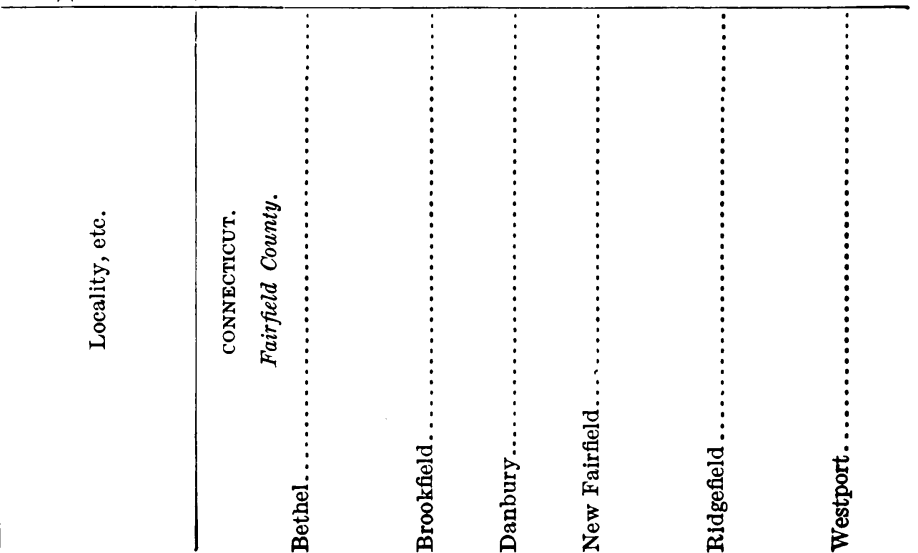




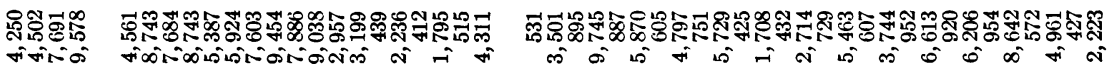

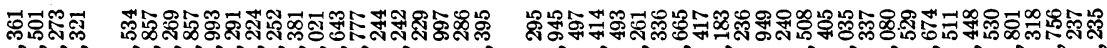

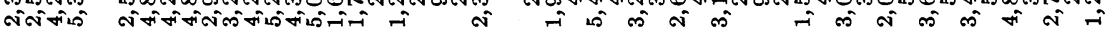

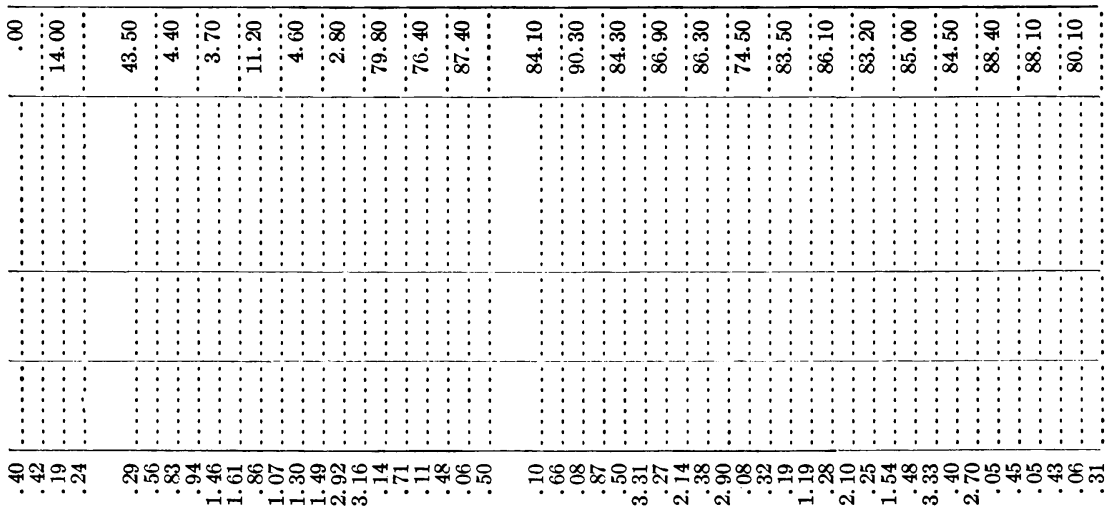

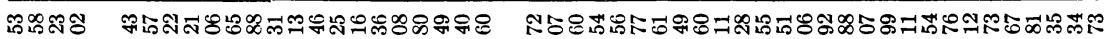

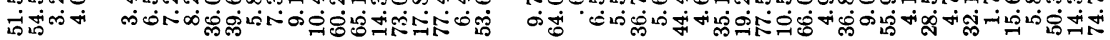

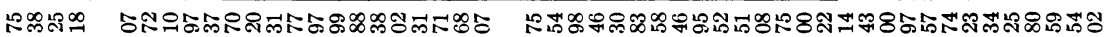

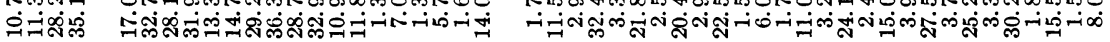

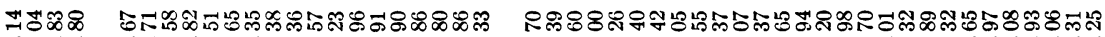

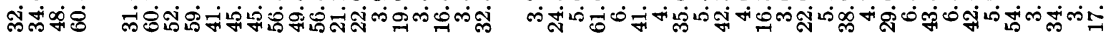

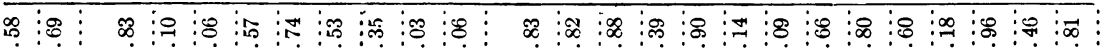

山

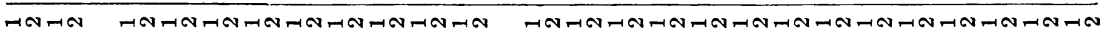

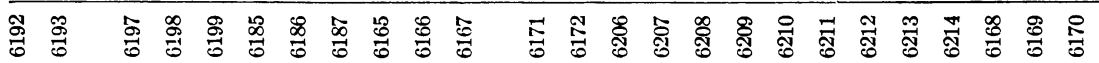

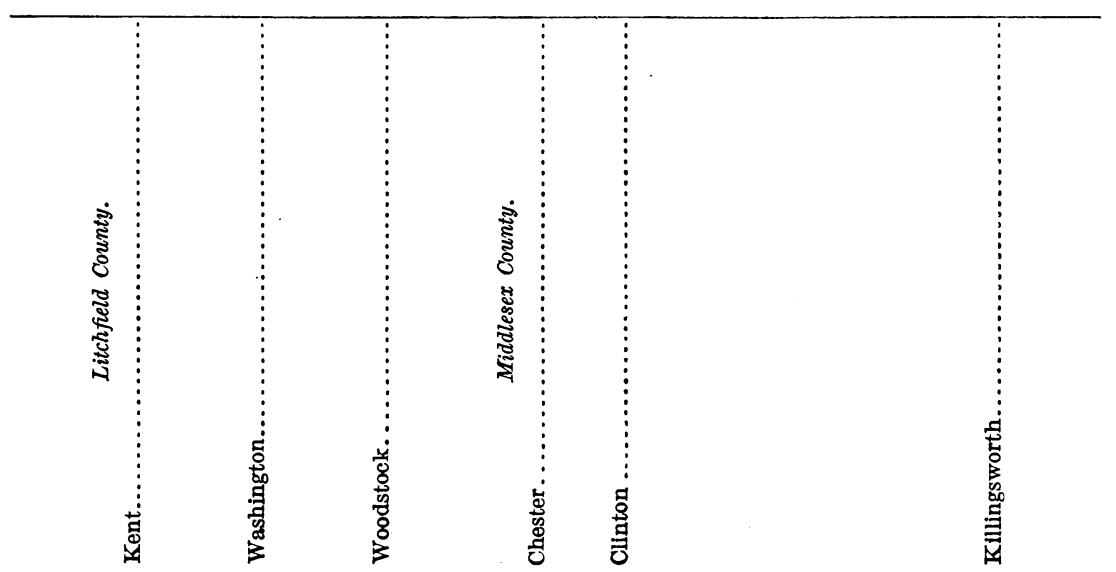




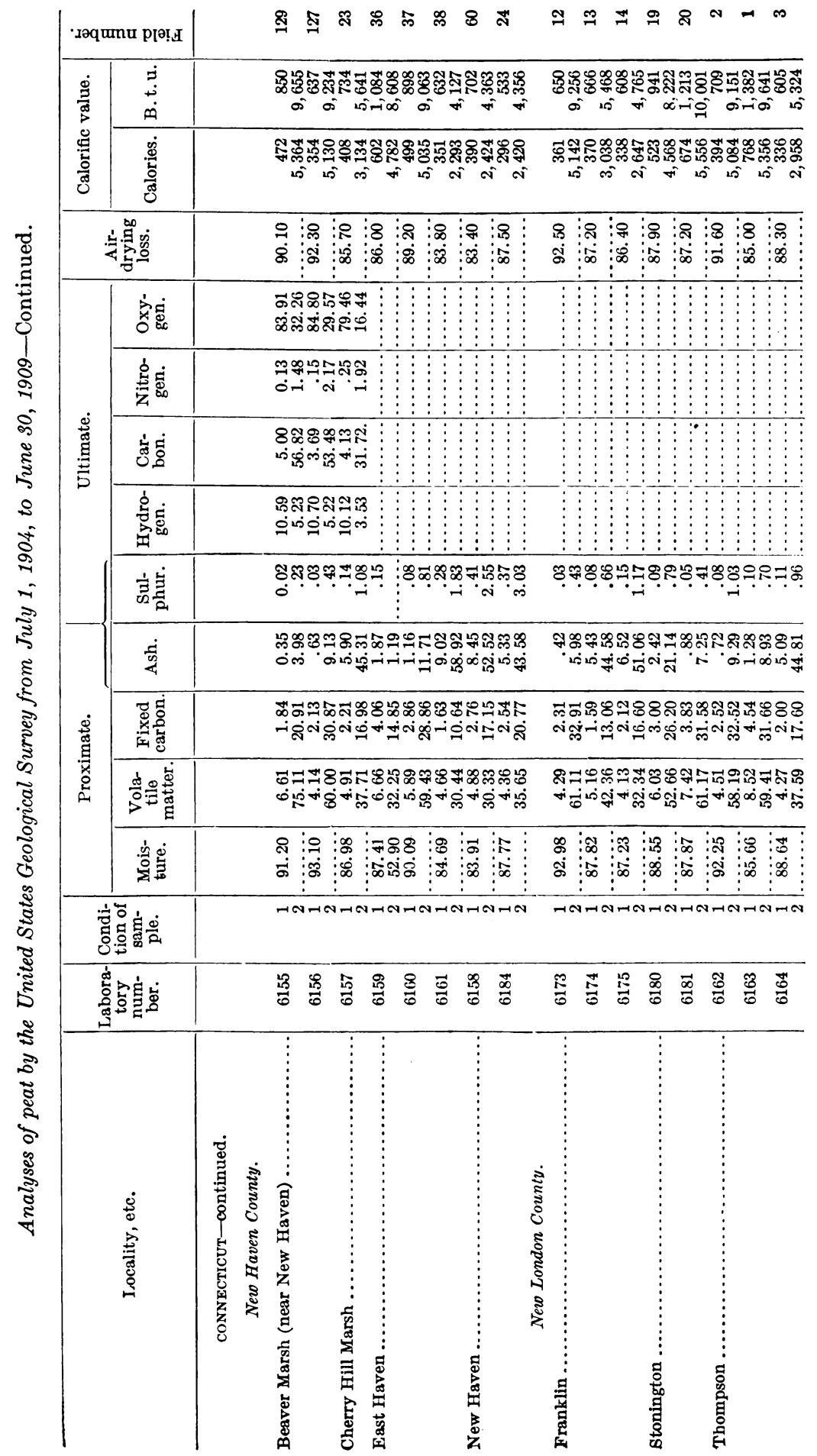




\begin{tabular}{|c|c|c|c|c|c|c|}
\hline$\stackrel{\infty}{\sim} \stackrel{2}{\sim}$ & 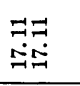 & in & 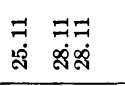 & 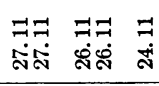 & $\begin{array}{l}\exists=1 \\
\text { तंत्र }\end{array}$ & 兽 \\
\hline 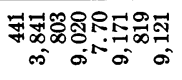 & 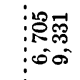 & & 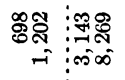 & 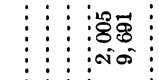 & 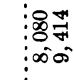 & 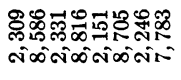 \\
\hline 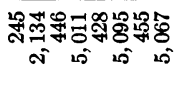 & $\begin{array}{l}\text { : } \\
\vdots \\
\vdots \\
\vdots\end{array}$ & & 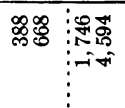 & 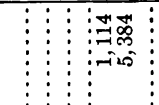 & 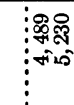 & 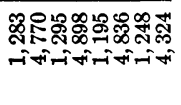 \\
\hline 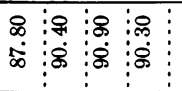 & $\begin{array}{l}\text { \&: } \\
\infty \text { : }\end{array}$ & 通 & 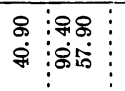 & 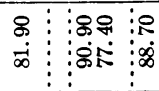 & 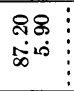 & 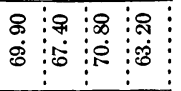 \\
\hline & & & & : & & 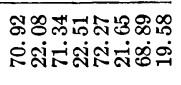 \\
\hline & & $\because \Re$ & & & & 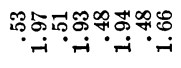 \\
\hline & & & & & & 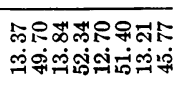 \\
\hline & & & & : & & 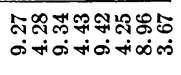 \\
\hline 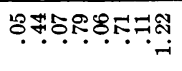 & : & $\stackrel{\infty}{\circ}$ & 웅ำ & :® & ఏळ\% & 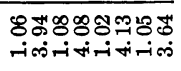 \\
\hline 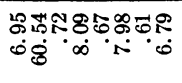 & $\begin{array}{l}\text { is } \\
\vdots \infty \\
\infty \text { id }\end{array}$ & 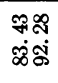 & 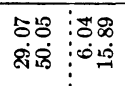 & 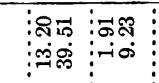 & : & 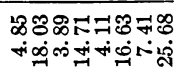 \\
\hline 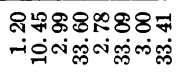 & 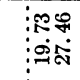 & 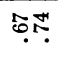 & 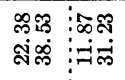 & 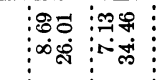 & $\begin{array}{l}\infty \\
\vdots \\
\vdots \infty \\
\vdots 0\end{array}$ & 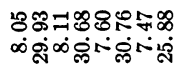 \\
\hline 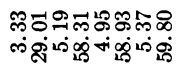 & 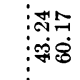 & 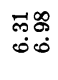 & 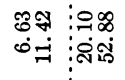 & 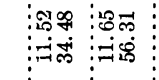 & 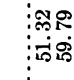 & 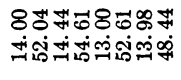 \\
\hline 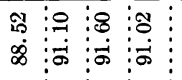 & 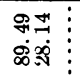 & 总 & 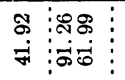 & 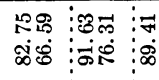 & $\begin{array}{l}8= \\
\text { 8: } \\
\text { s.t. }\end{array}$ & 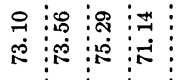 \\
\hline
\end{tabular}

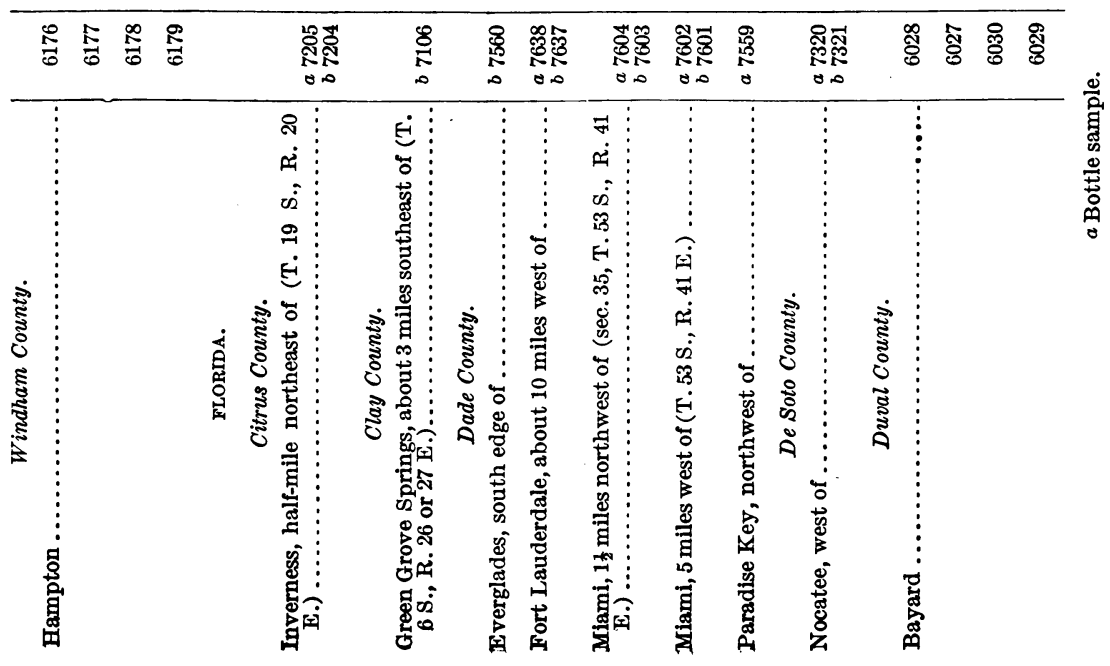




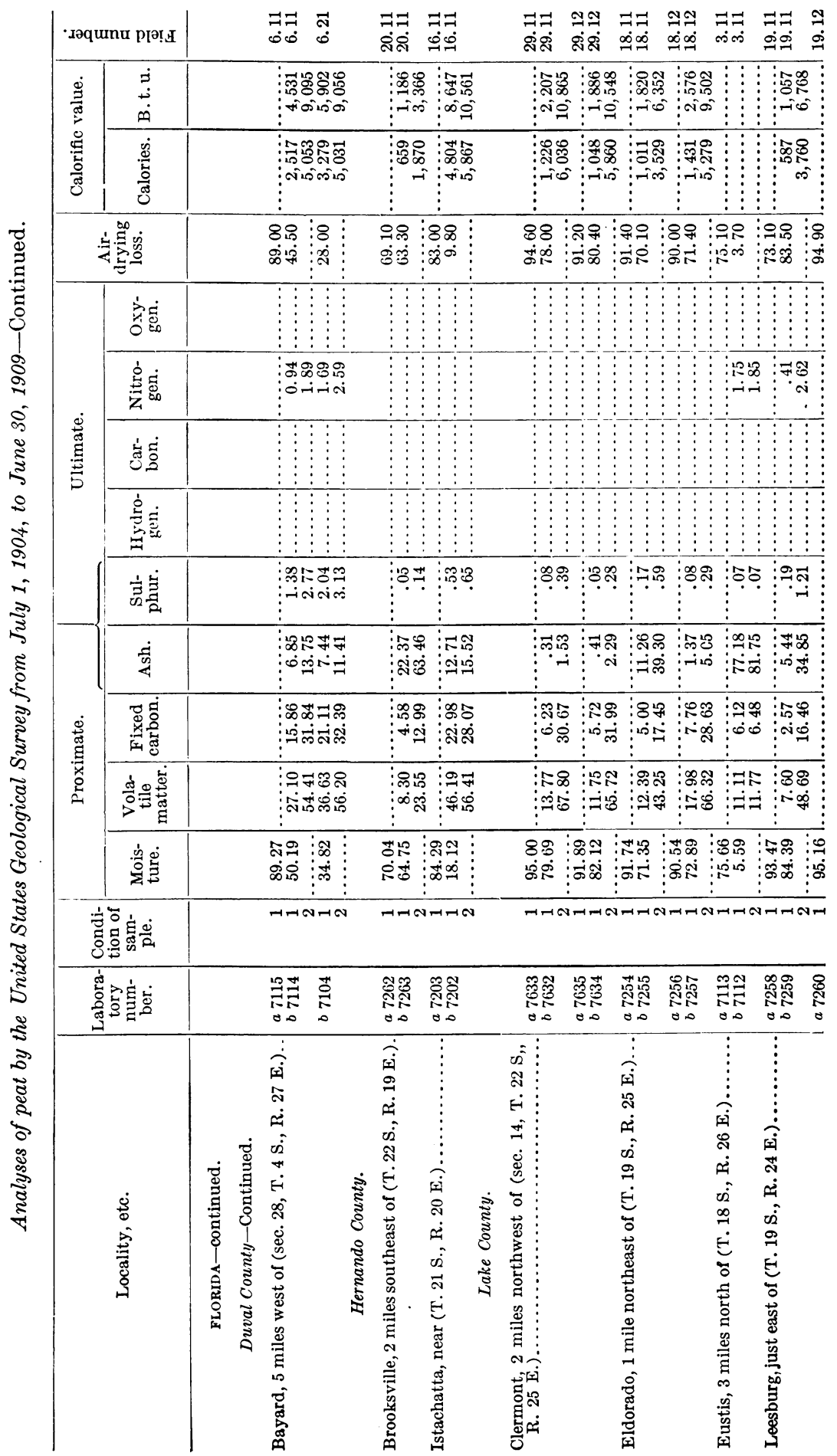




\begin{tabular}{|c|c|c|c|c|c|c|c|c|c|c|c|c|c|c|c|}
\hline \multicolumn{2}{|c|}{ · גəqumu prə!. } & & $\begin{array}{l}=\vec{Z} \\
\text { มี่ }\end{array}$ & 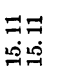 & & $\begin{array}{l}\Rightarrow= \\
\Rightarrow \infty \infty\end{array}$ & $\begin{array}{l}\vec{\pi} \vec{N} \\
\infty \infty \infty\end{array}$ & & $\begin{array}{l}\Rightarrow= \\
\therefore=\end{array}$ & 곳군 & & 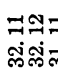 & & & \\
\hline \multirow{2}{*}{ 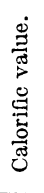 } & $\begin{array}{r}\dot{\dot{m}} \\
\dot{\oplus} \\
\end{array}$ & & 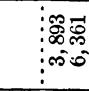 & $\begin{array}{l}\vdots \\
\vdots \\
\vdots \\
0\end{array}$ & & $\begin{array}{l}\vdots-17 \\
\vdots \\
\vdots-\infty \\
-\infty \infty\end{array}$ & 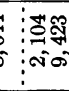 & & 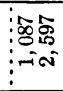 & $\begin{array}{l}\sigma_{0}^{\circ} \\
\sigma_{\alpha}^{\circ} \\
\vdots\end{array}$ & & & & & \\
\hline & 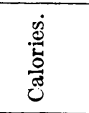 & & 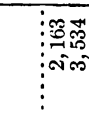 & 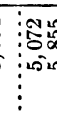 & & 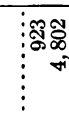 & 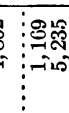 & & : & $\begin{array}{l}\vdots \\
\vdots \\
\vdots \\
\vdots \\
\vdots\end{array}$ & & & & & \\
\hline \multicolumn{2}{|c|}{ 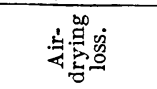 } & & 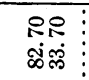 & $\begin{array}{l}889 \\
\text { tin }\end{array}$ & & 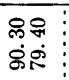 & 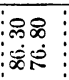 & & 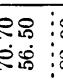 & & & 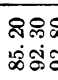 & & & : \\
\hline \multirow{5}{*}{ 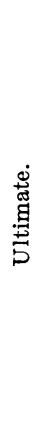 } & 㝓总 & & & & & : & & & & & & & & & \\
\hline & 总㻤 & & & : : & & $\vdots \vdots$ & & & $\vdots \vdots$ & & & & & & \\
\hline & 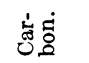 & & : : & : : & & $\vdots \vdots$ & & & $\vdots \vdots \vdots$ & $\vdots \vdots \vdots \vdots$ & & & & & \\
\hline & 产㻤 & & & : & & & : & & : : & & & & & & $\vdots \vdots \vdots$ \\
\hline & 离急 & & ". & $\vdots$ & & 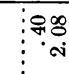 & $\begin{array}{l}0 \\
\vdots\end{array}$ & & 冓 & : & & & & & t. \\
\hline \multirow{4}{*}{ 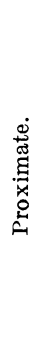 } & 这 & & 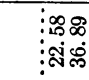 & $\begin{array}{l}\mathbb{J} \\
\vdots \\
\text { sin }\end{array}$ & & $\begin{array}{l}\infty \\
\vdots \\
\vdots \\
\vdots \\
\vdots \\
\vdots\end{array}$ & 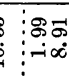 & & 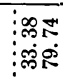 & $\begin{array}{l}: \\
\vdots \\
\vdots\end{array}$ & & & & & $\begin{array}{l}88.8 \\
\text { sion }\end{array}$ \\
\hline & 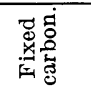 & & 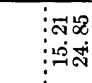 & 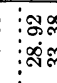 & & $\begin{array}{l}\infty_{\infty}^{\infty} \\
\vdots \\
\vdots \\
0\end{array}$ & 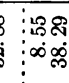 & & 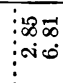 & $\begin{array}{l}08 \\
\vdots \\
\vdots\end{array}$ & & & & & 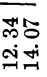 \\
\hline & 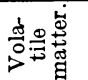 & & 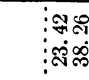 & : & & 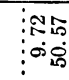 & 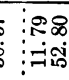 & & $\begin{array}{l}\text { :84 } \\
\vdots \\
\vdots\end{array}$ & $\begin{array}{l}\infty \\
\vdots \\
\vdots \\
0 \\
0\end{array}$ & & & & & 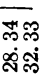 \\
\hline & 商递 & & $\begin{array}{l}\infty \propto: \\
\infty \\
\infty \infty\end{array}$ & 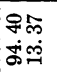 & & $\begin{array}{l}\infty \\
\infty \\
\dot{\infty} \infty \\
\dot{\infty}\end{array}$ & 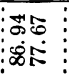 & & 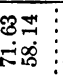 & 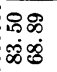 & & 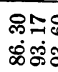 & & & ֶֻ. \\
\hline \multicolumn{2}{|c|}{ 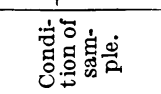 } & \multicolumn{4}{|c|}{ 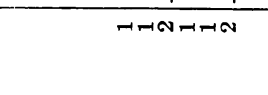 } & \multicolumn{2}{|c|}{ આーNエエN } & \multicolumn{4}{|c|}{ ЛПNTIN } & $A \pi-1$ & & & $\sqrt{-N}$ \\
\hline \multicolumn{2}{|c|}{ 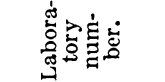 } & & 总芯 & 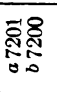 & & 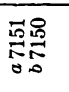 & 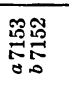 & & స్త్రిన్స & 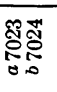 & & 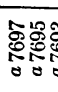 & & & ํㅗㅇ \\
\hline \multicolumn{2}{|c|}{ 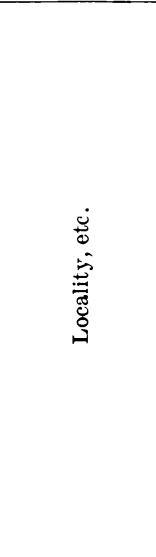 } & 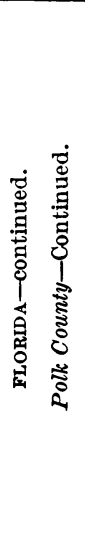 & 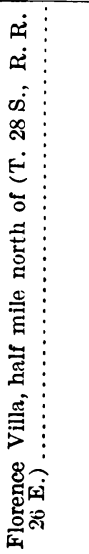 & 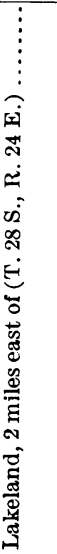 & 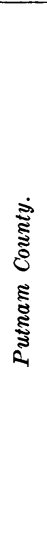 & 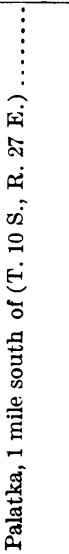 & & 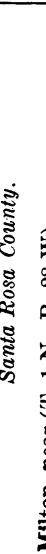 & 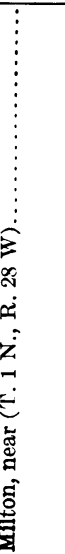 & & 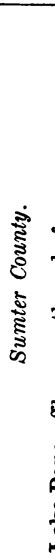 & 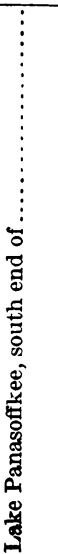 & 这 & 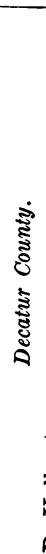 & 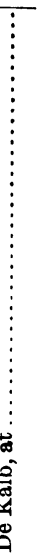 \\
\hline
\end{tabular}


$\neg$ N

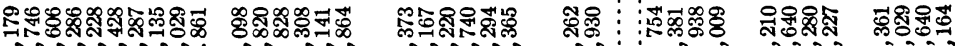

in

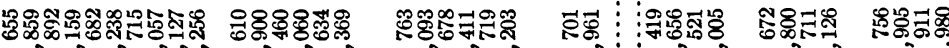

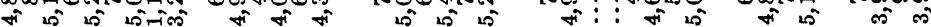

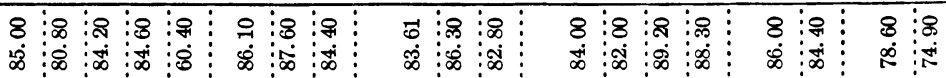

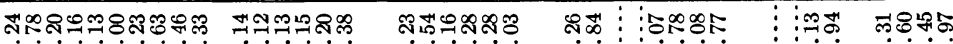

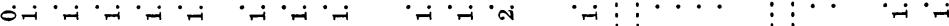

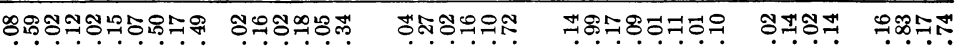

\begin{tabular}{|c|c|c|c|c|c|}
\hline 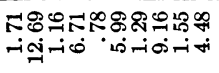 & 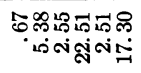 & 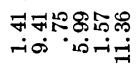 & 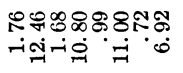 & அோ\& & 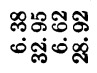 \\
\hline 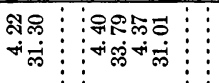 & 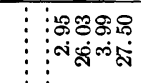 & $\begin{array}{l}\infty \\
\vdots \\
\vdots \\
\vdots \infty \\
\vdots\end{array}$ & 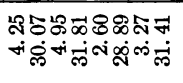 & \begin{tabular}{l}
$\infty \infty \infty$ \\
\hdashline$+\infty$
\end{tabular} & \\
\hline 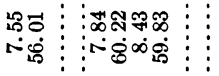 & $\begin{array}{l}\vdots \\
\vdots \\
\vdots \\
\vdots\end{array}$ & 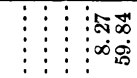 & 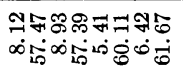 & $\begin{array}{l}\infty \\
\vdots \infty \\
\infty \\
\infty\end{array}$ & \\
\hline 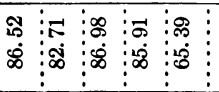 & 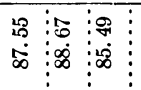 & 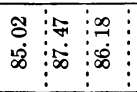 & 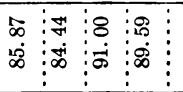 & $\begin{array}{l:c}\infty & \vdots \\
\infty & \vdots \\
\infty & \vdots\end{array}$ & 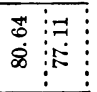 \\
\hline
\end{tabular}

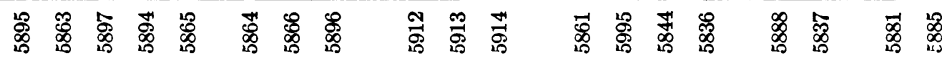

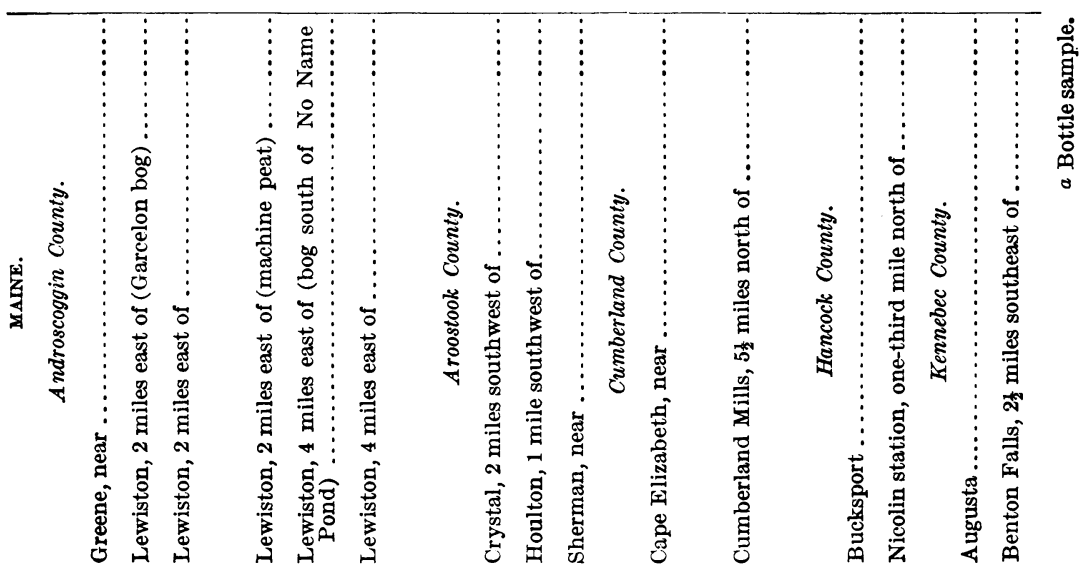


USES OF PEAT FOR FUEL AND OTHER PURPOSES.

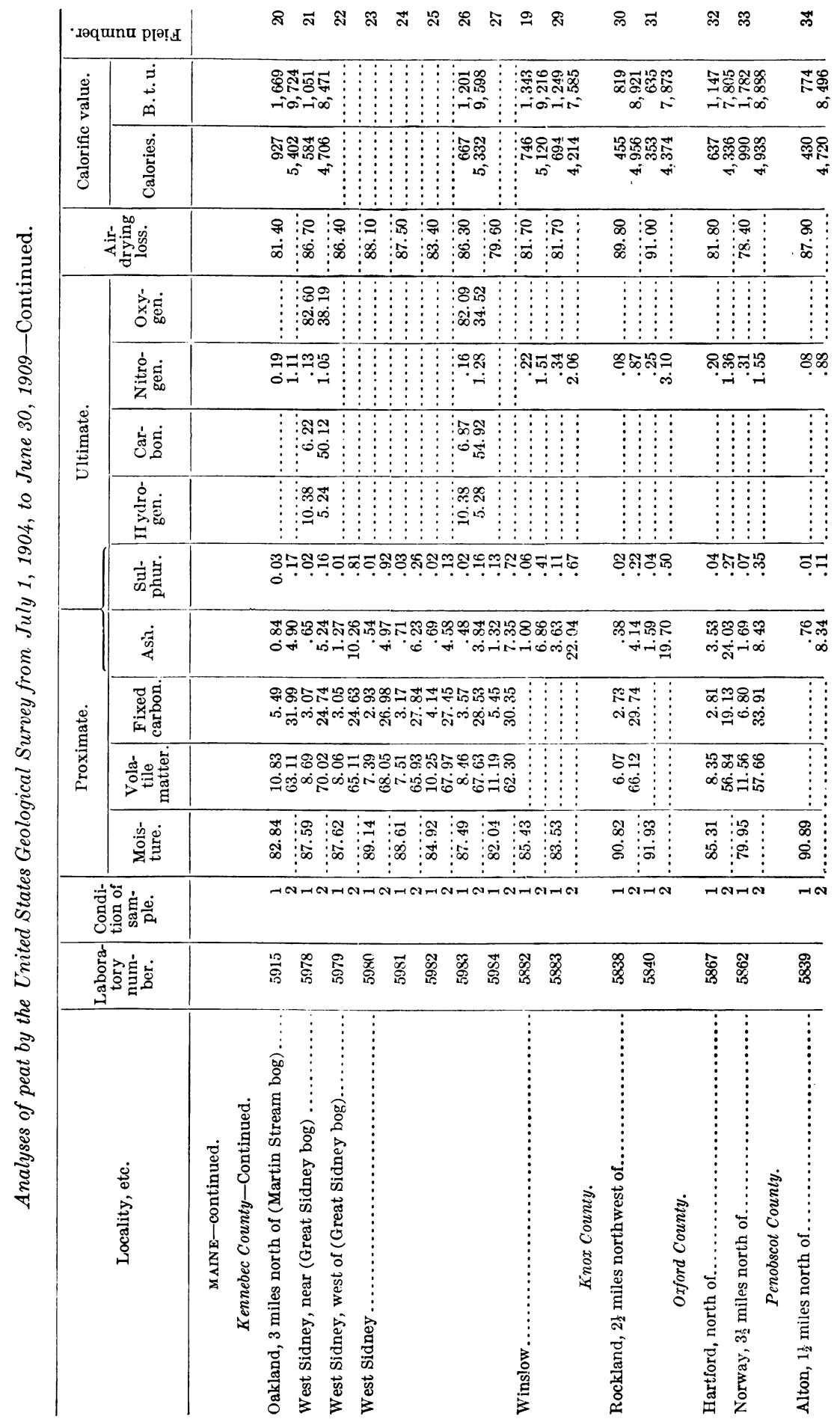




\begin{tabular}{|c|c|c|c|}
\hline 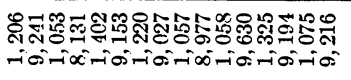 & 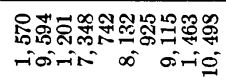 & 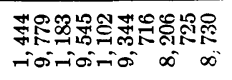 & 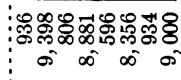 \\
\hline $0=$ & 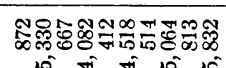 & & \\
\hline
\end{tabular}

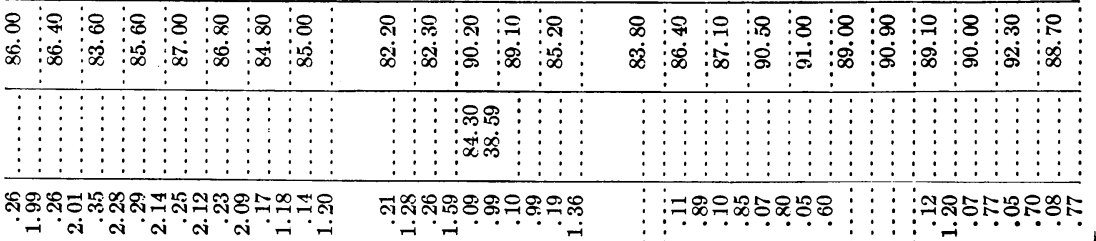

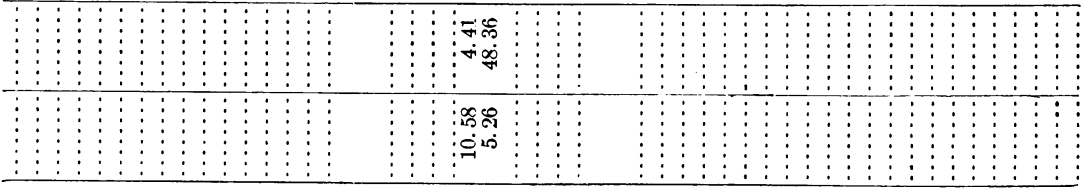

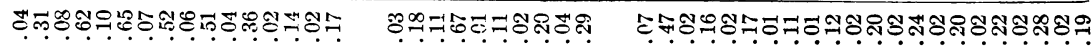

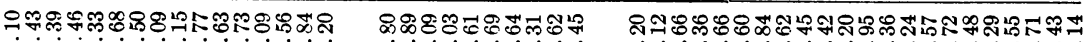

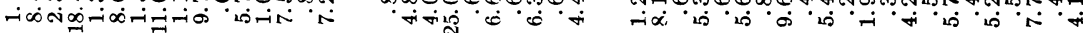

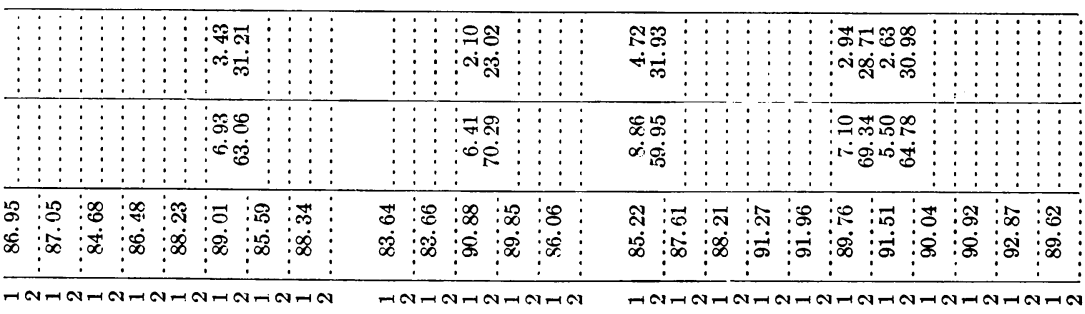

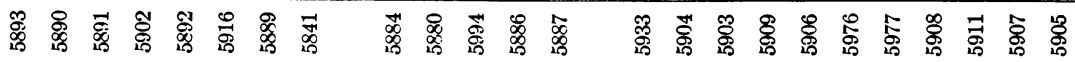

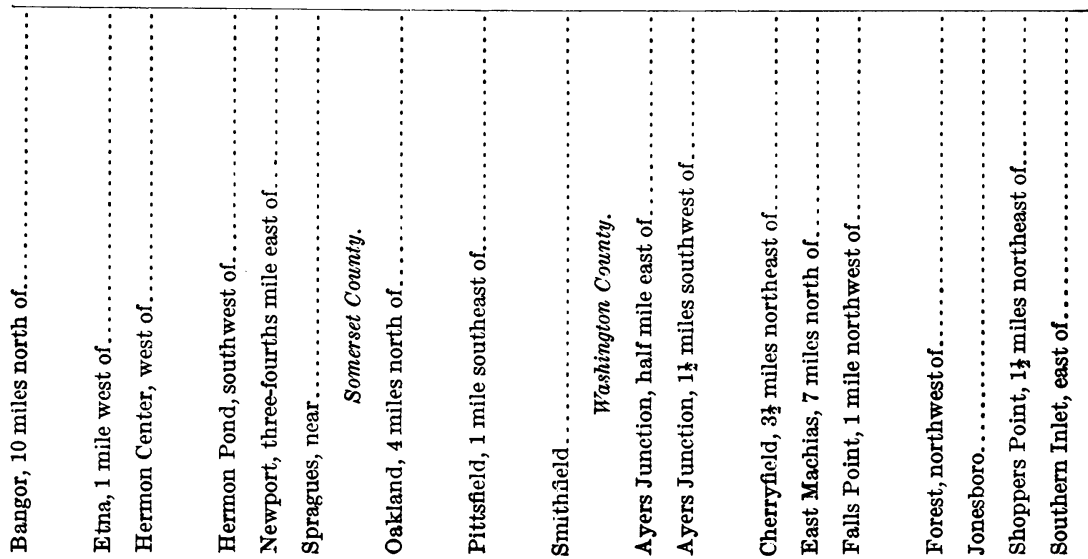




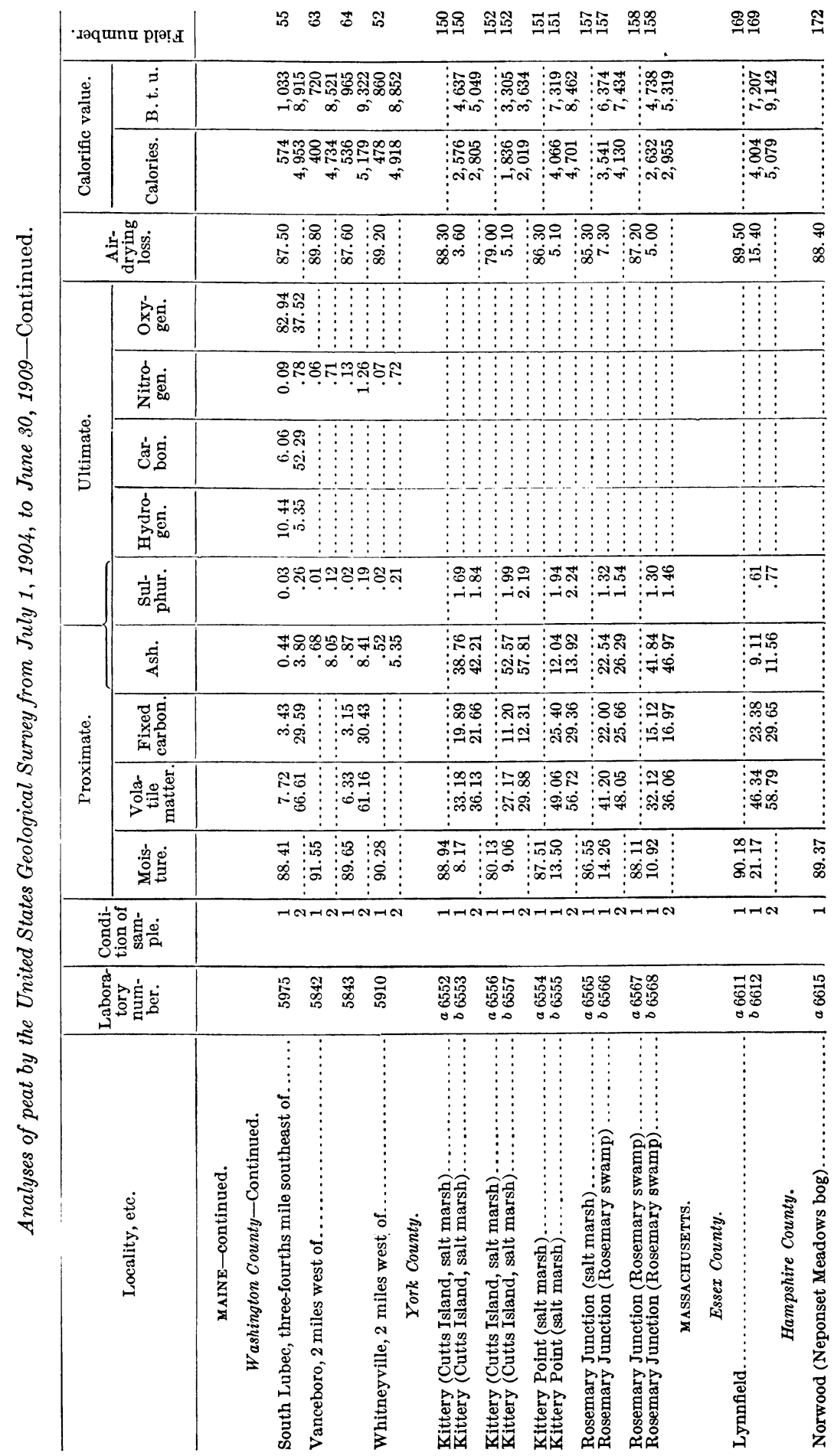


USES OF PEAT FOR FUEL AND OTHER PURPOSES.

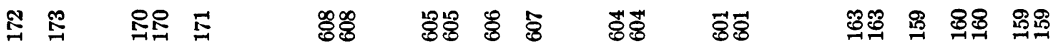

\begin{tabular}{|c|c|c|c|c|c|c|c|c|}
\hline 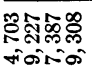 & 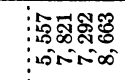 & 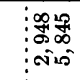 & 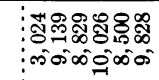 & 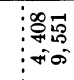 & 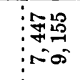 & 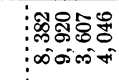 & 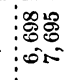 & 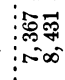 \\
\hline 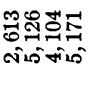 & 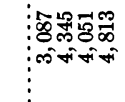 & 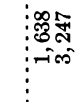 & 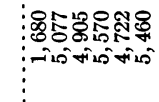 & 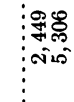 & 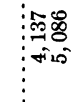 & 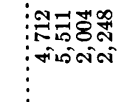 & 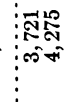 & 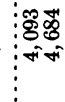 \\
\hline 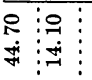 & 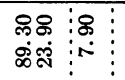 & $\begin{array}{l}\text { 유 } \\
\text { 요 } \\
\text { pio }\end{array}$ & 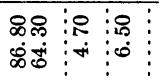 & $\begin{array}{l}\text { 아유 } \\
\text { idi }\end{array}$ & $\begin{array}{l}88: \\
\dot{\infty}= \\
\dot{\infty}:\end{array}$ & $\begin{array}{l:l}8 R & 8 \\
\infty & \vdots \\
\infty & \vdots\end{array}$ & $\begin{array}{l}\infty \& 0 \\
\infty \infty \\
\infty 00\end{array}$ & 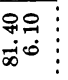 \\
\hline & & & 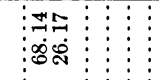 & & & & & \\
\hline & & & $\begin{array}{l}\vdots-\infty \\
\vdots \\
\vdots\end{array}$ & & $\vdots \vdots$ & & & \\
\hline & & $\vdots \vdots$ & 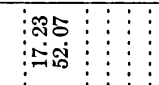 & & & & & \\
\hline & : : : & $\vdots \vdots \vdots \vdots \vdots \vdots \vdots \vdots$ & $\begin{array}{l}148 \\
\vdots \infty \\
\infty \\
\vdots+1\end{array}$ & & & & & \\
\hline 욤ำ & : & ఏల్లి下 & : & 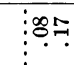 & 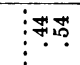 & 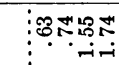 & ن. & : \\
\hline 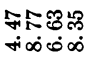 & 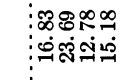 & 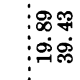 & 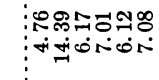 & $\begin{array}{l}\infty \mathbb{8} \\
\vdots \\
\text { ico }\end{array}$ & $\begin{array}{l}-\infty \\
\infty \\
\infty\end{array}$ & 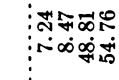 & 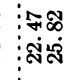 & 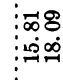 \\
\hline 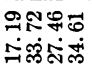 & 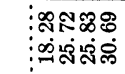 & $\begin{array}{l}0 \% \\
0 \infty \infty \\
0\end{array}$ & 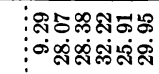 & 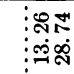 & 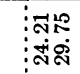 & 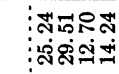 & $\begin{array}{l}\infty \\
\vdots \\
\vdots \text { ส่ส }\end{array}$ & 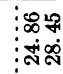 \\
\hline 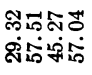 & 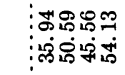 & 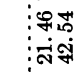 & 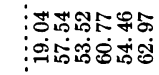 & 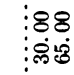 & $\begin{array}{l}\text { :m유 } \\
\vdots \\
980\end{array}$ & 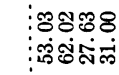 & 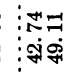 & 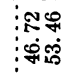 \\
\hline 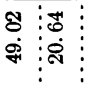 & $\begin{array}{l:l}\infty & \infty \\
\infty & \infty \\
\infty & \infty \\
\infty & \infty\end{array}$ & 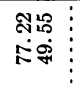 & 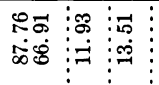 & 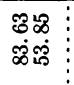 & 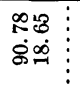 & 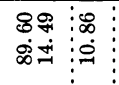 & $\begin{array}{l}85 \\
850 \\
: \mathcal{1}\end{array}$ & 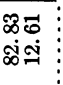 \\
\hline$v \rightarrow \infty$ & ПーNーN & $\because \pi N$ & HANAC & $-\pi \rightarrow \infty$ & $\pi-N$ & $\Rightarrow \rightarrow N-1$ & & \\
\hline
\end{tabular}

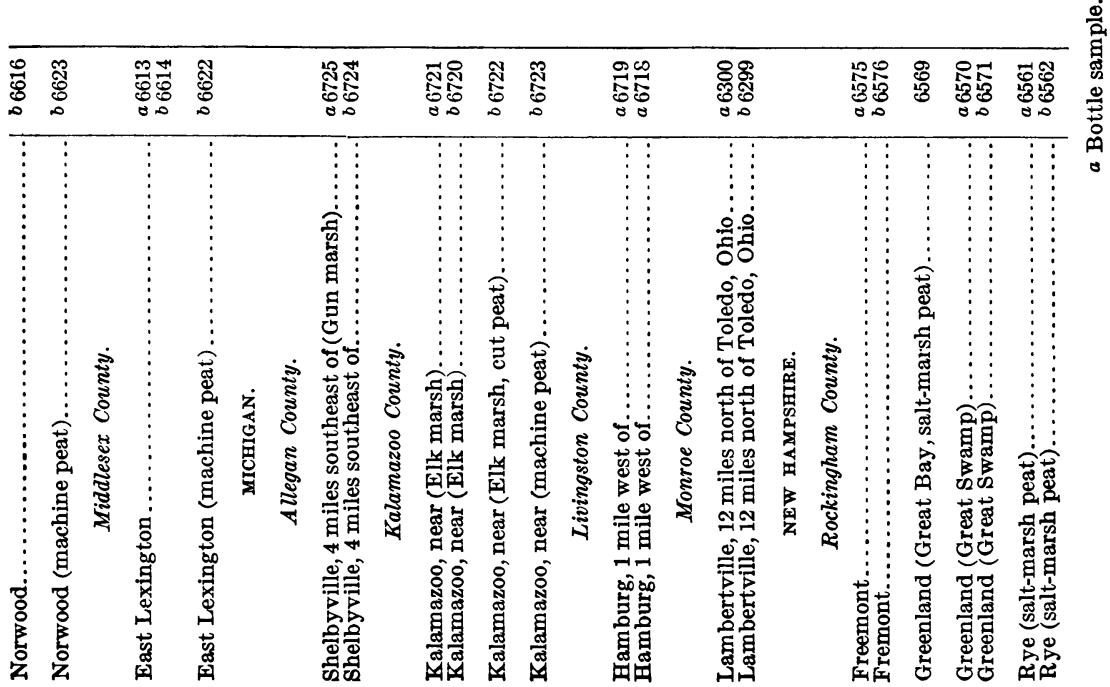




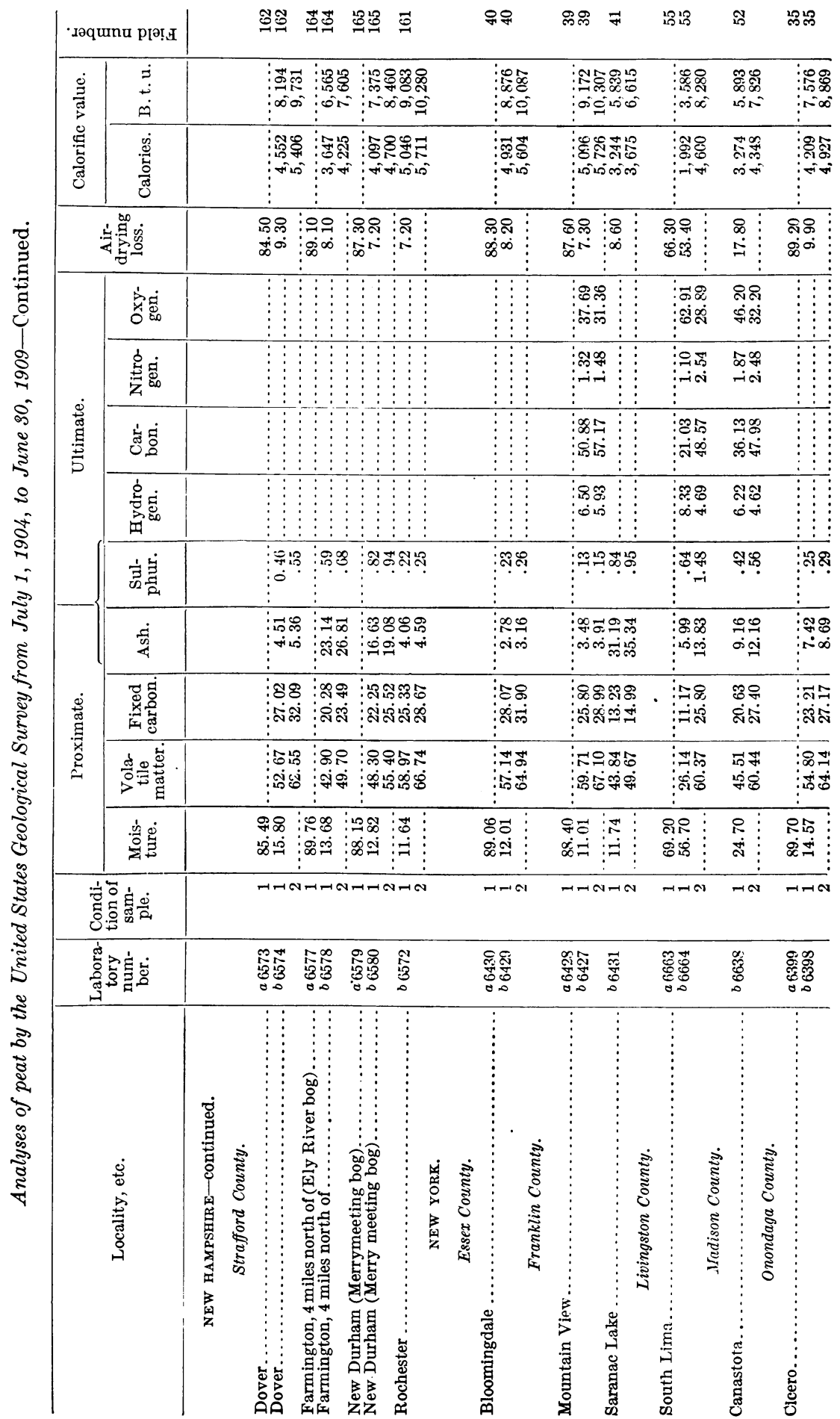


USES OF PEAT FOR FUEL AND OTHER PURPOSES.

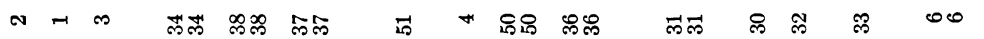

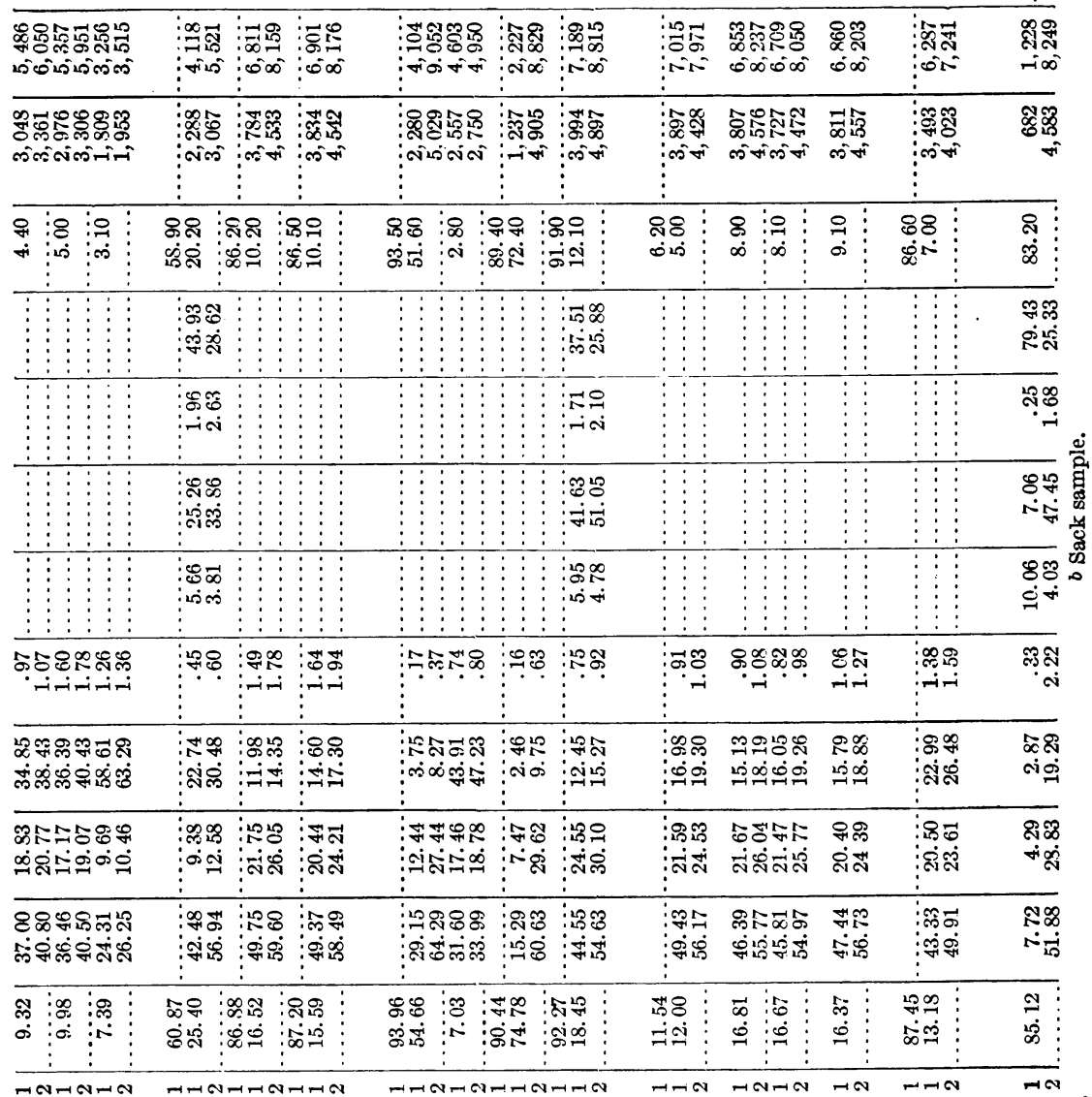

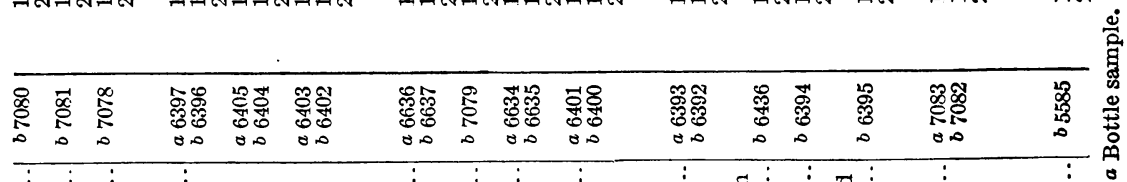

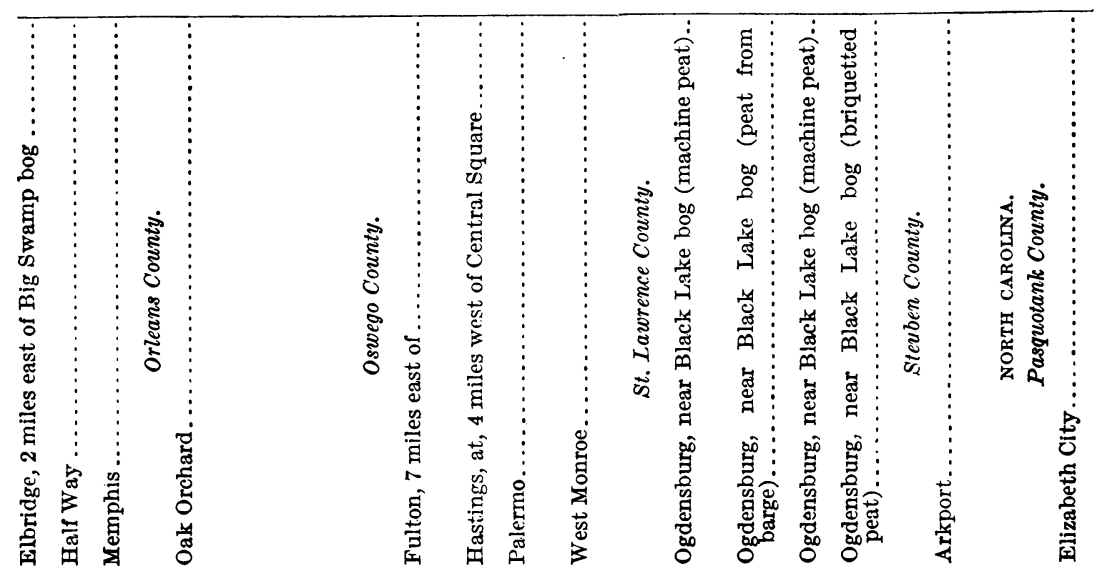




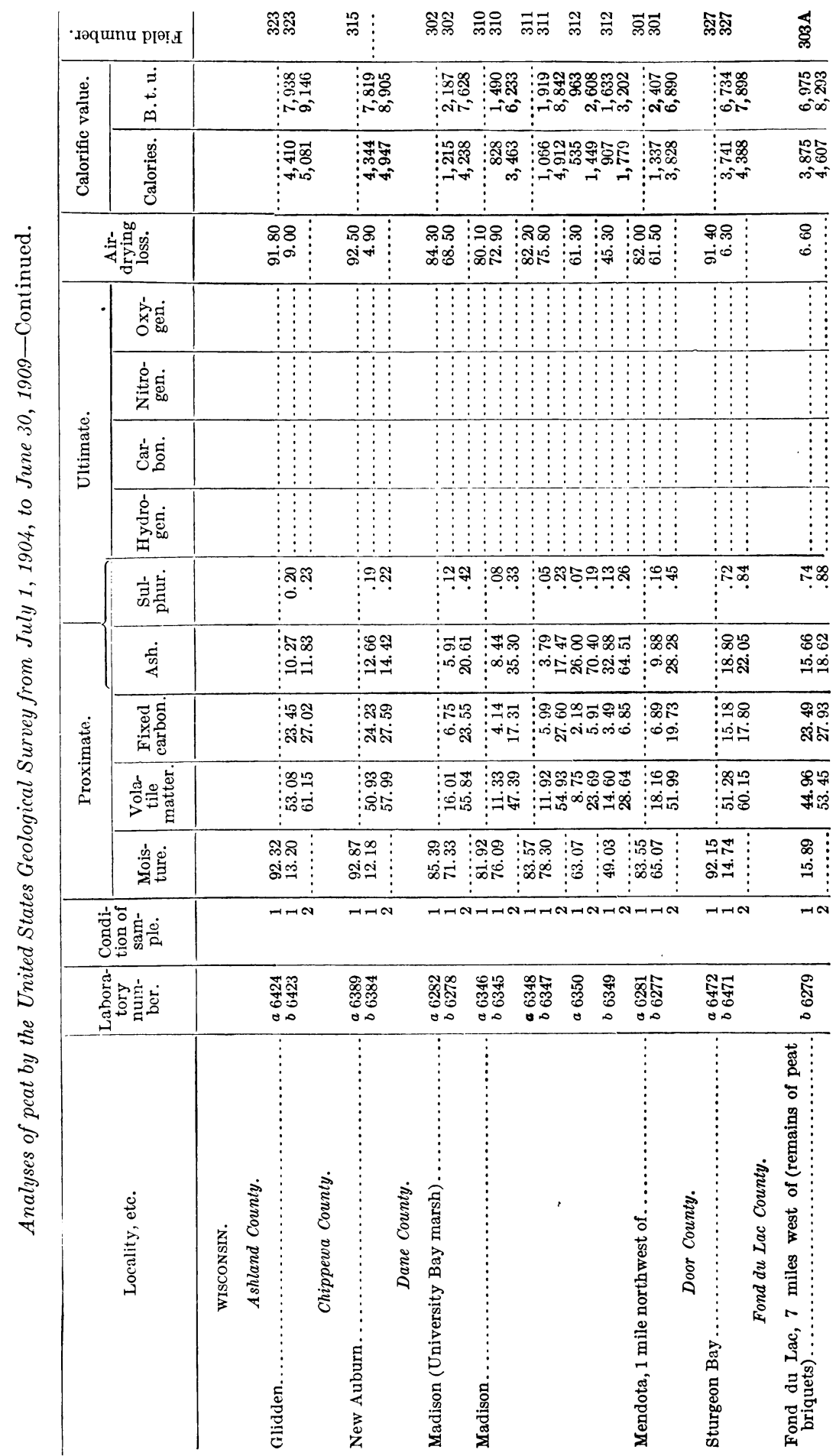


USES OF PEAT FOR FUEL AND OTHER PURPOSES.

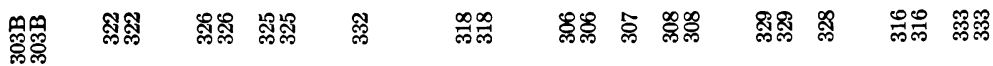

\begin{tabular}{|c|c|c|c|c|c|c|c|c|c|}
\hline 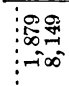 & 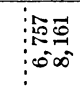 & 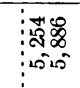 & $\begin{array}{l}38 \\
\infty \\
0 \\
0 \\
0\end{array}$ & 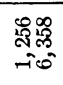 & 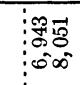 & 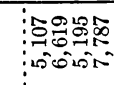 & 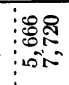 & 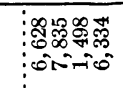 & 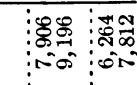 \\
\hline 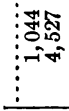 & 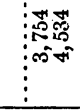 & $\begin{array}{l}\text { å. } \\
\text { बై } \\
\text { Nim } \\
\vdots \\
\end{array}$ & 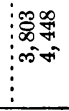 & 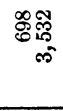 & 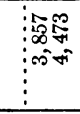 & 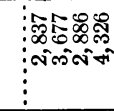 & 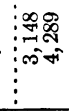 & 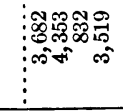 & 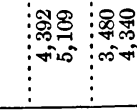 \\
\hline $\begin{array}{l}880 \\
8.8 \\
\infty 80\end{array}$ & 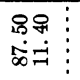 & 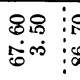 & $\begin{array}{l}\text { Ro } \\
\text { s. } \\
\infty\end{array}$ & $\begin{array}{c}8 \\
\stackrel{8}{0} \\
\infty \\
\infty\end{array}$ & 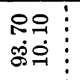 & 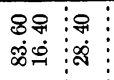 & $\begin{array}{l}\text { 8\% } \\
\text { ळ. }\end{array}$ & 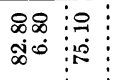 & 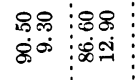 \\
\hline 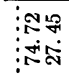 & & & & & & & & 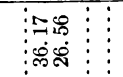 & \\
\hline $\begin{array}{l}\infty \\
\vdots \\
\vdots \\
\vdots \\
\vdots\end{array}$ & & & & & & & & זה & \\
\hline 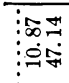 & : & & & & & & & 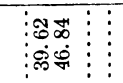 & \\
\hline 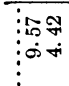 & $\vdots$ & & $::$ & $\vdots \vdots$ & & & & & \\
\hline$\vdots \cong$ & : & :สฺ & 转。占 & 20 & 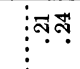 & 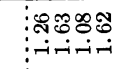 & : & : & : \\
\hline 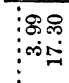 & 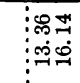 & 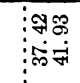 & 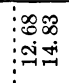 & 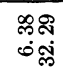 & 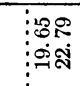 & 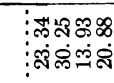 & 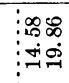 & 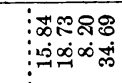 & 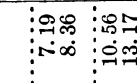 \\
\hline 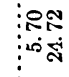 & 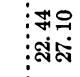 & 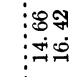 & 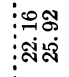 & $\begin{array}{l}\text { 궁여 } \\
\text { अंत }\end{array}$ & 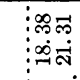 & 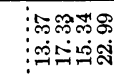 & 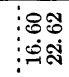 & 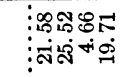 & 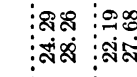 \\
\hline 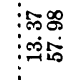 & 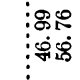 & 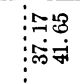 & 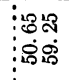 & 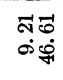 & 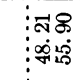 & 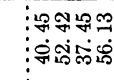 & 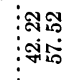 & 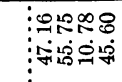 & 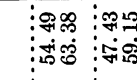 \\
\hline 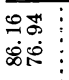 & 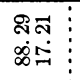 & 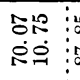 & 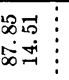 & $\begin{array}{l}\text { J゙ } \\
\dot{\infty}\end{array}$ & 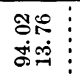 & $\begin{array}{l}\infty \\
\infty \\
\infty \\
\infty \\
\infty \\
\infty \\
\infty\end{array}$ & $\begin{array}{l}=8 \\
\infty \notin \infty \\
\infty \notin \infty\end{array}$ & 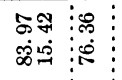 & 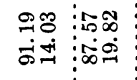 \\
\hline$\pi-\infty$ & $\because \pi N$ & ที & $A \rightarrow N$ & $\rightarrow N$ & $\operatorname{maN}$ & $\because \rightarrow N \neg 0$ & $\rightarrow N$ & $\| N \neg N$ & $-1-1$ \\
\hline
\end{tabular}

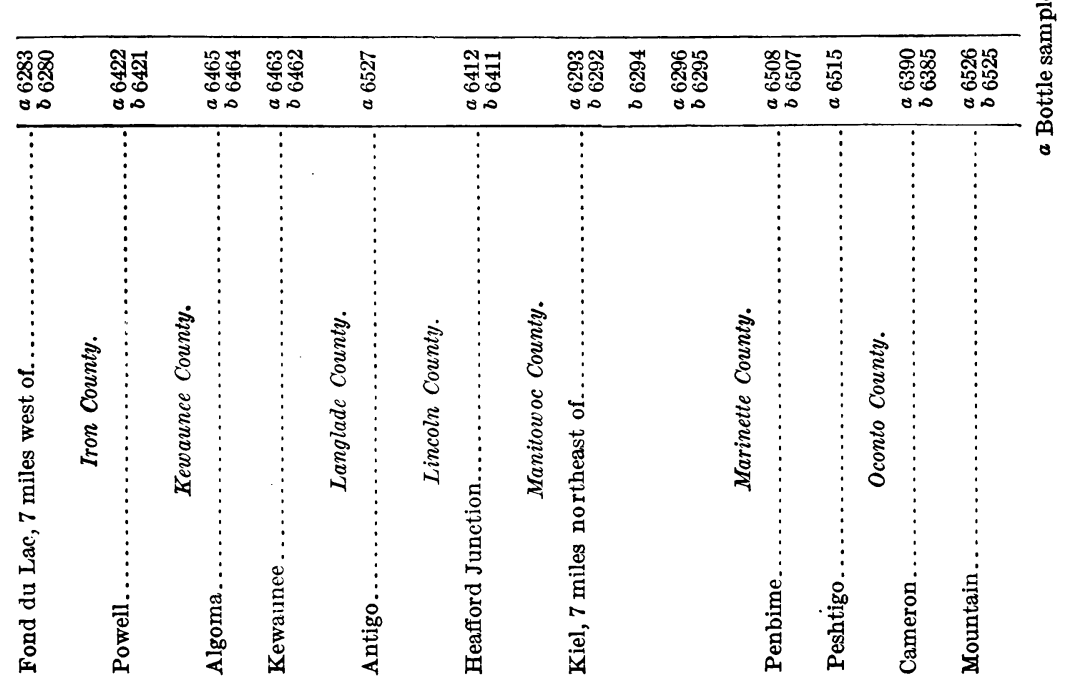


USES OF PEAT FOR FUEL AND OTHER PURPOSES.

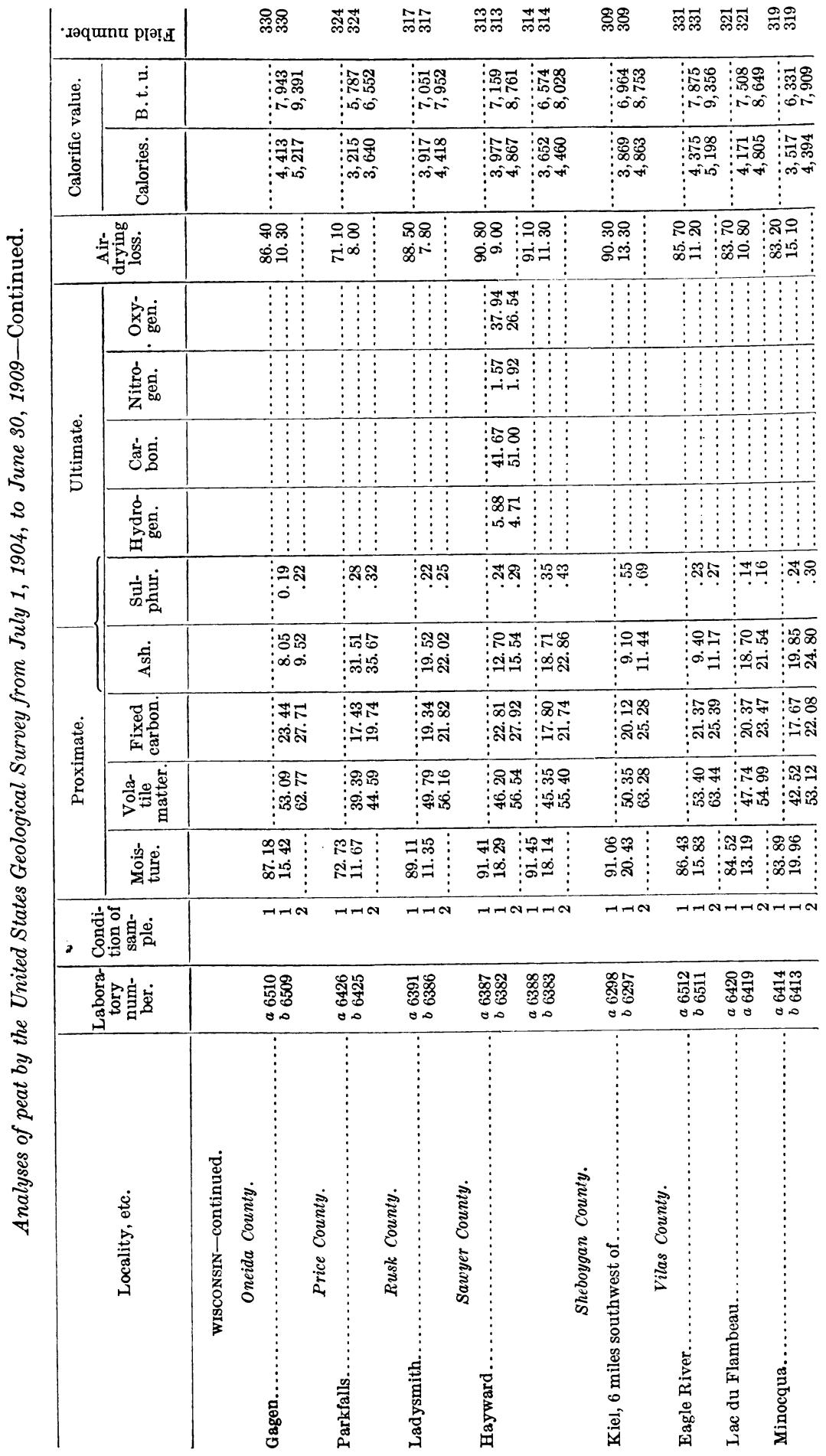


USES OF PEAT FOR FUEL AND OTHER PURPOSES.

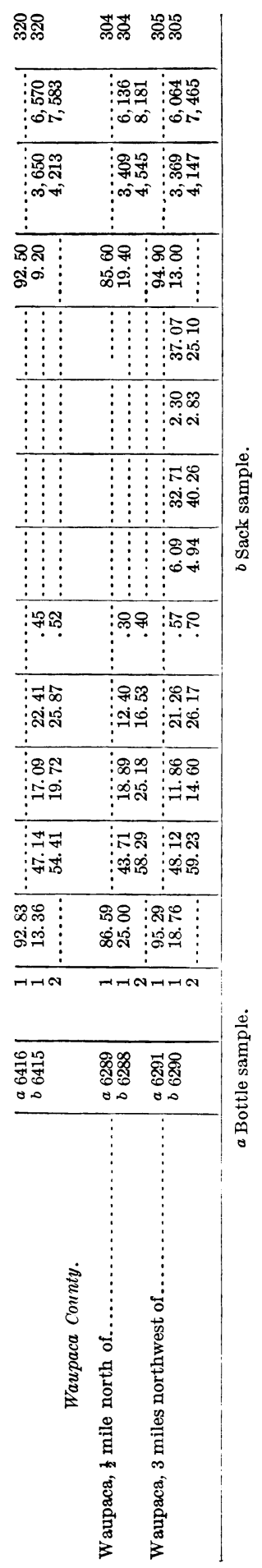




\section{SELECTED BIBLIOGRAPHY ON PEAT.}

Some of the more important publications on the uses of peat are the following:

ANREP, A., jr. Investigation of the peat bogs and peat industry of Canada during the season 1909-10. Canada Dept. Mines, Mines Branch, Bull. No. 4. 2d ed., 1910.

Beach, A. Peat fuel. Proc. Inst. Civ. Eng., vol. 147, 1900-1901.

Beyer, S. W. Peat deposits in Iowa. Iowa Geol. Survey, vol. 19, 689-733.

Bordollo, J. Peat fuel production. Engineer, Chicago, vol. 43, May 15, 1906, pp. 334-335.

Briquets as fuel in foreign countries. Special Consular Reports, No. 27, Washington, 1903. Gives an account of the use and manufacture of peat and other kinds of briquets in Europe.

Carter, W. E. H. Peat fuel; its manufacture and uses. Rept. Ontario Bureau Mines for 1903. Toronto, 1904. An excellent account of Canadian conditions and methods of peat manufacture at the time of publication.

DANGER, L. Torfstreu und Torfmull, Lubeck, Germany, 1901.

Davis, Charles A. Origin and distribution of peat in Michigan. Rept. Mich. State Bd. Geol. Survey, 1906. Lansing, 1907.

An estimate of the peat resources of the United States. Engineering Magazine, vol. 37, No. 1. New York, 1909.

The gasification of peat, Cassier's Magazine, vol. 36, No. 4. New York, 1909. Production of peat in United States in 1908. Mineral Resources of the United States, U. S. Geol. Survey. Washington, 1909.

Production of peat in United States in 1909. Mineral Resources of the United States. U. S. Geol. Survey, Washington, 1911.

The preparation and uses of peat as fuel in Alaska. Bull. U. S. Geol. Survey, 442, pp. 101-132.

Ekenberg, M. Fuel from peat. Journal Iron and Steel Inst., No. 1. London, 1909.

Ells, R. W. Peat Industry in Canada. Ann. Rept. Ontario Bureau Mines, vol. 2.

FrüH, J., and Schroeter, C. Die Moore der Schweiz, mit Berucksichtigung der gesamten Moorfrage. Beitr. Geol. Schweiz, Geotech., ser. 3. Bern, 1904. A full description of the peat deposits of Switzerland and a discussion of the distribution of peat over the earth. Has an extensive bibliography.

Gissing, E. T. Commercial peat; its uses and its possibilities. London, 1909.

- and BjöRling, P. R. Peat; its use and manufacture. London, 1907.

HARPER, R. M. Preliminary report on the peat deposits of Florida. Florida State Geol. Survey, 3d Ann. Rept., 206-375.

Hausding, A. Handbuch der Torfgewinnung und Torfverwertung. 2d ed. P. Parey. Berlin, 1904.

IowA Geological Survey Bull. 2. Preliminary report on the peat resources of Iowa. Des Moines, 1905. (See also BEYER, S. W., above.)

Johnson, S. W. Peat and its uses. New York, 1866.

KERR, W. A. Peat and its products. Glasgow, 1905.

Koller, T. Die Torfindustrie. Vienna, 1898.

Leavitt, T. H. Facts about peat. Boston, 1867. Reprinted in an abridged form, Boston, 1904.

Lesquereux, L. Origin of coal. Ann. Rept. Pennsylvania Geol. Survey, 1885, pp. 95-121. 
MacFartand, T. Moss manure. Bull. 97, Lab. Inland Rev., Dept. of Canada, Ottawa, 1904.

Michigan State Board Agriculture. Reports. Lansing, 1853, 1855, 1865, 1878, 1886.

- State Board Geological Survey. Ann. Reports. Lansing, 1902-1904, 19061908.

New Jersey. Annual Report State Geologist, 1905. Trenton, 1906.

NEw York. Reports State Geologist, Nos. 21, 23. Albany, 1903, 1904.

Nystrom, E. Peat and lignite, their manufacture and uses in Europe. Canada Dept. of Mines. Ottawa, 1908.

and ANREP, S. A. Investigation of the peat bogs and peat industry of Canada during the season 1908-9. Canada Dept. Mines, Mines Branch Bull. No. 1. Ottawa, 1909.

Parmelee, C. W., and McCourt, W. E. Peat deposits of northern New Jersey. Ann. Rept. State Geologist of New Jersey, 1905, pp. 223-313.

Ryan, H. Reports on the Irish peat industries. Econ. Proc. Roy. Soc., Dublin, vol. 1, parts 10, 13. Dublin, 1907, 1908.

SANKEY, H. R. The utilization of peat for making gas or charcoal with recovery of by-products. Engineering, Sept. 11, 1908.

Shaler, N. S. Fluviatile swamps of New England. Am. Jour. Sci., 3d ser., No. 33, 1887.

Fresh-water morasses of the United States. Tenth Ann. Rept. U. S. Geol. Survey, part 2. 1890.

Origin, distribution, and commercial value of peat deposits. Sixteenth Ann. Rept. U. S. Geol. Survey, part 4. 1895.

Peat and swamp soils. Twelfth Ann. Rept. U. S. Geol. Survey. 1891.

- Swamps of the United States. Science, vol. 7, Mar. 12, 1886, pp. 232-233.

TAylor, A. E. Peat deposits of northern Indiana. Ann. Rept. Indiana Dept. Geology and Nat. Res., 1906, pp. 73-298.

U. S. Department of Agriculture, Bureau of Soils. Soil Survey reports and maps. The maps show distribution and extent of swamps in the regions examined.

U. S. Consular Reports. Contain many references and notes on peat utilization in European countries.

U. S. Geological Survey. Peat deposits of Maine. Bull. 376. E. S. Bastin and C. A. Davis. Washington, 1909.

Topographic maps published by the Survey show the distribution and extent of swamps in the areas covered.

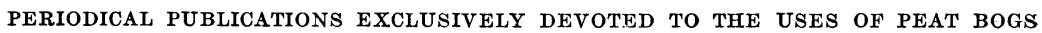
AND PEAT.

(1) The Journal of the American Peat Society. Quarterly. Toledo, Ohio.

(2) Mitteilungen des Vereins zur Förderung der Moorkultur im deutschen Reiche. Biweekly. Berlin, Germany.

(3) Osterreichische Moorzeitschrift. Monthly. Staab, Austria.

(4) Zeitschrift für Moorkultur und Torfverwertung. 4-6 numbers a year. Vienna, Austria.

(5) Svenska Mosskulturforeningens Tidskrift. Bimonthly. Jönköping, Sweden.

(6) Schreiber's Jahresberichte, Neues über Moorkultur und Torfverwertung. Annual. Staab, Austria.

(7) Die Verhandlungsberichte der Zentral-Moorkommission in Preussen.

(8) Mitteilungen des Hardekulturvereins für Schleswig-Holstein.

(9) Meddelse fra Mosindustrie-Foreningen. Viborg, Denmark.

(10) Finska Mosskulturforeningens Arsbok. Helsingfors, Finland.

(11) Hedeseskabets Tidskrift. Aarhus, Denmark.

(12) Mosebladet. Monthly. Viborg, Denmark. 


\section{PUBLICATIONS ON FUEL TESTING.}

The following publications, except those to which a price is affixed, can be obtained free by applying to the Director of the Bureau of Mines, Washington, D. C. The priced publications can be purchased from the Superintendent of Documents, Government Printing Office, Washington, D. C.:

\section{PUBLICATIONS OF THE BUREAU OF MINES.}

Bulletin 1. The volatile matter of coal, by H. C. Porter and F. K. Ovitz. 1910. $56 \mathrm{pp} .1 \mathrm{pl}$.

Bulletin 2. North Dakota lignite as a fuel for power-plant boilers, by D. T. Randall and Henry Kreisinger. 1910. 42 pp., 1 pl.

Bulletin 3. The coke industry of the United States as related to the foundry, by Richard Moldenke. 1910. $32 \mathrm{pp}$.

Bulletin 4. Features of producer-gas power-plant development in Europe, by R. H. Fernald. 1910. 27 pp., 4 pls.

Bulletin 5. Washing and coking tests of coal at Denver, Colo., July 1, 1908, to June 30, 1909, by A. W. Belden, G. R. Delamater, J. W. Groves, and K. M. Way. 1910. $62 \mathrm{pp}$.

Bulletin 6. Coals available for illuminating-gas manufacture, by A. H. White and Perry Barker. 1911. 77 pp., 4 pls.

Bulletin 7. Essential factors in the formation of producer gas, by J. K. Clement, L. H. Adams, and C. N. Haskins. 1911. $58 \mathrm{pp} ., 1 \mathrm{pl}$.

Bulletin 8 . The flow of heat through furnace walls, by W. T. Ray and Henry Kreisinger. 1911. 32 pp.

Bulletin 9. Recent development of the producer-gas power plant in the United States, by R. H. Fernald. 82 pp., 2 pls. Reprint of United States Geological Survey Bulletin 416.

Bulletin 11. The purchase of coal by the Government under specifications, by G. S. Pope. 80 pp. Reprint of United States Geological Survey Bulletin 428.

Bulletin 12. Apparatus and methods for the sampling and analysis of furnace gases, by J. C. W. Frazer and E. J. Hoffman. 1911. 22 pp.

Bulletin 13. Résumé of producer-gas investigations, by R. H. Fernald and C. D. Smith. 1911. 393 pp., 12 pls.

Bulletin 14. Briquetting tests of lignite, at Pittsburgh, Pa., 1908-9; with a chapter on sulphite-pitch binder, by C. L. Wright. 1911.64 pp., 11 pls.

Technical Paper 1. The sampling of coal in the mine, by J. A. Holmes. 1911. $18 \mathrm{pp}$.

Technical Paper 2. The escape of gas from coal, by H. C. Porter and F. K. Ovitz. 1911. $14 \mathrm{pp}$.

Technical Paper 3. Specifications for the purchase of fuel oil for the Government, with directions for sampling oil and natural gas, by I. C. Allen. $1911.13 \mathrm{pp}$. 


\section{PUBLICATIONS OF THE UNITED STATES GEOLOGICAL SURVEY.}

Professional Paper 48. Report on the operations of the coal-testing plant of the United States Geological Survey at the Louisiana Purchase Exposition, St. Louis, Mo., 1904; E. W. Parker, J. A. Holmes, M. R. Campbell, committee in charge. 1906. In three parts. 1492 pp., 13 pls. $\$ 1.50$.

Bulletin 261. Preliminary report on the operations of the coal-testing plant of the United States Geological Survey at the Louisiana Purchase Exposition, St. Louis, Mo., 1904; E. W. Parker, J. A Holmes, M. R. Campbell, committee in charge. 1905. 172 pp. 10 cents.

Bulletin 290. Preliminary report on the operations of the fuel-testing plant of the United States Geological Survey at St. Louis, Mo., 1905, by J. A. Holmes. 1906. 240 pp. 20 cents.

Bulletin 323. Experimental work conducted in the chemical laboratory of the United States fuel-testing plant, St. Louis, Mo., January 1, 1905, to July 31, 1906, by N. W. Lord. 1907.49 pp. 10 cents.

Bulletin 325. A study of four hundred steaming tests made at the fuel-testing plant, St. Louis, Mo., 1904, 1905, and 1906, by L. P. Breckenridge. 1907. 196 pp. 20 cents.

Bulletin 332. Report of the United States fuel-testing plant at St. Louis, Mo., January 1, 1906, to June 30, 1907; J. A. Holmes, in charge. 1908. 299 pp. 25 cents.

Bulletin 334. The burning of coal without smoke in boiler plants; a preliminary report, by D. T. Randall. 1908.26 pp. 5 cents. (See Bull. 373.)

Bulletin 336. Washing and coking tests of coal and cupola tests of coke, by Richard Moldenke, A. W. Belden, and G. R. Delamater. 1908.76 pp. 10 cents.

Bulletin 362. Mine sampling and chemical analyses of coals tested at the United States fuel-testing plant, Norfolk, Va., in 1907, by J. S. Burrows. 1908. 23 pp. 5 cents.

Bulletin 363. Comparative tests of run-of-mine and briquetted coal on locomotives, including torpedo-boat tests and some foreign specifications for briquetted fuel, by W. F. M. Goss. 1908.57 pp., 4 pls.

Bulletin 367. Significance of drafts in steam-boiler practice, by W. T. Ray and Henry Kreisinger. 1909. $61 \mathrm{pp.}$

Bulletin 368. Washing and coking tests of coal at Denver, Colo., by A. W. Belden, G. R. Delamater, and J. W. Groves. 1909. 54 pp., 2 pls. 10 cents.

Bulletin 373. The smokeless combustion of coal in boiler plants, by D. T. Randall and H. W. Weeks. 1909.188 pp. 20 cents.

Bulletin 382. The effect of oxygen in coal, by David White. 1909. 74 pp., 3 pls.

Bulletin 385. Briquetting tests at the United States fuel-testing plant, Norfolk, Va., 1907-8, by C. L. Wright. 1909.41 pp., 9 pls.

Bulletin 392. Commercial deductions from comparisons of gasoline and alcohol tests on internal-combustion engines, by R. M. Strong. $1909.38 \mathrm{pp}$.

Bulletin 393. Incidental problems in gas-producer tests, by R. H. Fernald, C. D. Smith, J. K. Clement, and H. A. Grine. 1909.29 pp.

Bulletin 402. The utilization of fuel in locomotive practice, by W. F. M. Goss. 1909. $28 \mathrm{pp}$.

Bulletin 403. Comparative tests of run-of-mine and briquetted coal on the torpedo boat Biddle, by Walter T. Ray and Henry Kreisinger. 1909. 49 pp.

Bulletin 412. Tests of run-of-mine and briquetted coal in a locomotive boiler, by Walter T. Ray and Henry Kreisinger. $1909.32 \mathrm{pp}$.

661 ${ }^{\circ}-$ Bull: $16-11-14$ 



\section{INDEX.}

A.

Page.

Aakerman, R., on producer gas............. 149

Absorbent, peat as...................... $\quad 179$

Acetic acid from peat.................... 133

yield of......................... 137

Acids, vegetable, in peat................. 46

Agriculture, use of peat in .............. 177-182

Alcohol from peat ................... 133, 136, 165

Alfred, Ontario, demonstration peat plant at. 98-99

Algoma, Wis., peat, analysis of............ 201

Alton, Me., peat, analysis of............... 194

Ammonium compounds from peat. 134, 136, 166-167

Analyses of peat....................... 48,

$53,58,59,61,62,63,110,122,136,137,186-203$

Analysis of peat, procedure in ............ 50,184 proximate, definition of ............... 49

ultimate, definition of .................. 50

Antigo, Wis., peat, analysis of............. 201

Arkport, N. Y., peat, analysis of ........... 199

Ash, composition of . . . . . . . . . . . . . . . . 47-48

determination of .................... 74

effect of ................ 48-49, 55-56,59,76

source of.......................... $76-77$

Ashes, peat, value of .................. 181-182

Ashton, Fla., peat, analysis of............. 191

Asphalt from peat, yield of............. 136,137

Auburndale, Fla., peat, analysis of........ 191

Augusta, Me., peat, analysis of............ 193

Ayers Junction, Me., peat, analysis of....... 195

B.

Bäck, Sweden, peat-powder plant at....... 112

Bangor, Me., peat, analysis of ........... 195

Bartow Junction, Fla., peat, analysis of..... 191

Bayard, Fla., peat, analysis of............ 189, 190

Beaver Marsh, Conn., peat, analysis of...... 188

Bedding for stock, peat as.............. 179-180

Benton Fadls, Me., peat, analysis of......... 193

Bethel, Conn., peat, analysis of............. 186

Beuerberg, Bavaria, peat-coking plant at .... 128,

129,133

Bibliography

204-205

Biochemical agencies in peat formation..... 40

Black Lake, N. Y., peat, heating value of... 53,

121-122

Blast-furnace gas, calorific value of.......... 148 composition of ...................... 148

Bloomingdale, N. Y., peat, analysis of....... 198

Bogs, peat, drainage of, importance of ....... 78 considerations determining......... 36, 78 extent of, computation of.......... $69-70,71-73$ location of, importance of............... 69 peat from, chemical tests of............. 73-75 mechanical tests of................ $75-76$ preparation of
Bogs, peat, price of, bearing of ........... 103-104 prospecting of........................ 71

considerations in .................. 72

importance of thorough.......... $72,73,75$

tool for........................ 71

smallest workable.................. 70

structure of, significance of . . . . . . . . . . 31, 39

utilization of ....................... 161

yield of, determination of ............. 73

Briquets, peat, advantages of............. 116

cost of making................ 119-121, 125

fuel efficiency of .................... 121-122

method of making................... 117

plants for, cost of.................. 119-121

preliminary peat treatment for....... 118-119

presses for......................... $\quad 117$

capacity of...................... 118

cost of.......................... 120

properties of....................... 117

British thermal unit, definition of .......... 50

Brookfield, Conn., peat, analysis of......... 186

Brooksville, Fla., peat, analysis of......... 190

Brown, W. F., peat-gas process of......... 142

Bucksport, Me., peat, analysis of.......... 193

Bureau of Mines, work of................ 7

By-products from coking peat, quantity of. 130-138 recovery of ....................... 130

C.

Cable cars at peat plants.................. 98-99

Cables, arial, at peat plants............... 99

Calcareous matter in peat, source of......... 41,42

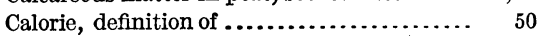

Calorific value, determination of............ 51 of peat......................... 52,186-203 of various fuels....................... 52

Cambridge, Mass., Gaslight Co., manufacture of peat gas by ......................... 142

Cameron, Wis., peat, analysis of........... 201

Canastota, N. Y., peat, analysis of.......... 198

Cape Elizabeth, Me., peat, analysis of....... 193

Capitalization of peat-fuel plants............ 84

Caro, N., on ammonia-recovery process...... 166 See also Frank-Caro.

Cellulose, as constituent of peat............. 46

Charcoal, peat, cost of making............. 139 distillation process of making......... 126-127 yield of............................ 136

New Haven, Conn., plant for.......... 138

Charcoal iron, manufacture of, from peat coke. $\quad 138$

Chemical tests of peat, directions for....... 73-75

Cherryfield, Me., peat, analysis of........... $\quad 195$

Cherry Hill Marsh, Conn., peat, analysis of.. 188

Chester, Conn., peat, analysis of ........... 187

Cicero, N. Y., peat, analysis of............. 198 
Page.

Cicero, N. Y., peat, heating value of........ 53

Clermont, Fla., peat, analysis of.......... 190

Cloth from peat.................... 169-170

Coal, compared with air-dried peat......... 56

heating value of ..................... 52,53

steaming tests of...................... 62

Coastal plain, peat deposits in............ 10

Coke, peat, conclusion regarding........... 163

combustion temperature of ............ 130

German method of making........... 127

carly manufacture of............... 127-128

in United States, manufacture of...... 138-139

Lange's method for making............ 127

plant for, requirements of............. 83

properties of...................... 130-131

retort-distillation for................. 128

uses of.......................... 130,138

Ziegler process for making............ 128-138

Coking retorts, permanent gases from...... 134-136

Combustion, effect of ash on............. 55

Connecticut peat, ash analysis of........... 47-49

Conveyers at peat plants, use of .......... 97,99

Creosote.from peat...................... 132 production of................ 132,136,137

Coke-oven gas, calorific value of............. 148 composition of...................... 148

Crystal, Me., peat, analysis of.............. 193

Cumberland Mills, Me., peat, analysis of.... 193

Cut peat, calorific value of............... 58

defects of ......................... 89-90

preparation of ..................... 86-89

used for briquets.................... 118

D.

Danbury, Conn., peat, analysis of ......... 186

DeKalb, Iowa, peat, analysis of . .......... 192

Digging machinery, types of.............. 96-97

Disinfectant, peat as a..................... $\quad 179$

Dover, N. H., peat, analysis of ............. 197

Dredges, dipper, use of . ................. 96-97

Drying, artificial, effects of............ 59-60,108

cost of ............................ 108

electric processes for ................ 122-123

methods of ....................... 100

profitable limits of................... $\quad 116$

utilization of waste heat for............ 109

Drying ground, preparation of ............. 100

Drying machines, efficiency of............. 115

rotary, double-shell................ 115-116

European type of.............. 114

single-shell................. 115-116

steam-plate....................... 114

Dye stuffs from peat..................... 168

E.

Eagle River, Wis., peat, analysis of.

East Haven, Conn., peat, analysis of.

East Lexington, Mass., peat, analysis of ..... 197

East Machias, Me., peat, analysis of ......... 195

Eaton Rapids, Mich., peat-drying plant

near............................. 122-123

Ekelund, - , peat-powder process of. . 112-113

Ekenberg, M., experiments of, on wet carbon-

ization........................... 123-126

Elbridge, N. Y., peat, analysis of . ............ 199

El_orado, Fla., peat, analysis of........... 190
Page.

Elevators at peat plants, use of............ $\quad 97$

Elizabeth City, N. C., peat, analysis of....... 199

Elizabethfehn, Germany, peat-coke plant at. . 139

Etna, Me., peat, analysis of................ $\quad 195$

Eustis, Fla., peat, analysis of.............. 190

Evaporative effect of peat............... 61,62 of various fuels .................. 61,62

Everglades, Fla., peat, analysis of......... 169

\section{F.}

Falls Point, Me., peat, analysis of.......... $\quad 195$

Farmington, N. H., peat, analysis of........ 198

Fertilizer filler, peat as. .......... 173-175, 178-179

Fixed carbon, determination of........... $\quad 74$

Florence Villa, Fla., peat, analysis of...... 192

Florida peat, analysis of................. 63

fuel test of................. 62

gas yield from ................ 150

Frank-Caro ammonia-recovery process..... 159, 166 gas producer............... 159

Franklin, Conn., peat, analysis of......... 188

Fond du Lac, Wis., peat, analysis of...... 200, 201

Forest, Me., peat, analysis of .............. 195

Fort Lauderdale, Fla., peat, analysis of . .... 189

Freemont, N. H., peat, analysis of......... 197

heating value of .................. 53

French thermal unit, definition of .......... 50,51

Fuel, requirements of an ideal.............. 54

powdered, use of .................... 111

See also Peat powder.

Fuel value, determining factors of.......... $\quad 54$

Fulton, N. Y., peat, analysis of........... 199

G.

Gagen, Wis., peat, analysis of............ 202

Gas, fuel, manufacture of, from peat........ 143 uses of ..................... 139-140,143

See also Producer gas, blast-furnace gas, illuminating gas, oil gas, peat gas, water gas.

Gas producer, features of .............. 144, 145 peat as fuel for .................... 147, 159-160

types of...................... 146, 158-159

Gas-producer plants, cost of ............ 156-158

Gases, permanent, from peat............ 134

Graphite, from peat tar............... 132

Grasses, formation of peat from............ 28

Green Grove Springs, Fla., peat, analysis of. . 189

Greene, Me., peat, analysis of............. 193

Greenland, N. H., peat, analysis of ........ 197 heating value of .................. 53

Glidden, Wis., peat, analysis of............ 200

"Half coke," definition of................ 131

H.

Half Way, N. Y., peat, analysis of......... 199

Halifax, Mass., peat, gas-producer test of .. 152-153

Hamburg, Mich., peat, analysis of ......... 197 heating value of ................. 53

Hampton, Conn., peat, analysis of......... 189

Hartford, Me., peat, analysis of ............. 194

Hastings, N. Y., peat, analysis of.......... 199

Hayward, Wis., peat, analysis of.......... 202

Heafford Junction, W is., peat, analysis of.... 201

Heating value. See Calorific value. 


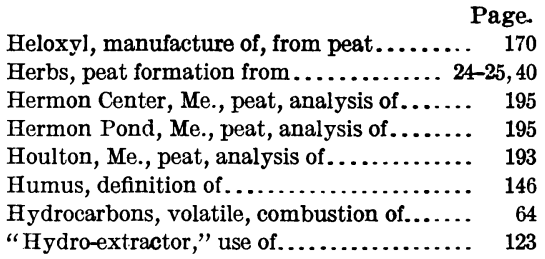

I.

Illuminating gas, calorific value of........... composition of.

from peat, composition of .............. manufacture of

Indiana peat, evaporative effect of.

Insulating matcrial, peat as .............

Inverness, Fla., peat, analysis of.............

Iron, charoal, peat coke for making .......... compounds in peat.

sulphide in peat, source of..

Istachatta, Fla., peat, analysis of..

\section{J.}

Johnson, S. W., on peat ash

Jonesboro, Me., peat, analysis of........... 195

\section{K.}

Kalamazoo, Mich., peat, analysis of

Kent, Conn., peat, analysis of............. 187 heating value of.................. 53

Kerr, W. A., on producer-gas............ 148-149

Kewaunee, Wis., peat, analissis of......... 201

Kicl, Wis., peat, analysis of . . . . . . . . . 201,202

Kilberry, Ireland, electric drying plant at.. 122-123

Killingsworth, Conn., peat, analysis of....... 187

Kittery, Me., peat, analysis of............ 196 heating value of.

Kittery Point, Me., peat, analysis of.......... 196

Koerting gas producer, gas yield from peat in. 150

\section{L.}

Lac du Flambeau, Wis., peat, analysis of.... Ladysmith, Wis., peat, analysis of...........

Lake Panasoffkee, Fla., peat, analysis of....

Lakeland, Fla., peat, analysis of.............

La Martine, Wis., peat, heating value of .......

Lambertville, Mich., peat, analysis of.......

Leesburg, Fla., peat, analysis of............

Lewiston, Me., peat, analysis of.............

Lignin, as constituent of peat...............

Loomis-Pettibone gas producer, gas yield from peat in.

Lynnfield, Mass., peat, analysis of.

Lyons, R. E., on evaporative effect of peat....

\section{M.}

Macerating peat, methods of ............. 90-92

Machine peat, air-dried, calorific value of....58,61 cost of........................... 104-105

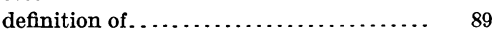
drying of....................... 107-110 labor required for making........... 106-107
Page.

..... 93-96

operating season for................. 106

plant for, cost of.................. 101-103

plant for, requirements of........... 100-101 probable output of............. 104

profit in.......................... 106

prices of, in Amsterdam, Holland....... 92 steam-dried, calorific value of........... 58 steaming test of...................... 62

selling prices of ................... 105-106

Madison, Wis., peat, analysis of........... 200

heating, value of................. 53

Market, probable, for peat fuel........... 67-68

Mason, F. H., on cost of peat-briquet plants. $\quad 120$

Mattresses, peat as material for.......... 170-171

Memphis, N. Y., peat, analysis of......... 199

Mendota, Wis., peat, analysis of.......... 200

Miami, Fla., peat, analysis of............. 189

Milton, Fla., peat, analysis of ............ 192

Minocqua, Wis., peat, analysis of.......... 202

Moisture in peat, determination of.......... 74 effect of on combustion...........54,59 See also Water.

Mond gas producer, gas yield from peat in.... $\quad 150$

Moss litter, manufacture of............. 171-172 marketing of...................... 172

Mountain, Wis., peat, analysis of.......... 201

Mosses, formation of peat from........... $\quad 30$

Mountain View, N. Y., peat, analysis of..... 198

Mull. See Moss litter.

Muck, definition of..................... 45

N.

Natural gas, calorific value of............. 148 composition of ....................... 148

New Auburn, Wis., peat, analysis of....... 200

New Durham, N. H., peat, analysis of....... 198 heating value of . ................. 53

New Fairfield, Conn., peat, analysis of...... 186 heating value of ................. 53

New Haven, Conn., peat, analysis of........ 188 peat-charcoal plant at................ 138

Newport, Me., peat, analysis of........... 195

Nicolin, Me., peat, analysis of............. 193

Nitrates, peat as source of............... 167-168

Nocatee, Fla., peat, analysis of........... 189

Norway, Me., peat, analysis of.............. 194

Norwood, Mass., peat, analysis of........ 196, 197

Nystrom, E., on gases from coking retorts... 134 on heating value of peat briquets....... 121 on peat-briquet plants................ 119 on peat machines...................... 95 on peat powder..................... 112 on producer gas from peat........... 149, 150 on wet carbonization................. 124

\section{o.}

Oakland, Me., peat, analysis of.......... 194, 195 Oak Orchard, N. Y., peat, analysis of........ 199 Ogdensburg, N. Y., peat, analysis of........ 199 Oil gas, calorific value of................. 148 composition of ...................... 148 Oldenburg, Germany, peat-coking plant at. 123, 134 Orlando, Fla., peat, gas-producer test of... 153-155 producer gas from................. 151 peat transportation at................ 99 
Packing material, peat as.

173,181

Palatka, Fla., peat, analysis of............ 192

Palermo, N. Y., peat, analysis of.......... 199

Paper, peat as material for .............. 168-169

Paradise Key, Fla., peat, analysis of....... 189

Paraffin from peat, yield of............... 136

Parkfalls, Wis., peat, analysis of.......... 202

Peat, advantages of as fuel................. 63

air-dried, calorific value of ........... 53,56

combustion temperature of......... 54

compared with coal................ 56

effect of air on.................... 43

moisture content of ............... 55

analysis of......................... $\quad 74$

as gas-producer fuel................. 147

calorific value of............... $58,63,122$

combustion of .................... 55, 63

classification of....................... 45

color of ............................ 38

significance of................... 38

composition of ................. 40-42,46-47

definition of...................... 8,37

density of ......................... 43-44

dried, fuel value of.................. 54

moisture in ..................... 109

specific gravity of................ 44

weight of per cubic foot........... 44

effect of air on ...................... 55

formation of, conditions favoring.. 16, 19, 29, 35 as affecting quality of............... 28 value of ................... 39

biochemical agencies in............ 40

depths of...................... 26-27

effect of climatic changes on....... 34

in coastal areas.................... 31

in depressions . . ............... 19,23, 34

in tidal marshes.................. 33

on flat-land surfaces.............. 28-31

principles of, application of......... 35-36

rate of........................ 35

regions in North America favorable

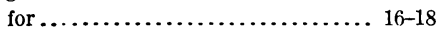

water as agent in ............... 8

freshly dug, composition of ............ 54 fuel value of .................... 54

fuel value of ...................... 161 conclusions regarding............... 27

ignition of, conditions of.............. 55

inorganic material in . .............. 40,41

mineral matter in................... 41

source of........................ 47

moisture capacity of................ 42-44

moisture in, as related to weight of..... 78

organic material in .................. 40

physical character of.................. 45

properties of................... 8-9, 37-44 quality of, as related to formation of ..... 36

to possible uses of............. 44

quantity of, in the United States....... 12-13

salt-marsh, characteristics of............ 32

formation of ..................... 32

value of ........................ 33

specific gravity of................... 43-44

texture of $\ldots \ldots \ldots \ldots \ldots \ldots \ldots \ldots \ldots \ldots, \quad 38$

significance of .................. 39
Page.

Peat, use of, in Canada .................. 10,11

in Europe..................... 9, 11,56,86

in United States.................. 10,11,14

variations in ........................ 37

causes of........................ 37

vegetable acids in ................... 46

matter in, significance of........... 44-45

water content of..................... 37

water-holding capacity of.............. 42

weight of ......................... 43-44

wet, transportation of . ............. 97-100

Peat beds, lateral growth of . . ............ 34-35

Peat bogs in North America, distribution

of .............................. 16,17

in United States, distribution of........ 13

map showing ................... In pocket

See also, Bogs.

Peat briquets. See Briquets.

Peat charcoal. See Charcoal, peat.

Peat coke. See Coke, peat.

Peat distillation, products from......... 126-143

Peat fuel, calorific value of................ 57-59

cost of, compared with coal............. 14-15

factory for, cost of ................. 101

processes in .................... 93

requirements of................. 101

in steam generation. ................ 57

machinery for, selection of............ 81

manufacture of, in United States........ 65

failures in ...................... 66

market for, development of........... 67-68

plant for, advantages of simple........ 81

capital for ...................... 83-84

capitalization of ................. 84

character of...................... 82-83

experimenting with . . . . . . . . . . . $85-86$

lay-out of .................... $79,80-81$

location of.................... 69,79

machinery for ................... $81-82$

plant site for, choice of.............. $79-80$

present interest in ................... 9

probable market for.................. $\quad 67$

relative value of ....................... 15

transportation of . . . . . . . . . . .

under boilers .......................63-64

use of, history of..................... 9-12

in Europe..................... 56-57

probable improvements in......... 63-64

value of . ........................ 15,161

See also Cut peat; Machine peat.

Peat gas, calorific value of .............. 141,148

composition of....................... 141

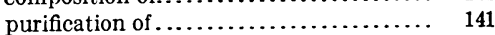

yield of............................ 142

Peat moss. See Sphagnum.

Peat powder, as fuel..................... 112

calorific value of..................... 122

Canadian process of making ........... 113

combustion of ...................... 111

Ekelınd's system of making ......... 112-113

equipment for, cost of . . ............. 114

European tests of................... 112-113

manufacture of ..................... 113

Peat presses, early.................... 92-93

modern types of ....................... 93

Peat soils, working of.................. 178 
Page.

Peaty Prairie, Fla., peat, analysis of........ 191 Pembine, Wis., peat, analysis of........... 201

Peshtigo, Wis., peat, analysis of ............ 201

Petroleum from peat, yield of ........... 136,137

Pittsfield, Me., peat, analysis of ............ 195

Plants, aquatic, in peat formation .. 19, 20, 23-24, 39 effect of depth of water on ............. 21-22 effect of sunlight on ................. 21-22 growth of, conditions favoring ........ 18-19,34 herbaceous, in peat formation.......... 20 seed, in peat formation............... 20 turf-forming, in peat formation......... $\quad 28$ woody, in peat formation.............. 30 zones of growth of ................. 21,23

Pneumatic collector for peat powder........ 113

Powell, Wis., peat, analysis of............. 201

Producer gas, calorific value of........ 148, 150,151 composition of....................... 148 definition of ......................... 144

formation of ....................... 145

from peat, manufacture of ....... 147-148, 155 tests of....................... 152-155 utilization of ................... 160-161 yield of....................... 149,150 See also Gas producer.

Producer-gas plants, use of peat in........ 161-162 Proximate analysis, definition of .

\section{R.}

Racks, use of, for drying peat............ 100 Redkino, Russia, peat-coking plant at..... 128, 129 Ridgefield, Conn., peat, analysis of ......... 186

Rochester, N. H., peat, analysis of ......... 198 heating value of

Rockland, Me., peat, analysis of ............ 194 Rosemary Junction, Me., peat, analysis of ... 196 Rushes, formation of peat from ............. 28 Ryan, Hugh, on calorific values of fuels...... 61 on peat by-products ................... 136 on producer gas from peat............. 150

Rye, N.H., peat, analysis of............. 197

\section{S.}

Salt-marsh peat. See Peat.

Sampling of bogs, chemical tests in ......... 73 considerations in ..................... 72 importance of .................... $72,73,75$ methods of....................... 183-184 tool for .......................... 71-72

Sanitary appliances from peat........... 170-171 Saranac Lake, N. Y., peat, analysis of ...... 198 Sedge mat, vegetation of .................. 24 Sedges, peat formation from ............... 28 Shelbyville, Mich., peat, analysis of ........ 197 Sherman, Me., peat, analysis of............ 193 Shoppers Point, Me., peat, analysis of...... 135 Shrubs, peat formation from............ 24-25, 27 Siliceous matter in peat, source of ......... 41, 42 Skaberjö, Sweden, producer-gas plant at.... $\quad 70$ Smithfield, Me., peat, analysis of........... 195 Smoke from peat fires, character of......... 64 South Lima, N. Y., peat, analysis of....... 198
Page.

South Lubec, Me., peat, analysis of......... 196 Southern Inlet, Me., peat, analysis of....... 195 Specific gravity, determination of.......... $\quad 75$ Sphagnum, growth of............. 25-26,27,30 peat formation from.............. 25, 30,39 texture of .......................... 39 Spragues, Me., peat, analysis of.......... $\quad 195$ Stock food, peat as..................... 180 Stonington, Conn., peat, analysis of........ 188 Sturgeon Bay, Wis., peat, analysis of....... 200

\section{T.}

Tallahassee, Fla., peat, analysis of ........ 191 Tanning materials, peat as source of ........ 168

Tar, peat, properties of.................. 131 purification of...................... 132

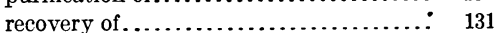
utilization of ....................... 131

Tar water, from peat, yield of ............. 136 utilization of ....................... 133

Tavares, Fla., peat, analysis of ........... 191 Taylor gas producer, gas yield from peat in... 150 Thermal unit, definition of.............. $\quad 50$ Thompson, Conn., peat, analysis of....... 188 Tramcars at peat plants.................. 98 Trees, coniferous, in peat formation........ 25 deciduous, in peat formation........... 26

U.

Ultimate analysis, definition of............

United States Geological Survey, analyses

by ................... 53,62,122, 186-203 fuel tests of ....................... 62 gas-producer tests by............ 7,152-155

V.

Vanceboro, Me., peat, analysis of .......... 196

Volatile matter, combustion of............ 64 determination of .................. 50,74

W.

Wallgren, Ernest, on peat powder......... 112

Washington, Conn., peat, analysis of....... 187

Water, as agent in peat formation.......... 8 colored, plant growth in............. 27,35 in peat, evaporation of .............. 109-110 percentage of ..................... 37,55 removal of, by pressure.......... 42,43 relation of, to cost of peat fuel....... 80 weight relation of, figure showing.... 110 plant growth in .................. 21,26 See Moisture.

Water gas, calorific value of.............. 148 composition of ....................... 148 definition of ........................ 143 enrichment of ..................... 143 Water level, relation of, to plant growth.... $\quad 26$ Waupaca, Wis., peat, analysis of .......... 203 heating value of..................... 53

West Apopka, Fla., peat, analysis of....... 191

West Monroe, N. Y., peat, analysis of ...... 199 West Sidney, Me., peat, analysis of ......... 194 


\begin{tabular}{|c|c|}
\hline Page. & Page. \\
\hline Westport, Conn., peat, analysis of.......... 186 & Winslow, Me., peat, analysis of............ 194 \\
\hline heating value of $\ldots \ldots \ldots \ldots \ldots \ldots \ldots \ldots$ & Woltereck, H., ammonia-recovery process \\
\hline Wet carbonization, claims for.......... 125-126 & of $\ldots \ldots \ldots \ldots \ldots \ldots \ldots \ldots \ldots \ldots \ldots \ldots \ldots \ldots \ldots \ldots+166-167$ \\
\hline cost of $\ldots \ldots \ldots \ldots \ldots \ldots \ldots$ & Wood, artificial, from peat.............. \\
\hline effects of, on peat.......... & Woodstock, Conn., peat, analysis of..... \\
\hline furnace for.....$\ldots \ldots \ldots \ldots$ & Wyer,'s. S., on producer-gas engines........ \\
\hline methods of ............... & \\
\hline 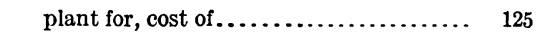 & Z. \\
\hline prospective value of...$\ldots \ldots \ldots \ldots$ & Ziegler, Martin, coking process of ......... 128-138 \\
\hline Whitneyville, Me., peat, analysis of......... & Ziegler gas producer, gas yield from peat in.. 150 \\
\hline
\end{tabular}




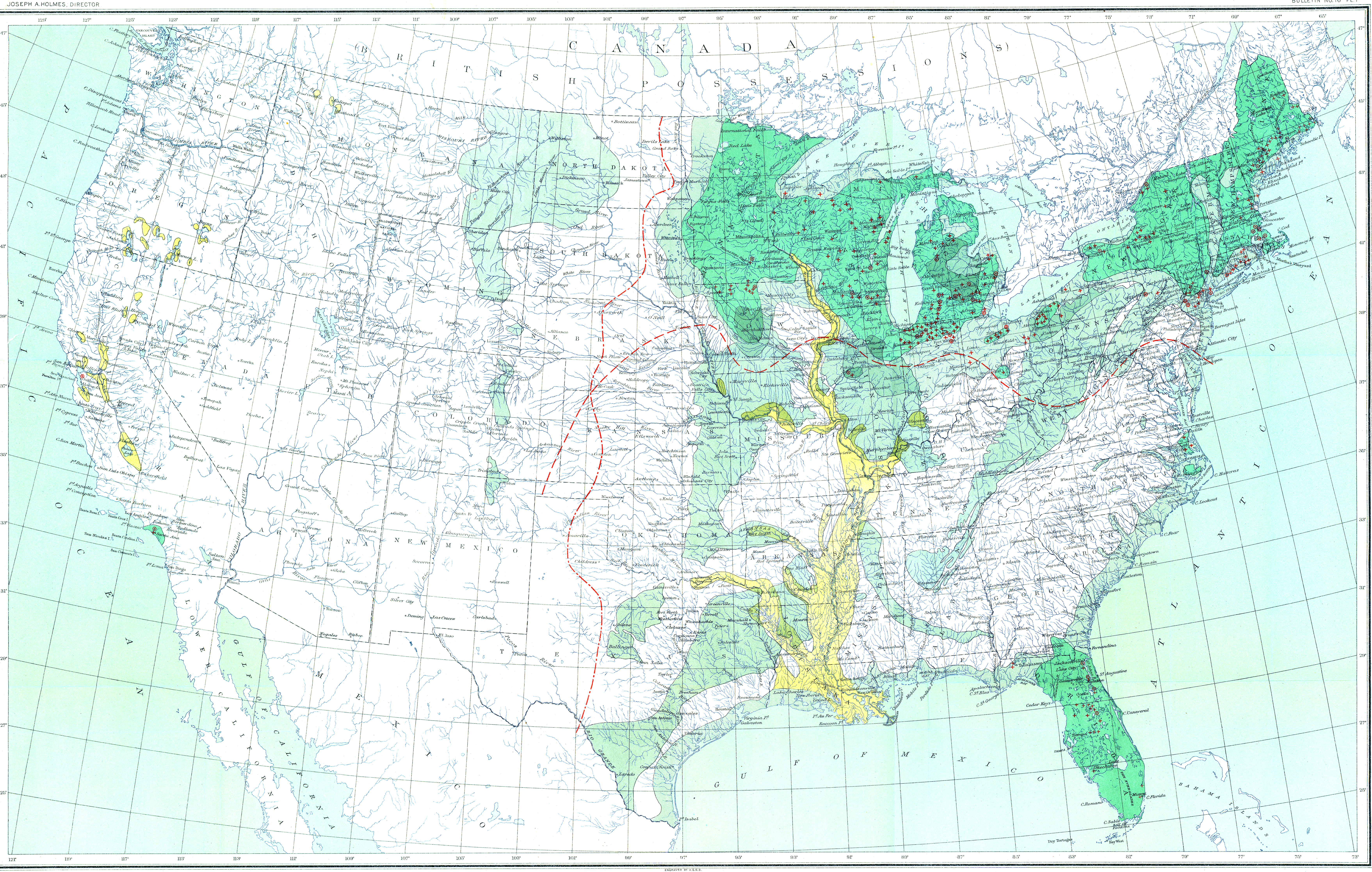

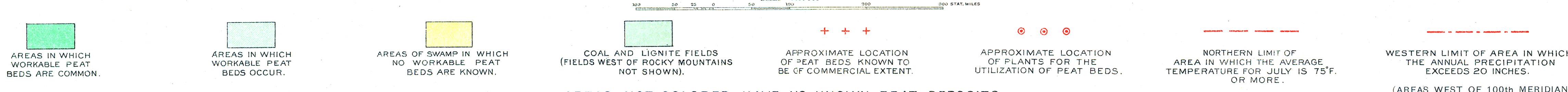

